\title{
Marta Wojakowska
}

\section{DÉVELOPPER LA COMPÉTENCE PLURILINGUE ET PLURICULTURELLE EN CLASSE DE FRANÇAIS SUR OBJECTIFS SPÉCIFIQUES}

(exemple du français de la diplomatie)
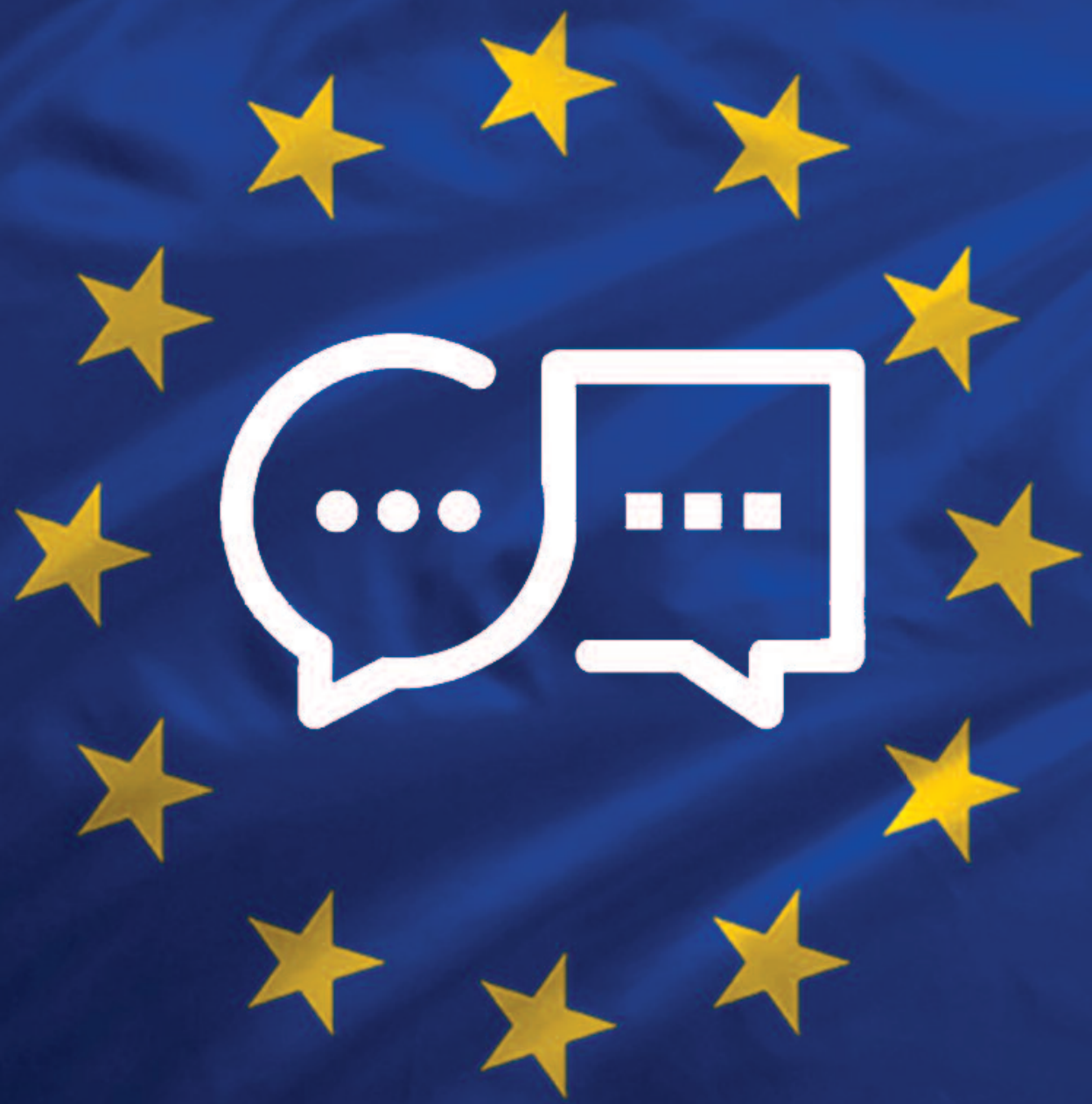


\section{DÉVELOPPER LA COMPÉTENCE PLURILINGUE ET PLURICULTURELLE EN CLASSE DE FRANÇAIS SUR OBJECTIFS SPÉCIFIQUES}

(exemple du français de la diplomatie) 

Marta Wojakowska

\section{DÉVELOPPER LA COMPÉTENCE PLURILINGUE ET PLURICULTURELLE EN CLASSE DE FRANÇAIS SUR OBJECTIFS SPÉCIFIQUES \\ (exemple du français de la diplomatie)}


Recenzent

Halina Widła

Redaktor prowadzący

Maria Szewczyk

Redakcja techniczna

Maryla Broda

Korekta

Sebastien Ducourtioux

Projekt okładki i stron tytułowych

Zbigniew Karaszewski

Skład i łamanie

Piotr Molski

Publikacja dofinansowana przez Uniwersytet Warszawski w ramach programu „Inicjatywa doskonałości - Uczelnia Badawcza”

(C) Copyright by Wydawnictwa Uniwersytetu Warszawskiego, Warszawa 2021

Marta Wojakowska ORCID: 0000-0003-3933-7148

ISBN 978-83-235-5052-5 (druk)

ISBN 978-83-235-5060-0 (pdf online)

Wydawnictwa Uniwersytetu Warszawskiego

00-838 Warszawa, ul. Prosta 69

e-mail:wuw@uw.edu.pl

księgarnia internetowa: www.wuw.pl

Wydanie 1, Warszawa 2021 
Moim Rodzicom 



\section{Od autorki}

Niniejsza monografia jest rozprawą doktorską, napisaną pod kierunkiem prof. dr hab. Jolanty Sujeckiej-Zając. Praca została obroniona na Wydziale Neofilologii Uniwersytetu Warszawskiego 25 czerwca 2019 r. Jej fragmenty zostały wykorzystane w następujących publikacjach:

Wojakowska, M. (2018), le Cadre de référence pour les approches plurielles des langues et des cultures au service de la formation interculturelle. Cas d'un cours de français sur objectif spécifiques [dans :] XXe école doctorale de l'Association Gallica \& École doctorale de l'Université Halle-Wittenberg, de l'Université de Szeged et l'Université Masaryk de Brno, pp. 275-285.

Wojakowska, M. (2020), Różnojęzyczność, codzienność i wyzwanie dla bezpieczeństwa w Europie [w :] Język w dyskursie o bezpieczeństwie, Dom Wydawniczy Elipsa, str. 55-65.

Wojakowska, M. (w druku), Enjeux liés à la perception de l'Autre dans l'enseignement du Français sur Objectifs Spécifiques, publikacja po konferencji « La Perception en langue et en disours (4e éd.) Colloque international de Sciences du langage à Banská Bystrica ».

Praca ta nie powstałaby, gdyby nie życzliwość, jak również krytyczne i pomocne uwagi wielu osób.

Na wstępie chciałabym serdecznie podziękować prof. dr hab. Jolancie SujeckiejZając za wsparcie w ciężkich dla mnie momentach oraz za pomoc w czasie planowania i redagowania pracy.

Gorące podziękowania chciałabym również złożyć na ręce recenzentki: prof. dr hab. Haliny Widły. Wielkie zrozumienie oraz wnikliwa ocena merytoryczna mojej 
pracy to są dla mnie cenne wskazówki, które bezsprzecznie posłużą poprawie jakości realizowanych przeze mnie przyszłych prac badawczych.

Dziękuję również dr hab. Radosławowi Kucharczykowi, który mi zaufał, uwierzył we mnie i pomógł mi rozwijać się naukowo w Instytucie Romanistyki UW.

Duże wsparcie otrzymałam także od Rodziców oraz Przyjaciół. Za wyrozumiałość, cierpliwość i pozytywne motywanie do pracy, z całego serca serdecznie dziękuję! 


\section{Table des matières}

Liste des principaux acronymes utilisés $\quad 13$

Introduction 15

\section{Chapitre 1}

Enseignement du français à des publics professionnels

en tant qu'objet d'études

1.1. Lévolution des dénominations liées au contexte professionnel 20

$\begin{array}{ll}\text { 1.1.1. La langue de spécialité/technique/scientifique } & 21\end{array}$

1.1.2. Le Français instrumental $\quad 22$

1.1.3. Le Français fonctionnel $\quad 23$

1.1.4. Le Français sur Objectif(s) Spécifique(s) (FOS) 24

1.1.5. Le Français à visée professionnelle et le Français Langue Professionnelle 26

1.2. Les approches méthodologiques proposées dans l'enseignement/ apprentissage

de la langue de spécialité $\quad 28$

1.3. Langue à des fins professionnelles - une pratique didactique revisitée 32

1.3.1. Langue à des fins professionnelles pour les débutants 32

1.3.2. Enseignement du français à des publics spécialisés : difficultés de l’enseignant 33

1.4. Le français de la diplomatie et sa place dans le contexte professionnel 35

1.4.1. Les cadres du français de la diplomatie $\quad 35$

1.4.2. Les besoins spécifiques des apprenants du français de la diplomatie
au Collège d'Europe de Natolin

1.4.3. le français de la diplomatie dans les matériaux didactiques 37

1.4.3.1. Analyse de la méthode Objectif Diplomatie A1/A2 : le Français des relations européennes et internationales 39

1.4.3.2. Objectif Diplomatie A1/A2 : le Français des relations européennes
et internationales et son côté interculturel

1.4.4. Diplomatie.com - recueil d'activités pour les autodidactes $\quad 43$

1.5. Pour faire le point $\quad 45$ 


\section{Chapitre 2}

\section{Des besoins aux compétences. Le rôle des compétences} dans la construction du programme du français de la diplomatie

2.1. Lapprenant au cour de la formation de FOS

2.1.1. La complexité de la représentation du métier de diplomate $\quad 48$

2.1.2. Le profil de l'apprenant du français de la diplomatie $\quad 50$

2.1.3. Les besoins spécifiques du public spécifique

2.2. Le manuel Objectif Diplomatie A1/A2 : le Français des relations européennes et internationales comme exemple de cours de français de la diplomatie

2.3. La spécificité du cours de français de la diplomatie

2.3.1. L'importance de la compétence plurilingue et pluriculturelle dans l'enseignement dans l'enseignement des langues

2.3.2. L'interculturel dans le monde professionnel

2.3.2.1. Louverture à l'altérité dans le monde diplomatique

2.3.2.2. La prise de conscience interculturelle - implications didactiques

2.3.2.3. Obstacles à l'éducation interculturelle

2.3.2.4. La pédagogie interculturelle : vers une mise en pratique

2.3.2.5. Approche interculturelle - bilan

2.3.3. La compétence sociolinguistique dans le cours de français de la diplomatie

2.3.3.1. Accès à la compétence sociolinguistique

2.3.3.2. Enseignement de la compétence sociolinguistique : importance des documents et des interactions authentiques

2.3.4. Compétence pragmatique dans le cours de français de la diplomatie

2.3.4.1. La compétence discursive et la diplomatie

2.3.4.2. La compétence fonctionnelle dans le domaine professionnel

\section{Chapitre 3}

\section{Opérationnalisation de la compétence plurilingue et pluriculturelle dans l'optique d'un Cadre de Référence pour les Approches Plurielles des Langues et des Cultures. L'exemple du français de la diplomatie}

3.1. La voie pour l'Europe plurielle

3.1.1. Le développement de la perspective plurielle dans la didactique des langues

3.1.2. La compétence plurilingue et la didactique du plurilinguisme

3.2. Les approches plurielles

3.2.1. La notion d'approches plurielles : conceptions

3.2.2. La didactique du plurilinguisme et la didactique des approches plurielles $\quad 89$

3.2.3. Les approches plurielles et les approches singulières

3.3. Cadre de Référence pour les Approches Plurielles des Langues et des Cultures les compétences

3.4. Cadre de Référence pour les Approches Plurielles des Langues et des Cultures : ressources et descripteurs

3.5. Cadre de Référence pour les Approches Plurielles des Langues et des Cultures quatre approches plurielles 
3.5.2.1. Intercompréhension entre les langues parentes - le plan didactique $\quad 106$

3.5.2.2. Intercompréhension entre les langues parentes - obstacles et contraintes $\quad 108$

3.5.2.3. Intercompréhension entre les langues parentes - quelle utilisation en classe français de la diplomatie?

3.5.2.4. Typologie des langues et didactique intégrée

$\begin{array}{ll}\text { 3.5.2.5. Didactique intégrée des langues : concepts pratiques } & 117\end{array}$

$\begin{array}{ll}\text { 3.5.2.6. Didactique intégrée des langues : limites et obstacles } & 119\end{array}$

3.5.2.7. Didactique intégrée des langues : les cours de français de la diplomatie $\quad 121$

3.5.3. Approche interculturelle

3.5.3.1. Approche interculturelle : une perspective pédagogique 123

$\begin{array}{ll}\text { 3.5.3.2. Prise de la conscience interculturelle } & 124\end{array}$

3.5.4. Les approches plurielles - bilan 126

3.6. Le Cadre de Référence pour les Approches Plurielles des Langues et des Cultures et l'enseignant de plurilinguisme

3.7. Le questionnement autour du Cadre de Référence pour les Approches Plurielles des Langues et des Cultures

3.8. Pour faire le point

\section{Chapitre 4}

Choix méthodologique pour la recherche empirique

4.1. La recherche en éducation

4.2. L'objet de la recherche

4.3. Choix de la posture épistémologique

4.4. Le choix de l'approche méthodologique

4.4.1. Les critères en recherche qualitative

4.4.2. Recherche qualitative : méthode recherche-action

4.4.2.1. Létude en groupe d'étudiants

4.4.2.2. Pré-test et post-test

4.4.2.3. Techniques de collecte de données

4.4.2.3.1. Portfolio européen des langues $\quad 153$

4.4.2.3.2. Observation

4.4.2.3.3. Enquête par questionnaire

4.4.2.4. Le travail avec des séquences pédagogiques 162

4.5. Le contexte de l'étude

4.5.1. Description du lieu d'intervention (le Collège d'Europe comme véritable 'microcosme' européen)

$\begin{array}{ll}\text { 4.5.2. Le profil de l'échantillon } & 167\end{array}$

4.6. Bilan

\section{Chapitre 5 \\ Présentation et interprétation des données recueillies dans la recherche empirique}

5.1. Les résultats du pré-test : diagnostic

5.2. Les résultats du Portfolio 
5.4. Réflexions écrites 195

5.5. Les résultats du post-test 201

5.6. Interprétation qualitative et quantitative des données - bilan 205

Conclusion générale 209

Streszczenie $\quad 211$

Summary 213

Résumé $\quad 215$

Bibliographie $\quad 217$

Liste des tableaux $\quad 226$

Liste des figures $\quad 227$ 


\section{Liste des principaux acronymes utilisés}

CARAP Cadre de Référence pour les Approches Plurielles des Langues et des Cultures

CE Conseil de l'Europe

CECRL Cadre européen commun de référence pour les langues

CELV Centre européen pour les langues vivantes du Conseil de l'Europe

CIEP Centre international d'études pédagogiques

CPLPC Compétence plurilingue et pluriculturelle

DLC Didactique des langues-cultures

DLE Didactique des langues étrangères

EPSO Office européen de sélection du personnel

FLE Français langue étrangère

FLP Français à visée professionnelle/ Français langue professionnelle

FLS Français langue seconde

FOS Français sur Objectif(s) Spécifique(s)

FOU Français sur objectifs universitaires

FS Français de spécialité

TCF RI Test de connaissance du français, version relations internationales

OCDE Organisation de coopération et de développement économiques

ONU Organisation des Nations unies

SGAV Méthodologie structuro-globale audio-visuelle 



\section{Introduction}

\begin{abstract}
Pour être soi, il faut se projeter vers ce qui est étranger, se prolonger dans et par lui. Demeurer enclos dans son identité, c'est se perdre et cesser d'être. On se connaît, on se construit par le contact, l'échange, le commerce avec l'autre. Entre les rives du même et de l'autre, l'homme est un pont.
\end{abstract}

Jean-Pierre Vernant $(2004)^{1}$

A l'heure actuelle les sociétés contemporaines sont toutes multiculturelles. Il est impossible de rencontrer des groupes complètement homogènes qui n'auraient pas eu d'échanges avec d'autres ou dont les membres ne connaitraient aucun lien économique, aucun dialogue, aucun mélange. Des nations entières se construisent aujourd'hui à nouveau sur les flux migratoires, les métissages de population, la cohabitation et l'assimilation de modes de vie, de rites, de valeurs. On observe un accroissement des rencontres interculturelles physiques, virtuelles, intellectuelles, spirituelles et identitaires. En raison de cette augmentation des mobilités de ces dernières décennies, accompagnées de peurs de l'Autre dues à l'accroissement des contacts, l'interculturel est devenu un sujet très prisé dans le discours politique mais surtout pédagogique. Dans les années 1970-1980, l'approche communicative considérait la langue comme une pratique sociale qui était le véhicule, le produit et le producteur de toutes les cultures. Plus tard, la publication du Cadre européen commun de référence pour les langues (2001), qui a profondément marqué la didactique des langues, a mis l'accent sur la prise de conscience interculturelle. Le document du Conseil de l'Europe recommandait de faire acquérir à tout citoyen européen une compétence plurilingue et pluriculturelle afin de faciliter la mobilité géographique et de préserver le plurilinguisme.

Aujourd'hui, la dimension interculturelle et la compétence plurilingue et pluriculturelle se trouvent au centre des réflexions concernant la didactique des langues étranges. Il semble qu'il n'y ait pas de meilleur lieu que la classe de langue où

\footnotetext{
${ }^{1}$ Le texte a été commandé pour le cinquantième anniversaire du Conseil de l'Europe.
} 
la réflexion sur les représentations de l'Autre, sur la rencontre de l'altérité et la prise de conscience que nous sommes tous soumis à des structures de pensée simplificatrices permettrait d'acquérir un regard plus objectif, plus conscient de l'Autre ou d'autres groupes. Il en résulte l'abandon de l'idéal monolingue qui a longtemps dominé en Europe et la promotion des approches plurielles, un nouveau paradigme pour l'enseignement/apprentissage des langues décrit en détail dans le Cadre de Référence pour les Approches Plurielles des Langues et des Cultures (2007).

Lorsque le plurilinguisme commence à être valorisé, il l'est sous une forme bien particulière dans la mesure où cette valorisation ne s'applique guère qu'à l'enseignement du FLE et pas du tout à l'enseignement du français à visée professionnelle. Pourtant, nous pensons que l'objectif interculturel et, par conséquent, la compétence plurilingue et pluriculturelle ne doivent pas être perçus comme un supplément aux formations destinées à des publics de professionnels, mais comme l'objectif " organisateur » des dimensions techniques, lexicales, grammaticales, phonétiques/phonologiques et discursives.

C'est dans cet esprit que s'inscrit le présent ouvrage. Nous nous proposons de démontrer que la compétence plurilingue et pluriculturelle mérite d'avoir une place à part dans le processus d'enseignement/apprentissage de langue française à destination d'un public de jeunes professionnels. C'est notamment l'apparition du Cadre de Référence pour les Approches Plurielles des Langues et des Cultures (CARAP) qui a incité une analyse beaucoup plus poussée de la compétence plurilingue et pluriculturelle cruciale dans la didactique moderne des langues étrangères. Il est donc fondamental de prendre en considération cette nouvelle réalité et de s'y adapter également dans le cas d'une formation qui s'adresse à de jeunes adultes, comme c'est le cas du public de futurs diplomates avec lequel nous travaillons.

Ainsi notre réflexion se concentrera-t-elle sur les questions suivantes :

- Quelles sont les représentations des étudiants sur le rôle de la compétence plurilingue/pluriculturelle dans le travail de futurs diplomates?

- Comment développer la compétence plurilingue et pluriculturelle en classe de FOS pour les futurs diplomates?

et sera basée sur une approche qualitative. La recherche s'inscrira dans le paradigme interprétatif. De ce fait, dans notre étude, nous aurons recours à la méthode rechercheaction.

En outre, l'évolution de la réflexion est répartie dans cinq chapitres dont le contenu se présente de la manière suivante :

- Dans le premier chapitre (L’enseignement du français à des publics professionnels en tant qu'objet d'études) nous présenterons l'importance de la langue à des fins professionnelles ainsi que l'évolution de différents courants linguistiques $\mathrm{du} \mathrm{XX}^{\mathrm{e}}$ siècle, mais aussi des réflexions sur la nature de ces changements. 
Dans un second temps, nous analyserons la didactique du français à des fins professionnelles, ainsi que les difficultés rencontrées par les concepteurs de ce type de cours. Le chapitre sera clos par une analyse du manuel Objectif diplomatie A1/A2: le français des relations européennes et internationales (2006) et le cahier d'activité Diplomatie.com (2005) permettant l'apprentissage du français dans le contexte des relations internationales et européennes.

- Le deuxième chapitre (Des besoins aux compétences. Le rôle des compétences dans la construction du programme $d u$ français de la diplomatie) commencera par la présentation du profil détaillé d'un diplomate qui mobilise avant tout la compétence plurilingue et pluriculturelle ainsi que la compétence sociolinguistique et pragmatique. Nous verrons également que, contrairement à ce que nous trouvons dans les manuels de Français sur Objectif(s) Spécifique(s), la langue professionnelle ne se réduit pas à un vocabulaire de spécialité et que le cours de français de la diplomatie ne devrait pas être limité aux aspects linguistiques comme c'est souvent le cas aujourd'hui. Enfin, ce chapitre mettra en lumière la problématique de l'approche interculturelle, l'une des préoccupations majeures de la didactique de notre époque.

- Dans le troisième chapitre (Opérationnalisation de la compétence plurilingue et pluriculturelle dans l'optique d'un Cadre de Référence pour les Approches Plurielles des Langues et des Cultures. L'exemple du français de la diplomatie) seront analysés les concepts théoriques et la mise en pratique des approches plurielles qui contribuent au développement de la compétence plurilingue et pluriculturelle. Ensuite, nous observerons comment les approches plurielles peuvent être implantées dans le cours de français de la diplomatie.

- Le quatrième chapitre (Choix méthodologique pour la recherche empirique) expliquera en détail la problématique de notre recherche empirique. Nous poursuivrons notre recherche sur le développement de la compétence plurilingue et pluriculturelle à travers l'examen des méthodes qualitatives ainsi que les techniques de recueil des données qui conviennent le mieux au sujet de notre étude.

- Tout ceci préparera notre recherche principale, dont les résultats seront analysés dans le cinquième chapitre (Présentation et interprétation des données recueillies dans la recherche empirique).

Notre ambition serait de soumettre au lecteur une perspective de l'évolution d'un domaine de recherche fascinant, riche et complexe, dans l'espoir de contribuer à la réflexion sur l'opérationnalisation de la compétence plurilingue et pluriculturelle en classe de langue à visée professionnelle. 



\section{Chapitre 1}

\section{Enseignement du français à des publics professionnels en tant qu'objet d'études}

\section{Remarques liminaires}

Depuis l'élargissement de l'Union européenne de mai 2004, la didactique des langues vivantes doit faire face, plus que jamais, aux nouveaux défis du plurilinguisme et du pluriculturalisme ainsi qu'aux nouvelles demandes de formation du public avec des objectifs précis. Il en résulte qu'il émerge des demandes de formation de formateurs et d'enseignants de nouveaux pays, essentiellement en langue non littéraire. Le français de l'entreprise, le français des relations internationales, le Business English, arrivent en première position, dopés par le mouvement d'intégration à l'Union européenne mais aussi par le désir d'accéder à une économie de marché mondialisée (MourlhonDallies, 2011 : 81). Étant donné cette dynamique géopolitique, il semble donc légitime d'analyser l'univers de la didactique du français dans un champ particulièrement touché et populaire aujourd'hui, celui des langues de spécialité. En effet, aujourd'hui, les enseignants de FLE sont de plus en plus sollicités pour une préparation de cours pour des adultes allant travailler dans un pays étranger ou des étudiants qui veulent atteindre des objectifs professionnels précis. Ainsi, il faut se donner les moyens de répondre à ces attentes et relever le défi lancé par la didactique de la langue étrangère au XX siècle.

Le chapitre qui suit se pose comme objectif de montrer l'importance de la langue à des fins professionnelles ainsi que l'évolution de différents courants linguistiques du $\mathrm{XX}$ siècle, suivi de réflexions sur la nature de ces changements. Nous commencerons par des réflexions sur le concept théorique de la langue de spécialité enseignée à un public spécifique. Nous montrerons l'essor des recherches sur des dénominations liées au contexte professionnel dû aux changements géopolitiques. Dans un second temps, en analysant des éléments tels que l'histoire, l'économie, la culture, nous verrons 
à quel point ces éléments ont joué un rôle primordial dans l'évolution du concept du français enseigné à des publics spécifiques et ses différentes déclinaisons. Dans la suite du chapitre, nous verrons de plus près la didactique du français à des fins professionnelles ainsi que les difficultés rencontrées par les concepteurs de ce type de cours. Ce sujet nous rapprochera de notre recherche empirique et de notre public, celui de futurs diplomates. Viendra après une analyse du manuel Objectif diplomatie A1/A2: le français des relations européennes et internationales et du cahier d'activité Diplomatie.com permettant l'apprentissage du français dans un contexte des relations internationales et européennes.

Nous voudrions remarquer que nos réflexions se situent au centre des recherches sur le français à des fins professionnelles qui recouvrent un grand champ d'investigations. Nous n'en avons choisi que les éléments influant sur notre recherche empirique.

\subsection{L'évolution des dénominations liées au contexte professionnel}

Les origines de la réflexion sur la nature et la didactique des langues de spécialité datent du Moyen Âge ${ }^{2}$ (Gajewska et Sowa, 2014 : 49). Cependant, c'est à une époque récente qu’apparait la volonté de proposer un enseignement du français « non général $»^{3}$. Ce sont les politiques linguistiques conduites depuis les années 1960, en réponse aux besoins de former des ingénieurs et techniciens dans les pays nouvellement indépendants et de prendre en compte les besoins des nombreux boursiers du gouvernement français, qui ont permis l'émergence de nouvelles pratiques méthodologiques. Parallèlement à ces aspects institutionnels, les didacticiens des langues ont amorcé une réflexion sur les démarches d'apprentissage en les fondant sur la pratique réelle de la langue et non sur un usage souhaité et normatif. Ainsi, sont apparues les premières études fréquentielles sur le français telles qu'on le pratique dans la vie quotidienne, menées par le Centre de recherche et d'études pour la diffusion du français (CREDIF) qui déboucheront sur le français fondamental en 1959 et serviront de référence pour l'élaboration de pistes d'apprentissage d'un français dit de spécialité.

De fait, il n'est pas possible d'analyser le français à des fins professionnelles sans creuser davantage la question du français de spécialité, d'autant plus cette notion

\footnotetext{
${ }^{2}$ On pourrait citer l'apparition des sabirs, les langues utilisées sur le pourtour méditerranéen pour faciliter les relations commerciales au Moyen Âge.

${ }^{3}$ « Le français général ou usuel s’entend comme la maîtrise langagière (donc également culturelle) des rôles d'usager dans les situations de la vie quotidienne tandis que le français sur objectifs spécifiques vise la maîtrise des rôles de spécialiste des différentes disciplines » (Mercelot, 2013 :15).
} 
instable pose des difficultés à tous les didacticiens. Nous sommes d'accord avec Denis Lehmann (1993 : 223) quand il affirme :

L’enseignement des langues étrangères aux publics dits spécifiques (en somme les publics scientifiques, techniques et professionnels) n'est pas une question très neuve. Mais c'est une question quelque peu empoisonnée, au point que l'on ne sait pas trop comment la nommer : certains emploient le terme de «langues de spécialité», tandis que d'autres parlent de «langues pour non-spécialistes» (à comprendre comme «nonspécialistes des langues»).

Pour comprendre ce qui se passe aujourd'hui dans le domaine du français de spécialité, surtout du point de vue de l'évolution tant sur les dénominations que sur les principes méthodologiques, il va falloir regarder quelques années en arrière. Rappeler l'évolution conceptuelle des expressions Français de spécialité (désormais FS) et Français sur Objectif(s) Spécifique(s) (désormais FOS) permet d'éclairer les termes en usage aujourd'hui et aussi de comprendre la politique linguistique de la France et de l'Union européenne en général.

En effet, la distinction des appellations de l'enseignement du français à des publics professionnels ou encore spécialisés dépendait beaucoup de la date d'apparition dans le champ du français langue étrangère. Ainsi, nous allons rapidement passer en revue des appellations ${ }^{4}$ telles que le Français de spécialité/technique/scientifique, le Français des professionnels, le Français instrumental, le Français fonctionnel, le FOS, le Français à visée professionnel et le Français langue professionnelle.

\subsubsection{La langue de spécialité/technique/scientifique}

Il n'est pas anodin de mentionner que c'était au niveau linguistique que l'on définissait le plus souvent le discours spécialisé en parlant de langue de spécialité; il s'agissait avant tout du contenu lexical. Comme le remarque Pierre Lerat (1995) la spécificité des textes spécialisés tient pour une large part à leur terminologie, c'est-à-dire à l'expression des connaissances. Toutefois, ce n'est pas seulement la prédominance $\mathrm{du}$ « sens conventionnel» sur le « sens naturel» qui est remarquable, mais aussi les moyens linguistiques du transfert des connaissances : l'écriture des énoncés, une morphologie composite, une syntaxe marquée, une énonciation stylisée.

Étant donné que dans la dénomination des années $1960^{5}$ apparait le terme français de spécialité, technique et scientifique, l'enseignement se focalisait sur un domaine concret comme la médecine, le droit, l'agriculture sans mettre d'aucune façon l'accent

\footnotetext{
${ }^{4}$ Différentes appellations proposées parmi d’autres par Lehmann (1993), Abry (2007) ou Mourlhon-Dallies (2006).

${ }^{5}$ Entre 1963 et 1973, surtout à l'époque de la méthodologie SGAV (structuro-globale audiovisuelle).
} 
sur la méthodologie. Ce terme était utilisé de façon interchangeable avec celui de Français des professions qui jusqu'à aujourd'hui se maintient sur les certificats délivrés par la Chambre de commerce et d'industrie de Paris que nous citons ci-dessous.

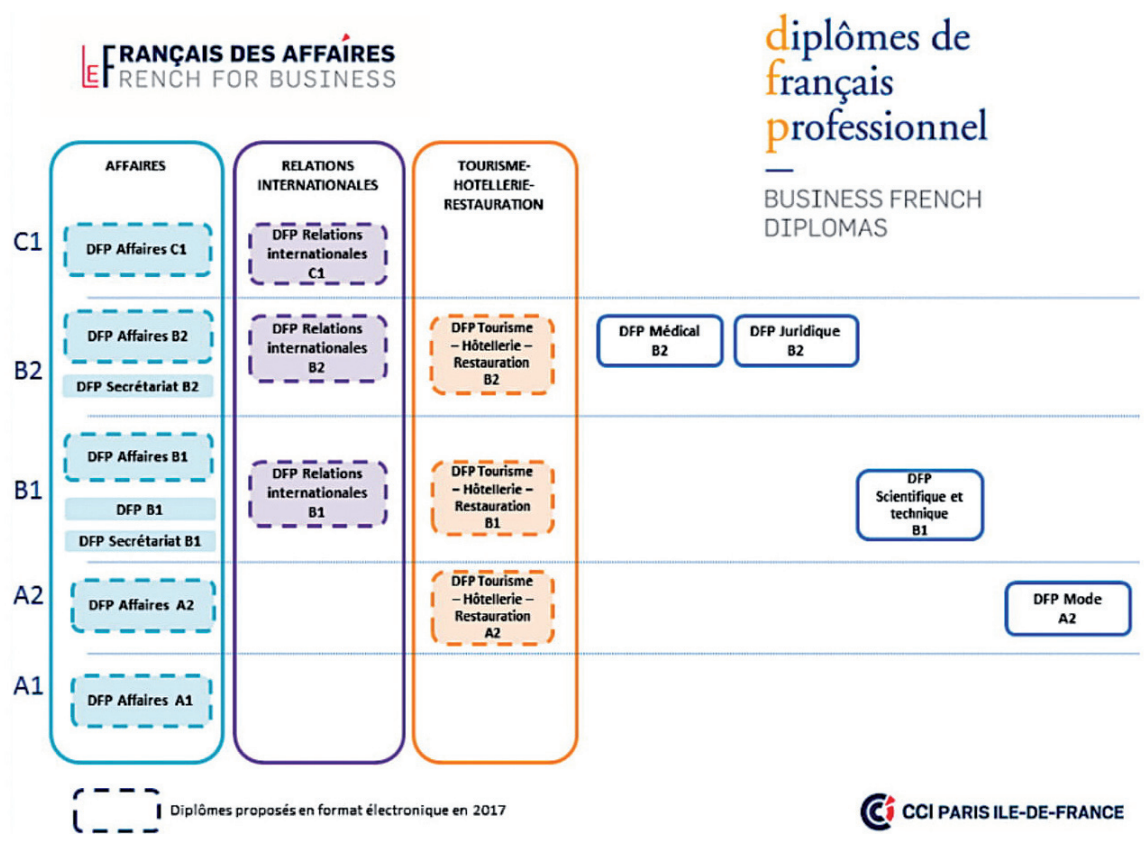

Figure 1. Répertoire de diplômes de français professionnel organisés par la Chambre de commerce et d'industrie de Paris (2017).

Source : https://www.lefrancaisdesaffaires.fr/tests-diplomes/diplomes-francais-professionnel-dfp/C.

Comme nous le voyons, certaines dénominations ne changent pas au fil des années. D'autres sont si populaires qu'en 2017 la Chambre de commerce et d'industrie de Paris a introduit des formats électroniques de certains diplômes.

\subsubsection{Le Français instrumental}

L'étape suivante, à partir des années 1970, était le développement du Français instrumental qui était une réponse à la crise dans l'enseignement du français langue étrangère. Effectivement, en Amérique du Sud, l'hégémonie de l'anglais comme langue étrangère de référence dans l'enseignement et langue de communication dans les échanges internationaux s'est très vite répandue. À cela s'ajoute le fait que le pouvoir a supprimé le français du cursus régulier dans les écoles publiques. De fait, la demande spécifique est apparue, surtout venant du public universitaire qui désirait apprendre à lire des textes scientifiques dans leur domaine d'études ou de 
recherche. La réponse est venue dans la langue française, avec pour objectif de faciliter la compréhension des textes spécialisés pour les doctorants et les universitaires ; c'était un certain type d'" un instrument » d'accès à la documentation scientifique et technique écrite.

Le public était formé par des étudiants et professeurs universitaires ayant pour but d'améliorer leurs compétences de lecture afin d'avoir accès aux bibliographies spécifiques pour le développement de leurs recherches, réussir à des examens d'accès aux programmes de master et doctorat ou même les rendre capables de faire des citations d'auteurs dans les travaux académiques. S'opposant aux cours réguliers de Français Langue Etrangère, le Français instrumental avait des caractéristiques très ponctuelles en ce qui concerne les questions méthodologiques. Selon Aupecle et Alvarez (1977 : 73), il s'agissait de mettre en valeur la réception plutôt que la production ; l'écrit plutôt que l'oral ; l'information plutôt que le plaisir esthétique ; l'orientation scientifique plutôt que la langue de spécialité ; l'orientation scientifique dans un sens très large ; la compréhension du contenu plutôt que la traduction; le niveau post-élémentaire.

Dans cette optique, les séquences didactiques mettaient en relief l'utilisation de stratégies de lecture, comme la reconnaissance des éléments transparents (entre le portugais et le français), les caractéristiques du genre textuel travaillé, les références iconographiques présentes dans les textes et aussi la prise en compte de la connaissance du monde des apprenants et les expériences de lecture en langue maternelle.

\subsubsection{Le Français fonctionnel}

La situation nouvelle de la demande linguistique plus étendue a conduit à considérer que l'enseignement du français devait être fonctionnel, c'est-à-dire répondre aux besoins et aux objectifs spécifiques des différents publics. La notion de spécialité commençait ainsi à se déplacer de la langue vers le public ${ }^{6}$. De ce fait, à la fin des années 1970 et au début des années 1980, le ministère des Affaires étrangères a mis en place le développement du Français fonctionnel ${ }^{7}$ visant à relancer le français sur la scène internationale. Ceci était lié au choc pétrolier et au conflit israélo-palestinien qui avait des répercussions négatives sur la popularité du français dans le monde. Le français fonctionnel reçoit l'appui des décideurs politiques qui, suite aux restrictions

${ }^{6}$ Il est intéressant de mentionner qu'en créant l’enseignement fonctionnel du français, les didacticiens ont insisté sur la pédagogie et l'évolution méthodologique induites par la prise en compte des besoins spécifiques de publics déterminés, constitués de boursiers effectuant une mise à niveau linguistique de 6 à 12 mois, appelée « l'année raccord », afin de leur permettre d'aborder des études ou de poursuivre des recherches avec efficacité.

${ }^{7}$ Terme lancé pour la première fois par Louis Porcher dans son article « Monsieur Thibault et le bec Bunsen », Études de linguistiques appliquée N.23, 1976. 
du budget alloué à la diffusion du français, encourageaient un enseignement du français plus ciblé, répondant à des besoins dans des domaines professionnels, scientifiques et/ou économiques.

Louis Porcher (1976 : 66) a proposé une définition du français fonctionnel ciblée sur le contenu linguistique :

[...] le français fonctionnel est constitué de tout ce qui n’est pas le français général. En réalité, il représente le nouvel accent mis sur des domaines apparemment spécifiques à l'intérieur de la langue française : discours des sciences, des techniques, de l'économie, bref de tout ce qui n'est ni littéraire, ni « touristique » (du type : où est la poste ?).

Pour la première fois, il est visible que le français diffère de la langue de culture et de littérature et devient une langue technique de la science.

Plus tard, Louis Porcher a remarqué que l'appellation nouvelle était maladroite en ce qu'elle suggérait, faussement, une antinomie entre un français fonctionnel et un français qui ne le serait pas. Cela a fortement décrédibilisé le français fonctionnel qui souffrait déjà de critiques dénonçant son ambiguité ${ }^{8}$.

\subsubsection{Le Français sur Objectif(s) Spécifique(s) (FOS)}

L'expression Français sur Objectif(s) Spécifique(s) ${ }^{9}$ (désormais FOS) qui s'est imposée au début des années 1990 était un calque de l'anglais English for special/ specific purposes ${ }^{10}$. Les théoriciens soulignent que cette vision de la langue renvoie essentiellement aux objectifs à atteindre plus qu'aux moyens pour y parvenir. Les formateurs qui enseignent le FOS ${ }^{11}$ projettent leurs leçons comme une demande

${ }^{8}$ Daniel Coste remarque que tous les emplois de «fonctionnel » ou presque sont considérés potentiellement ambigus (1980: 28 dans Holtzer, $2004: 11$ ).

${ }^{9}$ En ce qui concerne l'orthographe du terme, on en trouve deux. Le Français sur Objectifs Spécifiques au pluriel depuis 1980 était le calque de l'anglais qui est aussi au pluriel : English for Specific Purposes. La notion du Français sur Objectif Spécifique au singulier est apparue vers 2004. La différence majeure par rapport à la dénomination au pluriel s'appuie sur les caractéristiques et compétences du public auquel la formation s'adresse (Sowa, 2011 : 147). Le FOS au pluriel (Objectifs Spécifiques) signale qu'il existe une mosaïque d’objectifs incontournables, de natures diverses, que les enseignants combinent en vue d'atteindre des buts précis. Le FOS au singulier désigne les formations réservées à des opérations très ciblées, nécessitant la mise en œuvre d'une ingénierie de formation pointue (Mourlhon-Dallies, 2008 : 50).

${ }^{10}$ Hutchinson et Waters (1987) s'inscrivent comme les pionniers de l'ESP qui a vu le jour grâce à la publication de leur fameux livre «English for Specific Purposes, A Learning centred approach ». Dans cet ouvrage, ils soulignent le principe fondamental du FOS : « Toutes les décisions concernant le contenu et la méthodologie sont basées sur les raisons pour lesquelles l'apprenant apprend une langue étrangère » (Hutchinson et Waters, $1987: 19$ )

${ }^{11} \mathrm{Au}$ sein des milieux didactiques, on constate une vision quasiment partagée par la plupart des spécialistes de FOS. Ceux-ci s'accordent sur l'idée qu'il n'y a pas d'enseignement sans objectifs 
clairement identifiable et ceci en un temps de formation étroitement compté. Nous pouvons parler du FOS quand nous sommes face à une demande de formation qui provient d'un terrain concret (entreprise, institution ou l'université) qui est destinée à un public précis, clairement identifié, et qui a un lien direct avec un objectif de sortie (Abry, 2007 : 19).

Il est intéressant de remarquer que dans le contexte du FOS, les objectifs spécifiques sont avant tout des dimensions qui structurent l'intervention de l'enseignant qui ne peut former son public de «professionnels » sans prendre en compte conjointement les questions de discours, d'interculturel, de lexique spécialisé, etc. Effectivement, cela est possible, car les apprenants de FOS sont majoritairement des adultes déjà engagés dans la vie active. Ils manifestent fréquemment une perception claire de leurs besoins, restreints à un domaine langagier précis, d'où la formule pertinente de Lehmann (1993 : 115) : « ces publics apprennent DU français et non pas le français ».

Les éléments caractéristiques du FOS ont été exposés dans la figure ci-dessous :

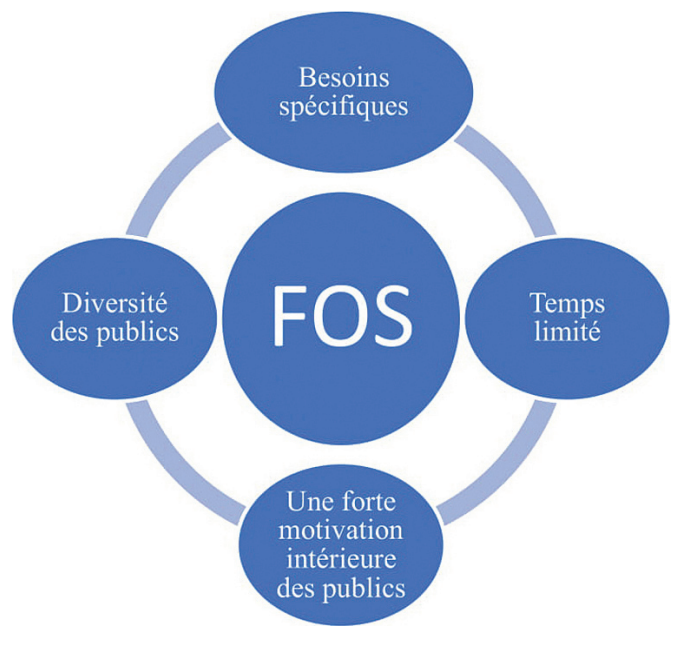

Figure 2. Caractéristiques du FOS. Source : élaboration propre.

Les apprenants du FOS disposent de peu de temps de formation, ce qui exclut de construire des parcours de formation longs avec langue académique, puis tronc commun de spécialité, et enfin langue de spécialité. En outre, ces apprenants visent une rentabilité de la formation, un retour significatif sur investissement en formation (d'où des exigences sur la qualité de la formation proposée) et présentent une forte motivation professionnelle et/ou sociale.

et qu'il n'y a pas d'enseignement sans spécification des objectifs. Il s'agit plutôt des priorités de l’enseignement visé par le public concerné. 
Il est important de souligner que le FOS n'est pas une méthode mais plutôt un terme qui se réfère aux situations concrètes. Le FOS est une partie de la méthodologie du FLE destiné à un public adulte porteur d'une demande communicative professionnelle. Le FOS propose à l'enseignant d'axer sa méthodologie sur une analyse des besoins de ses apprenants pour aboutir à la création d'un programme personnalisé.

\subsubsection{Le Français à visée professionnelle et le Français Langue Professionnelle}

Au début des années 2000, le Français à visée professionnelle ${ }^{12}$ et le Français Langue Professionnelle $^{13}$ (désormais FLP) ont vu le jour. Ces appellations ont commencé à coexister avec celle de FOS. Cependant, il faut remarquer que ces appellations récentes ne s'opposent pas aux précédentes mais les complètent.

Quant au FLP, nous trouvons que c'est dans le public concerné que réside la différence majeure par rapport au FOS. Florence Mourlhon-Dallies (2008 : 72) remarque que le FLP renvoie à une démarche d'enseignement du français à des fins professionnelles s'adressant à des salariés francophones ou non francophones qui exercent leur profession en français. Le FLP répond au contexte socio-économicopolitique français qui est lié à la création en 2004 du Droit Individuel à la Formation, notamment la formation linguistique, ainsi qu'à l'accroissement de la " part langagière » du travail, que ce soit à l'écrit ou à l'oral. Cette part langagière du travail nécessite de former une partie de la main d'œuvre illettrée française ou étrangère, pour développer ou maintenir l'employabilité des personnes. Effectivement, comme le niveau de professionnalisation de ce public n'est pas très élevé, nous avons affaire à des personnes qui soit se perfectionnent en français, soit l'apprennent pour la première fois dans le but d'accéder à l'emploi et de s'intégrer à une communauté professionnelle francophone. À cela s'ajoute l'augmentation des flux migratoires des professionnels bien qualifiés qui cherchent à s'intégrer dans la vie active en France ou dans un pays francophone. Ces migrants font face à une double difficulté pour accéder aux plans de formation : la non-maitrise de la langue et l'occupation de postes

${ }^{12}$ Cette nouvelle appellation a été introduite pour des raisons d’ordre stratégique et politique plutôt que méthodologique et didactique. à la source de ce nom, il faut voir l'apparition de nouveaux demandeurs de formation. Magdalena Sowa (2011 : 139) parle de la prolifération des appellations concernant l'enseignement du français tout en multipliant ses définitions et ses objectifs au prix de la confusion des notions trop nombreuses.

${ }^{13}$ Appellation proposée par Florence Mourlhon-Dallies (2006) : «On nous pardonnera donc d'accroitre une liste déjà trop longue, en faisant état de récentes mutations du FOS dont le français à visée professionnelle et le français langue professionnelle sont les derniers - et sans nul doute provisoires - avatars " (Mourlhon-Dallies, $2006: 25$ ). 
peu qualifiés. De plus, parmi ces migrants, nous trouvons des arrivants qui ont reçu une faible formation initiale ou pire, qui souffrent d'analphabétisme. Dans de telles conditions, ces migrants ont du mal à avoir accès à une formation qualifiante et à réaliser leur stabilité professionnelle. De ce fait, des formations à partir du FLP pourraient contribuer à améliorer le statut des migrants ou des réfugiés en France.

Quant au français à visée professionnelle ${ }^{14}$ - il s'adresse en priorité à un public étranger moins avancé en français et moins formé dans sa spécialité.

Pour finir, nous pourrions dire que le FOS a été obligé de s'adapter aux besoins du marché, basés notamment sur des demandes croissantes du monde professionnel. D'une part, nous assistons à une diversification des domaines professionnels qui sont de plus en plus pointus (la mode, l'aéronautique, l'art floral, etc.). D'autre part, nous pouvons de plus en plus voir l'émergence des demandes d'amélioration des compétences en français des professionnels de qualification faible. Ces demandes émanent dans la plupart des cas d'organisations professionnelles pointues (office de professions, fédérations professionnelles, écoles spécialisées, etc.).

En guise de synthèse, nous récapitulons les propos ci-dessus dans le tableau 1.

Tableau 1. Répertoire des appellations du FLE dans le contexte professionnel.

\begin{tabular}{|l|l|l|}
\hline \multicolumn{1}{|c|}{ Période } & \multicolumn{1}{|c|}{ Dénomination } & \multicolumn{1}{c|}{ Public } \\
\hline Années 1960 & $\begin{array}{l}\text { Français de spécialité } \\
\text { Français technique } \\
\text { Français scientifique }\end{array}$ & $\begin{array}{l}\text { Professionnels } \\
\text { (non scolaire) }\end{array}$ \\
\hline Années 1970 & $\begin{array}{l}\text { Français instrumental } \\
\text { (Amérique du Sud) }\end{array}$ & $\begin{array}{l}\text { Public universitaire } \\
\text { (étudiants, chercheurs) }\end{array}$ \\
\hline Années 1980 & $\begin{array}{l}\text { Français fonctionnel ou } \\
\text { enseignement fonctionnel du français }\end{array}$ & Professionnels, étudiants \\
\hline Années 1990 & Français sur objectif(s) spécifique(s) & Public précis \\
\hline Années 2000 & Français à visée professionnelle & $\begin{array}{l}\text { Public moins formé dans sa spécialité } \\
\text { et moins avancé en français }\end{array}$ \\
\hline Années 2000 & $\begin{array}{l}\text { Français langue professionnelle } \\
\text { (FLP) }\end{array}$ & $\begin{array}{l}\text { Salariés francophones ou non } \\
\text { francophones qui exercent leur } \\
\text { profession en français }\end{array}$ \\
\hline
\end{tabular}

Source : élaboration propre à partir du modèle proposé par Abry (2007) et Lehmann (1998).

${ }^{14}$ Par rapport au FOS et au français de spécialité, le français à visée professionnelle offre sans doute un marché plus porteur. Des flots détudiants étrangers (le poids en population de pays comme la Chine ou l'Inde) constituent un public qui ne nécessite pas obligatoirement l'envoi en mission de «super formateurs » spécialisés dans des domaines précis. D’où vient peut-être la tentation de faire oublier le FOS et les autres appellations, au profit du seul français à visée professionnelle, plus actuel et plus prometteur. 


\subsection{Les approches méthodologiques proposées dans l'enseignement/ apprentissage de la langue de spécialité}

Dans ce qui précède, nous avons vu que la différence entre des appellations de l'enseignement du français à des publics spécialisés ou professionnels dépend beaucoup du moment d'apparition dans le champs du FLE. Dans la littérature touchant à ce domaine, nous pouvons constater que l'évolution des idées didactiques tend vers deux directions précises.

Premièrement, il est question de dépasser le niveau de la langue au profit du discours et, deuxièmement, de ne pas s'arrêter au niveau spécialisé mais viser le professionnel. Magdalena Sowa (2011 : 53) souligne que cela n'aurait pas été possible si l'on avait enfermé cette réflexion dans la seule perspective linguistique tout en oubliant les aspects extérieurs de la langue. Les conceptions de l'enseignement/ apprentissage ont choisi d'articuler la langue avec le contexte dans lequel celle-ci fonctionne et se concrétise tout en prenant compte des éléments socioculturels, économiques, cognitifs et processionnels.

Pour comprendre ce que chaque dénomination désignait réellement, il serait utile de voir de plus près les approches méthodologiques proposées par chaque concept mentionné ci-dessus. Ce panorama semble nécessaire pour voir ce qu'a dû comprendre la didactique des langues pour en arriver à l'état actuel.

$\mathrm{Au}$ niveau méthodologique, la langue de spécialité/technique/scientifique des années 1960 rejoint le Français fondamental où l'accent était mis sur le contenu du cours et notamment le lexique. Ceci était illustré en 1961 par Roger-François Gaultier qui croyait qu'il y avait trois catégories principales : les sciences exactes et naturelles, les sciences humaines et les Arts/les Lettres. Selon son célèbre modèle repris en 1993 par Dennis Lehmann (page 29), l'enseignant préparait ses apprenants à travers quatre étapes dont les deux premières étaient consacrées au français fondamental qui était très populaire à l'époque. Seules la troisième et la quatrième étapes visaient à initier les apprenants aux langues spécialisées selon leurs domaines.

Cette approche favorisait l'écrit et l'usage des documents fabriqués. Ceci ne mettait pas les apprenants en contact direct avec de vrais documents spécifiques à leurs domaines spécialisés, ce qui pouvait être, aux yeux des apprenants, une sorte de fossé séparant l'apprentissage et la réalité qu'ils affronteraient plus tard.

Quant au français instrumental, il faut dire qu'une importance particulière était accordée au développement de la capacité de lecture et pas vraiment à l'expression ou à la compréhension orale ce qui était d'ailleurs souvent critiqué par des didacticiens. Magdalena Sowa (2011) remarque que l'inconvénient de cette approche réside dans le fait qu'elle n'active que les compétences de compréhension et de production écrite, tout en laissant de côté celles de compréhension et d'expression orale, indispensables dans les interactions face à face en milieu professionnel.

Quelques années plus tard, les didacticiens, conscients des manques et des limites des approches précédentes que nous avons mentionnées ci-dessus, ont 


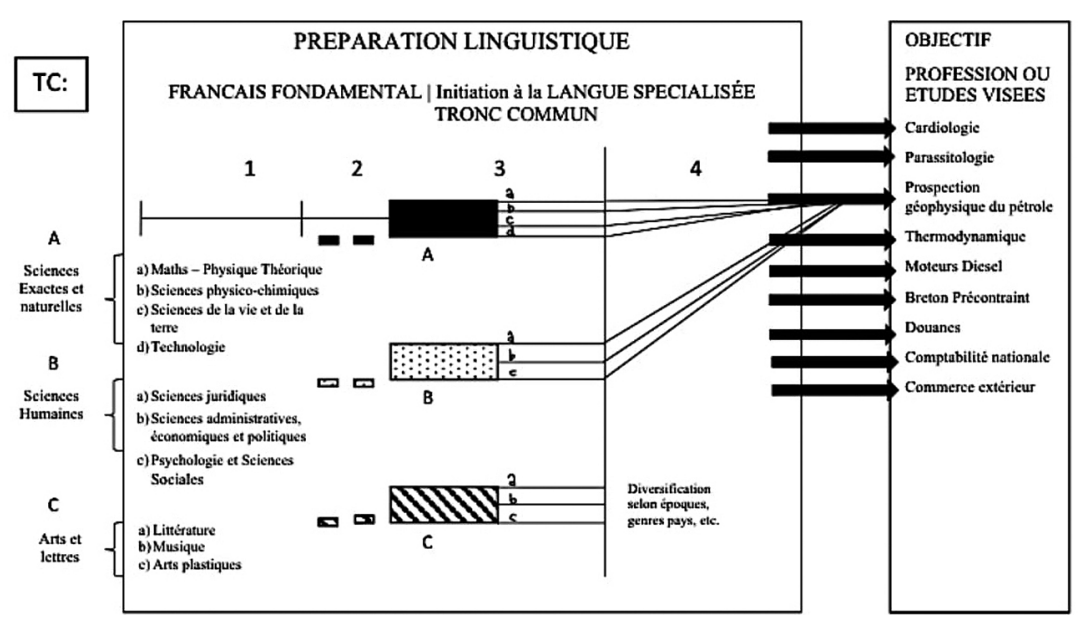

Figure 3. Modèle de la langue de spécialité/ technique et scientifique de R-F.Gaultier de 1961. Source : le modèle de Roger-François Gaultier repris par Dennis Lehmann (1993 : 72).

enfin été amenés à prendre en compte la personne de l'apprenant. Ainsi, l'approche méthodologique du français fonctionnel, marquée par les idées de Denis Lehmann (1998), Sophie Moirand (1978) et Rémy Porquier (2004) se concentre sur les besoins des apprenants, les situations de communication prévues (scènes à jouer), l'analyse des actes de parole et du discours. Les trois chercheurs ont tous rejeté les cursus longs, les méthodes lourdes, l'accent mis sur le lexique ainsi que les documents fabriqués. Cette nouvelle tendance ${ }^{15}$ ne fait que préparer le terrain aux termes connus aujourd'hui, comme celui de FOS.

Vient finalement l'analyse du Français sur Objectif(s) Spécifique(s). Nous constatons qu'il n'existe pas de moyens spécifiques, car l'enseignement du FOS implique un public restreint à des objectifs précis et c'est le rôle de l'enseignant de construire le matériel didactique adapté afin de pallier la thématique professionnelle généraliste des manuels. Le FOS privilégie avant tout les documents authentiques ${ }^{16}$ ou semi-authentiques qui travaillent sur les aspects culturels et les savoir-faire langagiers. L'approche communicative est basée sur l'analyse des situations de communication professionnelle et « pédagogie du projet ». La priorité est donnée à la communication et la participation

${ }^{15}$ Certes, le français fonctionnel néchappe pas aux critiques de certains didacticiens qui lui reprochent par exemple la linéarité de son processus (analyse de besoins, détermination des situations de communication, etc.).

${ }^{16}$ Selon Besse (1984 : 136), « le document authentique doit être un échantillon prélevé au sein des échanges ayant réellement eu lieu entre les natifs de la langue enseignée/apprise et donc être conforme à leurs pratiques langagières authentiques; il doit correspondre aussi précisément que possible aux intérêts et préoccupations des étudiants ». 
de l'enseignant est limitée ou discrète pendant le déroulement des activités. Comme le soulignent Jean-Marc Mangiante et Chantal Parpette (2004: 17) :

La classe devient le champ d'action des apprenants ; l'enseignant devant favoriser le plus possible une communication réelle dans le cours en favorisant l'échange d'informations et la concertation; il devra combiner le travail collectif avec des moments de travail individuel, voire autonome.

Quant aux exercices utilisés dans le FOS, ils ne diffèrent pas des exercices du cours de français général. Ce n'est donc pas la forme, mais leur objectif qui diffère dans ce type de formation. Cependant, il ne faut pas négliger le fait que la compétence linguistique n'est pas en FOS une fin en soi, mais un outil pour acquérir une compétence professionnelle (Abry, $2007: 41$ ).

En dernier point, analysons l'approche méthodologique du français professionnel dont la popularité et la demande ne cessent d'augmenter ${ }^{17}$. Face à de telles demandes de formation de FLP, le monde didactique essaye d'y répondre au niveau des institutions, de l'élaboration des manuels ${ }^{18}$ et des formations proposées ${ }^{19}$. Le FLP utilise des documents authentiques qui se focalisent sur la communication et l'action. Les compétences langagières sont subordonnées à la logique de la branche professionnelle. Nous avons affaire ici à l'approche post-communicative et aux apports d'autres disciplines : sociologie, ethnographie, pragmatique, etc.

De surcroit, il faut souligner le caractère ambigu du FLP. L'originalité du FLP réside dans le fait qu'il transcende les frontières entre les français langue maternelle (FLM), français langue seconde (FLS) et français langue étrangère (FLE) car il peut s'appliquer à des formations pour de jeunes Français sans emploi (FLM) ou pour des immigrés étrangers (FLS ou FLE).

Il s'ensuit de ce qui précède que l'interprétation du FLP donne beaucoup de liberté aux enseignants et son interprétation dépend du formateur ainsi que des besoins du public.

Afin de rendre les données plus lisibles, nous avons groupé dans le tableau ci-après les compétences visées, les supports utilisés en classe de langue à des fins professionnelles ainsi que la méthodologie didactique dominante dans l'approche analysée.

${ }^{17}$ Le FLP a connu une augmentation de $250 \%$ en 2005 (Mangiante 2005).

${ }^{18}$ Le Français.Com (Penfornis, 2002), Affaires.Com (Penfornis, 2003), Hôtellerie/Restauration. com (Corbeau, Dubois, Penfornis, 2006), Tourisme.com (Corbeau, Dubois, Penfornis, 2004), Les mots pour construire (Letertre, 2006).

${ }^{19}$ La Chambre de Commerce et d'Industrie de Paris (CCIP) propose le Certificat de Français Professionnel 1 et 2 (CFP1 et 2). 
Tableau 2. Approches méthodologiques relatives à l'enseignement des langues à des fins professionnelles.

\begin{tabular}{|c|c|c|c|c|c|}
\hline Période & Dénomination & $\begin{array}{l}\text { Compétences } \\
\text { visées }\end{array}$ & Supports & $\begin{array}{l}\text { Priorité } \\
\text { donnée à }\end{array}$ & $\begin{array}{l}\text { Méthodologie } \\
\text { didactique }\end{array}$ \\
\hline $\begin{array}{l}\text { Années } \\
1960\end{array}$ & $\begin{array}{l}\text { Français de } \\
\text { spécialitél } \\
\text { Français } \\
\text { techniquel } \\
\text { Français } \\
\text { scientifique }\end{array}$ & $\begin{array}{l}\text { Maîtrise d'un } \\
\text { vocabulaire } \\
\text { spécialisé }\end{array}$ & $\begin{array}{l}\text {-répertoires } \\
\text { de lexique } \\
\text { spécialisé }\end{array}$ & $\begin{array}{l}\text { la langue } \\
\Rightarrow \text { parler sur }\end{array}$ & $\begin{array}{l}\text { SGAV, } \\
\text { le Français } \\
\text { Fondamental }\end{array}$ \\
\hline $\begin{array}{l}\text { Années } \\
1970\end{array}$ & $\begin{array}{l}\text { Français } \\
\text { instrumental }\end{array}$ & $\begin{array}{l}\text { Lecture et } \\
\text { compréhension } \\
\text { écrite de la } \\
\text { documentation } \\
\text { spécialisée }\end{array}$ & $\begin{array}{l}\text {-textes } \\
\text { spécialisés } \\
\text { bruts }\end{array}$ & $\begin{array}{l}\text { la langue } \\
\Rightarrow \text { parler sur }\end{array}$ & $\begin{array}{l}\text { Méthode par la } \\
\text { lecture }\end{array}$ \\
\hline $\begin{array}{l}\text { Années } \\
1980\end{array}$ & $\begin{array}{l}\text { Français } \\
\text { fonctionnel ou } \\
\text { enseignement } \\
\text { fonctionnel du } \\
\text { français }\end{array}$ & $\begin{array}{l}\text { Compétence de } \\
\text { communication } \\
\text { (lire, écouter, } \\
\text { parler, écrire) } \\
\text { liée aux besoins } \\
\text { et objectifs de } \\
\text { l'apprenant }\end{array}$ & $\begin{array}{l}\text {-documents } \\
\text { authentiques } \\
\text { ou semi- } \\
\text { authentiques }\end{array}$ & $\begin{array}{l}\text { la langue } \\
\text { et la com- } \\
\text { munication } \\
\Rightarrow \text { parler sur }\end{array}$ & $\begin{array}{l}\text { Approche } \\
\text { communicative } \\
\text { basée sur } \\
\text { l'analyse des } \\
\text { besoins }\end{array}$ \\
\hline $\begin{array}{l}\text { Années } \\
1990\end{array}$ & FOS & $\begin{array}{l}\text { Compétence de } \\
\text { communication } \\
\text { (souvent partielle) } \\
\text { focalisée sur les } \\
\text { besoins immé- } \\
\text { diats liés au mé- } \\
\text { tier exercé ou au } \\
\text { posté occupé }\end{array}$ & $\begin{array}{l}\text {-documents } \\
\text { authentiques } \\
\text { ou semi- } \\
\text { authentiques }\end{array}$ & $\begin{array}{l}\text { la commu- } \\
\text { nication } \\
\text { parler avec } \\
\Rightarrow \text { agir sur }\end{array}$ & $\begin{array}{l}\text { Approche } \\
\text { communicative } \\
\text { basée sur } \\
\text { l'analyse des } \\
\text { situations de } \\
\text { communication } \\
\text { professionnelle } \\
\text { et "pédagogie } \\
\text { du projet» }\end{array}$ \\
\hline $\begin{array}{l}\text { Années } \\
2000\end{array}$ & $\begin{array}{l}\text { Français } \\
\text { à visée } \\
\text { professionnelle } \\
\text { /Français } \\
\text { langue } \\
\text { professionnelle }\end{array}$ & $\begin{array}{l}\text { Compétences } \\
\text { langagières subor- } \\
\text { données à la logi- } \\
\text { que de la branche } \\
\text { professionnelle et/ } \\
\text { ou le métier }\end{array}$ & $\begin{array}{l}\text {-documents } \\
\text { authentiques }\end{array}$ & $\begin{array}{l}\text { la commu- } \\
\text { nication et } \\
\text { l'action } \\
\Rightarrow \text { parler } \\
\text { avec } \\
\Rightarrow \text { agir avec }\end{array}$ & $\begin{array}{l}\text { Approche post- } \\
\text { communicative } \\
\text { (avec les } \\
\text { apports d'autres } \\
\text { disciplines) }\end{array}$ \\
\hline
\end{tabular}

Source : élaboration propre à partir du modèle proposé par Sowa (2011 op.cit.). 


\subsection{Langue à des fins professionnelles - une pratique didactique revisitée}

Nous avons vu que les mutations qui se sont produites au sein de l'économie, de la technologie et de la société ne sont pas restées sans influence sur les conceptions relatives à l'enseignement/apprentissage des langues. Néanmoins, il est à noter que malgré une forte conscience d'un lien étroit entre la langue et le travail exercé chez les professionnels, les institutions officielles d'éducation ne se sont chargées de ce type d'enseignement qu'après la Seconde Guerre mondiale (Gajewska et Sowa, 2008 : 56). Il en résulte que, malgré de nombreuses recherches, la tradition des démarches didactiques en français à des fins professionnelles n'est pas si ancienne et que des pratiques pédagogiques spécifiques nécessitent d'être revisitées.

\subsubsection{Langue à des fins professionnelles pour les débutants}

Parler de la langue de spécialité revient à aborder le sujet du moment où l'apprenant peut commencer à étudier la langue de spécialité. On souligne à plusieurs reprises dans la littérature que c'est une question difficile à trancher, car le début de l'apprentissage de la langue de spécialité demeure un objet d'étude toujours difficilement explorable et peu palpable, vu que sa perception et par la suite sa définition posent de nombreuses difficultés.

Pendant longtemps, on persistait dans l'idée que la langue de spécialité devrait être enseignée au niveau intermédiaire/avancé. Les productions pédagogiques du français scientifique et technique du CREDIF ne faisaient que refléter cette tendance. ${ }^{20} \mathrm{En}$ effet, jusqu'aux années 2010, il existait une représentation très répandue selon laquelle le FLP ou le FOS ne pourraient être abordés qu’après 200-300 heures de français général, c'est-à-dire après que les apprenants obtiennent au moins le niveau B1.

Cette tendance est reflétée dans des indications dans les manuels de français des affaires des années 2004, dans lesquels nous pouvons lire que « le débit du professeur ainsi que le vocabulaire utilisé est adapté à des étudiants de langue maternelle non francophone d'un niveau fin B1 selon le Cadre Européen Commun de Références (CECRL) » (Gautier, 2004 : 5), ou que : « les étudiants doivent avoir une formation initiale en FLE. Un niveau B1 est requis pour aborder le travail avec cette méthode ». Mangiante et Parpette (2004 : 72) suggèrent également qu'il est préférable pour l'enseignement d'utiliser une méthode généraliste en début de formation et de

${ }^{20}$ Les vocabulaires spécialisés : Vocabulaire d'initiation aux études agronomiques, Vocabulaire d'initiation à la critique et à l'explication littéraire, Vocabulaire d'initiation à la vie politique et Vocabulaire d'initiation à la géologie; le Vocabulaire Général d'Orientation Scientifique (VGOS), un inventaire permettant de combler les lacunes entre le Français fondamental et les langues de spécialité (Mercelot, $2013: 12$ ). 
consacrer l'énergie et le temps à la création d'un matériel spécifique destiné à un niveau un peu plus avancé.

Toutefois, nous pensons comme beaucoup d'autres experts que l'enseignement de la langue de spécialité est bel et bien possible aussi à un public débutant. Ainsi, nous sommes d'accord avec Laurence Riehl, Michel Soignet et Marie-Hélène Amiot (2007 : 1) que :

le FOS était souvent réduit à l'enseignement de la terminologie propre à un domaine spécifique. Par contre, le FOS doit aller plus loin que la terminologie : il inclut la capacité à accomplir des tâches professionnelles et donc la pratique des quatre compétences dans un domaine qui possède ses propres savoir-faire et savoir-être. Le prérequis d'un cursus de français général s’avère ainsi inutile.

En fait, nous croyons que le processus d'apprentissage doit être rapide et efficace et qu'un cours pour les publics spécifiques n'est pas forcément un cours sur un domaine spécifique mais englobe aussi bien le français général et permet également l'enseignement à des débutants. Il convient de mentionner à cette occasion des avantages présentés par une telle approche. Tout d'abord, l'exploitation du langage technique ou spécifique permet d'éviter l'un des problèmes pédagogiques principaux rencontrés dans l'enseignement des langues aux adultes. En effet, les faux débutants sont souvent découragés par le décalage évident entre leur niveau intellectuel et leurs capacités d'expression en langue étrangère. Le contenu des dialogues authentiques dans la langue quotidienne est souvent banal, et sans véritable intérêt. Lorsque l'on demande aux étudiants de travailler sur des versions simplifiées de ces dialogues, ils peuvent avoir l'impression de perdre leur temps avec des exercices enfantins. Le langage spécifique qui est lié à leur domaine, en revanche, permet d'exprimer des vérités profondes d'une manière claire et simple. Les spécialistes de la discipline connaissent mieux que les « natifs » non-spécialistes le vocabulaire approprié et les conventions rhétoriques couramment appliquées dans les textes techniques; cela ne peut que favoriser la motivation et donc l'apprentissage à partir du niveau élémentaire ${ }^{21}$.

\subsubsection{Enseignement du français à des publics spécialisés : difficultés de l'enseignant}

Un autre point qui nous semble important de discuter est la question liée au degré de compétence dans cette dimension spécifique du français, du fait que les enseignants ne sont généralement pas spécialistes du FOS. Il arrive que les formateurs

${ }^{21}$ Jolanta Zając remarque que (2004 : 15) le plus important dans cette approche serait d'intéresser les apprenants, d’éveiller leur curiosité, les inciter à s'engager personnellement. Les matériaux dans ce cas-là devraient s'appuyer sur l'expérience et les connaissances des apprenants, viser la communication, offrir de bons exemples d'une utilisation naturelle de la langue, offrir une possibilité de choix dans le contenu, tenir compte de différences d'intérêts, de styles, de rythmes d’apprentissage. 
travaillant dans le contexte professionnel se posent la question s'ils doivent être spécialistes du domaine dans lequel ils enseignent le français de spécialité. De ce fait, il nous semble judicieux de porter l'intérêt à cette question, récurrente dans le domaine de la didactique de la langue de spécialité, puisque la demande en FOS augmente et le nombre de formateurs préparés à ce type d'enseignement est relativement faible ${ }^{22}$.

Ainsi, la plupart des enseignants assurant les cours de FOS ont une formation de "français général ", c'est-à-dire une Maîtrise en langue et lettres françaises ou un diplôme supérieur dans l'une des spécialités relatives au français. Il est à noter que ces enseignants sont en grande majorité des professeurs d'enseignement secondaire détachés dans le supérieur. Il en résulte que cette formation de langue et lettres françaises ne prépare donc en rien à enseigner le français à des publics spécifiques. Les formateurs se trouvant dans cette situation, généralement par choix personnel ou pour des raisons autres que didactiques, n'ont d'autre alternative que de compter sur eux-mêmes pour s'assurer une mise à niveau et une autoformation dans le domaine du FOS. Dans la littérature traitant le sujet (Challe, 2002 : 18), on remarque que, quelle que soit l'expérience du professeur de français en enseignement des langues, il peut avoir la crainte de rencontrer un public spécialisé dans une profession ou une science.

En outre, il est à noter que face à un public, quasi spécialiste, les enseignants ne sont pas les seuls à détenir tout le savoir. Bien évidemment, ils maîtrisent mieux les connaissances langagières que leurs apprenants mais ce sont ces derniers, «spécialistes», "professionnels» qui connaissent mieux le domaine dans lequel ils travaillent, leur milieu «naturel». Une question s'ensuit : comment marier ces deux compétences?

Il s'agit en ce cas de trouver un nouvel équilibre. Pour y arriver, l'étudiant doit être vu comme un outil d'appui dans l'approfondissement de la spécialité et l'enseignant doit s'en servir et devenir le médiateur entre la langue étrangère et les apprenants. D'autant plus qu'enseigner le français de spécialité, c'est intervenir à deux niveaux. D'une part, animer un groupe que l'on pilote pour favoriser les actions et le faire cheminer dans une direction décidée en commun. D’autre part, il convient de suivre individuellement les participants à ce groupe, car leur origine, leur personnalité mais surtout leur projet professionnel et donc personnel les différencient les uns des autres.

${ }^{22}$ Les informations recueillies dans notre travail professionnel, nos entretiens personnels avec des enseignants ainsi que la littérature du sujet : "l'enseignant refuse aujourd'hui d'assurer des cours auprès de publics spécialisés (dont les besoins langagiers sont spécifiques) du fait de sa méconnaissance du domaine et/ou de son appréhension ainsi que de la multiplicité des investissements nécessaires à lélaboration d'un cours de FOS » Qotb $(2008$ : 81) ou encore « [...] les statistiques montrent que l'enseignement du français de spécialité progresse globalement autour de la planète $[\ldots] »($ Challe, $2002: 5)$. 
Par ailleurs, des didacticiens soulignent à juste titre que cette relation «les enseignants-spécialistes de langue » et "les apprenants-spécialistes dans le domaine ", ne présente aucun danger si elle est exploitée. Effectivement, si l'enseignant est bien préparé à cette rencontre, il ne court aucun risque d'être déstabilisé. Florence Mourlhon-Dallies (2003:4) remarque que :

si l'on aborde le lexique spécialisé selon des approches relevant tour à tour des logiques linguistique, disciplinaire et professionnelle, il est tout à fait possible d'entrer dans la spécialité sans maîtriser pour autant celle-ci dans son intégralité.

Pour résumer, l'enseignant ne peut rien faire contre cette crainte, excepté peut-être la minimiser en rendant son enseignement aussi efficace que possible. Il appartient aux enseignants de développer et de perfectionner leurs compétences. Pourtant, il ne faut pas oublier que les compétences que le professeur devrait développer ou améliorer sont surtout d'ordre méthodologique et didactique. Précisons qu'il s'agit avant tout de reconsidérer et redéfinir la notion de langue sur les objectifs spécifiques, «non comme un recueil de termes plus ou moins abrupts - mais comme une langue en situation d'emploi professionnel» (Mourlhon-Dallies, ibid.: 6), comme " langue en spécialité » et non « langue de spécialité » (Lerat dans Mourlhon-Dallies, ibid. : 7).

Nous venons de voir toute une panoplie de définitions et des appellations du français à des fins professionnelles ainsi que des défis majeurs liés à son enseignement/apprentissage. Il est temps d'analyser le français de la diplomatie et ses particularités.

\subsection{Le français de la diplomatie et sa place dans le contexte professionnel}

La recherche décrite dans cet ouvrage se concentre autour du concept de la langue à des fins professionnelles et notamment sur le français de la diplomatie. De ce fait, nous voudrions porter notre réflexion maintenant autour de la notion du français de la diplomatie et de la place qu'il occupe dans cette prolifération d'appellations décrites ci-dessus.

\subsubsection{Les cadres du français de la diplomatie}

Tout d'abord, remarquons que même si le métier de diplomate est l'objet de nombreuses représentations littéraires ou historiques, il reste cependant peu étudié. Entre l'image prestigieuse du diplomate, qui agit directement sur le cours des relations 
internationales et celle d'un monde plus futile tourné vers les réceptions et les mondanités, le grand public ne sait pas à quoi s'en tenir sur les métiers diplomatiques, en quoi ils consistent réellement.

Selon les chercheurs dans ce domaine (Loriol, Piotet, 2007 ou Boussard, Porteret, 2009), contrairement à d'autres emplois publics, les usagers ont peu l'occasion de rencontrer des diplomates ce qui favorise probablement des fantasmes et des représentations déformées de la réalité. Dans cette perspective, définir les cadres de la langue de la diplomatie semble encore plus difficile, flou ou divergent. Par ailleurs, la définition du français de la diplomatie serait différente pour différents usagers de cette langue.

En effet, la variété des diverses définitions du métier de diplomate influence la circonscription du français de la diplomatie d'une façon claire et nette. Cependant, derrière toutes ces formules, il nous semble possible de percevoir la présence d'une constance : le public.

Pour nous, la meilleure façon de caractériser le français de la diplomatie est de décrire le public qui veut l'apprendre. Ainsi, il s'agit des apprenants qui travaillent ou vont travailler dans des institutions européennes et apprennent cette langue pour en faire un usage déterminé dans un contexte déterminé, avec des objectifs concrets. Il ne faut pas négliger les cadres des organisations internationales ou régionales ayant besoin d'utiliser le français dans leur contexte professionnel, les fonctionnaires nationaux susceptibles d'avoir un rôle dans les travaux d'institutions internationales ou européennes et les apprenants souhaitant tout simplement acquérir ou perfectionner des compétences en français de la diplomatie pour des études supérieures. Enfin, il y a aussi les étudiants en relations internationales, administration ou sciences politiques comme ceux du Collège d'Europe à Natolin.

\subsubsection{Les besoins spécifiques des apprenants du français de la diplomatie au Collège d'Europe de Natolin}

Nous venons de constater que le français de la diplomatie échappe aux définitions et peut être enseigné différemment selon les besoins des publics concernés. Dans cette optique, la question dans quelle catégorie (FLP, FOS, Français instrumental ou Français fonctionnel) se placent les cours de français de la diplomatie pour les étudiants du Collège d'Europe à Natolin semble avoir autant de réponses qu'il y a de formateurs responsables de ceux-ci.

Il convient de rappeler que le programme du français de la diplomatie au Collège d'Europe de Natolin se focalise sur un public spécifique d'étudiants non francophones qui appartiennent à une communauté institutionnelle et participent à un projet commun : les études européennes interdisciplinaires. C'est un public qui ne veut pas « apprendre le français mais plutôt DU français POUR agir dans un contexte spécifique » (Lehmann, 1993 : 114). 
Par ailleurs, les apprenants en question sont majoritairement des adultes déjà engagés dans la vie active. Ils manifestent fréquemment une perception claire de leurs besoins. De plus, ils disposent de peu de temps de formation, ce qui exclut de leur construire, comme à l'époque des langues de spécialité, des parcours de formation longs avec langue académique, puis tronc commun de spécialité, et enfin langue de spécialité. Ces apprenants visent d'autre part une rentabilité de la formation, un retour significatif sur investissement en formation et présentent une forte motivation professionnelle et/ou sociale. Denis Lehmann (1993: 7) rassemblait au début des années 1990 les traits généraux des apprenants de FOS dans le portrait suivant : « ces publics se caractérisent à la fois par leur très grande diversité, par le fait qu'ils ont des besoins précis en matière de capacités langagières visées, et qu'ils disposent de peu de temps pour atteindre les objectifs que ces besoins permettent de définir ».

Les professeurs qui mènent les cours de français de la diplomatie du Collège d'Europe ${ }^{23}$ essayent d'analyser les besoins spécifiques de leur public d'apprenants donné avant le début du cours et ainsi cibler leurs cours (les besoins se modifient au fur et à mesure que l'enseignement se déroule). Nous voyons donc que ces caractéristiques sont propres à la démarche du FOS qui n'est pas un domaine séparé du FLE (Mangiante et Parpette, $2004: 144$ ).

En outre, soulignons encore que le cours de français de la diplomatie dispensé au Collège d'Europe n'est pas un objet en soi, ce n'est pas un enseignement disciplinaire, mais une certaine utilisation de la langue. Ce cours peut être considéré comme une passerelle entre le monde diplomatique et le monde " courant ». Nous nous inscrivons donc dans une optique « un français pour » qui accompagne une démarche FOS plutôt qu' "un français particulier » de l'optique du français fonctionnel ou français professionnel.

\subsubsection{Le français de la diplomatie dans les matériaux didactiques}

Depuis plus d'une décennie nous pouvons observer une prolifération des échanges au sein des instances européennes et internationales qui a causé une augmentation du nombre de fonctionnaires et de diplomates apprenant le français. Il semblerait alors que le français des relations internationales ou de la diplomatie arrivent en première position parmi les spécialités les plus souvent choisies par les apprenants du français.

Toutefois, face à de telles demandes, nous avons remarqué qu'il n'existe pas vraiment de large choix de cours ou de matériaux qui s'occupent de la question du français de la diplomatie. En dehors du manuel Objectif Diplomatie. Le français des

\footnotetext{
${ }^{23}$ C'est ce que nous a permis de constater notre questionnaire exploratoire soumis à certains enseignants du Collège d'Europe.
} 
relations européennes et internationale ${ }^{24}$ dont nous parlerons dans les détails plus tard et du recueil d'activités linguistiques Diplomatie.com ${ }^{25}$, il n'y a pas de grand choix de méthodes que les enseignants de français de la diplomatie ou des relations internationales pourraient utiliser en classe de $\mathrm{FOS}^{26}$. C'est d'autant plus intéressant que depuis 2006 le CIEP (Centre international d'études pédagogiques) organise l'examen TCF RI (Test de connaissance du français, version relations internationales) ${ }^{27}$ utilisé par l'Office européen de sélection du personnel (EPSO) pour évaluer le niveau de compétence en français des fonctionnaires et des agents recrutés dans des institutions européennes. Par ailleurs, depuis 2014, il existe un Diplôme de français professionnel « Relations internationales » créé à la demande du Ministère des Affaires étrangères et du Développement international et l'Organisation internationale de la Francophoni $\mathrm{e}^{28}$; les deux certificats sont également utilisés à l'ONU, à l'OCDE, à l'École de langues du Conseil de l'Europe et dans divers ministères étrangers.

Il en résulte que la demande de ce type d'enseignement existe, et pourtant il y a seulement un manuel qui traite cette thématique et c'est d'ailleurs le même manuel qui est conseillé par le CIEP ${ }^{29}$. Il s'agit de l'Objectif Diplomatie A1/ A2 : le Français des relations internationales, publié par Hachette Français langue étrangère en 2007.

${ }^{24}$ Objectif Diplomatie A1/A2. Le français des relations européennes et internationales, Hachette Français langue étrangère, Paris 2007, auteurs : Riehl, Soignet en collaboration avec Amiot.

${ }^{25}$ Diplomatie.com, CLE International, auteurs : Bassi et Chapsal.

${ }^{26} \mathrm{Il}$ convient de noter qu'en 2020 une nouvelle méthode de français professionnel des relations internationales apparait. En effet, CLE International vient d'annoncer la publication du nouveau manuel " Affaires étrangères » présenté en tant que méthode de français langue étrangère (FLE) dans le domaine du français sur objectif spécifique (FOS) pour grands adolescents et adultes aux niveaux B1/B2. L'ouvrage cible les apprenants désireux d'interagir en français auprès d’organisations internationales, d'institutions européennes, d'ambassades, de ministères, d'ONG, etc. a cause de la pandémie, la méthode n’est pas encore disponible en Pologne ; de ce fait, nous n'allons pas l'analyser dans cet ouvrage.

${ }^{27}$ « Le TCF version relations internationales est intégré au plan pluriannuel pour le renforcement du français dans l'Union européenne mis en place par l'Organisation Internationale de la Francophonie (OIF), avec la Communauté française de Belgique, le Grand-Duché de Luxembourg et la France » http://www.ciep.fr/pt/presentation.

${ }^{28}$ Ces deux institutions soutiennent l'usage de la langue française au sein des organisations internationales et dans les échanges politiques et diplomatiques à l'international. Ce diplôme a été réalisé avec la collaboration pédagogique du Département de français de l'Académie Diplomatique de Vienne. Il évalue le niveau atteint en compréhension et expression écrites ainsi qu'en compréhension et expression orales à travers l'accomplissement de tâches professionnelles propres au domaine des relations internationales : articles, conventions, présentations, négociations. Il répond au besoin en formation et en certification en français professionnel des diplomates, fonctionnaires internationaux, journalistes, dont le français est souvent la première ou la deuxième langue de travail.

${ }_{29}$ " Pour vous aider à préparer le TCF version relations internationales, vous trouverez, outre les sites et matériels utiles pour le TCF, le manuel : Objectif Diplomatie, le Français des relations internationales, publié par Hachette Français langue étrangère " http://www.ciep.fr/pt/ presentation. 


\subsubsection{Analyse de la méthode Objectif Diplomatie A1/A2 : le Français des relations européennes et internationales}

Nous venons de voir que dans le domaine de la diplomatie, il n'existe qu'un seul manuel publié ensemble par l'OIF, TV5MONDE, la Chambre de Commerce et d'Industrie de Paris Ile-de-France et Hachette FLE qui vise la formation linguistique des diplomates et fonctionnaires sur les questions internationales. Étant donné que le français de la diplomatie est l'objet de notre recherche, il est crucial de nous pencher plus en détail sur ce manuel.

Publié en 2006, Objectif Diplomatie A1/A2 : le Français des relations européennes et internationales et plus tard (2010) également Objectif Diplomatie B1/B2 : le Français des relations européennes et internationales reste la seule méthode ${ }^{30}$ pour débutants qui intègre la composante relations européennes et internationales. Selon les concepteurs, le manuel est prévu pour 150 heures d'apprentissage mais, en fonction du contexte et de la langue maternelle des apprenants, le volume horaire peut être ramené à 120 heures ou augmenté jusqu'à 180-200 heures.

Objectif diplomatie A1/A2 : le Français des relations européennes et internationales est composé de 3 dossiers de 4 unités et il couvre les niveaux A1 et A2 du CECRL avec une sensibilisation au niveau $\mathrm{B}^{31}$. Les auteurs annoncent dans l'introduction que le fait d'aborder dès la première leçon des situations professionnelles n'exclut pas l'acquisition de compétences en français dans des situations de la vie quotidienne puisque le manuel est soucieux d'un équilibre entre les deux.

De plus, Riehl et Soignet insistent sur le fait que les actes de parole proposés dans le manuel sont souvent très proches de ceux que l'on retrouve dans les méthodes généralistes. Il nous semble que leur nombre est largement suffisant pour éviter une recherche laborieuse de documents supplémentaires par l'enseignant.

Les concepteurs de l'Objectif diplomatie A1/A2: le Français des relations européennes et internationales accentuent le fait que la méthode travaille sur des documents déclencheurs authentiques adaptés à la sphère d'activité du public visé. Comme nous le montrons ci-dessous, pour la plupart des activités, les documents déclencheurs ont un lien direct avec les relations européennes et internationales.

\footnotetext{
${ }^{30}$ Le terme méthode est généralement employé dans le discours actuel avec deux sens distincts. Premièrement, cela signifie le matériel d'enseignement, c'est-à-dire un manuel incluant l'audio ou la vidéo. Deuxièmement, nous utilisons la notion de méthode pour l'ensemble de procédés et de techniques de classe visant à favoriser chez les apprenants un comportement ou une activité déterminée (Cuq, Gruca, 2005 : 253). Dans notre cas, nous parlons du premier sens du terme.

${ }^{31}$ Elżbieta Gajewska et Magdalena Sowa remarquent à juste titre qu'il existe des limites d’application des niveaux généraux du Cadre «bien qu'un même nombre d’heures d’apprentissage est exigé pour atteindre le niveau B1 du Certificat de français juridique et celui de français médical, on peut légitimement soupçonner qu’on y aboutit par des chemins distincts » (Gajewska, Sowa, $2007: 236)$.
} 
Documents déclencheurs authentiques

-Ordre de mission

- Carte de visite de diplomate

- Badges destinés aux délégués d'une conférence internationale

-Page d'accueil d'un ministère des affaires étrangères

- Ordre du jour de l'Assemblée générale des Nations Unies

- Demande d'autorisation de mission

-Extraits de l'organigramme de la Représentation permanente de la France auprès de

l'UE

Figure 4. Exemples des documents déclencheurs authentiques dans le manuel Objectif diplomatie A1/A2 : le Français des relations européennes et internationales.

Source: Objectif diplomatie A1/A2 : le Français des relations européennes et internationales.

Un autre point intéressant de cette méthode est le fait que l'apprenant entre directement dans les objectifs visés, en accomplissant des tâches ${ }^{32}$, en se fondant sur des situations concrètes auxquelles il peut s'identifier. Comme nous traitons de l'apprentissage/enseignement du français à des fins professionnelles, outre les compétences relatives à la langue étrangère, les tâches appellent forcement à mobiliser les connaissances et capacités liées au domaine professionnel en question. Nous voyons que l'apprentissage dans le manuel analysé est considéré comme l'occasion d'accomplissement d'actions à l'image de celles qui sont réalisées en vie professionnelle. Ceci veut dire que l'apprenant apprend par la résolution des tâches qui sont plus ou moins proches de la vie réelle et dans lesquelles l'activité langagière se trouve au service de l'action. Et comme la résolution des tâches a lieu dans la classe, cette dernière devient une microsociété avec ses codes, ses règles, ses composantes sociales. L'apprenant n'est plus une personne qui apprend une langue étrangère mais un acteur social qui doit agir avec d'autres en société (Perrichon, 2008 : 92)

Les tâches proposées dans le manuel Objectif diplomatie A1/A2 : le Français des relations européennes et internationales sont les suivantes:

${ }^{32}$ La nouvelle perspective soutenue depuis 2011 par le Conseil de l'Europe accentue davantage le lien qui existe entre la classe (où l'on accomplit des tâches) et la vie en société. La " tâche " et l'« action » deviennent ainsi des notions-clés de l'enseignement/apprentissage des langues étrangères. 


\section{Organiser la mission à l'étrangèr}

-Demander à l'assistante d'effectuer les réservations de vol et d'hôtel

- Remplir un ordre de mission

- Confirmer la venue par courriel

\section{Conduire une réunion de service}

- Fixer un ordre du jour

- Convoquer les collaborateurs

-Conduire la séance

\section{Recevoir la délégation francophone}

-Élaborer un programme de travail et de visites

- Accueillir la délégation à l'aéroport

-Prononcer un discours

Figure 5. Exemples de la réalisation de tâches dans le manuel Objectif diplomatie A1/A2 : le Français des relations européennes et internationales.

Source: Objectif diplomatie A1/A2 : le Français des relations européennes et internationales.

Il est visible que dans la réalisation des tâches, la compréhension écrite et l'expression orale occupent une place primordiale, la production écrite de documents reste moins présente. Quant aux autres exercices qui prennent appui sur le vocabulaire ou la grammaire, il faut souligner que la majorité des items constituent des références au contexte des relations européennes et internationales.

\subsubsection{Objectif Diplomatie A1/A2 : le Français des relations européennes et internationales et son côté interculturel}

Nous croyons que pour un public spécifique engagé dans les relations européennes et internationales, la place de l'interculturel est primordiale. Nous allons largement nous pencher dans le deuxième chapitre sur la question de l'interculturalité, d'où notre intérêt pour cet aspect en particulier. Ceci dit, il semble d'autant plus intéressant d'analyser la partie du manuel qui prend en compte des savoir-être dans une perspective interculturelle.

Effectivement, le manuel comporte des activités visant à faire réagir les apprenants sur les particularités socioculturelles de personnes de nationalités différentes travaillant dans un même contexte professionnel et à identifier des stéréotypes. Dans le cadre d'activités consacrées au savoir-être et savoir-faire dans une perspective interculturelle, nous pouvons avoir recours aux thèmes tels que : 
Thèmes prenant en compte des savoir-être et savoir-faire (perspective interculturelle)

-Les manières de saluer

- Les manières de se présenter

- Les manières de se tutoyer

- Les manières de téléphoner

- Les manières de gérer le temps et l'espace

-Les manières de réserver une chambre à l'hôtel

-Les manières de se comporter à table

- Les manières de se comporter dans le cadre d'une réception

-Les manières de se loger

- Les manières de parler/ de couper la parole

-Les manières de conduire la réunion

Figure 6. Exemples de thèmes qui prennent en compte des savoir-être dans une perspective interculturelle dans le manuel Objectif diplomatie A1/A2 : le Français des relations européennes et internationales.

Source: Objectif diplomatie A1/A2 : le Français des relations européennes et internationales.

On pourrait nous reprocher d'avoir classé dans les savoir-faire professionnels ceux qui n'y appartiennent pas à proprement parler. Réserver une chambre à l'hôtel, commander un plat dans un restaurant ou se comporter à table, etc. ne sont aucunement réservés au contexte professionnel. Cependant, nous sommes d'avis que leur attachement à une activité professionnelle contextualisée les fait traiter de façon spécifique. Réserver des chambres dans un hôtel pour une délégation avec un eurodéputé prend en compte des critères différents que lorsqu'on la réserve pour un groupe d'amis. Même si certaines situations d'action arrivent aussi bien dans la vie privée que professionnelle, c'est le contexte qui décide quel type de connaissances et/ou compétences il faudra mettre en place (Sowa, 2011 : 321). Le contexte de l'action, qui sera évoqué à plusieurs reprises dans ce qui suit, affecte également les connaissances et compétences professionnelles. Celles-ci sont activées et mobilisées en fonction des personnes, de leur position et statut hiérarchique, de leurs motivations et objectifs d'action, etc.

Les exercices traitant des savoirs-être sont amorcés par des dessins humoristiques qui sont censés favoriser une réflexion, provoquer des témoignages et des discussions sur les pratiques culturelles. Pourtant, cela peut provoquer des malentendus entre différentes cultures. Il se peut qu'il y ait aussi de la comparaison, cependant les auteurs expliquent que :

La comparaison se donne pour but de faire prendre conscience de la diversité culturelle et, par voie de conséquence, de la relativité des pratiques. C’est une ouverture, pas un apprentissage. Pour comparer, les apprenants utilisent une langue cible, le français, mais cette langue est destinée à être utilisée dans un contexte par définition multiculturel, ce qui interdit de privilégier une culture nationale par rapport à une autre (2006: 5). 
De surcroît, le manuel consacre toute une rubrique à la fin de chaque unité à l'interculturalité. Cela apparait de manière explicite et consiste à discuter des problèmes de société, de réactions personnelles non directement liées avec la pratique quotidienne des fonctionnaires nationaux, internationaux et des diplomates. Ces échanges devraient être fructueux sur le plan du dialogue des cultures, ils sont censés renforcer la conscience et la curiosité interculturelles des apprenants.

Pour conclure, chaque chapitre se termine avec des informations sur les institutions européennes et le fonctionnement de l'Union européenne. à titre d'exemple, voyons une page tirée au Dossier 1 qui introduit les institutions européennes.

Figure 7. Fragment du manuel présentant les plus importantes institutions européennes.

Source: Objectif diplomatie A1/A2 : le Français des relations européennes et internationales.

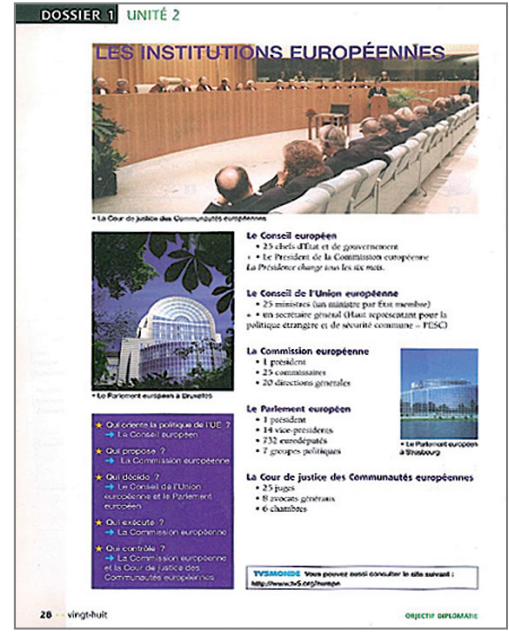

Cette partie explicite est strictement lexicale (sémantique ou morphologique). Nous repérons les informations (les savoirs) sans pour autant parvenir à effectuer les mises en œuvre qui favoriseraient l'appropriation et le réemploi. Nous pensons qu'elle pourrait viser la compréhension écrite si elle était accompagnée d'exercices. Il manque de pistes de travail avec ces documents, d'outils d'évaluation de la compréhension de ces informations; de nombreuses activités pourraient travailler cet aspect.

\subsubsection{Diplomatie.com - recueil d'activités pour les autodidactes}

L'autre proposition accessible sur le marché est l'ouvrage publié en 2005 par CLE International Diplomatie.com ${ }^{33}$ de Bassi et Chapsal.

${ }^{33}$ La collection «.com» est sortie dans les années 2000 comme « le titre phare » [...] « répondant aux besoins du développement de l'approche transversale aux différents domaines » (Mourlhon- 
Accessible à partir de 120 heures $^{34}$ de français, ce livre d'exercices comporte cinq parties traitant de la carrière diplomatique, de différentes fonctions du diplomate (politique, financière et culturelle), des multiples facettes du métier de diplomate français en administration centrale, à l'étranger ainsi que dans les relations bilatérales/multilatérales.

Diplomatie.com propose des exercices structuraux, à trous, de reconstitution et de réemploi, tous fermés, pas contextualisés et mettant tous l'accent sur le vocabulaire. ${ }^{35}$ En voici un exemple :

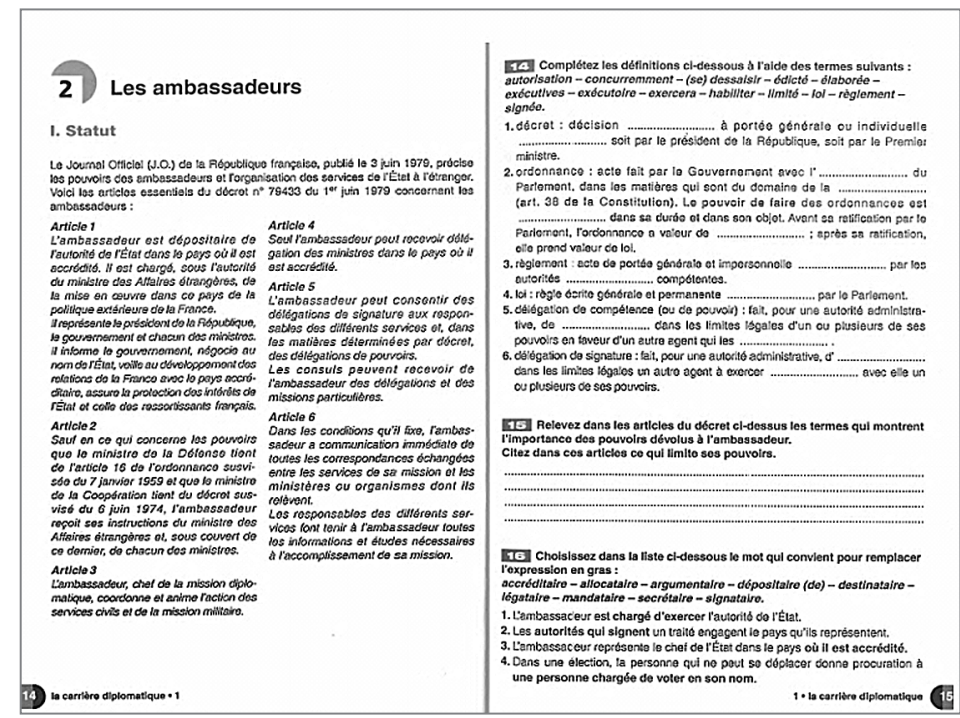

Figure 8. Fragment de l'ouvrage Diplomatie.com présentant les plus importantes institutions européennes.

Source : Diplomatie.com, CLE International, 2005.

Dallies, op.cit. : 41). Dans le même temps, la collection déclinait toute une série de fascicules témoignant de la vitalité des domaines de spécialités classiques comme Secrétariat.com (2003), Santé-médecine.com (2004) voire la multiplication de niches de plus en plus spécialisées (français de la mode, etc.). Ces recueils sont une alternative pour des enseignants qui se trouvent souvent face à un nouveau domaine par rapport à leur formation. Il nous semble que l'enseignement du français de la diplomatie demande à un concepteur du cours beaucoup de temps et d'efforts. Collecter des données et ensuite préparer ces ressources découragent souvent les enseignants de s'engager dans l'élaboration de cours, donc ils profitent de la collection «.com» qui regroupe des articles spécialisés, des exercices, des tâches que les enseignants utilisent dans la classe.

${ }^{34}$ Cette information a été fournie par les auteurs du livre.

${ }^{35} \mathrm{Il}$ nous semble que la focalisation sur un seul aspect de la langue de spécialité (en l'occurrence le lexique) appauvrit la représentation que les apprenants peuvent avoir de cette langue et par conséquent, le degré des compétences que celle-ci est censée activer. 
Le livre met l'accent sur le lexique, il n'est basé ni sur la perspective actionnelle ni communicative. Les textes déclencheurs authentiques ne sont accompagnés ni de questions ni d'exercices qui pourraient exploiter diverses compétences. Ceci prouve que ce recueil d'activités s'appuie sur une pédagogie où prévaut l'autonomie.

Qui plus est, cet ouvrage vise surtout des apprenants connaissant déjà le contexte de la diplomatie, qui travaillent dans des structures européennes, qui sont plongés dans ce contexte socio-culturel particulier et ont seulement besoin de peaufiner leur connaissances sur le monde de la diplomatie. Nous voyons ce cahier d'activités en tant que complément au cours de français de la diplomatie et non en tant que source du travail didactique qui pourrait être utilisé par l'enseignant.

Nous venons de voir la présentation du manuel de l'Objectif diplomatie A1/ A2: le Français des relations européennes et internationales et du cahier d'activités Diplomatie.com. Ceci montre que le choix des méthodes dans le domaine du français de la diplomatie n'est pas large. Il en résulte que les enseignants deviennent des concepteurs de matériaux didactiques. Les programmes de l'enseignement du français de la diplomatie doivent être élaborés individuellement par les enseignants qui peuvent s'inspirer des ouvrages mentionnés ci-dessus.

En outre, faute de matériaux didactiques pertinents, les enseignants en langues de spécialité doivent connaître de plus près les mondes professionnels sur lesquels ils travaillent. Certes, ils découvrent ces mondes à travers les discussions qu'ils ont avec les apprenants, cependant, cela reste une connaissance médiate et il se peut que les représentations qu'ils en ont, y compris les activités langagières qui s'y déroulent, soient assez éloignées de la réalité.

\subsection{Pour faire le point}

Ce chapitre met en lumière l'évolution de la langue enseignée dans un contexte professionnel à partir des années 1960 jusqu'à aujourd'hui. Nous avons vu que sous la houlette des changements économiques et politiques, la langue de spécialité n’a cessé et ne cessera jamais de se développer pour mieux s’adapter aux spécificités des contextes.

Pour des raisons de notre recherche, nous avons accordé la priorité à la notion de FOS qui nous a servi de référence dans notre étude sur le terrain. En effet, analyser et comprendre comment fonctionne la langue de spécialité nous permet de comprendre le français de la diplomatie auquel nous accordons une attention particulière. Cela nous a également aidé à voir dans quelle approche méthodologique il s'inscrit. Mieux connaître la spécificité du français de la diplomatie a pour objectif d'élaborer une méthodologie plus adaptée à notre public spécifique, ce que nous montrerons plus tard. 
D’autre part, l'analyse du parcours de FOS nous a également permis de mieux comprendre les spécificités du FOS : difficultés de l'enseignant, niveau du public etc. Ces spécificités représentent les fondements de la problématique du FOS et les connaître a pour objectif d'élaborer une méthodologie plus adaptée.

Enfin, au cours de ce chapitre nous avons analysé la méthode : Objectif diplomatie A1/A2: le Français des relations européennes et internationales et le cahier d'activités Diplomatie.com qui depuis des années le plus important matériel didactique accessible sur le marché pour l'enseignement/l'apprentissage du français de la diplomatie. Les tableaux de thèmes traités dans ces matériaux pédagogiques nous ont montré qu'il $\mathrm{y}$ a des questions et problèmes qui pourraient inspirer des formateurs lors de leur préparation de cours. Néanmoins, ils ne suffisent pas pour autant pour un cours complet de français de la diplomatie qui, selon nous, devrait traiter en profondeur les questions du plurilinguisme et de l'interculturel que nous analyserons largement dans le deuxième chapitre de cet ouvrage. 


\section{Chapitre 2}

\section{Des besoins aux compétences. Le rôle des compétences dans la construction du programme du français de la diplomatie}

\section{Remarques liminaires}

Les recherches menées sur les concepts relatifs au français à des fins professionnelles ont permis de comprendre l'ampleur de la demande et l'importance de cette langue. Cette distinction terminologique de nombreuses appellations qui se sont succédées au cours des soixante dernières années nous a rappelé que nous sommes en train de vivre un nouveau changement de direction dans le monde d'aujourd'hui qui, de nouveau, laisse son empreinte sur le domaine de la didactique des langues-cultures. Prendre en compte ces variations est la seule façon de répondre aux besoins des apprenants/ usagers et de les préparer ainsi à une insertion réussie dans ce monde en mutation où les individus vivent, travaillent et apprennent tout au long de leur vie ${ }^{36}$.

Le panorama de dénominations que nous avons esquissé dans le chapitre précédent a également pris en compte le contexte dans lequel la langue fonctionne et prend sa forme définitive. Cette réflexion était influencée par des facteurs socioculturels,

${ }^{36}$ Jacques Delors, 1996 « L'apprentissage tout au long de la vie, le lifelong learning, est indispensable pour permettre à l'humanité de progresser vers les idéaux de paix, de liberté et de justice sociale ». La coopération européenne en matière d'éducation et de formation s'est développée graduellement. Des étapes préliminaires importantes ont abouti à la démarche actuelle du Lifelong Learning : l'introduction du concept de l'éducation permanente (Conseil d'Europe 1970), la Charte communautaire des droits fondamentaux des travailleurs ayant fixé un droit d'accès à la formation continue pour tout travailleur (1989), le Livre blanc sur léducation et la formation « Enseigner et apprendre. Vers la société cognitive» (1995) et l’année européenne de « l'Éducation et de la Formation tout au long de la vie " (1996) d'où vient la phrase fameuse du président de la Commission européenne. 
économiques, cognitifs et professionnels qui ont permis de voir la langue à des fins professionnelles en dehors de la perspective linguistique. Nous avons déjà constaté une forte interrelation entre la langue à apprendre et le contexte externe dans lequel cette langue s'attribue une fonction concrète. Ce point sera développé dans le passage qui suit.

Après avoir défini la langue à des fins professionnelles et le contexte dans lequel notre recherche s'inscrit, le présent chapitre se donne pour objectif de mettre en valeur un profil détaillé du public FOS, en l'occurrence le public du français de la diplomatie. Sera par la suite analysée la mobilisation des compétences plurilingue et pluriculturelle, sociolinguistique et pragmatique dans le cours de français de la diplomatie. Enfin, nous observerons les répercussions desdites compétences sur le processus d'apprentissage de la langue sur objectifs spécifiques.

Ce que nous proposons comme objet de discussion dans les sections qui suivent ne constitue, certes, qu'une partie de toute cette problématique vaste et variée, liée à la question des compétences dans l'enseignement d'une langue en vue d'une formation professionnelle.

\subsection{L'apprenant au cœur de la formation de FOS}

La mise en place d'un programme de FOS est le résultat de démarches. Dans les recherches portant sur l'enseignement de FOS, on se focalise traditionnellement sur l'identification des besoins langagiers d'un public précis qui se fait avant le début de la formation. Toutefois, il nous semble intéressant d'aller au-delà et d'analyser dans un premier temps le profil du métier qu'exerce ou exercera l'apprenant du cours de FOS.

Cerner ce profil est primordial pour mieux comprendre la réalité de ce public spécifique, ayant des besoins spécifiques, différant des publics de FLE.

\subsubsection{La complexité de la représentation du métier de diplomate}

Pour concevoir un cours de français de la diplomatie utile, adapté au métier, il nous semble indispensable de caractériser le métier de diplomate.

Il existe actuellement deux images complètement différentes du métier de diplomate qu'il faudrait approfondir. D’un côté, nous avons un modèle romantique qui selon l'opinion publique se réduit à la fonction représentative, de l'autre, un modèle plus technocratique qui présente le diplomate comme un représentant des intérêts d'un pays sur la scène internationale.

Une question s'ensuit : quel modèle du métier de la diplomatie devrait prendre en considération le cours du FOS de la diplomatie? 
Le métier de diplomate suscite bien des préjugés, voire des caricatures, ${ }^{37}$ nourris pendant des années par des romanciers ou des auteurs de théâtre ${ }^{38}$. Des stéréotypes réduisent ce métier à une forme d'oisiveté élégante ou à une fonction similaire à celle d'agent secret. Pour d'autres, le diplomate n'est qu'un enfant de l'aristocratie ou une marionnette qui est presque toujours tenue en marge des décisions importantes.

Pourtant, les mémoires de diplomates, les manuels de procédure et de protocole soulignent que le métier de diplomate n'a rien à voir avec ces descriptions romantiques du XIXe siècle qui ont accrédité cette image assez superficielle. Le diplomate est plutôt un intermédiaire (un haut fonctionnaire) attitré et permanent entre les autorités officielles de deux pays ou entre la délégation d'un pays et une organisation internationale. Il s'agit d'une personne qui a reçu une formation dans une grande école ou une université et qui a ensuite réussi le concours national du ministère des Affaires étrangères. Les carrières des hauts fonctionnaires français, ainsi que leurs homologues européens, se caractériseraient par l'importance de la formation initiale et la sélection opérée par l'École nationale d'administration (ENA) et l'École polytechnique. Les principales voies d'accès aux emplois de catégorie sont l'ENA, d'où sortent les conseillers des Affaires étrangères du cadre général intégrant le ministère des Affaires étrangères, le concours pour l'accès à l'emploi de conseiller des Affaires étrangères du cadre d'Orient (13 postes au titre de 2005), celui pour l'emploi de secrétaire des Affaires étrangères du cadre général (17 postes au titre de 2005), le concours pour l'accès à l'emploi de secrétaire des Affaires étrangères du cadre d'Orient (4 postes en 2005), les IRA pour les secrétaires des Affaires étrangères d'administration (1 poste en 2005). ${ }^{39}$

En outre, rappelons que les diplomates font partie du noyau décisionnel politique et administratif qui est important pour comprendre les façons d'élaborer des décisions de politique étrangère. La diplomatie constitue un des moyens de la politique régalienne de l'État, même si elle se réalise de façon interétatique à travers des sommets et des conférences internationales. Bien évidemment, les diplomates s'occupent des négociations et de la rédaction des rapports des actions de coopération

${ }^{37}$ « Il y a les inévitables clichés au sujet des réceptions de l'ambassadeur menant grand train de vie dans de somptueuses résidences. D’aucuns voient encore dans le diplomate la figure - si finement décrite par Marcel Proust - de Monsieur de Norpois fréquentant les salons de la duchesse de Guermantes. La diplomatie ne serait qu'un exercice de mondanités réservé à la haute société et aux détenteurs d'un nom à particule » Delcorde $(2009: 1) »$.

${ }^{38}$ Il est intéressant de remarquer qu'il manque de travaux sur la diplomatie. La majorité des clichés liés à ce métier vient de la littérature. Martin Wight (1966:22), un des fondateurs de l'école anglaise de relations internationales constate que : «Les diplomates ont toujours été sous les projecteurs de la scène internationale, mais paradoxalement, peu d'études systématiques de leur comportement et de leur pensée ont été entreprises ».

${ }^{39}$ Marc Loriol, « La carrière des diplomates français : entre parcours individuel et structuration collective ", Sociologies [En ligne], Théories et recherches : http://journals.openedition.org/ sociologies/2936, 
(bi et multilatérale), de la politique générale ${ }^{40}$ et de la diffusion de la culture dans leur pays d'affectation. Ils ont aussi pour rôle d'assurer l'analyse et l'interprétation politique, économique et culturelle du pays de résidence. Finalement, remarquons que le diplomate est quelqu'un qui développe une véritable empathie pour les autres cultures et dont tout l'art est de détecter les éléments favorisant un rapprochement entre son pays et celui où il se trouve.

Comme nous venons de le voir, il est impossible de fournir une seule et unique caractéristique du métier de diplomate. Bien sûr, il existe des connotations dévalorisantes, des représentations ordinaires et la littérature, mais les recherches sur la diplomatie demeurent marginales dans le panorama des études politiques internationales. Cela est dû au fait que la spécificité de la diplomatie échappe aux définitions, elle est trop complexe et la mettre dans un cadre serait trop simpliste.

Nous voyons par ce qui précède que concevoir un cours de français de la diplomatie n'est pas un exercice facile. La multitude et la complexité des tâches dont s'occupent les diplomates empêchent de dégager une définition commune à tous les acteurs de ce métier. Comment choisir un modèle du métier de la diplomatie qui devrait être pris en considération pour le cours du FOS de la diplomatie?

Nous sommes d'avis que le formateur du programme devrait élaborer ce dernier en tenant compte de toutes les représentations de la diplomatie mentionnées ci-dessus. Cela l'aidera à mieux connaître le domaine et bien comprendre les milieux où travaillent les apprenants, à avoir toutes les informations nécessaires en vue de mieux adapter la formation aux caractéristiques des publics. Comprendre l'essence de ce métier permettra par la suite de préparer les objectifs du cours et obtenir les effets visés : préparer un apprenant au travail dans la fonction publique nationale et européenne.

\subsubsection{Le profil de l'apprenant du français de la diplomatie}

La multiplication des échanges au sein des instances européennes et internationales a entrainé une augmentation conséquente du nombre de fonctionnaires et de diplomates qui apprennent le français. Beaucoup d'entre eux ont, en effet, compris que la maîtrise, même élémentaire, du français, était importante : pouvoir amorcer une conversation dans les couloirs ou dans le cadre d'une réception permet de nouer plus

${ }^{40}$ Comme le remarque Tomasz Orłowski ${ }^{*}$ le diplomate a le devoir d'informer progressivement, au jour le jour, son chef d'État et le gouvernement de la République de l'évolution de la conjoncture internationale et de la situation des États étrangers » (Orłowski, 2015 : 27).

*Tomasz Orłowski, est un diplomate polonais. Il a notamment été ambassadeur de Pologne à Paris de 2007 à 2014. Brièvement sous-secrétaire d'État à la Coopération et au Développement de septembre à novembre 2014, il est devenu ambassadeur de Pologne en Italie et à Saint-Marin en 2015. Il est auteur du Protocole et pratique diplomatique. 
facilement des contacts avec des homologues francophones. Dans certaines situations, le fait de ne pas comprendre le français peut même constituer « un handicap majeur » (Riehl et Soignet, $2006: 1$ ).

Pour quel profil la langue française et sa variété diplomatique et européenne s'avéreront-elles d'une importance primordiale?

L'analyse du profil des candidats à un poste dans les organismes publics européens $(\mathrm{EPSO})^{41}$ nous a permis de comprendre qu'un utilisateur potentiel du français de spécialité diplomatique est un fonctionnaire chargé des dossiers internationaux ou un étudiant $t^{42}$ des filières d'études européennes ou de relations internationales. Les débouchés qui s'ouvrent devant les diplômés en Études des relations internationales comprennent des possibilités de carrière dans le domaine de la fonction publique européenne ou dans les institutions publiques nationales responsables des affaires européennes ou internationales. Certains sont recrutés par des sociétés privées multinationales ou en contact avec des entreprises européennes. D’autres possibilités sont les différents emplois dans les ONG, les agences européennes, les think tanks, les sociétés de conseil et de gestion de projets financés par les fonds de l'Union européenne dans le pays cible. Reste encore la possibilité choisie par une grande partie des étudiants de continuer leurs études en master et doctorat dans un domaine européen spécifique.

De plus, l'utilisateur du français de la diplomatie travaille avant tout dans l'administration publique nationale et locale. Il s'agit du personnel des ministères, agences, instituts, centres, préfectures et mairies, inspections régionales et autres. Cette catégorie est définie dans les documents réglant les formations en langue française spécialisée dans le cadre d'un mémorandum soutenu par l'OIF comme «fonctionnaires chargés des dossiers européens $»^{43}$. Soulignons que les personnes concernées occupent des rangs et des postes d'une grande variété.

${ }^{41} \mathrm{https} / /$ epso.europa.eu/why-eu-careers_fr.

${ }^{42}$ Les débouchés qui s'ouvrent devant les diplômés en Études des relations internationales, comprennent les possibilités de carrière dans le domaine de la fonction publique européenne ou dans les institutions publiques nationales responsables des affaires européennes ou internationales. Certains sont recrutés par des compagnies privées multinationales ou en contact avec des entreprises européennes. D’autres possibilités sont les différents emplois dans les ONG, les agences européennes, les sociétés de conseil et de gestion de projets financés par les fonds de l'Union européenne dans le pays respectif. Reste encore la possibilité choisie par une grande partie des étudiants de continuer leurs études en master et doctorat dans un domaine européen spécifique. Il est évident que pour se lancer dans ces types de carrière, les jeunes seront d'autant plus compétitifs et efficaces, s'ils maitrisent plusieurs langues européennes.

${ }^{43} \mathrm{Ce}$ programme de coopération mis en place par l'OIF concerne annuellement 13000 fonctionnaires de 26 pays européens, avec un budget de $2300000 €$. Il est déployé grâce à des accords-cadres conclus entre l'OIF et les organismes de formation dans les capitales européennes : écoles normales d'Administration, Instituts diplomatiques des ministères des Affaires étrangères et d'Institutions de formation à la fonction publique. 
En outre, la majorité des apprenants du français de la diplomatie se présenteront à un concours national dont nous avons parlé plus haut ou passera l'un des concours des institutions européennes (EPSO). L'une des conditions générales d'éligibilité déterminées dans l'Article 28 du Statut des fonctionnaires des Communautés européennes est de "posséder une connaissance approfondie d'une des langues des Communautés et une connaissance satisfaisante d'une autre langue des Communautés dans la mesure nécessaire aux fonctions qu'il est appelé à exercer ${ }^{44}$. Dans les avis de concours pour administrateurs et assistants, le plus souvent les exigences linguistiques sont formulées de la sorte : « le candidat doit posséder une connaissance approfondie d'une langue principale qui peut être l'une des langues de ficelles et de travail de l'Union européenne (UE), ainsi qu'une connaissance satisfaisante d'une deuxième langue, différente de la langue principale, et qui doit obligatoirement être l'anglais, le français ou l'allemand».

Nous résumons ci-dessous le profil des utilisateurs potentiels du français de la diplomatie, étant donné le statut du français en tant que langue de travail au sein des institutions européennes.

Figure 9. Profil de l'apprenant du français de la diplomatie. Source : élaboration propre.

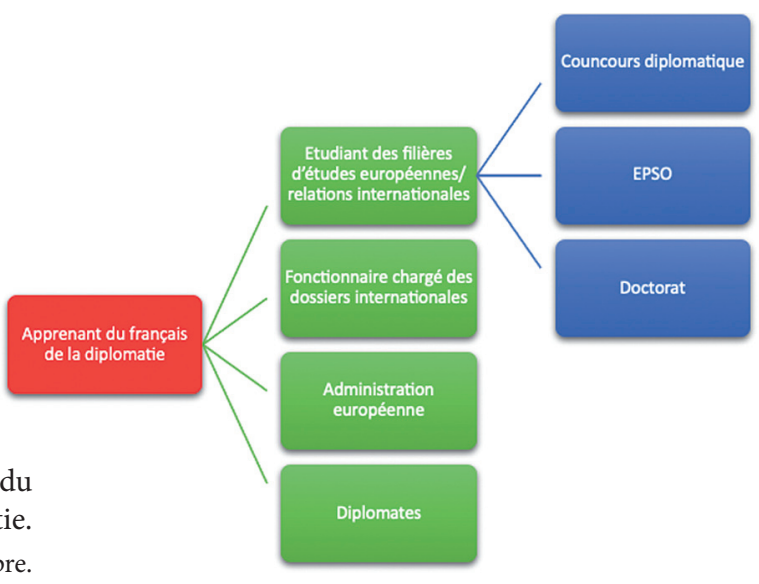

Comme nous pouvons le voir, l'apprenant du français de la diplomatie peut signifier un diplomate qui travaille dans ce métier depuis longtemps mais aussi un étudiant qui n'est qu'au début de sa carrière professionnelle et qui passera ensuite le concours diplomatique, le concours EPSO ou se lancera dans un doctorat. Toutefois, le trait commun de ces utilisateurs est leur intérêt pour les relations internationales, le besoin du langage utilisé pour communiquer sur les questions internationales et finalement le savoir-faire diplomatique. La complexité de ces besoins forme la spécificité de ce public.

\footnotetext{
${ }^{44}$ https://eur-lex.europa.eu/legal-content/FR/TXT/?uri=CELEX\%3A01962R0031-20140101.
} 


\subsubsection{Les besoins spécifiques du public spécifique}

Impliquées dans le domaine des affaires internationales, les catégories de professionnels et d'apprenants décrits plus haut montrent des besoins linguistiques bien spécifiques. La connaissance du français, deuxième langue de travail au sein de l'UE, ${ }^{45}$ fait souvent partie de leur profil de compétences nécessaires à exécuter leurs tâches professionnelles quotidiennes.

Les thématiques de la communication spécifique de ces groupes relèvent d'un côté de l'ordre institutionnel et juridique unique que présente l'Union et qui s'est enrichi dans un processus d'élargissement important. D'un autre côté, sont traitées des questions relevant des différents projets de coopération, actions et politiques qui se développent au niveau européen, par exemple : le marché intérieur ; l'Union économique et monétaire ; l'Espace de liberté, de sécurité et de justice ; les politiques de cohésion dans les domaines régional, agricole et social; les politiques d'innovation, comme la protection de l'environnement, la recherche et l'innovation technologique, l'énergie.

La spécificité de cette communication détermine les besoins particuliers des groupes d'utilisateurs concernés. Ils doivent maîtriser non seulement la langue française générale, mais aussi être capables de manipuler le vocabulaire spécialisé. Ce qui semble encore plus important est que ce public doit également posséder des savoir-faire qui lui permettent d'interagir et de négocier en respectant le code socioculturel de la communication formelle et non formelle caractéristique du milieu pluriculturel européen.

Voyons maintenant le parcours de formation en langue des diplomates proposé dans un manuel du français des relations internationales et de la diplomatie.

\subsection{Le manuel Objectif Diplomatie A1/A2 : le Français des relations européennes et internationales comme exemple de cours de français de la diplomatie}

Comme nous l'avions dit au premier chapitre de cet ouvrage, la méthode Objectif Diplomatie A1/A2 : le Français des relations européennes et internationales (Hachette FLE, 2006) était pendant des années le seul matériel didactique accessible sur

${ }^{45}$ En effet, dans le contexte du multilinguisme au sein de l'Union européenne, le français possède le statut de langue officielle ainsi que de langue de travail, notamment en tant que deuxième langue de travail à la Commission, une des six langues pivots au Parlement et langue du délibéré à la Cour de justice et au Tribunal de première instance. Il se voit donc reconnaitre un rôle de langue véhiculaire dans la communication au sein des institutions européennes. En situation de communication internationale, il peut servir de langue alternative à l'anglais, qui ne constitue pas la seule lingua franca partout et dans toutes les situations. 
le marché pour l'enseignement /l'apprentissage du français de la diplomatie ${ }^{47}$. L'enquête $^{48}$ faite auprès des institutions où le français des relations internationales et de la diplomatie est enseigné montre qu'en dehors de quelques documents mis sur le site web TV5 Monde ${ }^{49}$, la grande majorité des enseignants utilisent la méthode Objectif Diplomatie : le Français des relations européennes et internationales. Posons donc la question suivante : le manuel Objectif Diplomatie A1/A2 : le Français des relations européennes et internationales est-il en mesure de satisfaire les besoins du public des diplomates? Puisque les pratiques d'enseignement traditionnelles deviennent de plus en plus inadaptées aux attentes du public spécialisé, il nous semble qu'il y a des éléments qui doivent être revisités.

Afin d'ouvrir des pistes de réflexion, il reste à passer à l'analyse des relations existantes entre les compétences nécessaires dans le métier de diplomate et celles qui devraient être développées dans le cours de français de la diplomatie. Pour le faire, nous explorons ci-dessous le programme du français de la diplomatie proposé dans le manuel Objectif Diplomatie B1/B2 : le Français des relations européennes et internationales.

Prenons à titre d'exemple le premier dossier de l'Objectif Diplomatie B1/B2: le Français des relations européennes et internationales (Hachette, 2010) :

\section{DOSSIER 1 TABLEAU DES CONTENUS}

\begin{tabular}{|c|c|c|c|c|}
\hline Situations & Manières de dire/d'écrire & Grammaire & Vocabulaire & On en parle \\
\hline UNITÉ 1 & \multicolumn{3}{|c|}{ Ce poste vous intéresse? } & pp. $10-2$ \\
\hline $\begin{array}{l}\text { (1) Appel à } \\
\text { candidature }\end{array}$ & $\begin{array}{l}\text { - Lancer un appel à candidature; } \\
\text { définir les diplômes et l'expérience } \\
\text { requis; définir les qualités du candidat; } \\
\text { examiner une candidature } \\
\text { - Poser des questions sur un appel } \\
\text { à candidature }\end{array}$ & $\begin{array}{l}\text { - La voie passive } \\
\text { - Subjonctif présent ou } \\
\text { indicatif présent }\end{array}$ & $\begin{array}{l}\text { - Procédure et critères } \\
\text { de recrutement } \\
\text { - Les attributions }\end{array}$ & $\begin{array}{l}\text { À l'occasion du Xl' } \\
\text { Sommet de la } \\
\text { Francophonie }\end{array}$ \\
\hline $\begin{array}{l}2 \text { Avez-vous } \\
\text { vos chances? }\end{array}$ & $\begin{array}{l}\text { - Parler de son expérience } \\
\text { professionnelle } \\
\text { - Comment écrire une lettre } \\
\text { de motivation? }\end{array}$ & $\begin{array}{l}\text { - Questions et } \\
\text { réponses: adverbes/ } \\
\text { pronoms interrogatifs } \\
\text { et pronoms relatifs }\end{array}$ & $\begin{array}{l}\text { - Caractériser } \\
\text { une expérience }\end{array}$ & \\
\hline $\begin{array}{l}3 \text { Tu les as } \\
\text { convaincus? }\end{array}$ & $\begin{array}{l}\text { - Parler de ce qu'on a déjà fait, } \\
\text { de ce que l'on sait faire } \\
\text { - Exprimer des stratégies pour } \\
\text { «se vendre» }\end{array}$ & $\begin{array}{l}\text { - Les propositions } \\
\text { interrogatives indirectes }\end{array}$ & & \\
\hline
\end{tabular}

Figure 10. Tableau des contenus du l'ObjectifDiplomatie B1/B2 : le Français des relations européennes et internationales.

Source : l'Objectif Diplomatie B1/B2 : le Français des relations européennes et internationales. 
Nous pouvons voir ci-dessus que le premier dossier, qui se concentre sur les aspects et étapes de la vie et de la carrière d'un fonctionnaire à l'international, est organisé autour des Manières d'écrire et de dire/s'écrire qui fournissent des outils de communication ainsi que de la Grammaire et du Vocabulaire. Finalement, le dossier se termine avec la rubrique On en parle pour découvrir des institutions européennes et internationales. Les auteurs du manuel soulignent que cette dernière rubrique favorise la compréhension d'extraits de documents authentiques ${ }^{50}$ (Soignet, $2011: 10$ ).

${ }^{46}$ La production éditoriale de manuel et d’ouvrages consacrés à l'enseignement des langues de spécialité témoigne qu'ils sont élaborés par les équipes enseignantes pour satisfaire les besoins immédiats en matériel pédagogique dans la filière respective. Leurs titres contiennent presque tous l'expression "à l'usage des étudiants de... (nom de la filière) ", mettant ainsi en valeur le domaine de spécialisation du public. L'approche que les auteurs ont retenue pour l'enseignement du français à ces publics privilégie l'acquisition du lexique spécialisé. Lobjectif principal se veut pragmatique : acquérir des compétences de compréhension des textes de leur spécialité à l'aide d'un dictionnaire général ou spécialisé. En effet, les textes utilisés représentent une variété de discours qui circulent dans le domaine mais sont souvent dépassés.

${ }^{47}$ Nous avons consulté les sites des Instituts français à Berlin, Madrid, Sophia, Porto ainsi que les sites LinkedIn des universités qui offrent ce type de cours. Nous avons également appelé l'Alliance française-Bruxelles Europe et avons parlé avec le responsable des cours FOS de Bruxelles.

${ }^{48} \mathrm{http}$ ://enseigner.tv5monde.com/collection/francais-des-relations-internationales

${ }^{49} \mathrm{Il}$ est important de constater que le texte authentique à lui tout seul ne garantit pas le succès dans l'acquisition de la compétence pragmatique. Nous sommes d'accord sur ce point avec Kathleen Bardovi-Harlig (1996 : 15) qui constate que : « il est clair que le but de mettre la pragmatique en classe de langue représente un grand projet. Cependant, certains matériaux ne doivent pas être développés, ils ont besoin dêtre tout simplement collectés. Même si nous collectons des documents authentiques, les utilisons, les apprenants les écoutent et répètent jusqu'à ce que les dialogues soient mémorisés, cela n’achèvera ni nos objectifs pédagogiques ni les besoins communicatifs des apprenants. Chaque document authentique utilisé de cette façon sera voué à léchec ». Il nous semble que Kathleen Bardovi-Harlig touche ici à un point très important. Lusage et l'exploitation des textes authentiques doivent être bien réfléchis et cela devra contenir une réflexion méthodologique. Il se peut que même avec les documents authentiques parfaitement structurés et avec un syllabus ambitieux, il soit impossible d'augmenter la conscience pragmatique. Ce processus revendique plus d'efforts humains et d'engagements que des matériaux. Mentionnons à cette occasion les études menées à Indiana University à Blomington et à Columbia University à New York montrent que ce sont les apprenants qui devraient jouer un rôle clé dans le processus de découverte de la conscience pragmatique, ils devraient être acteurs cherchant eux-mêmes la connaissance pragmatique dans la vie quotidienne. Les apprenants à presque tous les niveaux peuvent collecter leurs sources et données en dehors de la salle de classe et puis en discuter avec leurs camarades. Cette technique, mise en place dans plusieurs écoles au Midwest en 1993, a montré que l'observation des natifs dans leur travail ainsi que les entretiens que les apprenants ont pu effectuer avec eux, a remarquablement approché les étudiants de l'usage pragmatique de la langue. Jean-Marc Dewaele et Nathalie Wourm, (op.cit. : 153) soutiennent ce point en ajoutant que « Tout le monde sera d'accord qu'on ne peut pas apprendre un sport quelconque en s'enfermant dans la bibliothèque avec un manuel. C’est donc dans la classe de langue qu'on pourra éveiller la conscience des règles sociopragmatiques, mais ce n'est cependant qu'en dehors de la classe que la compétence sociopragmatique des apprenants pourra se développer[...]. Les échanges linguistiques avec des locuteurs natifs ou les périodes passées à l'étranger permettront aux apprenants dêtre «dans le bain» et de développer leur compétence sociopragmatique ». Nous croyons que sortir avec des apprenants du français de la diplomatie de la 
Les objectifs des autres dossiers sont les suivants :

- découvrir les particularités stylistiques des documents officiels de l'UE;

- développer des compétences d'expression écrite et orale sur des sujets liés à l'intégration européenne, aux institutions et aux activités de l'UE;

- renforcer la capacité de recherche de documents ;

- développer les compétences linguistiques et la compréhension des institutions et des politiques européennes ;

- connaître le lexique spécifique du domaine du droit communautaire ;

- acquérir des compétences en traduction ;

- connaître les étapes principales de la création, du développement et de l'élargissement des institutions les plus importantes dans le monde;

- observer les caractéristiques et le mode de fonctionnement des organisations mondiales et des institutions européennes.

Nous pouvons voir qu'une attention particulière dans ce manuel est portée à l'apprentissage systématique du vocabulaire ayant trait aux relations européennes et internationales. La grammaire et le vocabulaire sont mis à la disposition des apprenants pour accomplir des tâches qui leur sont demandées, et ceci dans le contexte des relations européennes et internationales fortement contextualisées. Le vocabulaire est regroupé de manière thématique en relation avec le contenu de la situation traitée. L'auteur du guide pédagogique qui accompagne la méthode souligne qu'il est essentiel qu'à chaque étape l'apprenant dispose d'un volume de vocabulaire correspondant à son niveau.

Il est visible que l'enseignement du français de la diplomatie dans le manuel Objectif Diplomatie B1/B2: le Français des relations européennes et internationales est surtout centré sur le lexique, en privilégiant la compétence de réception de textes écrits. Dans ce cas-là, l'enseignement/apprentissage se fait à travers la simple lectureanalyse-traduction de textes spécialisés.

Nous avons ici affaire à la théorie construite dans les années 1960 qui prônait une démarche essentiellement lexicologique. Comme le remarque Jean-Jacques Richer (2008: 3), " cette focalisation sur le lexique se rencontre encore actuellement dans le FOS ». En effet, les études sur l'enseignement du FOS montrent bien la difficulté à sortir d'une vision traditionnelle, imprégnée par les approches des années 60 et $70^{50}$.

Or, les approches didactiques ont subi un développement significatif au cours des dernières décennies, se centrant surtout autour de la communication et, à présent,

classe, par exemple aux institutions européennes, pourrait avoir un effet encore plus bénéfique que l'usage des documents authentiques ou sinon être une bonne alternative pour éveiller la conscience pragmatique.

${ }^{50} \mathrm{Il}$ faut néanmoins souligner qu’il y a des domaines comme la langue juridique où le lexique ainsi que l'analyse des propriétés des textes normatifs semblent plus importants que dans d'autres domaines (Lerat 2016). De ce fait, il paraît juste de dire qu'une approche didactique dans l'enseignement de la langue du droit français s'impose d'un point de vue lexical, syntaxique et discursif. 
de l'action. L'approche focalisée sur le vocabulaire ne laisse pas une large place aux variations interculturelles. En nous bornant uniquement à l'apprentissage du lexique, nous n'amènerons pas nos apprenants, actuels ou futurs hauts fonctionnaires, au dialogue qui développe des modalités de coopération, qui noue des relations avec les citoyens d'un pays (Delcorde, 2009 : 7). Sur ce point, notre opinion diverge de celle de George Kahn (1995: 146) selon qui « la chose paraît logique : maîtriser un domaine c'est maitriser les mots qui y circulent » ou d'Odile Challe (2000: 79) « la première compétence chez les spécialistes est lexicale».

Qui plus est, le profil de l'apprenant du français de la diplomatie montre qu'il est déjà initié au domaine de spécialisation. L'enseignant doit surtout le rendre capable de réaliser des tâches communicatives dans le domaine en se servant du français. Par conséquent, il s'agit de construire un parcours d'enseignement-apprentissage autour de la réalisation de tâches (qui peuvent aussi être appelées projets, car l'approche s'inscrit également dans la logique de la pédagogie du projet). Bien ancrées dans un contexte authentique relevant, par exemple, du domaine de l'intégration européenne, celles-ci donnent lieu à un entrainement dans toutes les activités langagières de réception et de production en français de spécialité. La mise en œuvre d'une telle approche s'impose naturellement en tant qu'alternative à la pratique traditionnelle proposée dans Objectif Diplomatie: le Français des relations européennes et internationales.

Afin de suivre les pistes de réflexion ouvertes, il importe maintenant de voir l'importance des compétences qui selon nous devraient être développées en cours de français de la diplomatie.

\subsection{La spécificité du cours de français de la diplomatie}

Tout d'abord, il faut rappeler qu'il ressort de cette description du public travaillant dans le secteur de la diplomatie certaines caractéristiques nécessaires pour concevoir et adapter un programme de français de la diplomatie qui ne serait pas un cours essentiellement lexicologique. Le fait qu'un apprenant connaisse la terminologie spécialisée ne veut pas dire qu'il est préparé à travailler dans cette langue dans le contexte professionnel spécifique. Nous sommes d'accord avec Magdalena Sowa (2017 : 174) qui remarque que la seule connaissance de mots et de termes ne suffit pas pour que la compétence lexicale soit considérée comme développée.

De plus, la compétence lexicale peut être considérée comme réussie seulement si le vocabulaire de la langue donnée est utilisé correctement par rapport au lieu, au temps, aux évènements et dans une situation avec des interlocuteurs. De ce fait, il ne faut pas réduire le lexique à une liste de mots dépourvus de contexte ou même de questions de la terminologie. Dans l'acquisition du vocabulaire y compris le vocabulaire spécialisé - le plus important est d'attirer l'attention sur son fonctionnement discursif. 
Afin de rendre les éléments cités plus lisibles et pour résumer tout ce que nous savons sur le cours de français de la diplomatie de l'analyse du profil de notre apprenant, nous proposons la figure 11. Cette figure nous servira d'amorce et permettra de reprendre par la suite et d'approfondir certains points qui s'y trouvent.

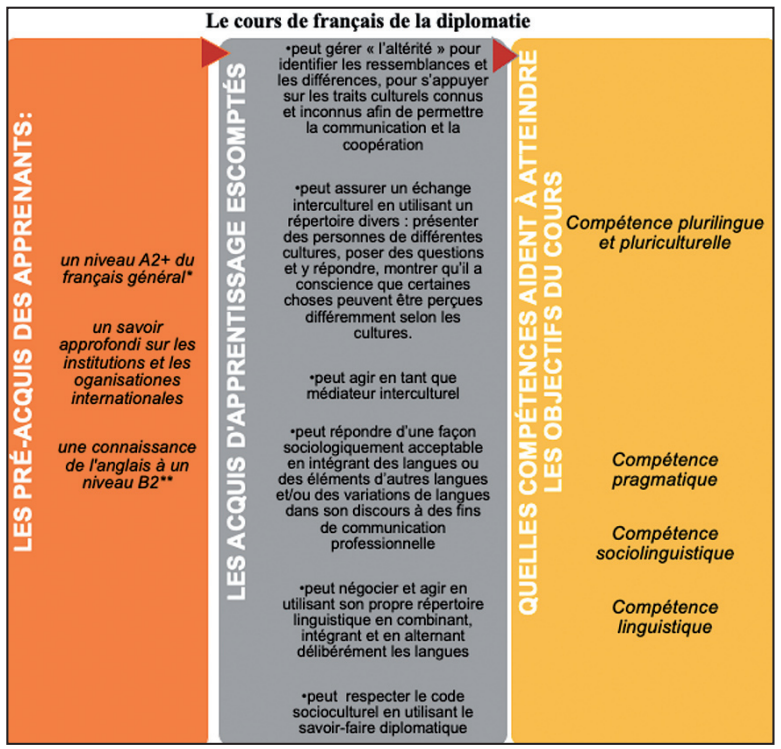

Figure 11. Apports de l'analyse du profil du diplomate et de l'apprenant du français de la diplomatie à notre cours.

Source : élaboration propre.

Nous avons vu que les apprenants potentiels du français de la diplomatie sont impliqués dans les affaires internationales ou européennes, ils peuvent connaître aussi l'eurolecte ${ }^{51}$. De ce fait, nous croyons que si l'enseignement du français de la diplomatie comporte une spécificité, cette dernière ne réside pas dans le lexique ni dans la syntaxe, mais elle est à chercher dans le lien étroit entre la langue et la culture

${ }^{51}$ Dénomination donnée au langage spécifique de l'Union européenne qui abonde en nouvelles unités lexicales utilisées pour dénommer les réalités nées au cours de la construction européenne.

* L'utilisation d'un vocabulaire compliqué et bureaucratique, de termes administratifs spécifiques de certains secteurs ou domaines, de phrases trop longues, souvent à la voix passive, le manque d'explication des références aux articles des traités et des actes du droit dérivé, la prolifération des sigles et acronymes incompréhensibles pour les non-initiés. Par conséquent, maîtriser le français général ne pourrait pas suffire à accomplir efficacement des tâches professionnelles dans le domaine en question.

** l’apprenant bénéficie de certaines connaissances préexistantes (par exemple des connaissances métalinguistiques, des stratégies d’apprentissages, des connaissances générales) qu'il peut transférer pour l'acquisition de la nouvelle langue (Wokusch et Lys, 2007 :15). 
qu'impose le monde contemporain du travail. Le cours de français de la diplomatie ne peut pas être pensé comme un cours de terminologie qui privilégie la compétence lexicale. La communication en français langue de travail dans et avec les institutions internationales et européennes est centrée non seulement sur la recherche, la compréhension et la rédaction de documents professionnels, mais aussi et surtout sur l'ouverture à l'altérité, le respect d'autres cultures et la reconnaissance de leurs valeurs, la curiosité linguistique et culturelle. Pour répondre à ces besoins, le cours de français de la diplomatie devrait développer avant tout la compétence plurilingue et pluriculturelle. Ainsi l'ouverture à l'altérité, l'éveil aux langues et aux cultures différentes, la sensibilité interculturelle et la connaissance de l'anglais vont s'inscrire dans la compétence plurilingue et pluriculturelle.

De plus, il ne faut pas négliger l'importance de la négociation, des débats et la recherche de consensus (le savoir-faire). Cette partie des objectifs du cours de français de la diplomatie est développée dans la compétence pragmatique.

En outre, il existe selon nous un savoir-faire diplomatique qui permettra de respecter le code socioculturel qui s'inscrit dans la compétence sociolinguistique. Ce savoir-faire permet d'interagir et de négocier en respectant le code socioculturel de la communication formelle et non formelle caractéristique du milieu pluriculturel international. On souligne actuellement l'importance de la compétence sociolinguistique qui comporte, entre autres, la capacité à réaliser les actes de parole dans la langue cible de manière appropriée.

Finalement, il reste la compétence qui est privilégiée dans les cours actuels, à savoir la compétence linguistique.

Pour finir, il convient de remarquer que les compétences linguistiques, sociolinguistiques et pragmatiques mentionnées ci-dessus font partie des compétences communicatives langagières ${ }^{52}$ nécessaires à développer en langue étrangère d'après le CECRL (2001) et nous en parlerons plus loin. Nous nous focaliserons ci-après sur la compétence qui nous paraît la plus importante et la plus négligée dans des objectifs des cours actuels, à savoir la compétence plurilingue et pluriculturelle.

\subsubsection{L'importance de la compétence plurilingue et pluriculturelle dans l'enseignement dans l'enseignement des langues}

Dans ce chapitre, nous avons déjà vu que la spécificité du public des diplomates oblige à se concentrer sur des compétences particulières qui auprès d'autres publics, ne joueraient pas un rôle primordial. Il est important de relever que la nature et

${ }^{52}$ Compétences Linguistiques : Compétence lexicale, Compétence grammaticale, Compétence sémantique, Compétence phonologique, Compétence orthographique, Compétence orthoépique. Compétences sociolinguistiques: Marqueurs des relations sociales, Règles de politesse, Expressions de la sagesse populaire, Différence de registre, Dialecte et accent. Compétences pragmatiques: Compétence discursive et Compétence fonctionnelle. 
la spécificité des métiers de diplomate nécessitent la capacité du traitement intensif des éléments culturels ${ }^{53}$. De ce fait, le cours de français de la diplomatie impose non seulement la connaissance des compétences communicatives, mais avant tout l'acquisition de la compétence plurilingue et pluriculturelle.

L'approche interculturelle est devenue, à l'époque de la mondialisation des échanges, l'un des principes fondamentaux dans l'éducation linguistique en Europe. Ces mobilités internationales sont intrinsèquement liées à des interactions interculturelles. En effet, l'acquisition des langues comprend aussi l'ouverture à l'Autre et par conséquent l'acquisition d'une compétence culturelle. Nous pouvons observer qu'aujourd'hui la majorité des pays européens traitent l'éducation plurilingue ${ }^{54}$ et interculturelle comme la priorité des activités des institutions éducatives. Dès à présent, la politique linguistique ${ }^{55}$ des institutions européennes se prononce en faveur du plurilinguisme afin de répondre aux besoins individuels et sociaux d'une Europe où les mouvements migratoires s'intensifient de plus en plus. Dans cette optique, le CECRL met en place les principes d'une diversification linguistique et culturelle.

${ }^{53}$ Dans le Livre Blanc ${ }^{\star}$ de 2008 (mesure $n^{\circ}$ 9.1) nous pouvons lire que : « le métier de diplomate n’est pas un métier généraliste. Il requiert une large gamme de compétences et d'aptitudes spécialisées : notamment maîtrise des langues, intimité avec la culture et la société de nombreux pays, connaissance des organisations et du droit internationaux, de l'économie internationale, des techniques de négociation, des institutions et des procédures multilatérales et européennes, que tous, ou presque, sont amenés à rencontrer dans leur parcours. Les qualités qu'il exige : la capacité d'écoute et de compréhension des positions des autres, la fermeté et la force de conviction dans la défense des nôtres, l'adaptabilité à de nombreuses situations parfois dangereuses ou urgentes, ne se trouvent pas spontanément réunies : elles doivent être développées au fil de parcours professionnels diversifiés, mais où ces différentes qualités sont à un moment ou à un autre mobilisées (nous soulignons) ».

* (« Le Livre blanc sur la défense et la sécurité nationale 2008 », publié le 17 juin 2008, est un livre blanc chargé de définir une stratégie globale de défense et de sécurité pour la France de 2009 à 2020. Le programme, élaboré par une commission, servira de bases aux deux prochains projets de lois de programmation militaire, qui seront votés par le Parlement français. Ce livre blanc fait suite à deux précédents livres blancs sur la Défense nationale publiés en 1972 par Michel Debré et en 1994 par le gouvernement d'Édouard Balladur.)

${ }^{54}$ À la base du terme d'éducation pluriculturelle se trouvent les notions de culture, de pluriculturalisme et de société pluriculturelle. Il convient ici de faire la différence entre bi, pluri, inter, multi. Cette distinction qui entraine des ambiguïtés répond à des raisons d’ordre méthodologique et à la différence des angles et des objets détude. "Le bi, duo, duel ou couple, mobilise des images d'équilibre ou de déséquilibre, de communion ou de distinction, de dialogue ou d'opposition " (COE, 2009 :10). Le pluri, entendu comme "plus de deux » évoque une complexité ingérable et incontrôlable et suscite le recours nécessaire à une instance unificatrice ou dominante, choisie à l'intérieur ou en dehors de cette pluralité attestée (COE, op.cit.). L'inter, indicateur de relation et non de simple juxtaposition, oscille entre le mode du bi et celui du pluri. Multi par contre, se focalise uniquement sur la quantité des éléments ajoutés (COE, op.cit.). On opposera le plurilinguisme à la quantité de langues supposées différentes (multilingue).

${ }^{55}$ Nous pouvons lire dans le Guide pour l'élaboration des politiques linguistiques éducatives en Europe partie 1.3.1. (Beacco et Byram, 2007) que : «La mise en place d'une éducation plurilingue et interculturelle est un projet éducatif global qui sétend sur plusieurs années et qui vise à améliorer la qualité de léducation et à influer positivement sur la société en général ». 
Le Cadre ${ }^{56}$ définit une compétence à la fois plurilingue et pluriculturelle ${ }^{57}$ comme la compétence à communiquer langagièrement et à interagir culturellement d'un acteur social qui possède, à des degrés divers, la maîtrise de plusieurs langues et l'expérience de plusieurs cultures, tout en étant à même de gérer l'ensemble de ce capital langagier et culturel. On considérera qu'il n'y a pas là superposition ou juxtaposition de compétences distinctes, mais bien existence d'une compétence complexe, voire composite, dans laquelle l'acteur peut puiser (CECRL, 2001 : 129). Une telle définition de la compétence plurilingue et pluriculturelle, dont le développement devient l'objectif du processus d'apprentissage et d'enseignement des langues étrangères constitue une révolution de la pensée de la DLE. Jusqu'à maintenant, la compétence de communication s'est chevauchée sur la compétence analogique que l'apprenant possédait déjà dans la langue maternelle (Kucharczyk, 2018 : 60). Cependant, ce nouveau concept de la compétence plurilingue s'écarte de la dichotomie classique la langue maternelle/la langue étrangère en faveur d'une compétence communicative commune qui englobe tout le répertoire linguistique de l'apprenant. Cette compétence, commune pour toutes les langues, permet aux apprenants de puiser dans leur répertoire de langues selon la situation de communication dans laquelle ils se trouvent.

De plus, Danièle Moore et Véronique Castellotti (2008:18) remarquent à juste titre que la compétence plurilingue peut alors se définir de manière plus précise comme la capacité à mettre en œuvre, en situation et dans l'action, un répertoire constitué de ressources plurielles et diversifiées qui permet de se reconnaitre et de s'affirmer en tant qu'acteur plurilingue, apte à gérer le potentiel, le déséquilibre et l'évolutif en fonction de ses interprétations locales de la situation et de ses intentions, symboliques ou non.

Ainsi, la compétence pluriculturelle et plurilingue est perçue comme une base de données linguistiques dont dispose le locuteur et qu'il utilise en fonction de la

${ }^{56}$ Il faut mentionner que la définition citée apparaît déjà en 1997 dans le document : «Compétence plurilingue et plurielle. Vers un Cadre Européen Commun de référence pour l'enseignement et l'apprentissage des langues vivantes : études préparatoires » dont les auteurs sont : Coste, Moore et Zarate.

${ }^{57}$ Il convient d'expliquer ici que dans le Guide du COE de 2010, Lenz et Berthele clarifient que la compétence interculturelle est considérée comme une compétence à part entière. «En substance, la compétence interculturelle a rapport avec l'intégration de l'altérité dans son mode de pensée et de fonctionnement. À cet égard, elle diffère significativement de la notion de compétence pluriculturelle, qui met l'accent sur la pluralité des cultures auxquelles on peut s'identifier et que l'on connait. Développer la compétence interculturelle suppose de développer un minimum d'identité interculturelle. La compétence interculturelle n’est pas nécessairement liée à la connaissance d'autres langues, mais celle-ci élargit considérablement le champ des possibilités en matière d'expérience interculturelle et de contacts interpersonnels, qui, à leur tour, peuvent renforcer la compétence interculturelle» (2010:6-7). Quant à notre travail, nous nous référons au point de vue de Christian Puren selon lequel : «La compétence interculturelle s'intègre dans la compétence pluriculturelle ; c'est une compétence interculturelle multiple, mise en oeuvre sur plusieurs cultures et non seulement sur les deux cultures source et cible » (2011: 12). 
situation de communication, du rôle et de la position qu'il veut prendre durant l'interaction. Cette opinion est aussi soutenue par Lüdi (2016 : 43 dans Kucharczyk, op.cit. : 61) pour qui la compétence plurilingue et pluriculturelle est une compétence intégrée d'un caractère utilitaire :

Les ressources [répertoire linguistique de l'apprenant] (...) ont la forme d'ensemble demi-organisés de moyens parfois hétéroclites, comparables à une "boite à outils » pour bricoleurs ; certains de ces moyens sont préfabriqués et mémorisés, d’autres permettent la création d'énoncés inédits, parmi lesquels on trouve aussi des moyens heuristiques destinés à renforcer les ressources expressives déjà disponibles. Ils sont mis en ouvre de manière située en fonction, entre autres, de la configuration des connaissances linguistiques - des profils linguistiques- des interlocuteurs (...), qui ont constitué un répertoire des ressources et qui y recourent en fonction de leurs besoins, connaissance ou caprices, en les modifiant ou en les combinant si nécessaire. Autrement dit, ils permettent de créer et de jouer, de conduire une activité verbale dans des contextes particuliers, donc de prendre des risques.

Le caractère dynamique, singulier (différent pour chaque individu) de cette compétence permet aux apprenants de sortir du système hermétique de la langue qui n'était jamais ouverte aux influences contextuelles de l'acte de communication. Cela favorise l'apprentissage des langues étrangères, élimine la peur de la perfection linguistique et facilite la communication.

De même, Weronika Wilczyńska (2007 : 29-30) remarque que :

La compétence plurilingue et pluriculturelle outrepasse le concept strictement linguistique et reste toujours dans une relation proche avec le parcours de vie d'une personne, ce qui suppose la présence (plus ou moins grande) d’une personne dans la définition des choix de ses préférences. L’aspect « la langue/la culture » constitue une très importante étape dans le parcours de vie de cette personne. ${ }^{58}$

Il va de soi que l'enseignement des langues étrangères est un lieu parfait où les apprenants ont accès aux cultures diverses. Chacun des apprenants est porteur de comportements, de valeurs et d'hypothèses fondamentales d'ordre culturel, partagés au sein du groupe ou pays d'appartenance. La rencontre interculturelle est celle qui met en contact et en relation des personnes provenant de diverses cultures, nationales notamment ${ }^{59}$. Pour réussir ces interactions et donc pour bien comprendre

${ }^{58}$ „Różnojęzyczność wykracza poza wymiar ściśle językowy i zawsze pozostaje w bliskim związku z tak zwaną drogą życiową jednostki, co zakłada mniejszy lub większy udział danej osoby w określaniu własnych wyborów i preferencji - a aspekt język-kultura stanowi bardzo ważny wymiar tej drogi życiowej", notre traduction.

${ }^{59}$ Remarquons ici que les habitants d'un territoire multilingue ne seront pas forcément plurilingues et pluriculturels. De même, les habitants d'un territoire monolingue comme la Pologne peuvent en revanche être plurilingues et pluriculturels. 
ses interlocuteurs, et se faire comprendre par eux, le développement de la compétence plurilingue et pluriculturelle est indispensable.

Les spécialistes en didactique sont convaincus que la formation à l'interculturel dans la classe de langue contribue elle aussi au développement personnel de l'individu étant non seulement l'éducation pour, mais également par les langues/cultures. Comme le remarque Gisèle Pierra (2001 : 71 dans Jastrzębska, 2011 : 33) «l'apprentissage de la langue et de la culture étrangères modifie le rapport à soi, aux autres et au monde de l'apprenant ». Ce concept nous semble particulièrement important dans l'enseignement des langues et surtout de la langue à des fins professionnelles dont la problématique nous avons développé dans le premier chapitre.

\subsubsection{L'interculturel dans le monde professionnel}

Les résultats de l'étude Cross-cultural Curricula for European Students and their Regions (CEReS) réalisée par l'équipe de Lucyna Aleksandrowicz-Pędich à l'Université de Białystok montrent que le manque d'interculturel peut être une cause de déception et de frustration dans le monde professionnel. Nous touchons ici probablement à l'un des aspects les plus complexes concernant l'enseignement du FOS et notamment l'intégration de l'employé dans l'entreprise ou l'institution. Il s'avère que les éléments culturels qui sont rarement explicites jouent un rôle important dans l'organisation des institutions et dans les relations entre les individus, tant sur le plan comportemental que langagier (Mangiante et Parpette, $2004: 23$ ).

En outre, nous sommes d'avis qu'en FOS plus qu'en FLE, les besoins culturels acquièrent une dimension fondamentale ce qui a été très longtemps négligé dans la didactique de la langue de spécialité. Comme le relève Daniel Lehmann : «les conceptions (classiques) du français de spécialité reposent, toutes, sur une vision trop étroite du problème, parce qu'elles négligent une dimension essentielle, qui est la dimension culturelle» (Lehmann, $1993: 8$ ). Et pourtant la préparation à la compréhension d'une culture d'entreprise avec ses codes, ses modes de fonctionnement est comme nous l'avons vu avec l'Objectif Diplomatie : le Français des relations européennes et internationales absente dans les matériaux pédagogiques.

D'autre part, il serait imprudent de supposer d'emblée que les relations professionnelles sont exactement les mêmes dans un autre pays. Ainsi, la tâche de l'enseignant de langue de spécialité sera de préparer ses apprenants à l'interaction dans une langue étrangère avec des partenaires représentant des normes et des valeurs culturelles différentes. Elżbieta Gajewska et Magdalena Sowa $(2014: 238)^{60}$ remarquent

\footnotetext{
${ }^{60}$ Zadanie nauczyciela [przygotowanie powierzonych mu profesjonalistów do interakcji z partnerami z innych kultur] wydaje się niezwykle trudne, zwłaszcza jeśli dysponuje się w tym celu mała liczba godzin. Wobec rozległości składających się na te sferę aspektów, przekazanie
} 
qu'un nombre limité d'heures ${ }^{61}$ rend cette tâche extrêmement difficile ${ }^{62}$ et ajoutent que transmettre des détails sur des phénomènes de la communication culturelle dans un domaine en question est presque impossible. À cela s'ajoute encore le fait que la langue utilisée dans la communication professionnelle dans un milieu plurilingue n'est pas la langue native des partenaires et donc des éléments socioculturels de l'interaction appartiennent à un système étranger pour tous les locuteurs. De ce fait, nous croyons qu'il serait primordial de transmettre aux apprenants dès le début de leur carrière professionnelle le savoir sur le fonctionnement de jeunes professionnels face à la pluralité des cultures. Cependant, n'oublions pas que pour comprendre des relations interculturelles, il ne s'agit pas seulement d'un savoir théorique mais surtout de la pratique. Les leçons de langue de spécialité devraient alors servir à sensibiliser de futurs employés aux attentes et aux différentes méthodes de gestion des entreprises ou des institutions étrangères (Kic-Drgas, 2017/4 : 10).

\subsubsection{L'ouverture à l'altérité dans le monde diplomatique}

L'institution diplomatique représente un exemple de la communication interculturelle dans la pratique, car de facto elle représente la rencontre internationale. Face aux difficultés liées à l'acquisition pratique des normes culturelles, il semble nécessaire que l'on privilégie l'approche interculturelle qui est citée dès les premières pages du CECRL comme contribuant étroitement au développement personnel souhaitable de l'apprenant.

Dans une approche interculturelle, un objectif essentiel de l'enseignement des langues est de favoriser le développement harmonieux de la personnalité de l'apprenant et de son identité en réponse à l'expérience enrichissante de l'altérité en matière de langue et de culture (CECRL, $2001: 9)$.

La prise de conscience interculturelle est définie comme la capacité des personnes à observer et analyser tous les aspects du comportement de leurs interlocuteurs

kompleksowej wiedzy na temat kulturowych uwarunkowań komunikacji w danej dziedzinie jest praktycznie niemożliwe.

${ }^{61}$ Effectivement, la principale difficulté qui persiste dans tous les cas de formations existantes est la contrainte «temps » marquée par trois limitations : les professionnels ont une disponibilité limitée, les étudiants disposent d'une offre universitaire d'un horaire limité et dans le cadre de la formation pour fonctionnaires, les organisateurs ont dû diminuer les heures d'enseignement en raison de la disponibilité limitée des apprenants, ce qui mène sans doute au ralentissement de leurs progrès.

${ }^{62}$ Cette difficulté est également exprimée par Margalit Cohen Emerique (2011:3) « En fait, la tolérance à la diversité culturelle, la compréhension du différent, très différent de soi est difficile, très difficile. On peut dire même qu'elle n'est pas le fort de l'humanité comme l'histoire contemporaine et l'actualité nous le prouvent chaque jour. C'est un processus long et difficile qui doit s'apprendre ; une construction et non un acquis d'emblée, qui se développe progressivement soit depuis l'enfance par une éducation familiale très ouverte, soit par une formation spécifique à lâge adulte ». 
étrangers, à en prendre conscience ainsi qu'à en tirer des enseignements pour y adapter leur propre comportement (Abry, 2007 : 45). Il faut mentionner que la conscience interculturelle s'actualise au cours d'une rencontre ${ }^{63}$ dans l'acte de compréhension de l'Autre (Jastrzębska, 2011 : 35). Pour comprendre l'Autre, il faut se comprendre soi-même, savoir définir son identité individuelle et son identité sociale, regarder sa culture et soi-même de l'extérieur, y porter le regard de l'Autre. Il paraît évident que les connaissances déclaratives (sur le pays et la culture cible) n'y suffiront pas et devront être complétées par de nombreux savoir-faire interculturels et un savoir-être englobant des attitudes, des traits personnels, des motivations, des valeurs personnelles ainsi que le savoir-apprendre (CECRL, 2001 : 16-17).

Nous voyons que la nécessité d'un apport culturel dans le contenu de séquences d'apprentissage se trouve affirmée, tant dans les publications des didacticiens que dans les programmes officiels. Cette nécessité est particulièrement visible dans le métier de la diplomatie. Effectivement, les métiers de la diplomatie consistent dans l'ouverture sur la société, à un dialogue constant et négociations avec des représentants d'une autre culture ainsi que dans l'écoute approfondie de l'Autre. L'apprenant du français de la diplomatie devrait se montrer expert dans les relations entre sa culture d'origine et la culture étrangère.

Par ailleurs, il devra posséder la capacité à jouer un rôle d'intermédiaire culturel pour gérer efficacement des situations de malentendus et de conflits culturels. Il devra savoir reconnaitre et utiliser des stratégies variées pour établir le contact avec des gens d'une autre culture et surtout être capable d'aller au-delà de relations superficielles stéréotypées (CECRL, 2001 : 84).

Toutefois, les visions du diplomate devraient se heurter à ses stéréotypes et préjugés. Comme le remarque Jolanta Sujecka-Zając (2011 : 27), le stéréotype constitue, certes, un obstacle dans notre rencontre avec l'Autre, mais il n'est pas infranchissable, il n'est pas non plus simplement "éliminable » de nos structures cognitives. Il se laisse relativiser à force de rencontres intenses et personnelles avec l'altérité. Dans son travail, le diplomate aura maintes occasions pour faire face à la diversité des terrains, aux situations imprévisibles, aux différentes manières de travailler et par conséquent relativiser les stéréotypes.

Bien évidemment, la prise de conscience interculturelle fait partie des savoirs de l'apprenant du français de la diplomatie, de ses compétences générales. Il est clair que ce type de savoir ne s'acquiert que progressivement, par immersion dans la vie quotidienne. Cela résulte de l'interaction entre des compétences culturelles

${ }^{63}$ « La rencontre entre les personnes se réalise toujours dans l'espace de la culture et par l'intermédiaire des codes culturels et donc toutes les formes d'expression aussi bien verbales (la langue) que non verbales » Kłoczowski, 2005 : 26 dans Jastrzębska $2011: 35$ ). „Spotkanie międzyosobowe odbywa się zawsze w przestrzeni kultury i za pośrednictwem kodów kultury, czyli wszystkich form ekspresji zarówno werbalnej (języka) jak i niewerbalnej”, notre traduction. 
que l'apprenant a incorporées au cours de son expérience, de ses contacts, de ses études, etc.

De même, nous croyons que l'apprenant du français de la diplomatie devrait se montrer en tant que plus grand expert des contacts avec les autres cultures que les apprenants de FLE. On demande aux futurs fonctionnaires de l'État une réflexion profonde sur les représentations de l'Autre et la prise de conscience que nous sommes tous soumis à des structures de pensée simplificatrices. Le locuteur interculturel devient à la fois conscient de sa propre identité et de celle de ses interlocuteurs. Il est de ce fait en mesure d'accepter la réciprocité des regards. Ainsi, il nous semble fondamental de préparer l'apprenant du français de la diplomatie aux situations de terrain qu'il aura à affronter et de le guider dans sa formation de la compétence plurilingue et pluriculturelle.

\subsubsection{La prise de conscience interculturelle - implications didactiques}

Nous remarquons que même si la composante culturelle est devenue un élément incontournable de l'enseignement des langues étrangères, donc aussi des cours sur objectifs spécifiques, la notion de culture est souvent abordée de manière implicite dans les classes de langues et fréquemment de manière plus explicite dans les cours de civilisation. Il arrive que l'apprentissage ressemble davantage à une accumulation de connaissances plus qu'à un processus continu, une observation ou une analyse comparative. Elżbieta Gajewska (2011 : 137) souligne à juste titre que l'intégration de la composante interculturelle dans un cursus de FOS est très compliquée :

le concepteur d'un cours de FOS doit faire face non seulement à un discours et des connaissances procédurales qui lui sont dans beaucoup de cas peu familiers ou inconnus, mais aussi à une culture professionnelle dont il ignore les règles.

En outre, comme nous l'avons vu, malgré l'abondance de méthodes de français sur le marché éditorial, il n'y a pas beaucoup d'ouvrages pour l'enseignement du FLE/ FOS qui contiennent des matériaux et des techniques permettant le développement de la compétence interculturelle ou la présentation des aspects culturels d'un groupe donné. Face à cette pénurie de ressources pédagogiques, les enseignants sont obligés de créer leurs propres matériaux et méthodes d'enseignement.

\subsubsection{Obstacles à l'éducation interculturelle}

L'un des sujets les plus souvent touchés dans le cadre des discussions autour de l'interculturalité est la formation des enseignants et, plus précisément, leur préparation à jouer le rôle de médiateurs interculturels ${ }^{64}$.

${ }^{64}$ D’autres termes utilisés sont les suivants: intercultural speaker ou intermédiaire culturel (en polonais pośrednik kulturowy, Aleksandrowicz-Pędlich, 2005). 
Comme le remarque Tomasz Róg (2016: 9) :

L’enseignement de la langue étrangère égale à l'enseignement de la culture des locuteurs de la langue en question. De ce fait, pour que les enseignants puissent enseigner la compétence interculturelle, ils doivent eux-mêmes entrer dans un rôle des médiateurs culturels $s^{65}$.

L'enseignant en tant que médiateur interculturel n'est pas seulement une personne qui transmet du savoir sur la langue et la culture, mais plutôt un animateur qui développe chez les apprenants de nombreuses habiletés communicatives et interculturelles. En effet, l'exposition à d'autres cultures génère la conscience de la diversité culturelle et favorise la volonté non seulement de tolérer cette diversité, mais aussi d'en tirer profit, d'explorer de nouvelles possibilités et de partager des informations avec d'autres. Cela améliore les styles et les techniques d'enseignement.

Cependant, les résultats des recherches menées dans le cadre du Programme d'activités à moyen terme du CELV 2000-2003, Projet 1.2.3, "Compétence en communication interculturelle dans la formation d'enseignants " par Ildikó Lázár, ne démontrent pas un intérêt particulier pour l'éducation interculturelle dans la professionnalisation des enseignants.

De plus, le rapport indique que les enseignants de nombreux pays européens sont conscients de l'importance de la compétence interculturelle dans l'enseignement des langues étrangères. Ils confirment néanmoins qu'ils n’ont jamais été formés pour cela de façon systématique. D’après leur opinion, la compétence interculturelle n’a été enseignée que de manière implicite pendant leurs cours de civilisation.

Qui plus est, les résultats des recherches effectuées par Carmen Guillén Diaz de l'Université de Valladolid sont encore plus pessimistes. Les enseignants seraient intéressés par la dimension linguistique de leur enseignement en n'introduisant de l'interculturel que « sous forme des thèmes étudiés à partir des textes " (Guillén Diaz, 2007 :193 dans Jastrzębska, $2011: 34$ ).

Pour améliorer la situation donnée et remédier à ce problème présent dans toute l'Europe, les didacticiens travaillant avec de futurs professeurs de langue étrangère proposent des entrainements interculturels tels que :

- l'usage des projets interculturels accessibles sur Internet ;

- l'analyse des documents médiatiques en ligne ;

- l'analyse de la littérature ;

- des séminaires consacrés à la sensibilisation de la compétence interculturelle (Siek-Piskozub, 2013);

65 "Nauczanie języka obcego uznawane jest za tożsame z nauczaniem kultury użytkowników tego języka, a zatem postuluje się, że aby uczynić międzykulturową kompetencje komunikacyjną celem działań nauczycielskich, nauczyciele sami muszą wejść w role mediatorów kulturowych" notre traduction. 
- le travail avec des documents visuels;

- des voyages d'études ;

- des projets interculturels ;

- des pratiques relationnelles comme les jeux d'expression dramaturgique

Néanmoins, nous voulons souligner que certaines universités ${ }^{66}$ introduisent dans leurs programmes officiels d'études de futurs enseignants de nouvelles matières pédagogiques favorisant le développement de la compétence interculturelle.

\subsubsection{La pédagogie interculturelle : vers une mise en pratique}

Il convient de rappeler qu'il est fondamentalement utile d'intégrer l'approche interculturelle dans le parcours éducatif scolaire ou extrascolaire. Il existe des démarches qui permettent de poser un regard neuf sur sa culture d'origine. L'une de ces démarches est une formation centrée sur l'apprenant. Des composantes de la compétence interculturelle, telles que savoir-être, savoir-faire et savoir-apprendre sont mieux dynamisées si l'apprenant est autonome, s'il prend la responsabilité de ses études, s'il s'engage consciencieusement dans une autoformation. Un apprenant autonome est quelqu'un qui démontre de l'initiative, de l'indépendance et de la persistance dans l'apprentissage, qui accepte la responsabilité de son apprentissage et appréhende les problèmes comme des défis, non des obstacles, qui est capable d'autodiscipline et manifeste un haut degré de curiosité.

Outre cela, il existe des techniques (Bandura, 2007 : 48-49) utiles dans la conception des cours visant la prise de conscience interculturelle parmi lesquelles nous trouvons :

- des documents authentiques ${ }^{67}$ (par exemple, grâce à la richesse des images et du son, le document audio-visuel peut apporter des repères situationnels déterminants : les caractères, les comportements, les attitudes, les schémas communicatifs quotidiens et professionnels);

- les discussions ;

- les jeux de rôles ;

- la dramatisation ;

- la simulation;

- le travail avec le Portfolio ;

- la rédaction du journal personnel (atelier d'écriture biographique);

${ }^{66}$ À la philologie romane de l'Université de Zielona Góra, depuis quelques années, on a introduit dans le programme officiel des futurs enseignants de FLE, trois nouvelles matières pédagogiques favorisant le développement de la compétence interculturelle, à savoir : Éducation interculturelle, Communication interpersonnelle et Pédagogie de la créativité. Source : http://www.in.uz.zgora.pl.

${ }^{67}$ Selon Henri Besse (1984 : 136), un document authentique « doit être un échantillon prélevé au sein des échanges ayant réellement eu lieu entre les natifs de la langue enseignée/apprise et donc être conforme à leurs pratiques langagières authentiques; il doit correspondre aussi précisément que possible aux intérêts et préoccupations des étudiants ». 
- l'atelier de théâtre (Feldhendler, 2001 : 47);

- le «culturogramme " (une description des différences culturelles avec du vocabulaire nécessaire) (Gajewska et Sowa, $2014: 244)$;

- l'assimilateur culturel ${ }^{68}$;

- une digression culturelle à titre de commentaire spontané, induit par le thème du cours

- une capsule culturelle (la description d'un trait culturel donné, suivie d'une discussion sur les différences de celle-ci avec la culture d'origine);

- la recherche des ressemblances entre les cultures (surtout au niveau des proverbes, des locutions idiomatiques, etc.);

- l'analyse des incidents critiques ;

- les jeux de société et les jeux stratégiques ${ }^{69}$.

Pour finir, il convient d'ajouter que la compétence interculturelle pourrait être développée durant les stages professionnels, des voyages d'études en groupes plurinationaux où la présence des langues et des cultures différentes permet l'apparition d'une capacité à l'ajustement culturel.

Finalement, nous devons souligner ici que l'interculturalité ${ }^{70}$ est un concept très difficile à saisir, mais, en même temps, il est un pré-requis indispensable à la réussite des affaires internationales ${ }^{71}$. Nous avons mis en lumière les différentes facettes de ce concept qui se compose des éléments tels que la conscience interculturelle, la compétence interculturelle et finalement l'approche interculturelle. Pour les objectifs de ce travail, il est important de mentionner que les chercheurs (Besse 1993 ; Beacco

${ }^{68}$ Ang. "culture assimilator training ", une description d'un malentendu culturel et choix de l'interprétation appropriée de ses sources parmi les solutions proposées (Bandura, $2007: 48$ ).

${ }^{69}$ Nous pensons ici au jeu Interact (Bolten, 2007 : 35) dont l'objectif est de préparer aux négociations interculturelles.

${ }^{70}$ Dans le domaine de la didactique des langues « l'interculturel » a été officiellement introduit à Lomé, lors de la troisième rencontre mondiale des départements universitaires détudes françaises, organisée par l'AUPELF du 18 au 24 juillet 1982, comme en témoigne le $\mathrm{N}^{\circ} 170$ du FDLM de la même année, intitulé « Les voies de la communication interculturelle ».

${ }^{71} \mathrm{Il}$ est couramment admis que la mondialisation des échanges amène un nombre croissant de salariés à entrer en contact avec des partenaires étrangers. De ce fait, des « compétences interculturelles " seraient de plus en plus nécessaires pour atteindre les résultats escomptés. Le «management interculturel », qui s'est développé au cours des vingt dernières années, fait l'objet de nombreuses publications, interventions de conseil et séminaires, jusquà devenir parfois une industrie. On y développe la nécessité de " connaître l'autre ", d'accepter les différences et de comprendre les modes de pensée du partenaire afin de ne pas commettre d'impairs et de s'adapter à ses raisonnements. Il est intéressant de remarquer que la littérature interculturelle a connu un essor considérable dans les années 1980-1990, c'est-à-dire à une époque qui voit le développement des entreprises multinationales nord-américaines et européennes. La mondialisation des échanges était encore limitée, les économies de l'Atlantique Nord dominaient. La perspective de base de cette littérature était la question de l'implantation de filiales nord-américaines ou européennes dans des pays « exotiques ", l'envoi de cadres « expatriés » ou encore le transfert de technologies du Nord, vers le Sud ou vers l'Est. 
2000) ont des difficultés à affiner la différence entre la compétence interculturelle qui a été décrite ci-dessus et l'approche interculturelle. Nous croyons que l'interculturel a introduit une réflexion sur la compétence culturelle et interculturelle (qui selon nous déborde la compétence culturelle ${ }^{72}$ ). Cette nécessité de se focaliser sur l'interculturel a engagé ensuite l'approche interculturelle (CARAP : 2007) qui sera développée en détail dans le chapitre 3.

\subsubsection{Approche interculturelle - bilan}

Comme nous venons de le voir, l'enseignement de la culture de l'Autre est une tâche très délicate qui exige de repenser et de contextualiser l'ensemble des savoir-être culturels suscités par la langue cible et exprimés par elle. Faire de l'interculturel, c'est dépasser la simple comparaison et l'identification à un autre groupe culturel et bâtir des passerelles entre les cultures dans le but d'un échange et d'un enrichissement mutuels. Cette approche est par conséquent une reconstruction constante de l'identité dans la relation avec l'altérité ; il s'agit, d'une part, d'accepter la diversité des regards, de rencontrer d'autres points de vue et de comprendre des modes de vie différents et d'autre part, de comprendre que l'on est soi-même rarement le produit d'une seule appartenance culturelle.

Ceci doit constituer un objet d'étude à aborder dans un ensemble comme le repérage d'indices spécifiques d'une communauté : on touche ainsi au niveau social qui englobe le niveau professionnel, où comme nous l'avons mentionné plus haut, il s'agit moins d'apprendre que de réfléchir ensemble sur soi et l'Autre, sur l'identité et l'altérité.

Nous croyons qu'en prenant en compte la dimension culturelle du français, l'enseignant de langue guidera mieux l'apprenant : il lui fournira les moyens pour acquérir une compétence véritablement communicative, ayant sa pleine composante interculturelle. Dans ce sens, les apports purement linguistiques vont reculer, au profit d'apports socioculturels. Ceci sera plus un travail par l'échange que par la transmission pure de savoirs. En outre, l'apprenant du FOS doit aussi parfaitement connaître la culture organisationnelle ${ }^{73}$ ou la culture d'entreprise partagée par les

${ }^{72}$ La compétence interculturelle déborde la compétence culturelle parce que « entre la connaissance des différences culturelles (dimension ethnographique) et la compréhension de la variation culturelle (dimension anthropologique), il n'y a pas qu'une simple différence de formulation mais le passage d'une analyse en termes de structures et d'états à celle de processus, de situations mouvantes, complexes, imprévisibles et aléatoires compte tenu de l'hétérogénéisation culturelle croissante au sein même de ce que l'on appelle traditionnellement les cultures » (AbdallahPretceille, $1996: 32$ ).

${ }^{73}$ Les termes de culture organisationnelle ou culture d'entreprise (parfois le management interculturel) sont couramment utilisés dans la littérature de langue anglaise pour souligner le fait que l'exercice d'une activité professionnelle ne se réduit pas à la mise en œuvre de compétences et de technique, mais suppose également l'adhésion à un micro-univers social caractérisé par des valeurs, des façons explicites ou implicites de faire face à différents problèmes (van Zanten, 2003 : 161) 
représentants du même métier. Il convient de mentionner ici que les représentants du même métier constituent souvent un public hétérogène avec une grande variabilité sociobiographique et culturelle. La valorisation des compétences plurilingues de ces participants pourrait faciliter la mise en place d'un enseignement réflexif tenant compte des connaissances précédentes des apprenants.

Pour finir, nous avons vu que l'approche interculturelle avec la compétence plurilingue et pluriculturelle (qui sera développée en détail dans le chapitre 3) constitue une partie primordiale du cours de français de la diplomatie. Cependant, ce cours ne serait pas complet s'il ne développait pas d'autres compétences comme celles sociolinguistique, pragmatique et linguistique.

\subsubsection{La compétence sociolinguistique dans le cours de français de la diplomatie}

La description du travail dans la diplomatie nous a montré que l'un des éléments nécessaires dans ce type de profession sont les marqueurs des relations sociales compris dans la compétence sociolinguistique ${ }^{74}$. De futurs fonctionnaires devraient savoir utiliser des formes et des usages différents pour s'adresser à leur entourage.

En outre, nous croyons que les diplomates devraient manifester une bonne maîtrise des expressions idiomatiques et dialectales avec la conscience des niveaux connotatifs de sens ainsi qu'apprécier complètement les implications sociolinguistiques et socioculturelles de la langue utilisée par les locuteurs natifs. Il peut arriver qu'en tant que fonctionnaires de l'État, ils soient amenés à jouer un rôle de médiateur entre des locuteurs de la langue cible et de celle de sa communauté d'origine. Par conséquent, la reconnaissance d'un large éventail d'expressions idiomatiques et dialectales peut s’avérer cruciale.

Effectivement, le travail du diplomate revendique probablement plus qu'aucun autre métier le fonctionnement de la langue dans sa dimension sociale. Le diplomate est un acteur social qui doit accomplir des tâches (qui ne sont pas seulement langagières) dans des circonstances et un environnement donnés. Certainement, l'apprenant du français de la diplomatie a besoin d'un ensemble de compétences qui prendront une forme bien concrète dans les activités de communication langagière, partie inhérente de chaque communication. Néanmoins, il n'est pas anodin de

\footnotetext{
${ }^{74}$ Nous comprenons par la compétence sociolinguistique la capacité à utiliser et interpréter des marques linguistiques qui expriment la relation sociale, la politesse, les registres, les dialectes et les accents. Cette compétence sociolinguistique représenterait selon Harley, Allen, Cummings et Swain (1990) l'une des trois composantes de la compétence communicative ou compétence à communiquer (CECRL). Les composants clés de la compétence sociolinguistique sont : les marqueurs des relations sociales, des règles de politesse, les expressions de la sagesse populaire, les différences des registres, le dialecte et l'accent (CECRL).
} 
remarquer que la seule communication ne suffit pas pour agir efficacement. Elle peut même parfois "gêner l'action » (Sowa 2011 : 161). L'objectif de la communication des diplomates n'est donc plus la communication même dans le sens d'une simple transmission d'un message. C'est l'action à accomplir, inscrite dans un contexte social précis.

À cela s'ajoute que les énoncés formulés par les diplomates à l'aide des mots et des règles de grammaire s'inscrivent dans un contexte social qui est caractérisé par différents facteurs : les interlocuteurs qui y participent (souvent les ministres ou les présidents), leurs rôles et statut, les relations entre eux, le milieu d'où ils proviennent, etc. Ainsi, en fonction de paramètres spatiaux et interpersonnels, le locuteur choisit des outils linguistiques et discursifs chaque fois différents. Il y a donc une dimension sociolinguistique qui intervient sous forme de marqueurs de relations sociales, de règles de politesse, de sagesse populaire, de registre, de dialecte ou d'accent et ceci est indispensable à activer pendant le cours de français de la diplomatie, où l'apprenant devra savoir communiquer conformément à la position qu'il occupera dans l'avenir.

\subsubsection{Accès à la compétence sociolinguistique}

Nous avons mentionné plus haut que même si la maîtrise des formes linguistiques de base est nécessaire, ni le lexique, ni la grammaire, ni la syntaxe n'assureront un apprenant « sociolinguistiquement compétent ». Comme le remarque Claire Kramsch (2015:15) :

L'apprenant peut produire une phrase grammaticalement correcte que le récepteur comprendra, mais il est possible qu'il ne sache pas comment transmettre le sens social communiqué dans le contexte donné ${ }^{75}$.

Cela est encore plus important en classe de futurs fonctionnaires qui représenteront leurs pays.

Il semble donc légitime de nous demander maintenant comment la compétence sociolinguistique pourrait être enseignée en classe de français de la diplomatie.

Les chercheurs (par exemple Tyne, 2012), soulignent le fait que l'accès à la compétence sociolinguistique est le résultat d'un long processus d'apprentissage qui cause bien des difficultés ${ }^{76}$. Il est à noter que si la didactique du FLE apporte des

75 "Learner may produce a perfectly grammatical utterance that the listener can understand, but he or she may not know how to convey the social meaning communicated in the target context", notre traduction.

${ }^{76}$ Kecskes et Papp (2000) expliquent les causes de la difficulté d’apprendre la compétence sociolinguistique en suggérant que lors de l'acquisition de la première langue, les enfants développent 
réponses assez précises sur l'importance de la compétence sociolinguistique, elle semble plus floue sur la manière de son enseignement. Évidemment, faire comprendre que certains mots, expressions, constructions syntaxiques ne sont appropriés que dans certains contextes spécifiques n’est pas une tâche facile.

Nous sommes d'accord avec Jean-Marc Dewaele et Nathalie Wourm (2002 : 140) affirmant que :

il est possible de dresser une liste des mots, expressions et constructions spécifiques à apprendre par cœur, mais il est plus difficile d'enseigner les nuances que ceux-ci transmettent, et les innombrables facteurs dans la situation qui déterminent leur usage.

Il s'agit ici des normes sociales qui seraient l'expression d'une collectivité, qui assureraient le lien social. Elles seraient la manifestation de l'esprit collectif (Costa-Giomi et Descombes, 1996), elles feraient l'objet d'un apprentissage social et résulteraient du savoir commun. Dans des situations données, les apprenants doivent savoir développer un éventail de schémas possibles comme les diplomates devraient « non nécessairement conclure une négociation, mais créer un espace de négociation $»^{77}$.

Ce pouvoir de produire et reconnaître un style de langage relatif à une situation donnée s'avèrera primordial pour notre public. Jean-Marc Dewaele et Nathalie Wourm (op.cit. : 143) remarquent que :

Il y a aussi des scripts plus diffus, comme le fait de parler d'émotions ou féliciter un ami ou un supérieur ou parler de l'éducation des enfants ou de la politique. Ces scripts dépassent de loin les formules toutes faites d'actes de communication qu'on enseigne dans un enseignement "communicatif". C’est évidemment utile et nécessaire d'être capable de demander le chemin ou de commander une bière, mais il faut se rendre compte que ces formules sont extrêmement superficielles et limitées.

la compétence linguistique en même temps que la compétence conceptuelle. La situation est différente pour l'appropriation de la deuxième langue puisque de nouveaux concepts entrent en compétition avec les concepts existants de la première langue. Reprenant à Grosjean l'idée qu'un bilingue n'est pas la somme de deux monolingues, « Kecskes et Papp développent le concept de la Common Underlying Conceptual Base (CUCB, base conceptuelle commune sous-jacente) qui contient les représentations conceptuelles liées aux différentes langues apprises par l'individu. Cette base serait toujours dominée par une des langues présentes, mais l'influence des langues pourrait aller dans les deux sens (transfert bidirectionnel), c'est-à-dire qu'il y peut y avoir influence de la L1 sur la L2, mais aussi de la L2 sur la L1 au niveau de l'ordre des mots, de l'organisation de la phrase, des métaphores et des expressions idiomatiques » (Jean-Marc Dewaele et Nathalie Wourm, 2002 : 140). En outre, l'étalonnage de niveaux de compétence sociolinguistique s'est avéré problématique pour le CECRL (95).

${ }^{77}$ https://www.diplomatie.gouv.fr/fr/le-ministere-et-son-reseau/missions-et-organisation62169/metiers-de-la-diplomatie/l-activite-diplomatique-en-poste/article/negociation 
Pour préparer les apprenants à la spécificité du métier de diplomate, les enseignants doivent rejeter tout ce qui est artificiel, préparer les apprenants à une communication dans un contexte authentique en se focalisant avant tout sur les documents authentiques.

\subsubsection{Enseignement de la compétence sociolinguistique : importance des documents et des interactions authentiques}

En didactique du FLE, l'utilisation des documents authentiques s'est peu à peu répandue, mais ne concerne généralement que les activités de compréhension et n'intervient souvent que dans la phase de confrontation. Le recours à de tels documents pour l'apprentissage/enseignement de l'expression orale reste exceptionnel. De fait, l'intégration du document authentique en tant que support et stratégie didactique est encore timide. Et pourtant, le document authentique permet non seulement de bannir le côté artificiel qui a longtemps caractérisé les pratiques de classe dans le passé, mais assure le transfert de la vie réelle en classe et permet aux apprenants d'avoir un contact direct avec l'utilisation réelle de la langue. Le document authentique permet alors l'acquisition de la compétence sociolinguistique en permettant l'analyse des mêmes éléments que ceux utilisés par les locuteurs natifs. Ceci est encore plus important dans les situations où les apprenants ont rarement l'occasion d'utiliser leur langue cible comme authentique instrument de communication en dehors de la classe de langue. La variation sociolinguistique à laquelle les apprenants sont exposés dans la classe de langue est donc relativement limitée. Comme les apprenants ont rarement l'occasion de s'engager dans des interactions authentiques avec leurs professeurs ou avec des locuteurs natifs de la langue cible en dehors de la salle de classe, ils sont incapables de développer suffisamment leur compétence sociolinguistique. Nous sommes d'accord avec Jean-Marc Dewaele et Nathalie Wourm selon lesquels ces apprenants risquent donc de demeurer « monostylistiques dans leur deuxième langue» (op.cit. : 150).

Par ailleurs, les études menées par Roy Lyster ${ }^{78}$ (1994), puis par Jean-Marc Dewaele $^{79}$ (2002) ont relevé que l'observation et surtout la participation à des

${ }^{78}$ Lyster analyse l'effet de la stratégie fonctionnelle-analytique sur des aspects de la compétence sociolinguistique de 106 écoliers anglophones de Toronto inscrits dans un programme d'immersion française. Il constate que « seul un usage authentique de la langue seconde permettra à l'apprenant d'adopter la norme sociolinguistique française " (Lyster, $1994: 281$, nous soulignons).

${ }^{79}$ Dewaele (2002) a étudié l'usage des pronoms d'allocution dans un corpus de conversations endolingues et exolingues entre 53 participants qui étaient étudiants du département de français de Birkbeck College, à l'Université de Londres. Il constate que « l'usage authentique de la langue cible entraîne un développement concomitant des schémas et scripts. Les apprenants qui ont utilisé le français plus fréquemment semblent avoir acquis la compétence sociolinguistique nécessaire, et sans doute aussi la confiance, qui leur permet d'utiliser le $t u$ dans les interactions sans craindre de commettre un faux pas social» (Dewaele, $2002: 18$, nous soulignons). 
interactions authentiques avec des locuteurs natifs semblent davantage stimuler l'acquisition de la norme sociolinguistique ${ }^{80}$. Les apprenants de la langue étrangère devraient avoir la possibilité d'écouter des documents authentiques en classe ainsi que pratiquer les formes du langage qui pourraient aboutir à des échanges réussis au-delà de la classe (Burns, $1997: 102)^{81}$.

Finalement, toutes ces études nous permettent de conclure que l'enseignement des normes sociolinguistiques en langues étrangères, même s'il n'est pas évident au premier abord, est tout à fait faisable. Néanmoins, comme nous l'avons mentionné, les méthodes de langue devraient contenir du matériel authentique. Les dialogues ne peuvent pas être artificiels, pauvres ou stériles, car cela risque de limiter le développement de la fluidité dans la langue étrangère. Les documents écrits devraient être accompagnés d'un maximum de documents vidéo (documentaires, débats, extraits de films) qui permettraient aux apprenants de saisir les normes sociales en contexte authentique.

\subsubsection{Compétence pragmatique dans le cours de français de la diplomatie}

Ainsi que vu plus haut, la compétence sociolinguistique apporte les éléments nécessaires pour l'intercompréhension de la situation de communication langagière, la culture, les coutumes, les habitudes, les rôles sociaux, les règles de vie et de politesse, les rituels d'une communauté, les valeurs, les différentes représentations de la réalité des différents pays (CECRL : 93-96). Toutefois, les études ${ }^{82}$ montrent que l'acquisition de la compétence sociolinguistique est un processus qui dynamise l'apprentissage d'autres compétences, y compris la compétence pragmatique.

La compétence pragmatique ${ }^{83}$ composée de la compétence discursive, fonctionnelle et de conception schématique, se définit comme l'aptitude du locuteur à sélectionner et arranger au mieux les éléments linguistiques, selon la visée d'effet recherché et les circonstances énonciatives dans lesquelles il se trouve. L’apprenant maîtrise la langue

${ }^{80}$ Ceci dit, il nous semble essentiel d'inviter aux cours de FOS des spécialistes dans le domaine étudié qui pourraient partager avec les apprenants leurs points de vue sur un problème donné.

${ }^{81}$ " The second-language learners should be given the opportunity to listen to authentic discourse within the language classroom and practice forms of language that will facilitate successful exchanges beyond the classroom ", notre traduction.

${ }^{82}$ Les recherches menées en 2006 à l'Université de Neuchâtel portent sur la socialisation langagière d'enfants et adolescents issus de familles immigrées dans un contexte social comme celui de la Catalogne. Accès à l'article : http://www.academia.edu/21230365/La_compétence_ sociolinguistique_pour_quoi_faire

${ }^{83}$ La compétence pragmatique n’est pas facile à définir de façon précise, cependant les études et les recherches sur le sujet ont un fil conducteur : l'usage contextualisé de la langue. 
afin d'organiser, de structurer son discours, de réaliser des fonctions langagières et de segmenter ses messages selon des schémas interactionnels et transactionnels. Concernant le public des diplomates, cela veut dire que pour la négociation d'un contrat difficile, le diplomate qui a des compétences pragmatiques développées, recherchera la meilleure façon de présenter ce qu'il a à dire et accordera un soin particulier aux axes les plus délicats de la négociation.

En fait, une communication effective dans une langue étrangère revendique non seulement la connaissance de la grammaire et du vocabulaire, mais aussi le savoir pragmatique concernant les aspects particuliers de la langue cible ${ }^{84}$. Comme le souligne Agnieszka Bryła-Cruz (2017 : 4), « le manque de savoir-faire pragmatique peut être la source de malentendus et de problèmes malgré une connaissance avancée de la langue étrangère (Cohen et Olshtain 1982 ; Kasper et Blum-Kulka 1993 ; BardoviHarlig 2002) ${ }^{85}$ et cela peut causer des malentendus irréversibles à éviter surtout dans le monde diplomatique.

De même, nous sommes d'accord avec Luciano Mariani (2015 : 123) que :

La compétence pragmatique constitue le cœur de l'apprentissage de la langue (maternelle, seconde ou étrangère) puisqu'elle concerne les modes dans lesquels les messages sont conçus, structurés et adaptés au contexte et utilisés pour réaliser des fonctions communicatives. Développer la compétence communicative signifie augmenter progressivement la connaissance de l'usage de la langue comme un système structuré (lexicale, grammaticale, sémantique, phonologique, orthographique) et comme un système d'interaction sociale. La maîtrise de ces systèmes n'est pas cependant la fin de soi, mais constitue la base pour l'efficacité pragmatique, c'est-àdire pour agir linguistique et réaliser des intentions communicatives, en utilisant la langue aux fins personnelles et sociales ${ }^{86}$

${ }^{84}$ Selon Gohard-Radenkovic (1999 : 95) « les compétences pragmatiques (...) peuvent développer des compétences stratégiques d'ajustement qui compensent en quelque sorte des lacunes linguistiques, des erreurs d'interprétation d'un énoncé ou la méconnaissance des codes socioculturels sous-tendant une situation de communication, afin d'atteindre le but de son discours ou de maintenir l'échange langagier ».

85 "Brak sprawności pragmatycznej może być źródłem nieporozumień i zaburzeń komunikacji pomimo zaawansowanego poziomu znajomości języka obcego (Kasper et Blum-Kulka 1993 ; Bardovi-Harlig 2002)", notre traduction.

${ }^{86}$ " La competenza pragmatica costituisce il cuore dell'apprendimento di una lingua (materna, seconda o straniera), poiché riguarda i modi in cui i messaggi "vengono concepiti, strutturati e adattati al contesto ... usati per realizzare funzioni comunicative. Sviluppare una competenza comunicativa significa aumentare progressivamente la conoscenza e l'uso della lingua come sistema strutturato (lessicale, grammaticale, semantico, fonologico, ortografico) e come sistema di interazione sociale. La padronanza di questi sistemi non è fine a se stessa, ma costituisce la base per la propria efficacia pragmatica, cioè per agire linguisticamente e realizzare intenzioni comunicative, utilizzando la lingua ai fini della propria espressione personale e sociale », notre traduction. 
Nous verrons dans ce qui suit que la compétence discursive, fonctionnelle et la compétence de conception schématique joueront un rôle important en classe du français de la diplomatie.

\subsubsection{La compétence discursive et la diplomatie}

Tout d'abord, il est à noter que toute activité langagière met en scène les participants et/ou les partenaires de la communication. Pour être plus efficaces et opérationnelles, toutes les interventions des interlocuteurs s'appuient sur un schéma communicatif approprié. Tout en tenant compte du nombre de personnes engagées dans la communication, l'attention de l'apprenant s'oriente vers les schémas monolingues (dans la communication diplomatique, il s'agira des communiqués de presse) ou dialogues (nombreuses discussions, correspondances, etc.).

Magdalena Sowa (2011 : 313) stipule que l'apprenant doit construire le discours conformément à la langue, à la convention sociale, aux valeurs reconnues par un groupe professionnel, etc. Si, dans le contexte scolaire de l'apprentissage d'une LE, la formulation correcte des phrases/énoncés en le est de première importance, d'autres éléments de la compétence discursive ne sont point négligeables. Mentionnons, entre autres, la cohérence, la cohésion, les liens logico-causaux, les maximes de coopération, les conventions textuelles définissant les genres de texte, sans lesquels le texte/discours, même absolument correct du point de vue grammatical, sera incompréhensible et/ou inacceptable pour un récepteur en un temps, un moment et un milieu donnés.

La compétence discursive renvoie à l'approche actionnelle et au choix de stratégies discursives pour atteindre un but précis, par exemple structurer ou organiser le discours. Elle fait le lien entre le locuteur et la situation en permettant de distinguer et d'identifier différents messages (récit, discours officiels, etc.). C'est elle qui répond au « pourquoi » de la compétence sociolinguistique décrite auparavant. La compétence discursive consiste à sensibiliser l'apprenant aux différents types de discours et à la notion d'acte de parole.

Il convient de dire que le CECRL met en lumière certains aspects de la compétence discursive : la souplesse, les tours de parole, le développement thématique et enfin la cohérence et la cohésion qui selon nous s'avèreront particulièrement importantes durant les missions diplomatiques. Cette compétence exige la connaissance de l'organisation des phrases, la capacité à les maîtriser au niveau des informations données. À cela s'ajoute encore la capacité à structurer le discours en respectant certains principes tels que l'organisation thématique. À titre d'exemple, prenons une lettre officielle que le diplomate rédige quotidiennement. Cette tâche suppose la production d'un texte universel et spécifique à la fois : même si elle existe dans toute société de tradition scripturale, chaque société a élaboré des principes différents de sa rédaction. La production d'une lettre officielle en français et en langue maternelle des diplomates est différente et peut ne pas respecter les mêmes 
règles de rédaction, comme c'est le cas du français et du polonais ${ }^{87}$. En matière diplomatique « les pays, comme des sujets souverains du droit international, et plus spécifiquement leurs représentants, mènent entre eux une correspondance décrite comme la correspondance diplomatique » (Orłowski $\left.2016: 6^{88}\right)$. Dans le protocole diplomatique (Constanze, $2006: 12$ ), nous pouvons lire que :

la correspondance diplomatique est l'ensemble des écrits échangés entre États par l'intermédiaire de leurs représentations diplomatiques. La préparation de cette correspondance répond à des exigences extrêmement précises et exige une attention particulière. La portée de chaque mot et de chaque phrase y est minutieusement pesée ${ }^{89}$.

Outre la forme, le message diplomatique est doté d'une fonction concrète : il devra informer, rendre compte, faire agir, argumenter, décrire, etc. En rédigeant son texte, le diplomate cherchera à produire un effet concert sur son locuteur potentiel. Un autre exemple est fourni par Florence Mourlhon-Dallies (2008 : 89) décrivant un diplomate libanais qui pour bien mener des négociations économiques avec des responsables français, devra organiser son discours de manière cohérente et logique en sachant comment et quand intervenir en vue de convaincre des partenaires et les amener à conclure l'accord visé.

Pour préciser, la compétence discursive concerne trois aspects. Tout d'abord, il s'agit de la capacité d'organiser des phrases et puis de maîtriser leurs composantes. Plus tard, il est question de savoir maîtriser les phrases dans leur ensemble comme : rhème/thème, cause/conséquence, etc.

Enfin, comme nous l'avons déjà mentionné et comme le remarque Radosław Kucharczyk (2018 : 78), la compétence discursive recouvre la capacité à gérer le discours en fonction de l'organisation thématique, de la cohérence et de la cohésion, du style et du registre, de l'efficacité thématique, etc. Pour bien gérer les échanges à l'oral, les interlocuteurs doivent reconnaître par exemple l'ironie ou bien savoir établir un contact avec le futur interlocuteur, ce qui exige l'enchaînement des

${ }^{87}$ Tout d'abord, il faut appliquer le modèle de normolettre convenable (police de caractères, interligne, marges, en-tête). Ensuite, il faut s’approprier les éléments de la structure formelle de la lettre (éléments constitutifs tels que les coordonnées du destinateur et du destinataire, l'objet, les références, le lieu, la date, la formule d'appel, le corps de la lettre, la formule de politesse finale, la signature, etc.). Après avoir choisi le sujet de la lettre, il faudra lui subordonner le contenu de la lettre en veillant à l'organisation de l'information au niveau de la phrase (microstructure) et celui de l'ensemble du texte (macrostructure). Ceci veut dire que les phrases doivent s'organiser en paragraphes thématiques relatifs à l'introduction, au développement et à la conclusion.

88 "Państwa, jako suwerenne podmioty prawa międzynarodowego, a konkretniej ich przedstawiciele prowadzą między sobą wymianę pism określaną mianem Korespondencji dyplomatycznej", notre traduction.

${ }^{89}$ C'est nous qui le soulignons. 
actes de paroles suivant : ouvrir l'interaction - demander des informations - clore l'interaction, différemment en fonction du niveau.

Ce sont les raisons pour lesquelles la compétence discursive est importante pour de futurs diplomates dont le travail quotidien sera composé des éléments mentionnés ci-dessus.

\subsubsection{La compétence fonctionnelle dans le domaine professionnel}

Comme nous l'avons déjà vu, dans chaque acte de communication, il faut tenir compte de l'interlocuteur. Il se peut que l'apprenant « malhabile » en langue étrangère ne soit pas seulement celui qui fait des fautes, mais celui qui ne sait pas entrer en relation avec son interlocuteur, c'est-à-dire celui qui ne sait pas aider son interlocuteur à construire le sens. En effet, c'est le contexte qui permet de fournir une interprétation, de savoir s'il s'agit d'une information, d'une promesse, d'un ordre. C'est une approche qui considère que le destinataire ou l'interlocuteur n'est pas passif.

La compétence fonctionnelle recouvre l'utilisation du discours oral et des textes écrits en termes de communication à des fins fonctionnelles particulières (Conseil de l'Europe, 2001 : 98). Dans le contexte d'un apprentissage du français aux objectifs spécifiques, la compétence fonctionnelle est une compétence centrale du fait que ce type d'apprentissage se base avant tout sur la réalisation des fonctions précises, d'où l'appellation du français fonctionnel utilisée au cours des années 1970. Cet aspect fonctionnel de l'apprentissage du FOS est lié à l'utilisation ultérieure de la langue par l'apprenant du FOS dans un contexte professionnel. La maîtrise de ces compétences fonctionnelles constitue une condition préalable pour que les apprenants puissent réussir à réaliser plus tard des tâches professionnelles.

La description détaillée de la compétence pragmatique et discursive nous a permis de formuler quelques suggestions pour améliorer l'enseignement des normes pragmatiques en classe de français de la diplomatie.

Tout d'abord, nous pensons que les enseignants de langue doivent être conscients des différences sociopragmatiques qui peuvent exister entre la langue maternelle de leurs apprenants et celles de la langue cible. L'objectif serait donc d'essayer de sensibiliser les apprenants aux différences et de stimuler leur conscience métapragmatique (Kasper et Blum-Kulka, 1993). De ce fait, les enseignants devraient expliquer et expliciter ce qui est implicite dans la langue cible et stimuler les possibilités propres des apprenants à s'engager dans des analyses pragmatiques.

\subsection{Mise au point : le profil d'un cours de français de la diplomatie}

Il ressort de cette description du public travaillant dans le secteur de la diplomatie certaines caractéristiques nécessaires pour concevoir et adapter un programme de 
français de la diplomatie qui ne serait pas un cours essentiellement lexicologique ${ }^{90}$. Bien évidemment, la langue utilisée sur les questions internationales et européennes a ses particularités et dépasse la compétence en français général. Cependant, le fait qu'un apprenant la maîtrise ne veut pas dire qu'il est préparé à travailler dans cette langue dans un contexte professionnel spécifique.

De ce fait, nous croyons que si l'enseignement du français de la diplomatie comporte une spécificité, cette dernière ne réside pas dans le lexique ni dans la syntaxe, mais elle est à chercher dans le lien étroit entre la langue et la culture qu'impose le monde contemporain du travail.

Afin de montrer la corrélation entre les compétences que le cours de français de la diplomatie mobilise, nous présentons le schéma ci-dessous.

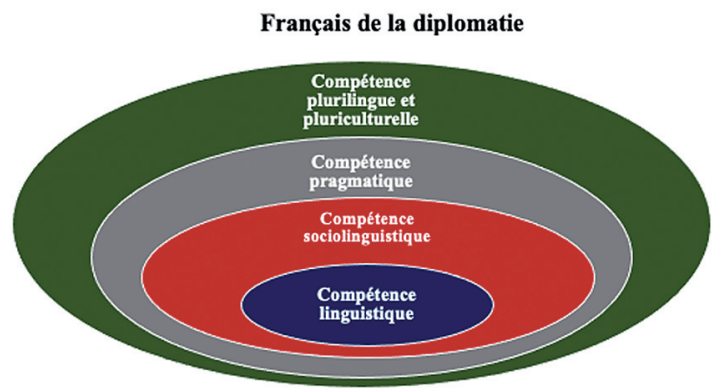

Figure 12. Mobilisation des compétences dans le cours de français de la diplomatie.

Source : élaboration propre.

Ce schéma montre que la connaissance plurilingue et pluriculturelle embrasse les autres compétences. Certes, la compétence linguistique constitue une partie importante des compétences qui sont mobilisées dans le cours de français de la diplomatie. Pourtant, comme nous l'avons démontré, même si elle est la base des autres compétences, elle ne constitue qu'un fragment de la totalité du cours de français de la diplomatie. En outre, il faut noter que la compétence linguistique est comprise dans la compétence sociolinguistique, pragmatique et puis dans la compétence plurilingue et pluriculturelle.

En effet, l'apprentissage du FOS implique l'acquisition de nombreuses compétences inextricablement liées les unes aux autres dont le couronnement est la compétence plurilingue et pluriculturelle.

${ }^{90}$ Nous sommes d'accord avec Magdalena Sowa $(2017: 14)$ qui affirme que la compétence lexicale peut être considérée comme réussie si le vocabulaire de la langue donnée est correctement utilisé par rapport au lieu, temps, évènements et dans une situation avec des interlocuteurs. Il ne faut pas réduire le lexique à une liste de mots dépourvus de contexte ou même de questions de la terminologie. Dans l'acquisition du vocabulaire (aussi du vocabulaire spécialisé), le plus important est d'attirer l'attention sur son fonctionnement discursif. 


\subsection{Bilan}

Force est de constater que le profil du diplomate possède ses propres caracteristiques. Cerner ce profil était primordial pour mieux comprendre la réalité de ces publics spécifiques différant des publics de FLE. Il ressort de cette description des diplomates certaines caractéristiques nécessaires pour la conception du cours de français de la diplomatie. Vient en premier lieu la nécessité de la préparation des diplomates au dialogue interculturel, l'élaboration des schémas d'orientations culturelles, la nécessité de se débarrasser d'une position dominatrice, d'un jugement dépréciatif des autres cultures, le besoin d'ouverture à l'Autre.

Ces informations sont nécessaires pour se pencher sur les compétences qui devraient être prises en compte pendant l'élaboration du cours de français de la diplomatie. En effet, le profil de diplomate mobilise avant tout la compétence plurilingue et pluriculturelle ainsi que la compétence sociolinguistique et pragmatique. Cependant, il faut remarquer que ces compétences ne restent pas isolées, elles se combinent de manière complexe, se chevauchent et toutes ensemble définissent le cours de français de la diplomatie.

Ce chapitre a également montré que, contrairement à ce que nous trouvons dans les manuels de FOS, la langue professionnelle ne se réduit pas à un vocabulaire de spécialité et que le cours de français de la diplomatie ne devrait pas être limité aux aspects linguistiques comme c'est aujourd'hui le cas. Dans le cours de français de la diplomatie, des savoir-faire professionnels et des savoir-être culturels l'emportent sur les savoirs linguistiques.

Enfin, ce chapitre a mis en lumière la problématique de l'approche interculturelle, l'une des préoccupations de notre époque. L'analyse des besoins des diplomates et de leur travail quotidien nous a obligés à trouver des techniques utiles dans la conception des cours de français de la diplomatie dans une perspective interculturelle. Par ailleurs, favoriser cette approche en classe du français de la diplomatie contribue à la réflexion sur soi-même, sur ses propres appartenances, sur ses propres valeurs ce qui est indissociable de l'enseignement basé sur les approches plurielles des langues et des cultures analysé largement dans le troisième chapitre. 


\section{Opérationnalisation de la compétence plurilingue et pluriculturelle dans l'optique d'un Cadre de Référence pour les Approches Plurielles des Langues et des Cultures. L'exemple du français de la diplomatie}

\section{Remarques liminaires}

Dans le chapitre précédent, nous nous sommes penchés sur le rapport qui existe entre le profil du diplomate et la conception d'un cours de français de la diplomatie. Nous avons montré que certaines caractéristiques propres au travail quotidien du diplomate devraient être incluses dans un cours de français qui vise ce public particulier. De surcroit, cette analyse a mis en lumière le fait que la langue professionnelle ne se réduit pas à un vocabulaire de spécialité et que le cours de français de la diplomatie ne peut pas être limité aux aspects linguistiques. De plus, outre les compétences linguistiques, nous avons souligné l'importance des compétences sociolinguistique, pragmatique, plurilingue et pluriculturelle dans le travail du diplomate. La sensibilisation à d'autres langues et d'autres cultures nous semble primordiale dans la conception d'un cours de français de la diplomatie. Par ailleurs, nous avons montré que favoriser l'approche interculturelle en classe de français sur des objectifs spécifiques contribue à la réflexion sur soi-même, sur ses propres appartenances, sur ses propres valeurs, ce qui est étroitement lié au métier exercé par les apprenants en question. La prise en compte de l'approche interculturelle, y compris la compétence plurilingue et pluriculturelle, nous dirige vers les approches plurielles des langues et des cultures.

Le présent chapitre met en exergue les concepts théoriques et pratiques des approches plurielles qui contribuent au développement de la compétence plurilingue et pluriculturelle. Ensuite, nous observerons comment les approches plurielles peuvent être implantées au cours de français de la diplomatie. Finalement, nous verrons de plus près la portée didactique du référentiel « Cadre de Référence pour les Approches Plurielles des Langues et des Cultures » (CARAP) mais aussi ses enjeux et de nombreux obstacles à surmonter. 


\subsection{La voie pour l'Europe plurielle}

Nous vivons dans une Union européenne de 27 États membres, dont l'unité et la diversité s'expriment au travers de 24 langues officielles ainsi qu'un grand éventail de langues régionales et de dialectes. Il convient de rappeler que les 500 millions d'Européens ont des origines ethniques et linguistiques différentes. La prise en compte de ces environnements socio-culturels divers, de différentes représentations des apprenants et des enseignants concernant la langue et la culture, nous dirige vers la notion de l'Europe plurielle : plurilingue et pluriculturelle.

Toutefois, il n'y a pas si longtemps, l'Europe était encore dominée par une idéologie monolingue. En effet, jusqu'aux années 2000 on croyait que la vie serait plus facile si l'on parlait la même langue ${ }^{91}$. Comme le remarque Christine Puren (Puren, 2005 cité par Candelier, $2007: 373)$ :

Il n'est pas facile de renoncer à l'habitus d'un "idéal monolingue » qu'il soit unique ou multiplié par deux, trois, quatre, etc. Les cultures éducatives de nombreux pays européens ont été construites sur le principe de la norme linguistique, sur la haine de l'erreur et la préférence du singulier, bien séparé de toute pluralité rimant, aux yeux de leurs décideurs, avec médiocrité : une seule bonne réponse, un seul mot qui convient, une seule variété de langue - le cas idéal serait de garder uniquement la langue standard nationale, basée sur une norme universelle, commune à tous.

Rappelons ici que même les états européens multilingues qui ont plusieurs langues officielles (la Belgique, la Suisse) promouvaient le monolinguisme juxtaposé par exemple en interdisant aux enfants d'être scolarisés dans d'autres langues que la langue officielle de la partie du pays où se trouvait l'école. Cela provoquait des inquiétudes, la réticence, des craintes par rapport à la langue différente. La langue parfaite et la pureté linguistique promues par l'idéologie du monolinguisme décourageaient et démotivaient les apprenants. Les changements commerciaux, l'adhésion de nouveaux membres au sein de l'Union européenne et les flux migratoires ont poussé à un changement. Finalement, tout cela a forcé les états à sortir du monolinguisme. L'homogénéité linguistique a été remplacée par la diversité linguistique.

Nous sommes d'avis que la construction de l'Europe de 27 ne peut que constater la diversité indubitable, surtout du point de vue des relations culturelles et linguistiques. Il fallait alors développer un regard positif sur l'hétérogénéité linguistique par la promotion du plurilinguisme.

${ }^{91}$ À l'époque on croyait qu'une nouvelle Europe devrait parler une seule langue et qu'une seule langue garantit une meilleure entente linguistique. L'idée de l'espéranto (inventée au XIXe siècle par Ludwik Lejzer Zamenhof) était que tous les citoyens seraient à égalité par rapport à leur propre langue. Cela signifierait qu'il ne serait pas question d'une domination d'un pays par rapport aux autres au travers de la langue. 
En effet, le plurilinguisme ${ }^{92}$ des nations, des régions, des institutions et des individus en Europe constitue aujourd'hui un emblème identitaire, une composante essentielle de la culture. Pour pouvoir vivre ensemble et travailler ensemble, il faut en effet pouvoir se comprendre et communiquer. D'où la nécessité tant pour l'Union européenne que pour le Conseil de l'Europe ${ }^{93}$ (le Comité des ministres du 17 mars 1998) de promouvoir l'Europe plurielle :

promouvoir le plurilinguisme à grande échelle [...] en encourageant tous les Européens à atteindre un certain niveau de compétence communicative dans plusieurs langues [et] en diversifiant les langues proposées et définissant des objectifs adaptés à chaque langue.

Cette tendance à promouvoir l'Europe plurielle est surtout visible dans le domaine de l'éducation. Depuis quelques années, les autorités européennes ${ }^{94}$ proclament le plurilinguisme en tant que l'un des principes fondamentaux de l'éducation linguistique en Europe. Cette notion, très répandue dans le cadre des politiques linguistiques éducatives, en constitue leur principe fondateur. Toutefois, l'engagement de mener une politique éducative autour du plurilinguisme met en lumière des conceptions du plurilinguisme diverses, et même conflictuelles entre elles, et nous mènent vers une didactique du plurilinguisme, voire vers une didactique des plurilinguismes que nous découvrirons dans ce chapitre.

\subsubsection{Le développement de la perspective plurielle dans la didactique des langues}

En Europe, l'approche interculturelle était répandue avant l'idéologie plurielle. En effet, la rencontre avec l'Autre constituait depuis toujours une expérience unique et fondamentale pour tout le monde. Reconnaître et encore accepter l'Autre qui porte des valeurs, des religions, cultures et traditions différentes des nôtres était

${ }^{92}$ Le plurilinguisme concerne la capacité intrinsèque d'une personne à maîtriser plusieurs langues à des niveaux qui ne sont pas nécessairement identiques, alors que le multilinguisme renvoie à la présence dans une zone géographique déterminée - qu’elle soit limitée ou étendue de plus d'une "variété de langues » (c'est-à-dire le mode d'expression d'un groupe social) reconnue officiellement ou non comme langue; dans une telle zone géographique, certains individus peuvent être monolingues et ne parler que leur propre variété de langue (Beacco et Byram, 2007 : 8).

${ }^{93}$ Dans le domaine des langues en Europe, la référence incontestée en matière de politique éducative est aujourd'hui l'ensemble conceptuel élaboré depuis les années quatre-vingt-dix au sein du Conseil de l'Europe. «Cette institution s'est détachée dans les années quatre-vingt-dix de préoccupations majoritairement didactiques pour se consacrer à un travail approfondi de politique linguistique éducative» (Candelier, $2008:$ 148).

${ }^{94}$ Le travail du Conseil de l'Europe dans le domaine de l'éducation aux langues est coordonné par deux instances complémentaires, le Centre européen des langues vivantes (CELV), à Graz en Autriche, et la Division des politiques linguistiques à Strasbourg. 
et est toujours l'un des plus grands défis de l'éducation. L'approche interculturelle qui privilégie l'acceptation de l'altérité est présente dans les méthodes de langues étrangères au moins depuis les années 2010. Il convient de souligner que pendant que les éléments de cultures différentes sont présents en classe de langue étrangère, l'approche plurilingue y est toujours absente. Et pourtant la philosophie plurielle est présente dans la vie quotidienne grâce aux échanges fréquents qui mobilisent les contacts entre les gens de différents coins du monde, évolutions géopolitiques, progrès technologique numérique, et finalement grâce à l'influence décisive dans le domaine de la didactique des langues introduite par la publication du CECRL. La perspective plurielle "forcée » par de nouveaux besoins reflète parfaitement ces changements dans le monde. Introduite parallèlement avec l'approche interculturelle, elle reste quand même une approche qui a fait l'objet de nombreux débats, remises en question et publications ces dernières années. Depuis que le sujet de l'approche plurielle est apparue, les linguistes, les sociologues, les didacticiens n'ont cessé de le travailler et retravailler dans un ensemble de travaux produits aussi bien dans que hors du Cadre européen. L'une des principales conséquences de ces changements dans le domaine de la didactique des langues étrangères est, selon nous, une prise de conscience de l'importance des approches plurilingues que nous développerons ci-après.

\subsubsection{La compétence plurilingue et la didactique du plurilinguisme}

Nous avons vu précédemment comment la perspective plurielle et l'interculturalité sont traitées sur la scène européenne et dans les documents statuant de la politique linguistique. Il convient maintenant de relever les caractéristiques de la compétence plurilingue et pluriculturelle, ce qui affecte directement la didactique des langues étrangères et concerne notre public de futurs diplomates participant au cours de français de la diplomatie.

En analysant les travaux du CECRL de 2001, du Guide pour l'élaboration des politiques linguistiques éducatives en Europe $e^{95}$ (Beacco et Byram, 2007), du Guide pour le développement et la mise en cuvre de curriculums pour une éducation plurilingue et interculturelle (Beacco et al. 2010), nous pouvons constater que la notion de compétence plurilingue et pluriculturelle comporte un certain nombre de traits caractéristiques. Comme le remarque Véronique Castellotti $(2008: 322)$ :

${ }^{95}$ Le Guide pour l'élaboration des politiques linguistiques éducatives en Europe est un document conçu par le Conseil de l'Europe dans le but de la réorganisation de l'enseignement des langues dans les États membres fondé sur le plurilinguisme. Il est organisé en trois parties : l'analyse des politiques linguistiques éducatives menées actuellement en Europe, les données nécessaires à lélaboration des politiques linguistiques éducatives partagées en Europe et leur mise en œuvre (analyse des formes d'organisation des enseignements et des apprentissages plurilingues). 
cette compétence est par essence partielle, plurielle, composite et hétérogène ; elle se caractérise également par une grande malléabilité et une capacité d'évolution constante, dans le temps et dans l'espace. En résumé, il s'agit donc de la capacité à mettre en œuvre, en contexte, un répertoire constitué de ressources plurielles et diversifiées, qui permet de reconnaître et de s'affirmer en tant qu'acteur plurilingue ${ }^{96}$.

La description ci-dessus montre que la compétence plurilingue et pluriculturelle est une notion complexe qui résulte de la cohabitation des langues. D'un côté, la compétence plurilingue et pluriculturelle combine des connaissances de la langue d'apprentissage avec les particularités d'usage socioculturel, d'un autre côté, elle engage la maîtrise de probables interférences entre les langues qui proviennent des connaissances linguistiques et socioculturelles qui sont déjà acquises. Nous croyons alors que le développement d'un répertoire plurilingue tout au long de la vie comprend aussi le développement de la compétence plurilingue et pluriculturelle.

Il n'est pas anodin que l'enrichissement de la compétence plurilingue et pluriculturelle permette la compréhension d'autres modes de vie, la capacité d'interprétation et d'explication de ce qui est différent. Prendre conscience d'autres langues et cultures, être plurilingue, peut mener des apprenants à devenir capables de nouer des relations avec les autres ou à comprendre par la suite les attitudes, les caractères et les valeurs d'autres groupes. Cela joue un rôle primordial dans l'éducation de notre public de diplomates.

Pour résumer les travaux sur la compétence plurilingue et pluriculturelle et ce que nous avons exposé jusqu'à présent, nous proposons un tableau qui montre des indicateurs de la compétence plurilingue et pluriculturelle et nous dirige ainsi vers les approches plurielles.

Tableau 3. Indicateurs de la compétence plurilingue et pluriculturelle.

Les indicateurs de la compétence plurilingue et pluriculturelle

Puiser dans le répertoire langagier et culturel lors de l'apprentissage d'une nouvelle langue étrangère
Les caractéristiques propres à la compétence plurilingue et pluriculturelle

Le caractère fonctionnel de la compétence plurilingue et pluriculturelle

${ }^{96}$ Véronique Castellotti (2008) se réfère ici à un concept selon lequel les apprenants bilingues ne sont pas forcément plurilingues si l'on peut détecter un "double semilinguisme ». La compétence bilingue (plurilingue) n'est pas simplement l'addition de deux compétences unilingues, mais représente au contraire un tout. De plus, comme l'ont montré les travaux de Bernard Py (1997 : 498) sur la communication bilingue « les bi- ou plurilingues ne possèdent pas simplement deux ou plusieurs langues qu'ils peuvent employer en fonction de leurs interlocuteurs ou de la situation de communication dans laquelle ils se trouvent. Ils disposent également des ressources linguistiques dont les monolingues sont privés ». 
Les indicateurs de la compétence plurilingue et pluriculturelle
Les caractéristiques propres à la compétence plurilingue et pluriculturelle

Puiser dans le répertoire langagier et culturel lors de la lecture des textes dans une nouvelle langue étrangère

Chercher dans le répertoire langagier et culturel les meilleures façons d’apprentissage d'une nouvelle langue étrangère

Chercher des similarités entre les langues connues au niveau du lexique et de la grammaire

Chercher des similarités entre les langues connues au niveau des émotions et de la grammaire

Le caractère intégré de la compétence plurilingue et pluriculturelle qui permet aux apprenants de transférer les savoirs et les savoir-faire entre les langues

Source : élaboration propre.

La compétence plurilingue et pluriculturelle est alors perçue comme une compétence qui englobe tout un répertoire langagier et culturel, composé de tout ce que l'apprenant a vécu dans sa langue maternelle et également dans d'autres langues ${ }^{97}$. Nous voulons souligner ici que cette compétence est fortement individualisée puisque le vécu de chaque personne est différent et parce que le bagage culturel de chaque apprenant est en constante évolution. Nous savons que l'apprentissage se fait tout au long de la vie, par retouches successives, par continuité du préscolaire à la vie adulte.

Enfin, il faudrait remarquer que même si la compétence plurilingue et pluriculturelle a été bien décrite dans le champ de la didactique des langues, elle n’a pas été suffisamment opérationnalisée dans les actions didactiques pratiques (Kucharczyk, $2018:$ 72). Voyons maintenant comment nous pouvons le faire.

${ }^{97}$ Léducation plurilingue a une double finalité. D’une part, elle favorise l'acquisition des capacités langagières et interculturelles : il s'agit de prendre appui, avec une économie de moyens, sur les ressources langagières et culturelles constituant les répertoires individuels et de les enrichir. D’autre part, elle vise la formation de la personne par lépanouissement de son potentiel individuel : il s'agit d'encourager les individus au respect et à l'ouverture face à la diversité des langues et des cultures dans une société multilingue et multiculturelle, et de favoriser leur prise de conscience de létendue de leurs compétences propres et de leur développement potentiel. 


\subsection{Les approches plurielles}

Qui dit plurilinguisme et éducation plurilingue et interculturelle dit aussi approches plurielles.

(Candelier et al., 2011)

Le développement de la compétence plurilingue et pluriculturelle a provoqué un changement de paradigme dans la didactique des langues étrangères. La prise en compte de cette compétence centrale dans l'enseignement/apprentissage des langues au XXe siècle a suscité des débats, des remises en causes et des interrogations sur la question de la didactique du plurilinguisme. Alors, nous pouvons nous demander quelle méthodologie et quelles approches conviennent pour la promotion du plurilinguisme ? Comment fabriquer des matériaux didactiques ou préparer des enseignants à travailler la compétence plurilingue et pluriculturelle en classe ?

Il est sans doute impossible de fournir une réponse unique. Si le Guide pour le développement et la mise en œuvre de curriculums pour une éducation plurilingue et interculturelle (Beacco et al. 2010), apporte des détails sur le contenu des savoirs, savoir-être et savoir-faire visés par l'éducation plurilingue et pluriculturelle, l'absence d'un référentiel de compétences spécifique à la didactique du plurilinguisme était une sorte de handicap pour la mise en œuvre de cette didactique.

C'est en fonction de ces besoins qu'un référentiel de compétences et de ressources commun créé sous la direction de Michel Candelier sous le nom de Cadre de Référence pour les Approches Plurielles des Langues et des Cultures ${ }^{98}$ (CARAP) a été élaboré.

\subsubsection{La notion d'approches plurielles : conceptions}

Toutes les occasions pertinentes doivent être utilisées pour encourager la mobilisation des acquis dans les langues enseignées ou connues des élèves afin de faire émerger des convergences [...] et de gérer au mieux le développement de leur répertoire plurilingue.

(Beacco, $2010: 22$ )

Le CARAP s'inscrit dans une vision globale des «langues de l'éducation » et des "langues pour l'éducation » que le Conseil de l'Europe ${ }^{99}$ promeut. Par son apport, il complète d'autres instruments, tels que le CECRL ou le Guide pour l'élaboration des politiques linguistiques éducatives en Europe.

${ }^{98}$ Le document élaboré en 2007 par Candelier, de Pietro, Facciol, Lőrincz, Pascual, avec la collaboration de Schröder-Sura et publié par le Centre européen pour les langues vivantes à Graz / Conseil de l'Europe. En anglais : A framework of reference for pluralistic approaches (FREPA).

${ }^{99}$ Il s'agit ici d'un projet lancé en 2005 par le Conseil de l'Europe portant sur le développement de compétences dans la (les) langue(s) de scolarisation, indispensables à un apprentissage réussi tout au long de la scolarité. 
L'essence du CARAP est constituée par les approches plurielles dont la définition est fournie par Michel Candelier (2007: 7)

Approches plurielles des langues et des cultures - des approches didactiques qui mettent en œuvre des activités d'enseignement-apprentissage qui impliquent à la fois plusieurs (= plus d'une) variétés linguistiques et culturelles.

Nous voyons que cette définition thématise la pluralité (nombre de variétés langagières et/ou culturelles concernées) et la nature des activités d'enseignement. Elle vise également l'établissement de liens entre plusieurs langues et se focalise sur un apprentissage/enseignement immédiat.

Nous trouvons que le concept de l'approche plurielle est à présent connu auprès du public plus large et relativement stable, surtout grâce à la description donnée par les concepteurs sur le site web du CARAP où nous pouvons lire que :

Les Approches plurielles des langues et des cultures (Éveil aux langues, Didactique intégrée, Intercompréhension entre les langues parentes, Approches interculturelles) [...] développent de façon concrète la conception de la compétence plurilingue et pluriculturelle promue par le Cadre européen commun de référence pour les langues. Elles offrent des outils permettant de concevoir et d'articuler des interventions didactiques favorables au développement et à l'enrichissement continu de cette compétence par les apprenants. Dédié aux dimensions plurilingues et pluriculturelles des apprentissages, le CARAP complète les autres instruments du Conseil de l'Europe. ${ }^{100}$

Les concepts clés du document supposent la prise de conscience de la nécessité d'une approche globale des ressources que l'apprenant doit se construire lors du développement de sa compétence plurilingue et pluriculturelle. Par ailleurs, l'auteur du CARAP souligne que le référentiel devrait « aider les enseignants à adopter des démarches générales telles que l'appui sur les compétences linguistiques préalables de tout apprenant et la mise en place de synergies entre les apprentissages » (Candelier, 2010).

\subsubsection{La didactique du plurilinguisme et la didactique des approches plurielles}

Après avoir analysé la notion des approches plurielles, nous nous demanderons maintenant comment enseigner dans l'esprit pluriel. Existe-t-il une didactique des approches plurielles, si oui diffère-t-elle de la didactique du plurilinguisme? Qu'est-ce qui changera quand nous passerons d'une discipline centrée sur le processus d'apprentissage d'une langue française à une discipline centrée sur un processus qui s'orientera vers la promotion du plurilinguisme?

${ }^{100}$ Le site web du CARAP : https://carap.ecml.at/CARAPFrance/Lesapprochespluriellesdeslangues descultures/tabid/3413/Default.aspx . 
Il n'existe pas de chemins simples qui donneront tout de suite des réponses claires et nettes. Tout d'abord, il convient de clarifier que le sujet reste complexe et le terme de didactique du plurilinguisme reste relativement récent. Il existe déjà des ouvrages ${ }^{101}$ considérés comme participant à la construction d'une didactique du plurilinguisme. Néanmoins, ils restent souvent en relation avec la compétence plurilingue et pluriculturelle et n'apportent pas de didactique ou de méthodologie concrètes.

Il convient de remarquer la proximité qui existe entre le critère que Michel Candelier utilise pour définir les approches plurielles et le premier volet de ce que recouvre la didactique du plurilinguisme selon Laurent Gajo (2006 : 63) qui admet que :

la didactique du plurilinguisme au sens fort recouvre plutôt les méthodologies relevant d'approches comparatives (didactique des langues voisines, didactique intégrée, certains aspects de l'éveil aux langues) et de l'enseignement bi-plurilingue [qui] peut se définir de la manière suivante : enseignement complet d'une ou de plusieurs disciplines non linguistiques (SNL) dans une langue seconde.

Toutefois, Michel Candelier et Véronique Castellotti $(2008$ : 75) précisent que :

L'enseignement bilingue ne peut s'inscrire dans la didactique du plurilinguisme que s'il y a un travail comparatif entre les langues.

Il est indispensable de souligner que l'enseignement bi ou plurilingue ${ }^{102}$ ne garantit pas la didactique du plurilinguisme. Il faut que cet enseignement bilingue soit une vraie alternance des langues. Dans l'enseignement des approches plurielles et dans la didactique du plurilinguisme, il ne faut plus réduire l'enseignement des langues à l'enseignement à chaque fois d'une langue précise dissociée des autres langues que l'apprenant pratique. Bien au contraire, l'idée est d'inscrire très explicitement l'enseignement de chaque langue dans l'ensemble des pratiques linguistiques. L'apprenant ne devrait pas apprendre séparément l'anglais, le français et l'allemand, mais il devrait apprendre à être plurilingue ${ }^{103}$.

${ }^{101}$ Nous nous référons ici à un ouvrage de Jacqueline Billiez de 1998 « De la didactique des langues à la didactique du plurilinguisme : Hommage à Louise Dabène ", à un ouvrage de Daniel Moore de 2006 «Plurilinguismes et école » à un ouvrage de Zarate, Levy et Kramsch « Précis du plurilinguisme et du pluriculturalisme » de 2008.

${ }^{102}$ Ces remarques sur „bi” ou „pluri” ne sont pas une affaire de nombre de langues traitées, mais de la façon dont on les traite " en lien et non isolément les unes des autres » (Candelier et Castellotti, $2008: 3$ ).

103 « Même entre spécialistes, la question de savoir ce que la caractérisation « bilingue » ou " plurilingue » veut dire ne fait pas l'unanimité. Pour certains, seul le produit d'une double (ou multiple) acquisition de la langue première et/ou une maitrise parfaite (et parfaitement équilibrée) de deux langues mérite ce label. D’autres, et ils sont majoritaires, préfèrent une définition fonctionnelle du bilinguisme : est bilingue (plurilingue) tout individu qui pratique couramment deux (plusieurs) langues et est en mesure de passer sans difficulté majeure d'une langue à l'autre en cas de nécessité ; par contre, la distance entre les langues, du mode d'acquisition et du degré de symétrie entre les deux compétences peuvent varier de manière considérable. Ainsi, le bilingue «idéal » avec son «native- 
Même s'il n'y a pas d'unanimité sur ce sujet, nous sommes d'accord avec Véronique Castellotti que la didactique des langues devient de plus en plus une didactique du plurilinguisme. Cette dernière traverse toute la didactique des langues en intégrant les démarches entreprises pour favoriser les développements des compétences dans chacune d'entre-elles (Castellotti, $2006: 16$ ).

Quant à la comparaison de la didactique du plurilinguisme et la didactique des approches plurielles, nous serions tentés d'écrire que les caractéristiques qui définissent la didactique du plurilinguisme et la didactique des approches plurielles sont si fortement liées que nous ne devrions pas les séparer et les traiter comme deux didactiques différentes. Dans le contexte du cours de français de la diplomatie qui favorise des approches plurielles, il serait nécessaire de mettre en œuvre des activités impliquant à la fois plusieurs variétés linguistiques et culturelles. Ceci refléterait la didactique des approches plurielles. Par contre, à cela on ajoute l'appui sur les connaissances linguistiques et culturelles préalables et on entre dans la didactique du plurilinguisme.

À la fin, il faut mentionner que le sujet de la didactique du plurilinguisme et des approches plurielles est non seulement en phase de conquête, ${ }^{104}$ mais s'oppose vivement à la conception héritée de la méthode directe. Il faudrait alors attendre pour qu'elle soit introduite par les enseignants de langues étrangères en classe.

\subsubsection{Les approches plurielles et les approches singulières}

Nous avons vu que les approches plurielles introduisent une démarche pédagogique dans laquelle l'apprenant travaille simultanément sur plusieurs langues. Cependant, la question à se poser est la suivante : comment être sûr que les approches plurielles ne soient pas abordées de manière isolée comme une somme d'approches singulières?

Michel Candelier (2008 : 12) attire l'attention sur le fait qu'une approche plurielle se distingue d'une approche singulière de façon considérable :

Nous les [approches plurielles] opposons aux approches que l'on pourrait appeler « singulières » dans lesquelles le seul objet d'attention pris en compte dans la démarche didactique est une langue ou une culture particulière, prise isolément. Ces approches singulières ont été tout particulièrement valorisées lorsque les méthodes structurales puis « communicatives » se sont développées et que toute traduction, tout recours à la langue première étaient bannis de l'enseignement ${ }^{105}$.

Il convient de souligner que les approches plurielles ne sont pas une juxtaposition

like control of two or more languages » selon la définition de Bloomfield (1933) ne constitue-t-il qu’un cas de figures parmi d’autres » (Lüdi \& Py, 2003 :127), nous soulignons.

${ }^{104}$ Nous pouvons ajouter ici que la didactique du plurilinguisme est en position dominante pour les domaines francophone et germanophone européens (Candelier et Castellotti, 2008 : 17).

${ }^{105}$ C’est nous qui le soulignons. 
artificielle de compétences singulières, mais un processus d'apprentissage intégré, holistique qui dure toute la vie. Il en résulte le répertoire composé de ressources acquises dans toutes les langues connues ou apprises et relatives aux cultures liées à ces langues (langue de scolarisation, langues régionales et minoritaires ou de la migration, langues étrangères vivantes ou classiques) ; la pluriculturalité désigne la capacité à participer à plusieurs groupes sociaux et à leurs cultures. C'est également la capacité à faire l'expérience de l'altérité et de la diversité culturelle, à analyser cette expérience et à en tirer profit. La compétence plurilingue et pluriculturelle développée de cette façon vise à mieux comprendre l'altérité, à établir des liens cognitifs et affectifs entre les acquis et les apports de toute nouvelle expérience de l'altérité, à permettre la médiation entre différents groupes sociaux et à questionner les aspects généralement considérés comme allant de soi au sein de son propre groupe culturel et de son milieu.

Cependant, la question reste complexe et peu évidente pour ceux qui sont chargés d'élaborer des curriculums ou des programmes scolaires. Dans cette perspective, lors de l'élaboration de curriculums, les objectifs doivent être à la fois spécifiques à l'enseignement d'une langue et de ses cultures, et transversaux à différents enseignements. L'adaptation au contexte éducatif particulier détermine la place relative à donner - à différents moments du curriculum - aux compétences de communication, aux compétences interculturelles, aux expériences esthétiques et littéraires, à la mise en place de capacités réflexives, au développement de stratégies transversales aux disciplines, au développement de l'autonomie, au développement cognitif.

Il est peut-être préférable, dans bien des situations, de mettre en avant le caractère fondamental du critère de distinction entre approches plurielles et approches singulières.

Pour expliciter cette distinction, nous proposons le schéma suivant :

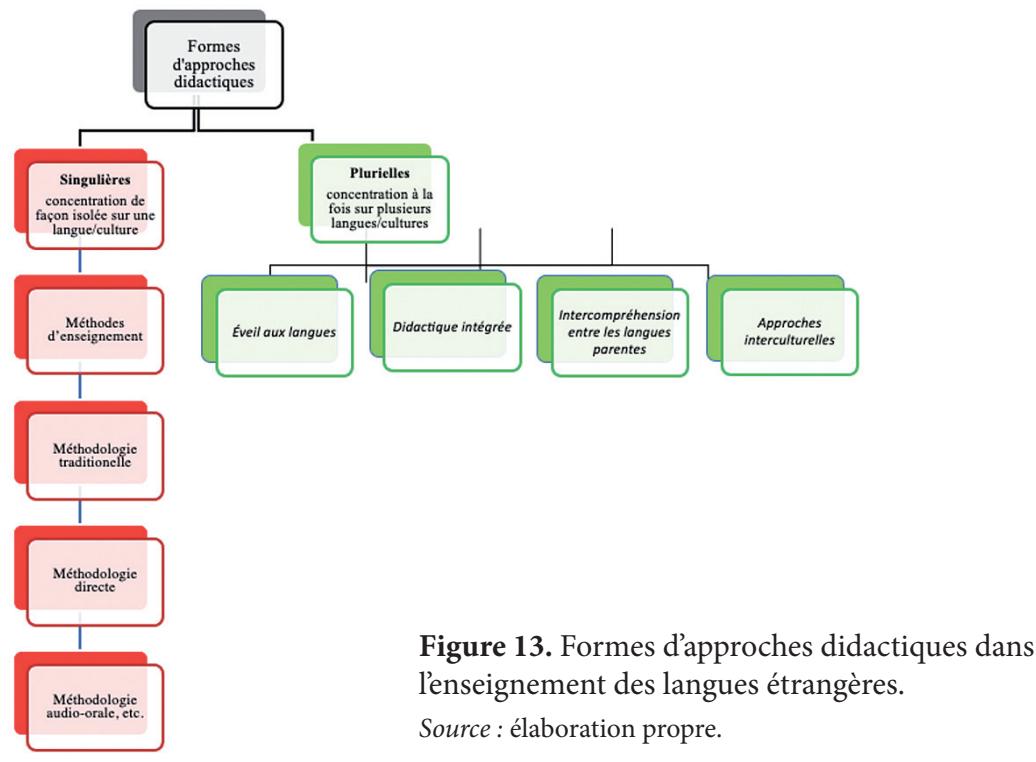


Il est donc important de se rendre compte de l'existence de ces deux formes d'approches didactiques en langues et de voir dans quelle mesure il serait envisageable d'enrichir des cours, comme un cours de FOS, basés sur les approches singulières du moins par des aspects des approches plurielles. Pour le faire, il nous serait utile de nous pencher sur le Cadre de Référence pour les Approches Plurielles des Langues et des Cultures (CARAP).

\subsection{Cadre de Référence pour les Approches Plurielles des Langues et des Cultures - les compétences}

\section{Le Cadre de Référence pour les Approches Plurielles des Langues et des Cultures} (CARAP) a été élaboré en 2007 par une vaste équipe coordonnée par Michel Candelier au sein du Centre européen pour les langues vivantes de Graz - institution du Conseil de l'Europe - comme produit du programme « Les langues pour la cohésion sociale : l'éducation aux langues dans une Europe multilingue et multiculturelle». Cette thématique propose de mettre en discussion un changement de paradigme majeur, par « 1 'évolution vers une conception globale de l'éducation aux langues, qui intègre l'enseignement et l'apprentissage de toutes les langues afin d'utiliser les synergies potentielles $»^{106}$.

Le projet CARAP - dont le but primordial consiste à offrir aux enseignants des outils opératoires pour travailler en classe au développement de la compétence plurilingue et pluriculturelle - s'appuie sur deux piliers principaux : les approches plurielles et un référentiel de compétences et ressources ${ }^{107}$ qui « «encadrent» en quelque sorte ce travail en explicitant les savoirs, savoir-être et savoir-faire » (CARAP, $2007: 20$ )

Le référentiel propose ainsi, d'une part, des compétences à la construction desquelles il est possible de contribuer grâce aux approches plurielles et, d'autre part, un ensemble structuré et hiérarchisé de ressources. Le document inclut par conséquent un tableau de compétences et trois listes de ressources relevant respectivement des savoirs, des savoir-faire et des savoir-être.

Les auteurs du CARAP indiquent 13 compétences globales en les divisant en 7 compétences globales principales (C1-C7), auxquelles sont attribuées les compétences secondaires (il y en a 6) (Kucharczyk, $2018: 75^{108}$ ).

${ }^{106}$ Conformément à la présentation des programmes CELV sur le site officiel de l'institution.

${ }^{107}$ Les auteurs du CARAP expliquent qu'ils utilisent le terme " ressources » pour désigner des ressources « internes». Les " ressources» sont parfois nommées, dans d'autres travaux, capacités, dispositions, ou encore connaissances ou composantes. "Nous avons retenu le terme « ressources »- quoiqu'il ne soit pas très courant - car c'est celui qui est le moins connoté » (CARAP $2007: 13)$.

108 „Autorzy CARAP (2007:20) wyróżniają 13 takich kompetencji, dzieląc je na 7 kompetencji głównych (K1-K7), którym przyporządkowanych jest 6 kompetencji pobocznych (np. K1.1, K1.2)”, notre traduction. 
Le tableau ci-dessous nous servira à comprendre le socle commun de compétences pour la construction d'un répertoire verbal de l'individu plurilingue.

Tableau 4. Compétences globales du CARAP.

\begin{tabular}{|c|c|c|c|}
\hline & Compétence globale principale & & Compétence globale secondaire \\
\hline \multirow{4}{*}{$\mathrm{C} 1$} & \multirow{4}{*}{$\begin{array}{l}\text { compétence à gérer la communication } \\
\text { linguistique et culturelle en contexte } \\
\text { d'altérité }\end{array}$} & C1.1 & $\begin{array}{l}\text { compétence de résolution des conflits, } \\
\text { obstacles, malentendus... }\end{array}$ \\
\hline & & C1.2 & compétence de négociation \\
\hline & & C1.3 & compétence de médiation \\
\hline & & C1.4 & compétence d’adaptation \\
\hline \multirow[b]{2}{*}{$\mathrm{C} 2$} & \multirow{2}{*}{$\begin{array}{l}\text { compétence de construction et } \\
\text { d'élargissement d'un répertoire } \\
\text { linguistique et culturel pluriel }\end{array}$} & C2.1 & $\begin{array}{l}\text { compétence à tirer profit de ses } \\
\text { propres expériences interculturelles / } \\
\text { interlinguistiques }\end{array}$ \\
\hline & & $\mathrm{C} 2.2$ & $\begin{array}{l}\text { compétence des démarches } \\
\text { d'apprentissage plus systématiques, } \\
\text { mieux contrôlées dans le contexte de } \\
\text { la diversité linguistique et culturelle }\end{array}$ \\
\hline $\mathrm{C} 3$ & compétence de décentration & & \\
\hline $\mathrm{C4}$ & $\begin{array}{l}\text { compétence à donner du sens à des } \\
\text { éléments linguistiques et/ou culturels } \\
\text { non familiers }\end{array}$ & & \\
\hline C5 & compétence de distanciation & & \\
\hline C6 & $\begin{array}{l}\text { compétence à analyser de } \\
\text { façon critique la situation et les } \\
\text { activités (communicatives et/ou } \\
\text { d'apprentissage) dans lesquelles on est } \\
\text { engagé }\end{array}$ & & \\
\hline C7 & $\begin{array}{l}\text { compétence de reconnaissance de } \\
\text { l'Autre, de l'altérité }\end{array}$ & & \\
\hline
\end{tabular}

Source : élaboration propre basée sur le CARAP (2007 : 20).

Il faut dire que la réflexion sur les compétences qui aident à construire et à développer des répertoires verbaux plurilingues est qu'elles ne sont pas directement enseignables. Bien évidemment, elles servent à fixer le point d'arrivée, elles sont également des points de référence pour la compétence plurilingue et pluriculturelle. Cependant, nous trouvons que leur caractère abstrait et leur complexité empêchent leur usage. Jolanta Sujecka-Zając et Maciej Smuk (2019:4) remarquent que :

Elles [les compétences] restent des balises qu'il faut « déconstruire » pour en arriver à des éléments plus petits qui sont, en l'occurrence, des ressources venant des savoirs, savoir-faire et savoir-être. Le modèle actuel du répertoire plurilingue fait penser à celui des molécules chimiques. Ces dernières sont « une structure de base de la matière /.../ 
comprenant plus d'un atome. L'assemblage d'atomes constituant une molécule n'est pas définitif, il est susceptible de subir des modifications, c'est-à-dire de se transformer en une ou plusieurs autres molécules.

De surcroit, dans l'optique du cours de français de la diplomatie, nous avons remarqué que les dénominations des compétences globales du CARAP montrent leur utilité dans la vie quotidienne. Il semble ainsi que les approches plurielles, et avec elles la didactique du plurilinguisme, ne visent pas le développement de compétences linguistiques, au sens classique du terme en didactique des langues, mais des compétences de gestion de la communication interculturelle et des compétences métacommunicatives et métacognitives. Et ce sont ces compétences-là que nous trouvons les plus importantes à développer lors du cours de français de la diplomatie.

\subsection{Cadre de Référence pour les Approches Plurielles des Langues et des Cultures : ressources et descripteurs}

Nous avons vu plus haut que le caractère complexe des compétences a empêché de les concrétiser indépendamment des tâches et des situations pour lesquelles elles sont activées (il est impossible de les enseigner directement). Cela a forcé les auteurs du CARAP à les distinguer des ressources. Comme il est indiqué dans le référentiel (CARAP, $2007:$ 19-20) :

Cela [le fait que les compétences ne sont pas enseignables] peut paraitre paradoxal : en effet, ce sont bien les compétences qui sont en jeu lorsque l'on est engagé dans une tâche, telle par exemple que chercher des informations dans un texte rédigé dans une langue qu'on ne connait pas; et ce sont ces compétences qui sont placées aujourd'hui au cœur même des finalités de l'enseignement et de l'apprentissage. Cependant, ce sont vraisemblablement les ressources (internes) qu'il est - jusqu'à un certain point - possible de décontextualiser, d'isoler et de lister, de définir en termes de maitrise et d'enseigner dans les pratiques éducatives ${ }^{109}$.

En d'autres termes, nous pouvons constater qu'il est possible de travailler les ressources du CARAP en classe, en plaçant les apprenants face à différentes tâches didactiques. L'enseignement contribue ainsi à la mise en place des compétences via les ressources que celles-ci mobilisent. De ce fait, les ressources sont présentées sous forme de listes de descripteurs dans chacun des domaines : savoirs, savoir-faire, savoir-être.

La liste des savoirs se compose de deux sous-groupes thématiques : Langue et Culture (ils sont au nombre de 211 ressources). Les savoir-faire correspondent à des

${ }^{109}$ C'est nous qui le soulignons. 
opérations telles que savoir observer / analyser; identifier / repérer, savoir comparer, savoir parler à propos des langues et des cultures, etc. (les savoir-faire comptent 169 ressources).

Enfin, la liste des savoir-être (avec 153 ressources) prend en compte des facteurs personnels, tels que décrits dans le CECRL (2001, 84-85), liés aux attitudes, motivations, valeurs, identités, etc. « Dans ce domaine, les prédicats expriment des manières d'être du sujet comme attention à, sensibilité à, intérêt à, disponibilité à, etc. Ils sont tantôt orientés vers le monde (curiosité envers...) tantôt vers soi (confiance dans...)» (CARAP, $2007: 21)$.

Tableau 5. Exemples de descripteurs de ressources.

\section{SAVOIRS :}

\begin{tabular}{|c|l|}
\hline K 4 & Savoir que les langues sont en constante évolution \\
\hline K 4.1 & $\begin{array}{l}\text { Savoir que les langues sont liées entre elles par des relations dites « de } \\
\text { parenté »/ savoir qu'il existe des « familles » de langues }\end{array}$ \\
\hline K 4.1.1 & Connaitre quelques familles de langues et quelques langues qui en font partie \\
\hline
\end{tabular}

\section{SAVOIR-ÊTRE:}

A 2.2 $\quad$ Sensibilité aux différences ${ }^{\circ}$ langagières/ culturelles ${ }^{\circ}$

A 2.2.1

Être sensible à différents aspects de la ${ }^{\circ}$ langue/culture ${ }^{\circ}$ qui peuvent varier de langue à langue/ culture à culture ${ }^{\circ}$

\section{SAVOIR-FAIRE:}

\begin{tabular}{|c|l|}
\hline S 3.4 & Savoir percevoir la proximité lexicale \\
\hline S 3.4.1 & Savoir percevoir la proximité lexicale directe \\
\hline
\end{tabular}

Source : https://carap.ecml.at/Descriptorsofresources/tabid/2654/language/fr-FR/Default.aspx

Au total, le CARAP propose un référentiel composé de 7 grandes compétences pour lesquelles sont distinguées environ 533 ressources, différentes et complémentaires.

Il résulte de ce qui précède que les descripteurs permettent d'orienter le travail de l'enseignant et de l'apprenant à développer certaines compétences globales, ce qui conduit finalement au renforcement de la compétence plurilingue et pluriculturelle.

Au bout du compte, la question qu'il convient de se poser est de savoir comment il est possible d'utiliser les descripteurs en classe de français de la diplomatie.

Pour le voir de plus près, nous allons nous servir de l'une des catégories des descripteurs proposées par le CARAP et notamment celle du savoir-faire.

Le savoir-faire fait appel aux éléments pratiques, à la maîtrise par l'expérience aux connaissances autres que celles langagières. Cela est très important dans l'enseignement/apprentissage de la langue sur objectif spécifique. Magdalena Sowa (2014 : 31) remarque à juste titre qu'aujourd'hui : 
Il est à postuler que le formateur-concepteur propose les activités en classe de langue à des fins professionnelles dont le type est en accord pas seulement avec le savoir, mais surtout avec le savoir-faire et la logique des actions accomplies au travail visé110.

Les savoir-faire et les habiletés sont les aptitudes sociales qui constituent de nos jours la clé d'une communication réussie. Les savoir-faire sont indispensables dans la coopération, le contrôle des émotions ou dans l'interaction correcte. Les didacticiens les appellent souvent « primordiaux » en raison de leur importance dans le processus d'apprentissage/enseignement des langues étrangères, mais aussi en raison de leur rôle dans la vie professionnelle. Le professionnel doit non seulement savoir exécuter ce qui est exigé, mais devrait savoir aller au-delà du prescrit. De ce fait, le savoir-faire désigne chez les employés et les entreprises la capacité indispensable à s’adapter à différentes situations imprévisibles de travail.

Jean-Jacques Richer (2011 : 72) note que :

Savoir mobiliser les ressources est un élément fondamental de la compétence dans le monde du travail. Ce savoir mobilisé fonctionne sur le mode de la sélection des ressources pertinentes en fonction du contexte, des objectifs, et sur le mode de la combinaison des compétences en un mouvement qui les fait interagir, les modifie et permet d'élaborer une réponse inédite, économique et "élégante".

Effectivement, pour faire face à un événement, pour réaliser une activité ou pour résoudre un problème, le professionnel doit savoir non seulement sélectionner les éléments pertinents dans un répertoire de ressources, mais avant tout savoir les organiser.

Quant au CARAP (2007 : 21), les descripteurs 'savoir-faire' se composent des catégories suivantes : savoir observer, analyser, identifier, repérer, comparer, parler des langues et des cultures, savoir utiliser ce que l'on sait dans une langue pour comprendre une autre langue ou produire dans une autre langue, savoir interagir et apprendre. Il faut cependant souligner que les frontières entre toutes ces catégories sont peu visibles et se réfèrent à des opérations peu distinctes.

De ce qui précède, nous pensons que la classe de FOS constituée de futurs diplomates et fonctionnaires est un lieu par excellence où le savoir-faire professionnel devrait être pris en compte. Il ne s'agit pas seulement des tâches ou des projets, donc deux outils méthodologiques qui permettent de mettre en œuvre la perspective actionnelle revendiquée par le CECRL, mais avant tout d'utiliser le potentiel des expériences de nos apprenants. Ainsi, il faut non seulement enseigner le vocabulaire propre aux relations diplomatiques et internationales, mais surtout des compétences et des habiletés pratiques utilisées dans le milieu diplomatique.

${ }^{110}$ C’est nous qui le soulignons. 


\subsection{Cadre de Référence pour les Approches Plurielles des Langues et des Cultures - quatre approches plurielles}

Comme nous l'avons vu plus haut, le CARAP met à la disposition de la communauté éducative un référentiel de compétences et de ressources concernant ce que nous appellerons du terme le plus large possible des «attitudes » face aux langues, aux cultures, à l'apprentissage des langues. Le CARAP est conçu comme une tentative de mise en cohérence de quatre courants didactiques qui ne visent pas directement à l'enseignement proprement dit de langues particulières. Ces approches favorisent les synergies et encouragent les situations où les langues sont mises en relation et examinées simultanément, ce qui n'est pas toujours le cas dans les écoles ${ }^{111}$. C'est pourquoi ces approches sont indispensables aux efforts didactiques qui ont pour but le développement de la compétence plurilingue des apprenants.

Le CARAP classifie les approches plurielles en quatre types : l'éveil aux langues, l'intercompréhension entre langues parentes, la didactique intégrée des langues et l'approche interculturelle.

Il convient de souligner que ces quatre courants se sont développés de manière séparée, ayant en commun le souci de travailler à la mise en relation de plusieurs univers linguistiques dans le cadre de la classe. Analysons maintenant de plus près les approches qui composent le CARAP ${ }^{112}$.

\subsection{1. Éveil aux langues}

L'approche éveil aux langues est née, sous cette désignation, dans le contexte européen, avec le projet Evlang qui a débuté en 1997. Avant, dans les années 1980, le concept était popularisé en Grande-Bretagne par Eric Hawkins sous le nom language awareness ${ }^{13}$ et visait meilleure intégration de différents groupes ethniques. Au cours

${ }^{111}$ Lorsque les auteurs du CARAP ont examiné la plupart des curriculums nationaux existants, ils ont observé que « la volonté de favoriser le plurilinguisme comme compétence tel que défini dans le CECRL (2001 : 129; chapitre 2) - ne s'y manifeste le plus souvent que par le nombre croissant de langues étudiées... sans réelles relations entre elles et sans liens entre les enseignements (CARAP, $2007: 26)$.

${ }^{112}$ Nous n’allons pas analyser ici l'approche interculturelle qui a été déjà analysée en détail dans le chapitre précédent.

${ }^{113}$ Il convient de mentionner ici que "l'éveil aux langues, tel qu'il a été développé depuis la fin des années quatre-vingt-dix dans les programmes Evlang et Jaling, se rattache explicitement au mouvement Language Awareness initié par Eric Hawkins au Royaume-Uni pendant les années quatre-vingt. Cependant, on considère que l'éveil aux langues constitue plutôt, aujourd'hui, un sous-ensemble de la perspective Language Awareness, qui donne lieu également à des travaux à orientation plus psycholinguistique que pédagogique, qui ne portent pas nécessairement sur la confrontation de l'apprenant à plusieurs langues. C'est pourquoi les promoteurs des programmes d'éveil aux langues ont préféré choisir un autre terme anglais pour désigner cette approche : Awakening to languages " (Candelier et al., 2011:7). 
des années quatre-vingt, en Suisse romande, dans un contexte fortement marqué par le plurilinguisme et par les phénomènes migratoires, de nombreux travaux visant l'éveil aux langues ont été entrepris sous le sigle " EOLE » (Éducation et Ouverture aux Langues à l'École).

À peu près à la même époque, l'équipe grenobloise animée par Louise Dabène a étudié deux aspects de l'éveil aux langues. D'un côté, on analysait des problèmes de nature linguistique résultant de la présence des enfants des migrants en classe, de l'autre côté, Louise Dabène se focalisait sur le rôle de la réflexion métalinguistique qui accompagne le processus d'apprentissage des langues étrangères ${ }^{114}$ (Troncy, $2014: 48$ ).

L'éveil aux langues a ensuite donné lieu en Europe à deux programmes de recherche et d'innovation (Evlang 1997-2000 et Janua Linguarum - The Gateway to languages ${ }^{115} 2000-2004$ ), soutenus par l'Union européenne et le Conseil de l'Europe. Les activités comprenaient la production de matériaux didactiques, la formation d'enseignants, la mise en place d'une expérimentation et une évaluation qui portait essentiellement, pour Evlang, sur les effets sur les élèves et pour Janua Linguarum sur les conditions d'implantation de l'approche dans les systèmes éducatifs (Candelier et Castellotti, 2008 : 14). Depuis, la diffusion de l'éveil aux langues s'est poursuivie grâce à la production de nombreux matériaux didactiques dans plusieurs pays européens ainsi qu'au Canada.

Il convient de remarquer que c'est à partir de l'éveil aux langues que se construit la notion des approches plurielles. Selon la définition qui a été donnée de l'éveil aux langues dans le cadre des projets européens récents qui ont permis de le développer plus largement, « il y a éveil aux langues lorsqu'une part des activités porte sur des langues que l'école n’a pas l'ambition d'enseigner» (CARAP, $2007: 7$ ).

Pourtant, cela ne signifie pas que la démarche porte uniquement sur les langues qui ne sont pas enseignées à l'école. Selon les principes, cette conception inclut également la langue que l'apprenant apprend à l'école et toute autre langue en cours d'apprentissage. Cependant, il convient de remarquer qu'elle ne se limite pas à ces langues apprises, bien au contraire, elle intègre toutes sortes d'autres variétés linguistiques, des dialectes de la famille, de l'environnement. Les auteurs du CARAP le définissent de la façon suivante (CARAP, 2007 : 6) :

Par le nombre important de langues sur lesquelles les élèves sont amenés à travailler plusieurs dizaines, le plus souvent - l'éveil aux langues peut apparaitre comme une

114 « Le rôle de l'activité métalinguistique dans l'appropriation d'une langue étrangère » et « les problèmes posés par l'absence de relation entre le travail métalinguistique en langue étrangère et en langue maternelle» (Dabène, $1995: 136$ dans Troncy, 2014 : 48).

${ }^{115}$ Le document est disponible ici : http://archive.ecml.at/documents/pub121e2004candelier.pdf. 
approche plurielle «extrême». Conçu principalement comme accueil des élèves dans la diversité des langues (et de leurs langues!) dès le début de la scolarité, comme vecteur d'une meilleure reconnaissance dans le contexte scolaire des langues "apportées» par les élèves allophones, comme une sorte de propédeutique développée à l'école primaire, il peut également être promu comme accompagnement des apprentissages linguistiques tout le long de la scolarité.

Les auteurs du référentiel soulignent cependant que même si cette approche peut paraître en quelque sorte " extrême ", son objectif ne consiste pas seulement à la sensibilisation à la diversité des langues. Les connaissances, attitudes et aptitudes visées par les activités se décomposent en objectifs précisément définis, en correspondance avec les besoins et capacités des élèves.

D’après Candelier (2006 : 1), les objectifs de cette approche sont de :

- développer l'intérêt et l'ouverture des élèves vis-à-vis de la diversité, y compris de leur propre diversité, dans le but de reconnaître, légitimer et valoriser les compétences et identités linguistiques et culturelles de chacun, notamment dans des classes multilingues;

- développer l'aptitude des élèves à observer et analyser les langues afin de favoriser leur aptitude à les apprendre et à mieux les maîtriser, y compris pour la langue de l'école ;

- favoriser le désir des élèves d'apprendre des langues diversifiées;

- développer chez les élèves des connaissances relatives à la présence des langues dans l'environnement immédiat, plus lointain et très lointain, ainsi qu'aux statuts dont elles bénéficient ou pâtissent avec les principes de cette approche.

Qui plus est, l'éveil aux langues tend à la préparation des apprenants à une communication efficace et réussie dans un monde plurilingue et pluriculturel. Ainsi, l'approche vise la création des conditions qui permettraient le développement de la compétence plurilingue et pluriculturelle.

L'approche plurilingue que préconise l'Éveil aux langues s'inscrit dans la problématique plus vaste que constituent la connaissance des langues et l'acceptation de leur diversité, et a pour visée spécifique, d'une part, de préparer les élèves à être de futurs locuteursacteurs de nos sociétés linguistiquement et culturellement plurielles et de contribuer, d'autre part, à la construction de compétences à apprendre les langues. Le but poursuivi est d'encourager chez les élèves une démarche de recherche explicite sur le langage et les langues et de favoriser la construction de nouvelles relations entre les langues - entre le français, langue de l'école et les langues de l'environnement proche, plus lointain. Les activités de découverte portent sur des langues de tout statut qui peuvent être connues par certains des enfants de la classe, et qu'il s'agit alors de les valoriser. (Candelier, Kervran et Rémy-Thomas, 2003 : 59). 
Enfin, il convient d'ajouter que l'approche éveil aux langues contribue à la transmission des valeurs démocratiques, à sensibiliser les élèves à la diversité des cultures et à développer leurs capacités à vivre ensemble dans l'optique d'éduquer à la citoyenneté.

Comme mentionné plus haut, l'un des objectifs des nouvelles approches était la préparation de matériaux didactiques qui permettraient le développement de la conscience linguistique. L'approche d'éveil aux langues, même si elle reste assez méconnue $^{116}$ des institutions, offre une perspective pluridisciplinaire et développe l'attitude nécessaire à l'apprentissage de langues étrangères en leur donnant du sens.

Par rapport à nos objectifs, la question qui se pose est la suivante : que peut-on attendre de l'approche d'éveil aux langues pour l'apprentissage d'une langue particulière, telle que le français de la diplomatie, dans le contexte particulier de futurs fonctionnaires de l'Union européenne?

Lapproche d'éveil aux langues du monde est fondée sur le principe de l'observation profonde des langues à travers différentes activités, mais aussi sur le développement d'une attitude d'apprentissage face aux langues. La découverte de différentes langues permet aux apprenants d'en comprendre le fonctionnement, de les comparer entre elles, de les comparer avec les langues déjà connues et ainsi éveiller la curiosité. En effet, introduire dans le programme en classe de FOS des activités qui visent la manipulation des langues, connues et peu connues, ouvre sur des réflexions métalinguistiques et métacommunicatives : réflexions qui nous semblent essentielles pour l'apprentissage d'une langue.

Nous croyons que la leçon de français de la diplomatie devrait régulièrement contenir des éléments de l'éveil aux langues. L'enseignant peut concevoir des activités mises dans le contexte des relations internationales où les apprenants s'impliqueraient activement. Selon nous, cela pourrait être visé par des savoir-faire du CARAP (2007: 50-58) comme :

\begin{tabular}{|l|l|}
\hline K3 & $\begin{array}{l}\text { savoir comparer les phénomènes linguistiques ou culturels de langues ou } \\
\text { cultures différentes (ou savoir percevoir ou établir la proximité et la distance } \\
\text { linguistiques ou culturelles }\end{array}$ \\
\hline
\end{tabular}

ou
K 2.3
savoir, à partir de différents indices linguistiques, identifier (ou repérer) des mots d'origines diverses

ou encore :

K 6.1 savoir communiquer dans des groupes bi/plurilingues en tenant compte du répertoire de ses interlocuteurs

${ }^{116}$ D’après le rapport de Candelier : http://eduscol.education.fr/cid46536/les-demarches-d-eveila-la-diversite- linguistique-et-culturelle-dans-l-enseignement-primaire.html. 
Concevoir des activités basées sur ce type de descripteurs nous parait très utile en classe du français de la diplomatie où l'on tient à former des diplomates qui devraient être à l'écoute des autres, y compris ceux ayant d'autres langues et cultures. Ce public spécifique devrait aussi se sentir à l'aise dans des situations où il devra sans cesse s'adapter à un nouveau contexte. Cela est surtout très important aujourd'hui où la culture occupe une place primordiale dans les relations internationales ${ }^{117}$.

Par ailleurs, nous avons vu que l'approche éveil aux langues ne consiste pas en l'apprentissage de la langue au sens strict de ce mot. Cela veut dire que les actions didactiques ne sont pas focalisées sur le développement de la compétence communicative dans la langue étrangère mais plutôt sur le développement des compétences métalinguistiques qui soutiennent l'apprentissage des langues étrangères. Cela est présenté dans le tableau ci-dessous.

Tableau 6. Implantation de quelques principes clés de l'approche éveil aux langues dans le processus d’apprentissage des langues étrangères.

\begin{tabular}{|c|c|}
\hline $\begin{array}{l}\text { Les principes de l'approche } \\
\text { éveil aux langues }\end{array}$ & Les objectifs didactiques \\
\hline $\begin{array}{l}\text { Développer les savoirs } \\
\text { métalinguistiques }\end{array}$ & $\begin{array}{l}\text {-faire remarquer aux apprenants l'existence de } \\
\text { différentes situations linguistiques } \\
\text {-développer la capacité d’observation et de l'analyse } \\
\text { du système linguistique } \\
\text {-développer les stratégies de communication et de } \\
\text { l'autoapprentissage } \\
\text {-soutenir la compétence de compréhension orale } \\
\text { (pour comprendre le sens) }\end{array}$ \\
\hline $\begin{array}{l}\text { Façonner la posture de l'ouverture sur } \\
\text { la diversité culturelle et linguistique }\end{array}$ & $\begin{array}{l}\text {-former chez les apprenants le respect envers } \\
\text { différentes langues et cultures représentées par } \\
\text { d'autres apprenants du même groupe } \\
\text {-sensibiliser les apprenants au fait qu'il y a plusieurs } \\
\text { langues maternelles }\end{array}$ \\
\hline $\begin{array}{l}\text { Soutenir la motivation pour apprendre } \\
\text { d'autres langues }\end{array}$ & $\begin{array}{l}\text {-soutenir l'idée des apprenants de connaître d'autres } \\
\text { langues (y compris des langues des apprenants } \\
\text { migrants) } \\
\text {-soutenir la volonté des apprenants à participer aux } \\
\text { cours de langue et de culture }\end{array}$ \\
\hline
\end{tabular}

117 «On a longtemps cru que les confrontations économiques et matérielles étaient le tout des relations internationales; il faut aujourd'hui prendre toute la mesure des forces spirituelles, intellectuelles et culturelles. On a longtemps cru que la politique mondiale nétait que la simple addition des relations entre États; il faut admettre que le pouvoir n'appartient plus seulement à celui qui détient la puissance militaire, industrielle, financière, mais aussi à celui qui a des valeurs à promouvoir, une culture à proposer, une histoire à raconter sur la destinée commune » Xavier Darcos, la séance solennelle du 14 novembre 2011, disponible sur le site web : http://www.academiefrancaise.fr/culture-et-diplomatie-academie-des-sciences-morales-et-politiques. 
Les principes de l'approche éveil aux langues

\begin{tabular}{|l|l|}
\hline \multicolumn{1}{|c|}{ éveil aux langues } & \\
$\begin{array}{l}\text { Développer les compétences sociales } \\
\text { et culturelles }\end{array}$ & $\begin{array}{l}\text {-entreprendre des actions didactiques qui influencent } \\
\text { positivement l'ambiance en classe } \\
\text {-renforcer chez les apprenants l'appartenance à } \\
\text { un groupe (par exemple la classe) ce qui est lié à } \\
\text { la construction du sentiment de l'unité et de la } \\
\text { collectivité }\end{array}$ \\
\hline Élargir le savoir déclaratif & $\begin{array}{l}\text {-acquisition du savoir sur différents systèmes des } \\
\text { langues } \\
\text {-faire comprendre aux apprenants l'existence de la } \\
\text { parenté entre les langues }\end{array}$ \\
\hline Intégrer la classe plus rapidement & $\begin{array}{l}\text {-l'intégration des apprenants } \\
\text {-stimuler les apprenants moins doués pour les langues }\end{array}$ \\
\hline
\end{tabular}

\section{Les objectifs didactiques}

-entreprendre des actions didactiques qui influencent positivement l'ambiance en classe -renforcer chez les apprenants l'appartenance à un groupe (par exemple la classe) ce qui est lié à la construction du sentiment de l'unité et de la langues -faire comprendre aux apprenants l'existence de la -stimuler les apprenants moins doués pour les langues

Source : Gębal (2013 : 54). ${ }^{118}$

En analysant ce tableau, nous voyons qu'une démarche comme l'éveil aux langues aura des effets bénéfiques pour les autres langues puisque cela contribue à former un apprenant plurilingue. En effet, cette approche renforce les capacités d'apprentissage du français (comme de toute autre langue étrangère ou seconde) en favorisant l'aptitude à l'articuler au répertoire antérieur. L'éveil aux langues prépare aussi ou accompagne - l'accès à d'autres approches plurielles (Intercompréhension entre langues parentes, Didactique intégrée, Approche interculturelle) que nous allons décrire ci-dessous.

118 „Założenia podejścia otwarcia na języki”

rozwijanie umiejętności metajęzykowych - Cele dydaktyczne (zwracanie uczniom uwagi na zjawiska językowe; rozwijanie umiejętności obserwacji i analizy systemu językowego; rozwijanie strategii komunikacyjnych i uczenia się; wspieranie umiejętności słuchania ze zrozumieniem).

Kształtowanie postawy otwartości na różnorodność językową i kulturową- Cele dydaktyczne: budowanie u uczniów szacunku wobec różnych języków i kultur; reprezentowanych przez uczniów danej klasy; uwrażliwianie uczniów na fakt istnienia kilku języków ojczystych.

Wspieranie motywacji do uczenia się języków- Cele dydaktyczne: wspieranie chęci uczniów do poznawania języków (w tym również języków uczniów migrujących); wspieranie chęci uczniów do uczestniczenia w zajęciach języka i kultury.

Rozwijanie kompetencji społecznych i kulturowych - Cele dydaktyczne: działania dydaktyczne wpływające pozytywnie na atmosferę w klasie; wzmacnianie u uczniów poczucia przynależności do danej grupy (klasa), co łączy się z budowaniem poczucia jedności i zbiorowości.

Poszerzanie wiedzy deklaratywnej-Cele dydaktyczne: nabycie przez uczniów wiedzy o różnych systemach językowych; uświadomienie uczniom istnienia więzi pokrewieństwa pomiędzy różnymi językami.

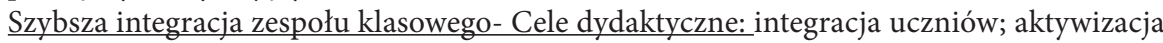
uczniów słabszych językowo", notre traduction. 


\subsubsection{Intercompréhension entre les langues parentes}

L'intercompréhension entre les langues parentes (en anglais intercomprehension of related languages) est l'une des quatre approches plurielles qui soulignent le développement de la compétence plurilingue et pluriculturelle auprès des apprenants des langues étrangères.

Par rapport aux autres approches plurielles, l'intercompréhension est une approche relativement nouvelle ${ }^{119}$. Les essais pour créer un outil qui permettrait de travailler selon les concept de l'intercompréhension entre langues sont apparus dans les années 1980.

Comme le soulignent Caddéo et Jamet (2013 : 28 dans Kucharczyk, $2018: 84-85)$

À l'époque (...), les initiateurs expliquent que leur intérêt pour l'intercompréhension, terme encore passe-partout, est né de l'observation des pratiques communicatives appliquées naturellement par les locuteurs vivant dans des zones de langues en contact (...), mais également des nombreux témoignages personnels rendant compte de situations ponctuelles ou d'activités habituelles qui mettent en jeu la compréhension écrite ou orale d'une ou plusieurs langues proches de la langue 1 (dans le milieu professionnel, par passion, pour le tourisme, etc.).

Il est à noter que cette définition a connu certains changements au fil des années, mais aujourd'hui la plupart des spécialistes acceptent la définition suivante, présentée dans l'étude de référence développée sur le sujet de l'intercompréhension pour le Guide pour l'élaboration des politiques linguistiques éducatives en Europe : "L'intercompréhension est une forme de communication dans laquelle chaque personne s'exprime dans sa propre langue et comprend celle de l'autre " (Doyé, $2005: 7$ ). Plus tard, les auteurs du CARAP (2007 : 7) ont enrichi la définition de Doyé et définissent cette approche ainsi :

L'intercompréhension entre les langues parentes propose un travail parallèle sur deux ou plusieurs langues d'une même famille (langues romanes, germaniques, slaves, etc.), qu'il s'agisse de la famille à laquelle appartient la langue maternelle de l'apprenant (ou la langue de l'école) ou de la famille d'une langue dont il a effectué l'apprentissage. On tire parti des atouts les plus tangibles de l'appartenance à une même famille - ceux relatifs à la compréhension - qu’on cherche à cultiver systématiquement.

${ }^{119}$ Escudé et Janin (2010 : 35) soulignent que les premières informations de l'intercompréhension apparaissent déjà au début du XXe siècle dans les textes du linguiste Dauzat. Ce dernier définissait l'intercompréhension comme la capacité des individus à comprendre des dialectes appartenant à la même famille de langues*. (Kucharczyk, $2018: 83$ ).

* „Escudé i Janin (2010:35) podkreślają, że tak naprawdę pierwsze wzmianki o interkomprehensji pojawiają się już na początku XX w. w tekstach językoznawcy Dauzata, który określa mianem interkomprehensji zdolność jednostek do rozumienia różnych dialektów języków należących do tej samej rodziny", notre traduction. 
Autrement dit, l'objectif de cette approche est de former chez les apprenants les compétences réceptives (surtout dans le cadre des textes écrits) dans des langues étrangères ou dans les langues parentes. Cependant, il faut ajouter que les auteurs du CARAP ne rejettent pas le travail simultané sur les compétences productives-une étape suivante des actions didactiques.

Pour mieux expliquer les mécanismes sur lesquelles est basée l'intercompréhension entre les langues parentes, les linguistes font appel à deux droits qui constituent le fondement de chaque système linguistique; il s'agit de la loi de fusion et la loi de diffraction ${ }^{120}$.

La loi de fusion stipule que chaque langue possède des structures logicosémantiques universelles, communes pour différentes langues, que l'on peut appeler des invariantes (Kucharczyk, 2018 : 83). Ainsi, il n'y a pas de texte qui serait complètement incompréhensible dans sa totalité. Comme le remarquent Escudé et Janin $(2010: 36)$ :

Il n'existe pas d'isolat linguistique. L'opacité absolue d'un texte ne peut exister : certes, sans apprentissage, un locuteur français actuel non averti n'entrera pas dans un texte écrit en mandarin du XIII ${ }^{e}$ siècle ; mais sans doute aura-t-il autant de mal avec un texte scientifique de neurolinguistique rédigé en français.

Bien évidemment, il est nécessaire de connaître des codes linguistiques. Pourtant, nous pouvons dire qu'une langue n'est, par définition, jamais entièrement opaque à une autre. Escudé et Janin (2010 : 36) mentionnent à cette occasion la langue basque :

Par exemple, une langue aussi énigmatique que le basque, désignée par les linguistes comme l'une des rares langues " pré indo-européennes » d'Europe, reste poreuse aux langues romanes par son lexique, qui provient pour un tiers des langues de contact que sont l'occitan gascon et le castillan.

Quant à la loi de diffraction, elle prévoit que chaque langue a de multiples variantes. La même phrase dans la même langue peut être prononcée, dite ou écrite, avec des variations provoquées par des facteurs tels que le changement géographique, social, générationnel, etc.

De ces principes, la didactique de l'intercompréhension entre les langues parentes déduit des concepts opérationnels ${ }^{121}$ qui peuvent ensuite motiver l'apprenant et construire sa compétence métalinguistique.

${ }^{120}$ Nous nous référons ici aux travaux de Escudé et de Janin (2010).

${ }^{121}$ Il s'agit du continuum langagier, l'intentionnalité, la prédictibilité par le contexte et par la forme ; l'intercompréhension entre les langues parentes appuie également les stratégies de l'approximation, du transfert et de l'entrée par l'écrit (Escudé et Janin, 2010 : 37). 
De fait, il faut dire que les travaux sur l'intercompréhension ont contribué de façon significative à mettre en lumière un potentiel encore insuffisamment exploité dans le cadre de la didactique des langues : tout être humain dispose d'une compétence plurilinguistique et multiculturelle unique qui lui permet de réinvestir ses acquis linguistiques (d'origines scolaires ou non) dans chaque nouvelle situation d'apprentissage. Aborder l'apprentissage d'une langue ne signifie donc plus devoir «tout recommencer à zéro ».

Les auteurs ${ }^{122}$ du livre le point sur l'Intercompréhension, Clé du plurilinguisme avancent que :

Il n'y a donc pas de langue complètement étrangère. Cette simple évidence va faire disparaitre la «peur » de l'opacité ou de l'étrangeté, à moins de reconnaître qu'opacité et étrangeté appartiennent avant tout à ma langue et qu'il me faut donc trouver les moyens de la rendre transparente à l'autre. Pour un enfant de huit ans, le mot « octaèdre » n'est pas plus transparent - ou opaque - que son équivalent « octaedro » espagnol, portugais ou italien. C'est la chose qui est opaque, les mots, eux, ne font que révéler cette opacité. Apprendre par plusieurs langues rendra transparente la vitre du langage par laquelle nous appréhendons le monde.

Nous sommes d'accord avec les auteurs que l'approche d'intercompréhension entre les langues parentes permet d'enlever cette peur associée à la diversité et à l'Autre. Cette approche garantit à l'apprenant la sécurité et l'envie d'aller plus loin dans sa connaissance d'autres langues. Elle contribue ainsi à cultiver les relations linguistiques et culturelles entre pays et continents, à réaffirmer les liens anciens d'amitié entre les peuples.

Voyons maintenant comment l'approche d'intercompréhension entre les langues parentes est mise en place sur le plan didactique.

\subsubsection{Intercompréhension entre les langues parentes - le plan didactique}

L'intercompréhension entre les langues parentes constitue sans doute une stratégie à valoriser dans le processus d'enseignement/apprentissage des langues étrangères. Il est vrai que depuis qu'existe le langage, l'intercompréhension est une réalité quotidienne et une stratégie de communication pour des millions de personnes. Malgré cela, son potentiel reste encore largement inexploité. En effet, une mise en œuvre plus générale de l'intercompréhension est porteuse d'enjeux qui touchent non seulement à la langue, mais aussi à la pédagogie.

Tout d'abord, il convient de rappeler que sur le plan didactique, la méthode de l'intercompréhension vise à former les apprenants à traiter en même temps deux aspects : reconnaître les phénomènes lexico-morphologiques communs sans être

${ }^{122}$ Escudé et Janin (2010 : 42). 
arrêté par la singularité propre à telle(s) langue(s) ; laisser agir en somme l'intuition à inférer le sens d'une langue vers l'autre, tout en restant conscient que cette régularité n’est jamais totalement acquise (Escudé et Janin, $2010: 44$ ).

En outre, l'intercompréhension privilégie le développement de compétences de compréhension, les stratégies cognitives et métalinguistiques qui favorisent ensuite la capacité à produire de manière autonome. Il nous semble que cette approche est le contraire de ce que prône l'apprentissage traditionnel des langues. Grâce à l'intercompréhension entre les langues parentes, un apprenant après avoir développé prioritairement les activités de compréhension écrite, possède des fondements pour développer par la suite les autres compétences (compréhension orale, production écrite et production orale). Ceci est particulièrement bien visible sur la figure ci-dessous.

\section{Progression traditionnelle}

\begin{tabular}{|l|c|c|c|c|c|c|}
\hline \multicolumn{1}{|c|}{ Habilité } & A1 & A2 & B1 & B2 & C1 & C2 \\
\hline Lire & & $\longrightarrow$ & & & & \\
\hline Écouter & & $\longrightarrow$ & & & & \\
\hline Parler & & & & & \\
\hline Écrire & $\longrightarrow$ & & & & \\
\hline
\end{tabular}

\section{Progression appuyée sur l'intercompréhension}

\begin{tabular}{|l|c|c|c|c|c|c|}
\hline \multicolumn{1}{|c|}{ Habilité } & A1 & A2 & B1 & B2 & C1 & C2 \\
\hline Lire & & & & & & \\
\hline Écouter & & & & & & \\
\hline Parler & & & & & & \\
\hline Écrire & & & & & & \\
\hline
\end{tabular}

Figure 14. Progression des compétences dans l'approche traditionnelle et dans l'approche d'intercompréhension.

Source : Escudé et Janin, op.cit. : 51.

Nous voyons que selon l'approche s'appuyant sur l'intercompréhension, la compétence développée en premier, facilite l'acquisition des autres compétences. En même temps, il faut dire que cela renverse complètement la pédagogie classique qui promeut la progression traditionnelle.

D'autre part, les didacticiens de l'intercompréhension relèvent cinq fonctions didactiques de l'intercompréhension entre langues parentes. Cette approche pourrait être utilisée pour différents objectifs pédagogiques: 
Tableau 7. Fonctions didactiques de l'approche d'intercompréhension entre langues parentes.

\begin{tabular}{|l|l|}
\hline $\begin{array}{l}\text { d'entrée ou d'introduction à l'apprentissage d'une langue cible } \\
\text { donnée }\end{array}$ \\
\hline $\begin{array}{l}\text { de soutien ou de renforcement de l'apprentissage d'une langue } \\
\text { cible en particulier }\end{array}$ \\
\hline $\begin{array}{l}\text { de déclencheur de motivation ou de revitalisation, par la mise } \\
\text { en situation rapide et authentique, des compétences dont on } \\
\text { dispose au préalable }\end{array}$ \\
\hline $\begin{array}{l}\text { de redéfinition de la finalité des apprentissages, par } \\
\text { hiérarchisation des objectifs autour d'un bouquet de langues } \\
\text { (Degache et Garbarino, 2012) }\end{array}$ \\
\hline $\begin{array}{l}\text { métacognitive d'acquisition des principales stratégies de } \\
\text { compréhension, applicables à toutes les langues et permettant } \\
\text { une plus grande autonomisation et émancipation de } \\
\text { l'apprenant dans l'apprentissage linguistique (Degache et } \\
\text { Garbarino, op.cit.) }\end{array}$ \\
\hline
\end{tabular}

Source : d'après Degache (op.cit.) et Gębal (2013 : 45).

L'analyse des fonctions didactiques de l'intercompréhension entre les langues parentes nous fournit des preuves que l'intercompréhension est étroitement associée à la notion de plurilinguisme. Les principes de cette approche sont en corrélation avec la notion de plurilinguisme dans la mesure où l'intercompréhension met en avant la notion de compétences partielles et déséquilibrées (compétences de production et de réception).

De plus, conformément aux principes du plurilinguisme et contrairement à l'apprentissage conventionnel juxtaposé et cloisonné, l'intercompréhension favorise l'apprentissage ouvert et simultané fondé sur le mouvement d'une langue à l'autre.

\subsubsection{Intercompréhension entre les langues parentes - obstacles et contraintes}

L'éducation à l'intercompréhension correspond aux recommandations du programme européen Éducation Formation 2020, puisqu'elle permet notamment :

- de réfléchir sur sa propre langue ;

- de repérer des stratégies de compréhension et de contribuer à apprendre à apprendre ;

- d'appréhender les différentes visions des disciplines dans les différentes langues et donc, de former cette compétence plurilingue et pluriculturelle européenne.

Il convient de remarquer que l'intercompréhension fait actuellement l'objet de travaux de recherche et figure dans des projets du Conseil de l'Europe en matière d'éducation.

${ }^{123}$ Degache et Garbarino (coord.), 2012, Actes du colloque IC 2012, Intercompréhension: compétences plurielles, corpus, intégration, Université Stendhal Grenoble 3 (France). 
Parmi les méthodes d'apprentissage les plus connues, développées autour de l'intercompréhension on trouve EuRom4 $4^{124}(1997), \operatorname{EuroCom}^{125}$ (2004), Galatea ${ }^{126}$ (19961999), Galanet (2003) ${ }^{127}$ et Intercompréhension européenne ${ }^{128}$ (ICE) (Kucharczyk,

${ }^{124}$ La méthode EuRom4, projet «Lingua » financé par la Communauté européenne, a été conçue par Claire Blanche-Benveniste dans les années 1990 avec la collaboration d'une équipe d'enseignantschercheurs de quatre universités européennes. L’expérience accumulée pendant plusieurs années dans le cadre de ce projet a permis d'aboutir au manuel « EuRom4 : méthode d’enseignement simultané des langues romanes" (1997). EuRom4 propose un parcours d'apprentissage vers l'intercompréhension à partir du développement de l'habileté de la compréhension écrite. La méthode s'adresse à des locuteurs d'une des langues cibles (portugais espagnol, italien et français), adultes, d'un niveau d'études supérieur et bons lecteurs en langue maternelle. Elle propose un entraînement à la lecture globale de textes de presse à caractère général.

Le manuel EuRom4 est aujourd'hui épuisé.

125 « EuroCom désigne la capacité de comprendre une variété de sa propre langue ou une langue étrangère sur la base d'une autre variété ou langue sans l’avoir apprise. En général, les variétés d'une même langue sont intercompréhensibles. Un Parisien comprend un Lyonnais, car leurs parlers régionaux appartiennent à une même langue. Un francophone comprend facilement l'italien (mais ni le russe ni l'allemand). La théorie de l'intercompréhension est en rapport avec une conception « ouverte » du terme langue. Pour le groupe EuroCom, une langue ne se définit pas exclusivement à partir de sa norme, mais des pratiques qui peuvent être celles des locuteurs natifs ou hétéroglottes, mais aussi des apprenants. Les langues sont des propriétés collectives qui se valorisent d'autant plus qu'elles sont utilisées » Source : https://www.cairn.info/revue-ela-2004-4-page-403.htm.

Le but d'EuroComRom est de doter le lecteur d'une compétence de lecture en langues cibles dès le départ.

${ }^{126}$ Le projet Galatea a été dirigé par Louise Dabène et piloté par l'une des équipes du Laboratoire Lidilem (Linguistique et Didactique des Langues Etrangères et Maternelles) de l'Université Stendhal (Grenoble 3), en partenariat avec 5 autres universités européennes.

Galatea est aujourd'hui une méthode d'entraînement à la compréhension des langues romanes qui aspire à l'optimisation du potentiel cognitif de l'apprenant. Galatea s'adresse à un large public, principalement à partir de 15 ans, qui souhaite découvrir ou redécouvrir une ou plusieurs langue(s) romane(s). Fondements méthodologiques :

- d'une part d'une langue romane par compétence dissociée ;

- et d'autre part, l'apprentissage consécutif de 3 langues romanes.

${ }^{127}$ Galanet est la première plate-forme sur laquelle a été pratiquée l'intercompréhension en langues romanes en ligne. Le projet Galanet a pour but de favoriser la communication plurilingue entre six langues romanes : le français, l'italien, l’espagnol, le portugais, le roumain et le catalan. Cette communication plurilingue dans les langues romanes permet l'apprentissage de la compréhension de toutes les langues romanes, principalement la compréhension de l'écrit, mais l'oral reste possible, dans un second temps.

${ }^{128}$ L'objectif du programme ICE est d'analyser de manière empirique, de développer et d'optimiser l'approche et la gestion de l'information et de la connaissance en multiples langues. L'une des applications de ce programme de recherche fondamentale est létablissement d'une méthodologie d'enseignement simultané de la compréhension de plusieurs langues européennes apparentées ou voisines qui permettra d'accéder à un immense réservoir d'informations et de connaissances en ne parlant que 2 langues (par exemple, français et anglais pour un francophone), mais en pouvant en comprendre 5 ou 6 de plus en fonction des besoins (par exemple, espagnol-portugais-italienroumain et allemand-néerlandais-suédois).

«Les perspectives envisagées seraient de substituer au marché lucratif des langues - qui fait la promotion exclusive de l'expression unilingue, uniculturelle et unidirectionnelle - un marché 
2018 : 91). Effectivement, ces méthodes permettent d'enseigner l'intercompréhension dans chaque milieu, soit comme un complément à l'enseignement traditionnel soit comme une matière à part.

Cependant, les études ${ }^{129}$ montrent que même si les diverses initiatives énumérées ci-dessus devraient accroître la conscience parmi les responsables pédagogiques, ce n'est pas toujours le cas. Il paraît que les responsables des systèmes éducatifs des pays multilingues qui devraient être les plus intéressés à l'implantation de l'approche d'intercompréhension et à son expansion n'en voient pas les avantages. Nous pensons que cela est dû au fait que l'intercompréhension n'entre pas dans les pratiques usuelles de l'enseignement classique. Elle est même souvent considérée comme s'y opposant : remettant en question à la fois l'exigence de rigueur d'approche, elle bouscule les habitudes de la didactique connue.

Nous sommes d'accord avec Daniel Coste qui affirme que (1995:69) :

Nos conceptions de l'apprentissage des langues restent très liées à un point de vue bilingue. Le couple langue maternelle/langue étrangère demeure déterminant dans nos analyses. Or, il nous faut dépasser cette vision binaire pour considérer que, dans un monde où la pluralité des langues et des cultures est la règle, c'est d'un point de vue plurilingue qu'il y a lieu de considérer l'apprentissage et l'enseignement des langues.

Effectivement, il semble que le milieu scolaire soit un milieu réservé à l'apprentissage traditionnel où l'enseignement très cadré ne laisse que peu de place à une certaine liberté. En résultat, les programmes des systèmes éducatifs restent très "nationaux " et ne prennent en compte que l'apprentissage des langues « nationales » ou régionales qui se trouvent sur leur territoires.

\subsubsection{Intercompréhension entre les langues parentes - quelle utilisation en classe français de la diplomatie?}

Tout d'abord, il convient de souligner qu'aujourd'hui la pratique de l'intercompréhension est une compétence à valoriser dans le monde professionnel. En effet, d'un côté le monde professionnel utilise de plus en plus de variantes d'anglais (globish) ${ }^{130}$

des idées et des débats en soutenant, au moins en Europe, une forme de plurilinguisme très pratique et très accessible, respectueux de l'identité européenne composée de pays avec des populations, des histoires et des cultures anciennes et variées, et assurant au plus grand nombre de citoyens européens l'autonomie linguistique dans la plupart des situations d'expression et de compréhension : comprendre plusieurs langues de ses voisins européens, mais conserver autant que possible sa langue maternelle pour s'exprimer » source : http:// logatome.eu/ice/ICE032007.pdf.

${ }^{129}$ Équipe de recherche de la méthode Eurom5. Les études sont disponibles ici : http://www. eurom5.com/p/chisiamo-fr/lastoria.

${ }^{130}$ Nous nous inspirons ici de l'article de Filomena Capucho (2013:2) «Accepter que la langue d'une puissance politique et économique puisse devenir la lingua franca de l'Europe, c'est se soumettre à cette puissance, en acceptant, au départ, un dénivèlement de pouvoir lors des échanges 
comme lingua franca, de l'autre côté le français ne joue plus ce rôle dans le monde diplomatique ${ }^{131}$. Cet état des choses ouvre la porte au plurilinguisme dans le monde du travail. Comme le remarquent Marie Benveniste et Sonia Di Vito (2012 : 78) ${ }^{132}$ :

Une alternative possible et souhaitable au modèle hégémonique de la langue unique pour la communication académique et professionnelle consiste à former des acteurs plurilingues sachant s'adapter à différentes situations de communication et cultiver de manière autonome leur plurilinguisme, ce tout au long de leur vie professionnelle et privée.

Quant à l'intercompréhension, de nouvelles études ${ }^{133}$ montrent que cette approche influe sur la communication au niveau des savoir-être et savoir-faire : en introduisant plus de réciprocité et en facilitant l'autonomie, l'utilisation de l'intercompréhension modifie les comportements et attitudes dans les échanges de manière extrêmement bénéfique. Cette pratique a d'ailleurs été préconisée dans le Guide des bonnes pratiques linguistiques dans les entreprises ${ }^{134}$ publié en 2014 par la délégation générale à la langue française et aux langues de France.

Dans cette optique, le français de la diplomatie paraît le lieu idéal pour introduire des pratiques pédagogiques développant l'approche d'intercompréhension. L'intercompréhension recourt à une méthode largement collaborative et donc la crainte de mal s'exprimer est neutralisée. Cette approche introduit un apprentissage qui n'est plus purement imitatif, qui ne relève plus d'un fonctionnement $e x$ cathedra, mais de différentes manipulations langagières, d'essais, d'erreurs ${ }^{135}$ et de reformulations, de constructions où langue source et langues cibles se répondent dans une constante interaction. De ce fait, les apprenants qui pourraient normalement être bloqués par l'utilisation du français dans un contexte européen et diplomatique n'auront plus cette peur. Ce qui nous semble important pour notre cours de français

discursifs : aucun étranger n’y aura la même aisance cognitive que les natifs. Tous ceux qui circulent dans les milieux où l'usage de l'anglais de communication fait loi reconnaissent les limites de la communication établie : on communique, certes, mais il s'agit d'interactions fonctionnelles et superficielles »disponible ici : http://www.dorif.it/ezine/ezine_articles.php?art_id=144.

${ }^{131}$ Les données disponibles ici : http://www.cslf.gouv.qc.ca/publications/pubd138/d138.pdf.

132 « Un'alternativa possibile e di sostegno al modello egemonico della lingua unica per la comunicazione accademica e professionale consiste nel formare attori multilingue in grado di adattarsi a situazioni comunicative differenti, e di coltivare in maniera autonoma il rispettivo multilinguismo, parallelamente alla propria vita professionale e privata », notre traduction.

${ }^{133}$ Eurobarometre Special Langues (2012:14) : http://ec.europa.eu/commfrontoffice/ publicopinion/archives/ebs/ebs_386_en.pdf.

${ }^{134}$ Disponible ici : http://www.culture.gouv.fr/Thematiques/Langue-francaise-et-langues-deFrance/Politiques-de-la-langue/Guide-des-bonnes-pratiques-linguistiques-dans-les-entreprises.

135 « L'enseignement de l'intercompréhension en classe réduit la lathophobie (concept développé par Jean Petit dans son ouvrage De l'enseignement des langues secondes à l'apprentissage des langues maternelles en 1989), c'est-à-dire l'aversion pour la faute» (Sheeren, 2016). Disponible ici :

https://journals.openedition.org/lengas/1060. 
de la diplomatie est le fait que cette approche préconise le sentiment d'équité et de confort des interlocuteurs. Ils seront tous sur un même pied d'égalité en mettant en place des stratégies qui mobilisent leurs acquis dans différentes langues. Il se peut que l'on demande au diplomate dans son travail de donner de la visibilité et de la légitimité à d'autres langues ou dialectes. Cette tâche ne lui posera pas de problèmes ou ne le mettra pas mal à l'aise s'il est bien préparé.

En outre, il nous paraît primordial que les futurs fonctionnaires de l'État parviennent à maitriser progressivement les nouveaux savoirs linguistiques nécessaires à leur intégration dans de nouvelles sociétés et, d'une manière plus précise, les savoirs procéduraux et comportementaux dont ils ont besoin pour établir une communication efficace avec les autres dans des pays où ils seront envoyés en mission.

Enfin, pour que l'apprentissage du français de la diplomatie s'inspire de l'intercompréhension entre les langues parentes, il faut multiplier les matériels disponibles en cherchant à produire des adaptations aux besoins spécifiques des apprenants. Nous croyons que cela est possible grâce aux activités listées dans le tableau ci-dessous.

Tableau 8. Typologie des activités promouvant l'approche d'intercompréhension entre langues parentes.

Activités de reconnaissance, d'association, d'identification... de langues, de segments textuels, d'expressions plus ou moins figées ;

Activités portant sur le lexique, toujours dans le but de garantir la transversalité

Activités portant sur des points de grammaire élémentaires (comment interroger, comment nier, le genre, le nombre)

Activités portant sur des actes de parole simples (saluer, se présenter, dire son âge...)

Activités interculturelles et éducatives ( un travail sur la typologie des discours, les catégories discursives)

Source : CARAP (2007, matériaux didactiques) et le projet Itinéraires romans ${ }^{136}$.

Pour conclure, nous devons constater que cette approche est positive, ludique même, qu'elle cherche à encourager plutôt qu'à bloquer. Cela peut aider les apprenants du français de la diplomatie à voir différemment le cours sur objectif spécifique dont les représentation $s^{137}$ sont d'habitude négatives. De même, la méthode

${ }^{136}$ Le projet Itinéraires romans s'inscrit dans le cadre des activités de promotion et enseignement des langues de l'Union Latine. Son objectif général étant cependant aussi de favoriser la reconnaissance des langues et d'aider à mettre au jour les capacités d'intercompréhension en langues néolatines (Tost-Planet, Synergies Chili N.6 - 2010 pp. 47-57), disponible ici : https://gerflint.fr/ Base/Chili6/manuel.pdf.

${ }^{137}$ Selon les résultats des enquêtes menées au Collège d'Europe à Bruges et à Natolin en 20122013 pour notre mémoire du Master 2 « Représentations du français de la diplomatie » de 2013, 
intercompréhensive valorise le plurilinguisme et la diversité linguistique. Elle peut également inclure ou prendre en compte la connaissance d'une langue mineure ce qui peut paraître primordial dans le métier de la diplomatie. Effectivement, les diplomates cherchent toujours l'interopérabilité et la coopération pour la performance dans leurs fonctions diplomatiques. Pour atteindre cette performance, le diplomate doit faire usage de plusieurs langues étrangères dans cette profession. Le diplomate français Romain Nadal, ${ }^{138}$ dans les cinq conseils importants pour devenir un diplomate accompli, souligne l'importance de la langue dans les fonctions d'un diplomate (Nadal, 2017) ${ }^{139}$ :

la langue permet d'être ouvert sur le monde, sur les autres cultures et sur les autres civilisations. Ainsi, le diplomate doit être capable de parler en plus de sa langue d'origine, la langue de l'État dans lequel il est appelé à exercer. ${ }^{10}$

Il est tout à fait vrai qu'à travers la langue officielle du pays hôte, le diplomate pourrait maitriser immédiatement les subtilités, les codes et les références de ses interlocuteurs.

Cela étant dit, nous passons maintenant à l'approche de didactique intégrée des langues.

\section{Didactique intégrée des langues}

La troisième approche plurilingue mettant l'accent sur le développement de la compétence plurilingue et pluriculturelle est la didactique intégrée des langues.

Tout d'abord, il convient de dire que comme c'était le cas avec les autres approches analysées avant, le concept de la didactique qui harmoniserait des enseignements linguistiques n'est pas un concept révolutionnaire ou nouveau. Actuellement, il est possible d'analyser la notion de didactique intégrée des langues sous différents angles. D'un côté, on pourrait prendre en considération l'existence de plusieurs termes qui désignent le même concept ${ }^{141}$, de l'autre, la même notion de pédagogie intégrée qui couvre plusieurs concepts.

dirigé par Véronique Castellotti au département de sociolinguistique et didactique des langues (SODILANG) à l'Université François Rabelais à Tours, France.

${ }^{138}$ Romain Nadal est un diplomate français. Il est actuellement le directeur de la communication et de la presse du ministère des Affaires étrangères, porte-parole du Quai d'Orsay.

${ }^{139}$ L’émission « France, la marque de fabrique du diplomate français » sur France Culture, avril 2017, disponible ici : https://www.franceculture.fr/emissions/les-enjeux-internationaux/france-lamarque-de-fabrique-du-diplomate-francais.

${ }^{140}$ C'est nous qui le soulignons.

${ }^{141}$ « On parle donc de integrierte Sprachendidaktik, mais également de integrative Fremdsprachendidaktik (Wokusch et al., 2007), et de integrale Sprachendidaktik (Cathomas, 2003), sans qu'il n'y ait nécessairement une différence épistémologique » (Troncy, 2014 : 402) ou des didactiques coordonnées en Suisse ou encore language across the curriculum (LAC) en Grande-Bretagne. 
Afin de mieux saisir le sens de ce concept, nous allons nous référer sur ce point à Danièle Moore et Véronique Castellotti (2001 : 74) qui affirment que :

Les chercheurs (Coste, 1993 ; Dabène, 1992 ; Hawkins, 1985 et bien d'autres) évoquent les méfaits de la séparation excessive entre les didactiques et les enseignements de langue maternelle et ceux de langues étrangères, et posent les jalons d'un décloisonnement des disciplines, à partir de modèles de développement des capacités langagières en langues maternelle et étrangères appuyés sur les répertoires des apprenants et sur la nécessité de recourir à des démarches de réflexion translinguistique dans la facilitation des passages d'une langue à l'autre ${ }^{142}$.

Nous voyons que le point de départ de cette approche est le rapprochement des répertoires langagiers que l'apprenant connait déjà bien. Une question s'ensuit : est-ce que tous les travaux portant sur la didactique intégrée des langues se réfèrent au décloisonnement des langues et/ou des disciplines?

En 1973, les travaux du symposium ${ }^{143}$ organisé par le Conseil de l'Europe sur les liens entre l'enseignement de la langue maternelle et l'enseignement des langues vivantes ont souligné l'importance de l'enseignement des langues de façon intégrée. Dans cette optique, les réflexions d'Eddy Roulet sur l'intérêt d'une didactique intégrée des langues maternelles et secondes ont préparé une action pour adapter cette démarche à tous les contextes d'enseignement de la langue. Plus tard, Louise Dabène a fourni des indications encore plus précises concernant la liaison des enseignements linguistiques (Dabène, 1992: 13). Sur le plan pratique, cette démarche a été mise en place d'une manière réussie dans l'enseignement du français à l'école

${ }^{142}$ C'est nous qui le soulignons.

${ }^{143}$ Les principes généraux inspirant la réflexion menée par IRRSAE Val d’Aoste sont résumés dans trois recommandations élaborées par les délègues des pays d'Europe occidentale réunis, en 1973 à Turku en Finlande dans un symposium dont le thème était Les liens entre l'enseignement de la langue maternelle et l'enseignement d'autres langues vivantes:

Première recommandation:

«Symposium a conclu que d'un point de vue pédagogique et à la lumière des théories linguistiques modernes, les similitudes entre deux langues devraient être jugées beaucoup plus importantes que les différences. Les efforts déployés en vue d’établir les liens qui existent entre l'enseignement de la langue maternelle et l'enseignement d'autres langues vivantes sont loin d'avoir été suffisants".

Deuxième recommandation :

«Un des principaux objectifs de l'enseignement de la langue maternelle et des langues étrangères devrait être d'intéresser les élèves à la nature et à la fonction des langues qu'ils apprennent».

Troisième recommandation :

«Les professeurs enseignant la langue maternelle et ceux qui enseignent d'autres langues vivantes devraient coordonner leurs activités pédagogiques et fonder leur enseignement sur des principes linguistiques communs ». 
moyenne bilingue au Val d'Aoste ${ }^{144}$. Plus récemment, le CECRL et puis l'équipe de Michel Candelier ont défini des orientations au sujet de cette démarche de la façon suivante :

La didactique intégrée des langues, qui est vraisemblablement la plus connue des trois, vise à aider l'apprenant à établir des liens entre un nombre limité de langues, celles dont on recherche l'apprentissage dans un cursus scolaire (qu'il vise de façon " classique " les mêmes compétences pour toutes les langues enseignées ou qu'il prévoit des compétences partielles pour certaines d'entre elles). Le but est alors de prendre appui sur la première langue (ou la langue de l'école) pour faciliter l'accès à une première langue étrangère, puis sur ceux deux langues pour faciliter l'accès à une seconde langue étrangère (les appuis pouvant aussi se manifester en retour) (CARAP, $2007: 6)^{145}$.

Il faut remarquer ici que dans cette optique s'inscrivent actuellement de nombreux travaux portant sur "l'allemand après l'anglais $»^{146}$ en tant que langues étrangères (les travaux portant sur les langues tertiaires). Nous retrouvons cette approche dans certaines modalités d'éducation bilingue (ou plurilingue) qui ont le souci d'optimiser les relations entre les langues utilisées (et leur apprentissage) pour construire une véritable compétence plurilingue. Les fondements de la didactique intégrée des langues constituent la construction de compétences dans deux ou plusieurs langues, en les concevant non pas comme des phénomènes disjoints, mais comme un processus articulé.

\subsubsection{Typologie des langues et didactique intégrée}

Il faut également ajouter que l'intégration peut s'articuler diversement selon la typologie des langues enseignées, elle peut par exemple emprunter des voies diversifiées selon que les langues sont typologiquement proches ou éloignées. La figure ci-dessous montre à quel point la parenté entre les langues détermine la didactique intégrée des langues.

${ }^{144}$ Les informations sur ce programme sont disponibles ici: http://www.regione.vda.it/ istruzione/Pubblicazioni/ecole_valdotaine_archives/24/18.pdf.

${ }^{145}$ C'est nous qui le soulignons.

${ }^{146}$ Le projet Apprendre efficacement plus d'une langue - l'enseignement et l'apprentissage d'une langue tertiaire en Europe. Exemple : l'allemand comme deuxième langue étrangère après l'anglais, a été réalisé dans le cadre du programme d'activités à moyen terme 2000-2003 du Centre européen pour les langues vivantes (Graz) en coopération avec le Goethe Institut. Ce projet visait à étudier les moyens de structurer l'enseignement et l'apprentissage des langues tertiaires pour que soient délibérément intégrées - et de manière plus efficace, les connaissances linguistiques et expériences d'apprentissage des langues acquises au préalable par l'apprenant (langue maternelle, première langue étrangère).

Le projet est disponible ici : http://archive.ecml.at/documents/pub112f2004hufeisenneuner. pdf. 
Langues typologiquement éloignées

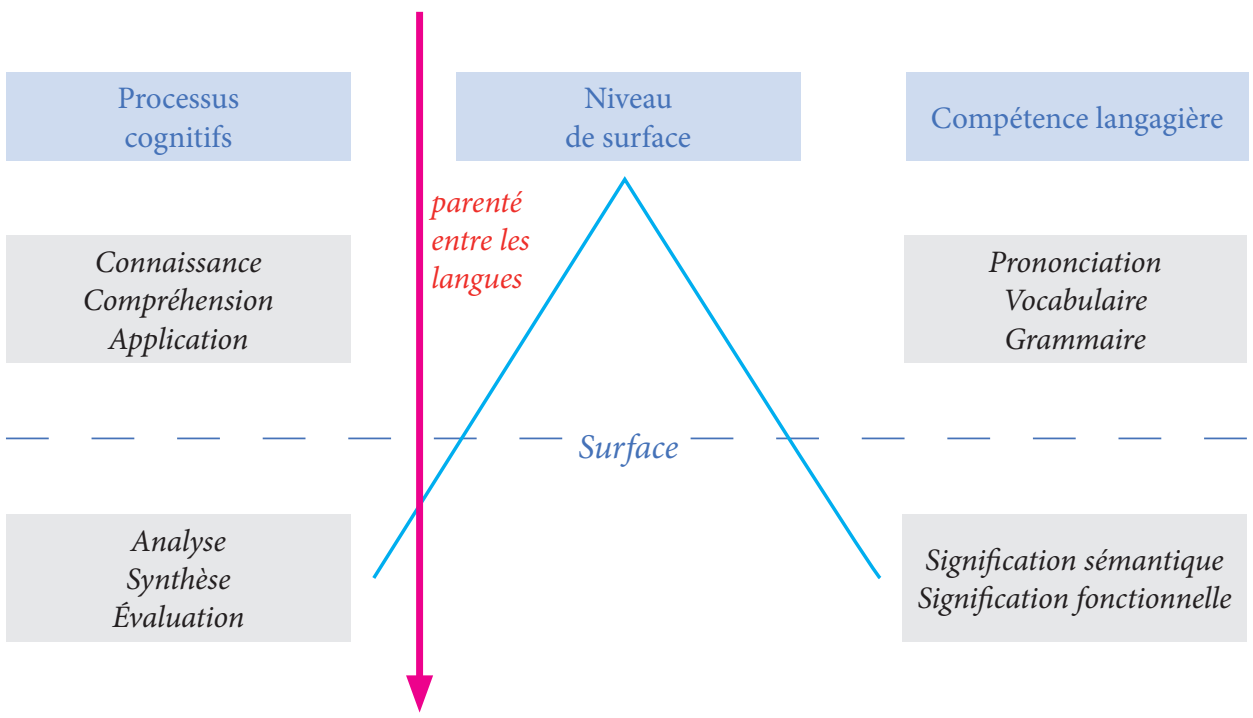

Langues typologiquement proches

\section{Compétence cognitive (niveau profond)}

Figure 15. Différents niveaux de l'intégration suivant la typologie des langues.

Source : la schématisation inspirée de l'iceberg de Jim Cummins (1980: 175). ${ }^{147}$

La plus grande parenté entre les langues (par exemple entre l'espagnol et le français) permet un travail sur les structures de surface. Cependant, pour les paires de langues typologiquement éloignées (par exemple le polonais et le portugais), l'intégration se fonde moins sur la surface, mais plutôt au niveau de la compétence cognitive-niveau profond. C'est à ce niveau que se situent, à notre avis, les enjeux les plus féconds de la didactique intégrée des langues. En effet, c'est là où résident les processus cognitifs (analyse, synthèse, évaluation) et les compétences langagières (signification sémantique et fonctionnelle) de plus haut niveau, celles qui sont à la base du développement cognitif et développement langagier plus avancé.

Enfin, nous croyons que ce savoir pourrait être utilisé par des enseignants de langues. La conscience de la parenté entre les langues pourrait être prise en compte lors de la préparation des cours dans une classe multiculturelle où la présence de différentes langues pourrait s'avérer une richesse et nonv un obstacle.

${ }^{147}$ «La théorie de l'iceberg » : l'hypothèse de Jim Cummins (1979 et 2001) sur l'interdépendance linguistique : cette hypothèse, représentée comme un "double iceberg ", postule que deux langues peuvent être très différentes en surface, alors qu'elles reposeraient en fait sur des processus cognitifs identiques. 


\subsubsection{Didactique intégrée des langues : concepts pratiques}

Dans une Europe plurilingue et pluriculturelle, la didactique des langues vivantes doit sans cesse se remettre en question face aux nouvelles attentes, tant des pouvoirs politiques que de la société dans laquelle nous évoluons. Pour ne donner qu'un exemple des questions que posent les nouvelles attentes de notre société, pensons aux problèmes qui résultent de l'introduction de plus en plus précoce de l'apprentissage des langues à l'école. Comme le remarque Susanne Wokusch (2008:12) «la grille horaire des élèves n'étant pas extensible, il faut chercher une "économie didactique" ». De ce fait, il semble qu'une collaboration très étroite entre tous les enseignants de langues qu'apporte la didactique intégrée des langues pourrait y apporter la solution. Les concepts fondamentaux de cette approche et ses implications pratiques ont été présenté dans le tableau ci-dessous (Gębal, $\left.2013: 46^{148}\right)$ :

Tableau 9. Concepts fondamentaux de la didactique intégrée des langues.

\begin{tabular}{|c|c|c|}
\hline & Les principes didactiques & Les implications pratiques \\
\hline 1. & $\begin{array}{l}\text { Le caractère cognitif du processus } \\
\text { de l'apprentissage des langues }\end{array}$ & $\begin{array}{l}\text { La comparaison des situations linguistiques } \\
\text { pour montrer aux apprenants l'existence d'une } \\
\text { base commune de toutes les langues }\end{array}$ \\
\hline 2. & $\begin{array}{l}\text { La compréhension comme une base } \\
\text { du processus de l'apprentissage des } \\
\text { langues }\end{array}$ & $\begin{array}{l}\text { Stimuler le savoir préexistant sur la langue } \\
\text { pour faire le transfert linguistique }{ }^{150} \text {, ce qui } \\
\text { vise l'effectivité de l'apprentissage des langues } \\
\text { tertiaires }\end{array}$ \\
\hline 3. & $\begin{array}{l}\text { Orienter le processus de } \\
\text { l'apprentissage des langues sur } \\
\text { le contenu concret }\end{array}$ & $\begin{array}{l}\text { Adapter le contenu du cours aux besoins } \\
\text { spécifiques et aux intérêts des apprenants pour } \\
\text { éveiller et/ou soutenir la motivation dans } \\
\text { le processus de l'apprentissage des langues }\end{array}$ \\
\hline
\end{tabular}

${ }^{148}$ Notre traduction.

${ }^{149}$ Le concept de transfert linguistique a été tout d'abord défini par Robert Lado (1957) dans le cadre de l'analyse contrastive. Pour Robert Lado (Lado 1957 : 59 dans Krashen $1981: 52)^{\star}$ : «Dans la situation où l'apprenant essaye de transférer les habitudes de sa langue maternelle, nous avons la principale source de difficulté ou de facilité pour apprendre la structure d'une langue étrangère. Les structures qui lui sont similaires seront faciles à apprendre puisqu'elles seront transférées directement dans une autre langue et pourront fonctionner de manière satisfaisante. Les structures qui lui sont différentes poseront problème, car une fois transférées elles ne fonctionneront pas de manière satisfaisante dans la langue étrangère et devront donc être modifiées. Nous pouvons dire que le degré de contrôle de ces structures différentes est un indice quant à l'apprentissage de la langue réalisé par un apprenant».

${ }^{*}$ « Since the learner tends to transfer the habits of his native language, we have here the major source of difficulty or ease in learning the structure of a foreign language. Those structures that are similar will be easy to learn because they will be transferred and may function satisfactorily in the foreign language. Those structures that are different will be difficult because when transferred they will not function satisfactorily in the foreign language and will therefore have to be changed. We can say that the degree of control of these structures that are different is an index to how much of the language a person has learned», notre traduction. 
(la continuation du tableau 9)

\begin{tabular}{|c|l|l|}
\hline \multicolumn{1}{|c|}{ Les principes didactiques } & \multicolumn{1}{c|}{ Les implications pratiques } \\
\hline $\mathbf{4 .}$ & $\begin{array}{l}\text { Orienter le processus de } \\
\text { l'apprentissage des langues sur } \\
\text { le travail avec le texte }\end{array}$ & $\begin{array}{l}\text { Encourager les apprenants à travailler avec } \\
\text { le texte ce qui facilitera la découverte des règles } \\
\text { de la langue qu'ils apprennent }\end{array}$ \\
\hline $\mathbf{5 .}$ & $\begin{array}{l}\text { Organisation effective du processus } \\
\text { de l'apprentissage des langues }\end{array}$ & $\begin{array}{l}\text { Promotion de l'enseignement qui est le mieux } \\
\text { adapté aux besoins des apprenants }\end{array}$ \\
\hline
\end{tabular}

Source: Gębal, $2013: 46^{150}$.

Piotr Gębal souligne que l'enseignement intégré des langues met en application les principes cognitifs et réflexifs du processus de l'enseignement/apprentissage des langues. Ainsi, il faudrait développer chez l'étudiant des stratégies de repérage, de comparaison, d'interprétation, d'élaboration d'hypothèses de sens dans un contexte précis, de synthèse, de systématisation, et d'analyse. De ce fait, l'enseignant doit chercher à mettre en œuvre des activités de réflexion capables de favoriser un transfert de compétences d'une langue vers l'autre, et de diminuer les interférences négatives. Radosław Kucharczyk (2018 : 94) nous rappelle à juste titre que :

L'aspect négatif des interférences, qui était pendant des années le centre d'intérêt des didacticiens et des linguistes, n’occupe pas ici [dans la didactique intégrée des langues] la place primordiale. Il faut le comprendre comme naturel, comme effet secondaire de l'apprentissage de plusieurs langues étrangères, qui disparaitra avec le temps » (notre traduction $\left.^{151}\right)$.

150 "1. Założenie dydaktyczne: kognitywny charakter procesu kształcenia językowego. Implikacje praktyczne: porównywanie zjawisk językowych w celu uświadomienia uczniowi wspólnej bazy dla wszystkich języków.

2. Założenie dydaktyczne: rozumienie jako podstawa procesu kształcenia językowego. Implikacje praktyczne: aktywizacja dotychczasowej wiedzy o języku w celu dokonania transferu interjęzykowego, co ma zwiększyć efektywność nauki kolejnego języka.

3. Założenie dydaktyczne: zorientowanie procesu kształcenia językowego na konkretne treści. Implikacje praktyczne: dopasowanie treści nauczania do potrzeb i zainteresowań uczniów w celu wzbudzenia i podtrzymania motywacji w procesie uczenia się języka.

4. Założenie dydaktyczne: zorientowanie procesu kształcenia językowego (działania i materiały dydaktyczne) na teksty. Implikacje praktyczne: zachęcanie uczniów do pracy z tekstem (rozumienie ogólne i szczegółowe), co ma im ułatwić odkrywanie reguł, jakim podporządkowany jest język, którego się uczą.

5. Założenie dydaktyczne: efektywna organizacja procesu kształcenia językowego. Implikacje praktyczne: skoncentrowanie działań dydaktycznych na treściach najbardziej odpowiadających potrzebom uczniów",

notre traduction.

${ }^{151}$ „[n] egatywny aspekt interferencji, będący przez lata obiektem zainteresowań glottodydaktyków i językoznawców, zajmuje drugorzędną pozycję. Pojmuje się go jako naturalny, uboczny produkt procesu uczenia się kilku języków obcych, który z czasem zanika”, notre traduction. 
Michel Candelier remarque aussi que l'approche de didactique intégrée des langues attache de l'importance au rôle des savoirs et des savoir-faire que l'apprenant a acquis dans le processus de l'enseignement/apprentissage de la langue tertiaire. Ceci est d'autant plus important que les Instructions officielles des Ministères de l'Éducation nationale des pays européens favorisent le réinvestissement de ces ressources dans l'acquisition d'une langue vivante étrangère. De ce point de vue, cela sert d'appui pour acquérir de nouvelles compétences en langue. Le but n'est plus d'appliquer le fonctionnement de la langue de l'école sur celui de la langue étrangère, mais plutôt de transférer des savoir-faire d'ordre méthodologique.

Il semblerait alors que les réflexions métalinguistiques encourageraient les élèves à reconsidérer leurs représentations de la langue étrangère et, à long terme, conduiraient les apprenants à améliorer leurs compétences en langues : langue maternelle, langue de l'école et langues étrangères.

Cette approche peut être très utile dans l'enseignement de la grammaire où l'on observe des similarités aussi bien dans le métalangage que dans les théories grammaticales. Cela demande de la part des enseignants et des écoles des directives communes concernant l'établissement de la terminologie identique pour toutes les langues. Or, comme nous allons voir ci-dessous, cela n’est pas si simple et évident.

\subsubsection{Didactique intégrée des langues : limites et obstacles}

Nous pensons que chaque discussion autour d'un concept novateur devrait également poser des questions critiques par rapport à sa pertinence, sa portée, et, le cas échéant, ses limites.

Nous avons dit plus haut que la didactique intégrée des langues demande beaucoup d'efforts de la part des institutions ainsi que les enseignants. En effet, sur le plan pratique, cette approche se base sur une coopération proche entre les enseignants. Remarquons cependant que cette collaboration peut se réaliser selon diverses modalités d'après le degré d'approfondissement de l'intégration et également celui de l'engagement individuel des enseignants. Il peut arriver que faute de données, manque de méthodes ou de temps il n'y ait aucun échange entre les différents enseignants de langue d'une classe. Les études de Susanne Wokusch menées au Canada (2014) et au Luxembourg (2016) montrent que les cours de langues restent toujours organisés de façon cloisonnée.

Les enseignants appréhendent des changements dans leurs cours; des réticences demeurent. Nous pouvons en lire dans la revue Babylonia 1/08 ${ }^{152}$ :

Des enseignants des langues craignent des interférences entre les langues et optent de ce fait pour un apprentissage relativement cloisonné. Ils ne veulent pas assumer des fonctions ancillaires pour d'autres disciplines. À cela s'ajoutent des peurs liées à une réduction d'heures de cours, "si on peut faire mieux ou plus avec moins ...".

${ }^{152}$ La Revue pour l'enseignement et l'apprentissage des langues, disponible ici : www.babylonia.ch 
De plus, Christian Merkelbach (2009: 50) constate quactuellement « les notions et concepts constitutifs de ce que l'on décrit sous didactique intégrée des langues demeurent encore très abstraits et les exemples qui les illustrent ne sont pas légion ». Nous croyons que cela peut être dû au fait que les enseignants qui connaissent et apprécient en théorie la didactique intégrée des langues, ne savent pas comment élaborer un cours basé sur ses principes. Nous songeons que la mise en pratique des séquences pédagogiques s’appuyant sur la didactique intégrée des langues semble pour certains « trop novatrice». Parfois, les formateurs introduisent occasionnellement des éléments liés à la didactique intégrée, mais rarement des curricula entiers qui engageraient toute l'établissement. Pourtant, comme le remarque Michel Candelier (2014 : 34) la didactique intégrée des langues ne peut pas se limiter à des pratiques ponctuelles ou des séquences spécifiques mais doit être une conception qui sous-tend de manière cohérente l'enseignement de toutes les langues. Il faudrait peut-être penser à mutualiser les pratiques existantes et créer des outils de formation des enseignants.

Il nous semble intéressant d'évoquer ici l'enquête " The negative aspects mentioned by the students related to the Curricular Unit of Integrated Didactics » réalisée en 2014 (les données recueillies auprès d'un échantillon de 57 étudiants) ${ }^{153}$ auprès des étudiants de la Lisbon School of Education. Les entretiens des chercheurs avec les apprenants qui ont suivi les cours de plusieurs disciplines (mathématiques, sciences sociales et physique) organisés selon l'approche de didactique intégrée des langues ont révélé qu'il existe un bon nombre d'aspects négatifs avec ce type de leçons ${ }^{154}$. Cependant, ce qui a le plus attiré notre attention c'était le fait que la grande majorité des réponses des apprenants indiquaient un manque de coopération entre les différents professeurs. Et pourtant, la collaboration interdisciplinaire implique avant tout un travail d'équipe. Comme le remarque Marisa Cavalli $(2003: 21)$ :

Il s'agit d'envisager le travail d'équipe comme relevant des compétences professionnelles incontournables de l'enseignant face à l'individualisme qui a longtemps caractérisé ce métier. Plus tard, il sera possible de ne voir, dans la collaboration étroite avec les

${ }^{153}$ Enquête disponible ici : https://www.researchgate.net/publication/284158334 INTEGRATED_DIDACTICS_AN_EXAMPLE_OF_A_CURRICULUM_MODEL_ENHANCING_ KNOWLEDGE_CROSSING.

${ }^{154}$ The negative aspects mentioned by the students related to the Curricular Unit of Integrated Didactics:

1) A certain lack of liaison between the professors in terms of sequencing, articulation, and even in the conception of integration expressed;

2) The articulation between the four areas should have had more examples;

3) More exemplification of strategies and integrator models;

4) The lack of opportunity to expose integration experiences developed by the teachers in training;

5) The absence of the artistic areas;

6) The difficulty to develop all the proposed work (in number and design);

7) An overloaded schedule. 
collègues, qu'une ressource d'une richesse considérable et un moyen pour évoluer en tant que personne et en tant que professionnel de l'enseignement.

Bien sûr, il convient de souligner que la collaboration d'une équipe d'enseignants qui programment ensemble un travail commun ou qui interviennent ensemble en coprésence dans la classe (quand cela est rendu possible par les chefs d'établissement) facilite énormément l'enseignement coordonné, et peut représenter le niveau le plus élevé d'intégration linguistique. Mais n'oublions pas que l'interdisciplinarité est également possible dans les situations où chaque enseignant travaille seul dans sa classe, à condition que l'esprit interdisciplinaire inspire les démarches de chacun.

Pour conclure, il faut admettre que la réalisation de la didactique intégrée des langues suscite beaucoup de questions. D'un côté, nous savons que cette approche pourrait par exemple donner la possibilité d'augmenter le nombre de langues apprises à l'école en diminuant la charge d'apprentissage pour les langues individuelles, mais de l'autre, il y a toujours de nombreux enjeux concernant son implication dans le cursus scolaire. Néanmoins, il est bien évident que l'avenir appartient certainement à un enseignement/apprentissage beaucoup plus intégré des langues et des disciplines que dans le passé.

\subsubsection{Didactique intégrée des langues : les cours de français de la diplomatie}

Tout d'abord, il faut dire que le cours de français de la diplomatie qui puise dans la didactique intégrée des langues devrait privilégier l'usage des textes écrits. Cette importance accordée aux textes écrits n'est pas un hasard. Les documents écrits fournissent la possibilité de procéder à l'analyse linguistique (le vocabulaire, la grammaire, les genres discursifs), ce qui invite les apprenants à faire des comparaisons, à trouver des différences et des similitudes entres les langues. De ce fait, l'enseignant doit choisir des textes écrits qui se prêtent bien à des analyses inter- et intralinguistiques. Quant à l'enseignant donnant un cours de français de la diplomatie, il pourrait utiliser des textes informatifs ou de presse mondiale rédigés en français, par exemple des articles de Courrier International ou le Monde diplomatique.

De plus, d'autres éléments peuvent être développés lors du cours de français de la diplomatie : des stratégies de repérage, de comparaison, d'interprétation, d'élaboration d'hypothèses, de synthèse, d'analyse. Ainsi, le travail par exemple sur le lexique peut être une occasion idéale pour faire le lien de manière cohérente entre les différents univers linguistiques des apprenants, la langue de l'institution et la langue étrangère enseignée. En didactique intégrée des langues, le lexique peut servir d'accroche à la mise en synergie des langues. Il permet de visualiser concrètement les similitudes entre les langues, notamment en ce qui concerne "le lexique 
international ». Cela permet de fusionner les différents enseignements linguistiques tout en enrichissant le bagage lexical des apprenants. La tâche de l'enseignant serait ici de chercher à mettre en ouvre des activités de réflexion capables de favoriser un transfert de compétences d'une langue vers l'Autre, et de diminuer les interférences. Cette démarche aide l'apprenant à créer progressivement de nouvelles représentations de la langue étrangère, de nouvelles habitudes et procédures cognitives.

D'autre part, nous croyons que le cours de français de la diplomatie est un lieu idéal pour effectuer des passerelles entre la langue française standard, la langue en usage chez les apprenants et l'anglais langue seconde, commune à tous ceux qui pensent au métier de diplomate ${ }^{155}$. Cependant comme le remarque Radosław Kucharczyk $(2018: 98)^{156}$ :

Il faut se demander si l'enseignant de langues devrait connaitre parfaitement les langues auxquelles il fait référence pendant ses cours. Cela serait sans doute une situation idéale, cependant, il est rare que l'enseignant de la langue tertiaire connaisse parfaitement une autre langue étrangère. De ce fait, il est possible que même avec une connaissance limitée d'une langue, l'enseignant puisse faire des références à d'autres langues qui s'inscrivent dans la didactique intégrée des langues à condition qu'il encourage les apprenants aux recherches autonomes interlinguistiques dans le cadre de leur répertoire langagier.

Effectivement, il est très important de sensibiliser les enseignants sur ce sujet. Le fait qu'ils ne parlent pas parfaitement d'autres langues ne devrait pas les limiter dans leurs pratiques basées sur la didactique intégrée des langues.

Finalement, comme nous l'avons mentionné plus haut, la didactique intégrée des langues se fonde sur la collaboration entre les enseignants. Au niveau minimal, cela pourrait prévoir l'information réciproque au sujet des contenus d'enseignement, l'élaboration d'un langage commun entre différents professeurs de langues (si le cours a lieu dans un centre linguistique ou à l'université), la concertation sur

155 «La maîtrise de l'anglais est impérative dans la diplomatie. En effet, de nos jours la langue anglaise est devenue, et pour plusieurs raisons, le premier véhicule linguistique de la communication internationale» (Erdos ${ }^{\star}$, International Relations Quarterly, Vol. 4. No.2. (Été 2013/2).

* l'Ambassadeur André Erdos est à la tête de la délégation de son pays à la réunion de Vienne de la CSCE de 1986 à 1989. Il est nommé en 1990 Représentant permanent de la Hongrie auprès des Nations Unies à New York. En 1992 et 1993, il représente son pays au Conseil de Sécurité. Il est secrétaire d'État adjoint aux Affaires étrangères en Hongrie de 1994 à 1997. Il se retrouve de nouveau à New York entre 1997 et 2002 à la tête de la mission hongroise auprès de l'ONU. Il est ambassadeur de Hongrie à Paris de 2002 à 2006.

${ }^{156}$ „Należy się jednak zastanowić, czy nauczyciel powinien doskonale znać języki, do których będzie się odwoływał na lekcji swojego języka. Niewątpliwie taki stan rzeczy byłby pożądany, ale sytuacja, w której nauczyciel języka tercjalnego zna doskonale inny język obcy, jest rzadka. Można więc przyjąć, że nawet przy ograniczonej znajomości innego języka nauczyciel może prowadzić działania dydaktyczne wpisujące się w założenia zintegrowanego kształcenia językowego, pod warunkiem że zachęci uczniów do autonomicznych poszukiwań międzyjęzykowych w obrębie zasobów własnego repertuaru językowego", notre traduction. 
certaines techniques de gestion de la classe à propos de questions aussi délicates et fondamentales que la façon d'affronter les erreurs.

\subsubsection{Approche interculturelle}

\subsubsection{Approche interculturelle : une perspective pédagogique}

L'approche interculturelle est apparue dans les années 1970, dans un contexte migratoire européen lié à la scolarisation des enfants de migrants. La pédagogie interculturelle adoptée visait l'insertion de ces enfants, notamment dans le système scolaire. Sans pour autant vouloir les couper de leur langue-culture d'origine, il était également prévu, dans le cas d'un éventuel "retour au pays », un enseignement de leur langueculture d'origine (Chaves, Favier, Pélissier, 2012 :15).

Dans les années 1970-1980, les réflexions menées par le Conseil de l'Europe en matière de migration et d'éducation ont encouragé l'élaboration de politiques permettant la reconnaissance de la diversité culturelle comme un enrichissement et non plus comme un handicap. De cette façon, l'interculturel est sorti du champ exclusif des migrations. Les divers travaux sur ce sujet ont insisté sur le fait que la pédagogie interculturelle était une option éducative globale et transversale qui devait s'appliquer à tous les apprenants, et ce, quelle que soit la matière enseignée.

Dans l'enseignement d'une langue, il est impossible de dissocier langue et culture. En effet, en 1997, Michael Byram parle de compétence de communication interculturelle qui accompagnerait les autres composantes de la compétence de communication et exigerait des connaissances, des attitudes et des aptitudes particulières. En réalité, cette compétence de communication orientée vers l'interculturel inclut des attitudes et des comportements orientés vers l'autre, considéré comme un partenaire de statut identitaire et culturel égal.

Le CECRL (2001) cite l'approche interculturelle dès les premières pages comme contribuant étroitement au développement personnel souhaitable de l'apprenant :

Dans une approche interculturelle, un objectif essentiel de l'enseignement des langues est de favoriser le développement harmonieux de la personnalité de l'apprenant et de son identité en réponse à l'expérience enrichissante de l'altérité en matière de langue et de culture (CECRL, $2001: 9$ ).

En effet, l'enseignement de la culture est sous-jacent à la pratique scolaire quotidienne de la langue cible. Nous convenons donc avec Geneviève Zarate (1995) qu'il est impossible d'apprendre une langue en en évacuant la culture. Martine Abdallah-Pretcielle (2001) est du même avis. Comment enseigner une langue étrangère sans l'ancrer dans sa culture?

Pour la chercheuse, la dimension interculturelle de l'enseignement s'impose d'ellemême parce que dès que l'Autre est convoqué, comme ici à travers sa langue, nous 
sommes d'emblée dans la diversité culturelle. Elle préconise donc de mettre en œuvre des démarches pédagogiques pour en favoriser la prise de conscience. En outre, Abdallah- Pretcielle (2004:28) souligne que, en effet, «le discours interculturel induit un questionnement autant sur les autres cultures, sur autrui, que sur sa propre culture. C'est ce processus en miroir qui fonde la problématique interculturelle».

Michel Candelier traite l'approche interculturelle comme "le quatrième "mousquetaire" de la famille des approches plurielles" (Candelier, 2008 : 71) qui a une influence irrécusable sur la didactique des langues "même si ce n'est pas toujours de façon explicite et réellement conforme à ses orientations fondamentales » (Candelier, 2007 : 7). Les auteurs du CARAP soulignent que l'approche interculturelle connait de nombreuses variantes qui ont en commun de reposer sur des principes didactiques préconisant l'appui sur des phénomènes relevant d'une ou plusieurs aire(s) culturelle(s) (conçues comme hybrides, perméables et dynamiques) pour en comprendre d'autres relevant d'une ou plusieurs autres aire(s) culturelle(s) (CARAP, 2007). Ces principes prônent également la mise en œuvre de stratégies destinées à favoriser la réflexion sur les modalités du contact entre individus disposant d'arrièreplans culturels différents.

\subsubsection{Prise de la conscience interculturelle}

Nous avons vu que depuis les années 1970, l'approche interculturelle est le point de départ de la nouvelle façon de penser l'éducation. L’apprenant a commencé à être considéré comme un intermédiaire culturel ${ }^{157}$.

De plus, accorder une place prépondérante à l'apprentissage interculturel a mené les didacticiens à trouver des moyens pour opérationnaliser l'interculturel. Le modèle de Byram, Zarate et Neuner (1997 : 13) prévoit qu'un apprenant ayant une compétence interculturelle sera capable d'interpréter et de mettre en relation des systèmes culturels différents, d'interpréter des variations socialement distinctives à l'intérieur d'un système culturel étranger, de gérer les dysfonctionnements et les résistances propres à la communication interculturelle.

À l'origine d'une prise de conscience interculturelle, CECRL et CARAP mettent la connaissance, la conscience et la compréhension des relations (ressemblances et différences distinctives entre "le monde d'où l'on vient » et «le monde de la communauté cible» (CECRL : 83). Il faut également souligner que la prise de conscience interculturelle inclut la conscience de la diversité régionale et sociale des deux mondes. Elle s'enrichit aussi de la conscience qu'il existe un plus grand éventail de cultures que celles véhiculées par la langue maternelle et la langue seconde de l'apprenant. Cela aide à les situer toutes les deux en contexte.

${ }^{157}$ Dans une rencontre interculturelle, le locuteur évolue au sein d'un espace où cohabitent et s'entrecroisent plusieurs cultures. Le locuteur interculturel devient à la fois conscient de sa propre identité et de celle de ses interlocuteurs. Il est en mesure d'accepter la réciprocité des regards. En ce sens, il est capable de vivre avec et dans la diversité culturelle. 
Enfin, dans le cadre de l'enseignement/apprentissage des langues-cultures étrangères, amener les apprenants à une prise de conscience interculturelle constitue un acte d'ordre cognitif. Cette organisation intellectuelle de la construction de la conscience interculturelle signifie que pour réussir la communication interculturelle, plutôt que d'acquérir des comportements culturels étrangers, il importe que les apprenants apprennent à savoir discerner/discriminer les ressemblances/convergences et les différences/divergences entre la culture étrangère et la culture maternelle et à savoir s'en servir pour une meilleure communication/interaction.

Nous avons montré que le développement de l'ouverture aux autres est devenu la composante stratégique de la maintenance ou la production de la communication. Cela concerne toutes les matières enseignées y compris le français de la diplomatie ou celui des relations internationales.

Il semble bien clair que de nos jours la situation sur le marché international a complètement changé. En raison de la mondialisation des échanges, des transferts davantage réciproques et de nouveaux pays dominant l'économie mondiale, ${ }^{158}$ les entreprises ont des frontières moins nettes que c'était le cas dans le passé. Le cours de langue relatif aux relations internationales est alors censé s'y adapter. La notion de " compétences interculturelles » a pu faire progresser la réflexion relative aux attitudes requises pour éviter l'ethnocentrisme et développer l'écoute du partenaire dans les relations internationales et diplomatiques. La prise de la conscience interculturelle semble alors un prérequis indispensable à la réussite des affaires internationales ${ }^{159}$ ainsi que les négociations diplomatiques. La capacité à comprendre les situations interculturelles et la capacité à s'y « adapter » pour aboutir à certains résultats espérés constitue le noyau de la communication.

En outre, il semble que toute relation internationale ou diplomatique nécessite une connaissance des manières de penser et de la culture du partenaire. Cela concerne aussi bien des relations à long terme qu'une série de relations marchandes. Il faut

${ }^{158}$ L'Asie, qui représentait 5,8 \% des entreprises multinationales dans les années 1990, en représente aujourd'hui $21,2 \%$. Vingt-six entreprises multinationales seulement avaient leur siège hors de l'Amérique du Nord, d'Europe et du Japon en 1988; en 2007, il y en a plus d'une centaine.

${ }^{159} \mathrm{Il}$ est intéressant de remarquer que parfois la démarche simplificatrice et globalisante constitue un vrai obstacle à l'approche de la diversité. Le manque de prise de conscience interculturelle a mené au fiasco plusieurs entreprises et diplomates. Par exemple, les cadres de Danone, entreprise implantée depuis longtemps en Chine, ont été incités à se familiariser avec la culture chinoise. Lalliance avec les Chinois se solde cependant par un échec, en 2009, dû à des maladresses juridiques du groupe Danone et à la cupidité effrénée du partenaire chinois. A aussi eu lieu l'affrontement de deux stratégies d'entreprises et de deux styles d'hommes (un ancien directeur financier diplômé de HEC et un patron de PME autodidacte).

Dans une revue de littérature sur les facteurs de réussite des partenariats internationaux, Moalla et Triki (Mayrhofer, 2001 :11) retiennent dix-huit facteurs principaux, au nombre desquels figurent la structure de gouvernance, la confiance entre les partenaires et la distance culturelle entre les entreprises représentées, la structure du capital, le nombre et l'expérience des partenaires, l'asymétrie de départ, etc. La moitié de ces facteurs peuvent être considérés comme étant de nature «culturelle». 
également souligner que les partenaires de la vie économique ou diplomatique occupent parfois des positions qui ne sont pas équivalentes ou symétriques ${ }^{160}$. De ce fait, être conscient de son propre bagage culturel ainsi que de celui du partenaire pourrait aider les diplomates, les partenaires économiques à trouver un accord, à trouver des solutions organisationnelles adaptées ou tout simplement à comprendre la deuxième partie.

Il en découle que le cours de français de la diplomatie doit développer la compétence interculturelle dont certains savoir-faire sont nécessaires pour établir une coopération durable. Il arrive que certaines cultures de métier ou certaines normes internationales ne suffisent pas à faire travailler ensemble des fonctionnaires issus de contextes culturels différents. En effet, si l'interculturel impliquait seulement des différences de normes, de codes et de valeurs dans l'interaction entre des personnes d'enracinement culturel différent, les difficultés de compréhension seraient relativement faciles à surmonter. Et pourtant, le rapport (décembre 2008) ${ }^{161}$ sur les métiers diplomatiques commandé par ministère des Affaires étrangères et réalisé par le laboratoire Georges-Friedmann dévoile qu'il y a aujourd'hui beaucoup de malentendus ${ }^{162}$. C'est probablement dû au fait que les cultures ne se développent pas dans des espaces aseptisés, elles sont actualisées dans un temps, un lieu marqué par l'histoire, l'économique et le politique (Abdallah-Pretceille, 1986 : 32). Elles s'inscrivent dans les hiérarchies qui caractérisent les sociétés humaines et dans les événements qui ont marqué la domination de certains peuples sur d'autres. En prendre conscience serait primordial pour de futurs fonctionnaires ou diplomates.

\subsubsection{Les approches plurielles - bilan}

Il est maintenant possible de dire que les approches plurielles sont un essai d'opérationnalisation des principes de l'approche plurilingue et pluriculturelle dans un contexte éducatif. Bien évidemment, les approches plurielles ont acquis au cours de la dernière décennie une place sans cesse croissante sur la scène didactique. Ce développement s'est accéléré pendant les dernières années et surtout avec la

${ }^{160}$ Notons que nous parlons ici de l'objet de controverses chez les sociologues. En effet, la notion de " pouvoir » est peu présente dans l'analyse des « compétences interculturelles ", alors qu'y sont plutôt développées des dimensions ayant trait à la bienveillance, à la transparence, à la confiance. Or, la notion de pouvoir permet de comprendre les jeux auxquels se livrent les partenaires, en utilisant stratégiquement leurs différences.

${ }^{161}$ Le rapport est disponible sur le site web du Ministère des Affaires étrangères ici : https:// www.diplomatie.gouv.fr/IMG/pdf/rapportfianl_sociologue.pdf.

${ }^{162}$ Ainsi, les relations interculturelles sont complexes et difficiles parce qu'elles réveillent le sentiment du "nous " par rapport à « eux ", mais aussi parce qu'elles peuvent raviver des blessures profondes, nées de l'oppression et des persécutions, qui se cicatrisent difficilement, car elles sont inscrites dans les identités collectives, transmises de génération en génération et toujours accompagnées d'une mobilisation émotionnelle puissante. 
publication du CARAP qui a joué un rôle déterminant pour la diffusion du concept d'approches plurielles.

Pour résumer, rappelons que l'éveil aux langues est basé sur le travail simultané avec plusieurs langues, souvent des langues moins connues, régionales ou des dialectes. Si ces langues sont moins présentes dans la réalité scolaire, elles peuvent être la langue du pays où le diplomate est accrédité. Le but de l'éveil aux langues est la sensibilisation des apprenants à la diversité linguistique, le développement de la réflexion linguistique ainsi que l'encouragement à apprendre des langues. Quant à l'approche intercompréhensive, elle précise le travail parallèle sur plusieurs langues parentes. Cela vise avant tout le développement des compétences réceptives des apprenants. Par contre, la didactique intégrée des langues a pour objectif d'aider l'apprenant à établir des liens entre un nombre limité de langues enseignées dans son cursus scolaire, en prenant appui sur sa langue maternelle pour l'acquisition des autres langues. Selon cette approche, l'apprenant prend appui sur le connu pour aborder le moins connu, et il utilise donc la langue de scolarisation pour aborder la première langue étrangère [etc.]. Finalement, il convient de mentionner l'approche interculturelle qui est particulièrement liée à la définition de l'interculturel et ouvre l'apprenant à tout ce qui est différent (Porcher, 1976 ; Conseil de l'Europe, 1983). L'approche interculturelle vise le développement de compétences communicationnelles basées sur l'acceptation, la compréhension de l'autre en tant que porteur d'une culture plus ou moins proche de sa propre culture.

Il s'ensuit de ce qui précède que ces approches s'inscrivent clairement dans la vision globale des langues dans l'éducation et des langues pour l'éducation promue par le Conseil de l'Europe. Enfin, il faut se rendre compte du fait que les approches plurielles qui développent l'analyse comparative et d'autres mécanismes envers l'apprentissage et l'enseignement des langues constituent à l'heure actuelle la base de l'éducation des langues. S'il s'agit de leur avenir, sans conteste, tout comme d'autres outils didactiques, les approches plurielles et le CARAP vont continuer à se construire par rapport à l'environnement et dans l'interaction avec l'environnement.

\subsection{Le Cadre de Référence pour les Approches Plurielles des Langues et des Cultures et l'enseignant de plurilinguisme}

Il faut dire que les auteurs du référentiel CARAP essayent de systématiser des approches didactiques qui tendent à développer la compétence plurilingue et pluriculturelle. Dans la perspective d'un déplacement du point de vue didactique vers des approches plurilingues et pluriculturelles, le rôle des enseignants de langues étrangères est déterminant. Michel Candelier souligne dans une interview donnée à Xavier Pascual Calvo que l'un des objectifs du référentiel est d'aider les enseignants : 
Les enseignants de langues vivantes peuvent avoir recours à ce référentiel pour : résoudre un "problème » lié à la pluralité culturelle et/ou linguistique, développer un projet touchant à la pluralité culturelle et/ou linguistique et pour analyser/comprendre une activité didactique concernant la pluralité culturelle ou linguistique (2011:3).

Il est clair qu'il serait impossible de suivre en classe tous les descripteurs du CARAP pour réaliser l'ensemble du " programme plurilingue ». Le référentiel reste néanmoins un appui pour l'enseignant, qui

l'aide à mieux percevoir ce qu'il/elle fait ou peut faire pour orienter davantage son enseignement vers le développement de compétences plurielles - que cette intention naisse de sa prise de conscience générale d'un écart entre sa pratique actuelle et ce qui lui parait souhaitable et possible [...] ou qu'elle émerge dans une situation qui demande en quelque sorte le recours à un tel référentiel ou à des activités relevant des approches plurielles (Candelier et alii, $2012: 37)^{163}$.

Cependant, malgré les efforts du Centre européen pour les langues vivantes à Gratz, le CARAP reste surtout connu en Suisse ${ }^{164}$. Dans un travail statistique d'ampleur, ${ }^{165}$ Dominique Montagne-Macaire montre que $89 \%$ des enseignants de langues étrangères interviewés ne sont pas conscients de l'existence du référentiel CARAP.

Par ailleurs, nous sommes d'accord avec Jolanta Sujecka-Zając et Maciej Smuk (2019:11) qu'il est beaucoup plus facile d'être enseignant d'une langue étrangère que d'être un enseignant-promoteur du plurilinguisme au sens où ce deuxième devrait changer de paradigme didactique et passer d'une approche singulière perçue comme synonyme de clarté, d'ordre et de certitude, vers une approche plurielle, perçue par ses adversaires comme synonyme d'incertitude, de risque et de dynamique mal domptée ${ }^{166}$. Certes, il serait idéal que l'enseignant puisse accompagner l'apprenant dans la construction du répertoire plurilingue et pluriculturel, cependant il est question d'un chemin que « l'enseignant n'a pas forcément parcouru lui-même et dont il ne connait pas non plus forcément le point d'arrivée » (Bigot, Vasseur dans Troncy, $2014: 285$ ).

${ }^{163}$ C'est nous qui le soulignons.

${ }^{164}$ Ces données sont accessibles ici : http://babylonia.ch/fileadmin/user_upload/ documents/2015-2/Baby2_15candelier_schroeder.pdf.

${ }^{165}$ Il s’agit ici des études menées par Dominique Montage-Macaire (2018:10) à l'Université de Bordeaux en 2013-2014 dans un groupe de 110 enseignants de langues étrangères travaillant dans des lycées bordelais.

${ }^{166}$ La critique du CARAP, Bruno Maurer, 2011, Enseignement des langues et construction européenne. Le plurilinguisme, nouvelle idéologie dominante, Paris, Éditions des Archives Contemporaines. 
Il est à souligner que même si les approches plurielles semblent révolutionnaires dans la didactique des langues étrangères, elles ne proposent pas un bouleversement des méthodes d'enseignement/apprentissage, mais essayent seulement de systématiser les approches existantes qui visent le développement des compétences plurielles et aussi sensibiliser les enseignants et les apprenants à la proximité des langues et des cultures. Ce développement des compétences plurielles est lié à la synergie qui existe entre les langues et cultures constituant l'identité de l'apprenant. Pendant que le CECRL décrit en détail la compétence plurilingue et pluriculturelle, le CARAP montre des propositions concrètes, des solutions didactiques permettant le développement des compétences plurielles lors du processus d'apprentissage.

Il semble alors que le recours aux approches plurielles puisse améliorer l'effectivité de l'enseignement. De ce fait, l'application de diverses approches - dont l'éveil aux langues, l'intercompréhension entre les langues parentes, la didactique intégrée des langues, l'approche interculturelle et, surtout, leur combinaison favorisent chez l'apprenant « l'acquisition du plurilinguisme» (Candelier, $2008: 73$ ).

\subsection{Le questionnement autour du Cadre de Référence pour les Approches Plurielles des Langues et des Cultures}

Le début des années 2000 marque un tournant historique dans la reconnaissance par l'Europe de la diversité linguistique longtemps ignorée, et pourtant originelle de son territoire. Le CARAP a mis en lumière ce qui était la réalité et notamment le fait que la société actuelle est marquée par le multiculturalisme, la mondialisation, la mixité et la mobilité. De ce fait, le référentiel a rejeté la sacro-sainte croyance selon laquelle il est bon de cloisonner l'enseignement des langues et de ne jamais faire de lien d'une langue à une autre.

Pourtant, comme tout autre ouvrage à visée scientifique, le CARAP est passé sous le feu des critiques. Nous sommes d'accord avec Gilles Forlot (2012: 70) que :

la didactique du plurilinguisme, autrement appelée approches plurielles des langues (Candelier 2005) ou éducation langagière globale (Coste 2008), $a$ sans conteste besoin d'être critiquée scientifiquement pour être affinée et surtout pour ne pas s'instituer comme doxa pédagogique dont les protagonistes principaux, apprenants et enseignants, ne comprendraient ni les tenants ni les aboutissants. ${ }^{167}$

Bien évidemment, la critique constructive mène à une amélioration significative, au développement et nous semble essentielle pour progresser. Ainsi, Bruno Maurer (2011: 31) avance l'hypothèse que si l'on continue à développer l'usage d'un instrument tel que le CARAP, il est probable que le temps consacré dans les

${ }^{167}$ C’est nous qui le soulignons. 
formations d'enseignants et dans la mise en œuvre en classe ne finisse par occuper l'essentiel des temps de formation et d'enseignement. Effectivement, Maurer touche ici un point délicat, et notamment la formation des enseignants à l'usage du CARAP qui est l'une des limites de ce référentiel constaté même par ses auteurs ${ }^{168}$. Nous nous rendons compte qu'un référentiel composé de 533 ressources est une machinerie très complexe et que cela pourrait décourager des enseignants. Les auteurs du CARAP recommandent vivement d'utiliser non pas les supports papier, mais les listes de descripteurs en ligne sur le site, qui permettent d'embrasser d'un seul coup d'œil les catégories globales (qui ont donc une fonction de repérage), avant « d'entrer » dans celle(s) qui correspond(ent) à ce qui est recherché. Nous croyons qu'il aurait été utile de préparer plus de séances, de séminaires pour des enseignants du monde entier voulant travailler avec le CARAP.

Un autre point important susceptible de donner lieu aux polémiques est le manque d'évaluation dans le CARAP. Il est vrai que l'évaluation qui n'est pas réduite à la vérification des savoirs ou à la pratique de la notation soutient l'apprentissage. Cependant, certains chercheurs en didactique soulignent la domination des certifications et des évaluations standardisées, dont le CECRL constitue à la fois le vecteur et le symptôme. En outre, Christian Puren (2013) qui expose depuis longtemps ses doutes vis-à-vis des travaux européens en didactique des langues critique l'idée utopiste du CARAP qui prévoit l'apprentissage tout au long de la vie ou hors l'école. Nous partageons ces craintes. En effet, il nous semble que l'on ne peut pas négliger les élèves de familles défavorisées qui n'auront pas la possibilité d'accès toute leur vie à ces supposés services éducatifs.

Dernièrement, Bruno Maurer et Christian Puren ont à nouveau critiqué169 le CARAP et sa "quête » d'une éducation plurilingue et pluriculturelle qui n’arrive pas à s'incarner face aux tensions, «pour ne pas dire la coupure idéologique que nous vivons, à l'ouest, au sud ou à l'est du puzzle européen ». Selon les auteurs, on a besoin aujourd'hui d'un réexamen de ce projet éducatif qui a «ignoré toutes les critiques formulées entre-temps ».

Pour résumer, ces réflexions et tous ces points de vue sont aussi bien légitimes que discutables. Rappelons à cette occasion Véronique Castellotti qui constate que la didactique des langues est une discipline discutable et évolutive qui ne se limite pas à « une technologie (réduite à un travail sur les moyens, les outils, ce que fait la méthodologie) et ne se conçoit pas comme une science, mais plutôt comme un humanisme " (2011 : 117). Il ne faut pas oublier que le CARAP est un référentiel en perpétuelle évolution qui s'est construit et continue à se construire par rapport à l'environnement et dans l'interaction avec l'environnement.

${ }^{168}$ Andrade, Candelier, De Carlo, Schröder-Sura : Quel cadre de référence pour la formation des enseignants aux approches plurielles des langues et des cultures ? 5-7 juillet, 2017, 7e Congrès International EDiLiC, Varsovie.

169 «CECR : par ici la sortie ! " de Bruno Maurer et Christian Puren. Éditions des Archives Contemporaines, Paris, 2019, disponible en libre accès sur : https://eac.ac/books/9782813003522 


\subsection{Pour faire le point}

Ce chapitre a mis en lumière le développement et l'évolution de la perspective plurielle dans la didactique des langues. Nous avons vu que l'Europe (singulière au passé) a réagi aux changements géopolitiques et sociaux en promouvant le plurilinguisme. En effet, le plurilinguisme des nations, des régions, des institutions et des individus en Europe constitue un emblème identitaire, une composante essentielle de la culture qu'il fallait maintenir. L'une des principales conséquences de ces changements en Europe dans le domaine de la didactique des langues étrangères était la prise de conscience de l'importance de la compétence plurilingue et pluriculturelle. L'image complète de cette compétence ainsi que son opérationnalisation ont été exposées dans un Cadre de Référence pour les Approches Plurielles des Langues et des Cultures (CARAP).

D’autre part, ce chapitre a montré en quoi le référentiel CARAP, qui représente un instrument important dans l'éducation - constitue un outil nécessaire à la mise en place de politiques linguistiques éducatives répondant à des finalités promues par le Conseil de l'Europe. L'examen didactique du CARAP, de ses ressources, ses compétences ainsi que les quatre approches (l'éveil aux langues, l'approche intercompréhensive, la didactique intégrée des langues et l'approche interculturelle) a révélé plusieurs qualités majeures qui devraient convaincre les enseignants, formateurs d'enseignants et responsables éducatifs de l'utiliser en classe. Ainsi, nous avons montré que le CARAP joue, sur le plan épistémologique, le même rôle pour la didactique du plurilinguisme que le CECRL pour la didactique des langues étrangères ${ }^{170}$.

${ }^{170}$ Le CECRL est un document politique (de 2001 et de 2018) statuant de la politique linguistique. Il convient cependant de souligner que le CECRL n'a jamais été un document didactique - ce nétait pas le but de sa publication. Le CECRL met en œuvre les principes du Conseil de l'Europe en matière de politique linguistique apparues au début du XXIe siècle, à savoir : assurer la cohérence de la politique linguistique au niveau européen. Quant à la compétence plurilingue et pluriculturelle, la version du CECRL de 2001 mentionne ce concept de manière uniquement théorique (en omettant son opérationnalisation). Cependant, dans le volume complémentaire de 2018, 3 nouveaux descripteurs apparaissent, qui sont décrits sur une échelle de Pré-A1 à C2 :

o exploiter un répertoire plurilingue

o exploiter un répertoire pluriculturel

o compréhension plurilingue

Le CARAP publié par le du Centre Européen des Langues Vivantes à Graz est un document didactique, opérationnalisant le concept de la compétence plurilingue apparu en 2001 au CECRL. Le CARAP opérationnalise la didactique du plurilinguisme, montre comment développer des ressources de descripteurs de connaissances / compétences / attitudes.

Il est important de souligner que ce ne sont pas des documents contradictoires. Ils ont une construction commune et un éditeur commun le Conseil de l'Europe. Le CARAP complète le CECRL 2001 et le volume complémentaire du CECRL de 2018 renvoie les lecteurs au CARAP.

Finalement, il convient de dire que le rang de ces deux documents pour les chercheurs est équivalent. En revanche, le rang empirique et applicable de ces deux documents n'est pas 
Enfin, nous avons vu que les approches plurielles, qui développent l'analyse comparative et d'autres mécanismes envers l'apprentissage/l'enseignement des langues, constituent également une très bonne base de l'éducation des langues sur objectif spécifique. Nous avons repéré, tout au long de ce chapitre, des exemples dans lesquels nous avons montré l'utilité du référentiel CARAP en cours de français de la diplomatie. Personne ne s'imagine que le groupe de futurs fonctionnaires de l'UE ne soit pas sensibilisé à la diversité langagière et culturelle. La construction d'une compétence plurilingue et interculturelle permet de gérer la communication linguistique et culturelle en contexte d'altérité et de construire ou élargir un répertoire linguistique et culturel pluriel. Cela nous semble primordial dans l'éducation de futurs diplomates.

comparable. La version du CECRL de 2001 a été traduite en 40 langues tandis que le CARAP l'a été en 8 langues. 


\section{Chapitre 4}

\section{Choix méthodologique pour la recherche empirique}

\section{Remarques liminaires}

Dans le chapitre précédent, nous avons analysé les concepts théoriques des approches plurielles et leur mise en pratique en vue de développer la compétence plurilingue et pluriculturelle. Nous avons stipulé que les quatre approches plurielles : l'éveil aux langues, l'approche intercompréhensive, la didactique intégrée des langues et l'approche interculturelle pourraient être incluses au cours de français de la diplomatie.

En outre, nous avons souligné que la compétence plurilingue et interculturelle, développée au travers des approches plurielles, permet de gérer la communication linguistique et culturelle en contexte d'altérité et de construire ou élargir le répertoire linguistique et culturel pluriel. Ceci nous semble primordial dans l'éducation des diplomates.

Finalement, le chapitre 3 a mis en lumière la portée didactique du Cadre de Référence pour les Approches Plurielles des Langues et des Cultures (CARAP). Nous avons également observé que les approches plurielles qui développent une analyse comparative et d'autres mécanismes pour l'apprentissage/l'enseignement des langues, constituent une très bonne base pour l'éducation des langues sur objectifs spécifiques.

Lobjectif du présent chapitre est de présenter en détail la problématique de notre recherche empirique. Les questions de la recherche seront présentées en fonction de notre intérêt pour le sujet du français de la diplomatie. Nous allons poursuivre notre recherche sur le développement de la compétence plurilingue et pluriculturelle à travers l'examen des méthodes qualitatives ainsi que les techniques de recueil des données qui conviennent le mieux au sujet de notre étude. Finalement, on décrira 
le lieu d'intervention et le public auprès duquel nous avons réalisé nos observations. Cela nous permettra de clore la partie de choix méthodologiques pour la recherche empirique.

\subsection{La recherche en éducation}

Le premier but de la recherche est la mise en doute, la contestation du sens commun, du bon sens, des théories et des manières de penser prônées par la majorité ou par les autorités. Il s'agit surtout de la contribution que les chercheurs espèrent apporter à un champ de recherche, de la transgression des savoirs admis.

La recherche qui nous occupe et que nous décrirons dans ce chapitre est celle en éducation et plus particulièrement celle qui est en rapport avec l'étude de l'enseignement en classe. Il n'est pas anodin de mentionner que la recherche en éducation est un domaine d'activité relativement jeune qui s'est surtout développé et intensifié dans les années 1960 et 1970. Les chercheurs en éducation ont longtemps donné l'impression que la recherche se limitait au modèle expérimental ou quasi-expérimental. On parlait de la recherche sur l'éducation, à propos de l'éducation et non pas de la recherche pour l'éducation. Il a fallu attendre les années 1990 pour que le milieu de la recherche en éducation comble ce retard et tire un plus grand profit de ses liens avec le monde des praticiens, au moment où leurs parcours respectifs commencent à s'entrecroiser. Cette convergence entre la recherche et la pratique se produit au moment où les sciences de l'éducation prennent leur place dans la communauté universitaire.

De surcroit, dans la recherche en éducation, aussi bien que dans toutes les sciences humaines, les facteurs qui interviennent et qui forment l'essence de l'étude sont plutôt des significations attribuées, les intentions postulées, les interprétations projetées sur les comportements et sur les événements perçus. Nous sommes d'accord avec JeanMarie De Ketele (2004:7) que :

la recherche en sciences humaines ne peut pas se contenter d'observer de l'extérieur la conduite des acteurs, car elle perdrait ce qui fait le propre du sujet humain : la réflexivité dans un système d'échanges symboliques.

Il en résulte que le chercheur seul ne peut rien. En tant qu'organisateur de sens, le chercheur n'est souvent, et en réalité, que l'interprète, le traducteur des significations dont les premiers auteurs sont les acteurs du terrain, dans notre cas- les apprenants.

Les réflexions sur la recherche en éducation nous mènent à nous poser la question de la place qu'occupe aujourd'hui la didactique des langues étrangères (DLE) au sein 
d'autres sciences. Avant d'entrer dans le vif du sujet, nous allons nous demander dans quel domaine s'inscrivent actuellement les langues étrangères. Il nous semble nécessaire d'expliquer ici notre vision de ce domaine puisque cela aura un impact sur la façon dont on considère la méthodologie de nos recherches didactiques.

Tout d'abord, rappelons que les travaux de la DLE sont centrés sur la construction du savoir dans le processus de l'enseignement/apprentissage des langues secondes et sur tous les effets qui l'accompagnent. La didactique des langues a pour objet l'étude des conditions et des modalités d'enseignement et d'appropriation ${ }^{171}$ des langues en milieu non naturel. Son objet, l'enseignement, est conçu comme le guidage des apprenants dans leur acte d'appropriation linguistico-culturel. Néanmoins, et dans la mesure où la frontière entre les situations dites en milieu naturel et les situations dites en milieu non naturel n'est pas bien définie, certains aspects de la recherche en acquisition concernent soit la didactique des langues, soit la linguistique, ou plus précisément la psycholinguistique.

Comme le remarque Weronika Wilczyńska (2010 : 19), cela signifie que l’objectif des chercheurs en DLE serait le développement et la systématisation des informations qui décrivent ou expliquent les phénomènes en question. Les données et les résultats qui en résultent ne peuvent pas prétendre à un savoir sûr, inchangeable, universel. Afin de mieux comprendre la spécificité du domaine qui entretient les proximités avec plusieurs disciplines, nous proposons la typologie des domaines de sciences suivants ${ }^{172}$.

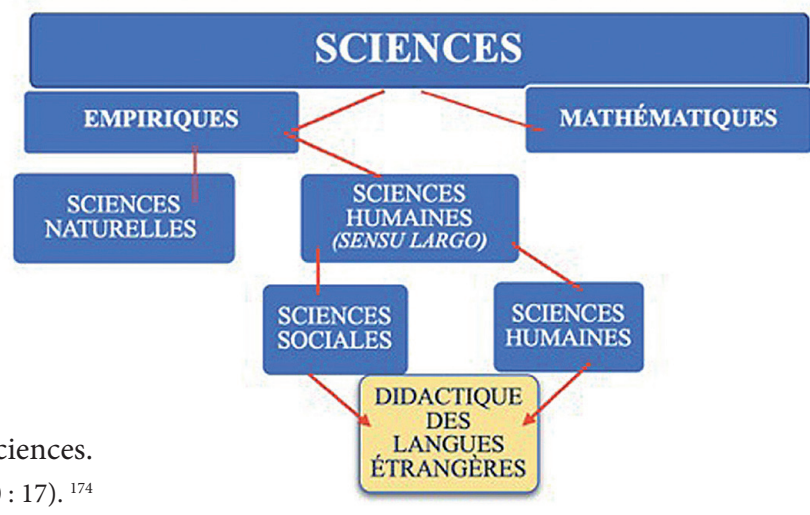

Figure 16. La classification des sciences. Source : à partir de Wilczyńska (2010 : 17). ${ }^{174}$

171 «[...] sont concernées par l’étude des modalités d'enseignement toutes les connaissances diachroniques et synchroniques qui peuvent être établies sur les conditions, les méthodologies et les techniques de guidage. Sont concernées par l'étude des modalités d’appropriation toutes les connaissances qui peuvent être établies sur les conditions, les méthodologies et les techniques d'appropriation sous guidage (apprentissage)»(Cuq, Gruca, $2005: 53$, auteurs soulignent.).

172 „Nauki: empiryczne, matematyczne (formalne)/ Empiryczne: przyrodnicze i humanistyczne (sensu largo)/ Humanistyczne (sens largo) : humanistyczne i społeczne/ humanistyczne i społeczne : Glottodydaktyka", notre traduction.

${ }^{173}$ Notre traduction. 
Il s'ensuit de ce qui précède que la DLE est un domaine empirique, ce qui signifie que nous pouvons l'observer dans la vie réelle, même si certains de ses aspects peuvent être moins visibles. N'oublions pas que le centre de l'étude de la DLE reste l'être humain et ses actions dans un domaine en question. Finalement, il faut dire que la DLE se trouve à la charnière des sciences sociales et des sciences humaines.

\subsection{L'objet de la recherche}

Depuis quelques années, nous voyons la multiplication du nombre d'articles, de publications et de conférences qui portent sur le plurilinguisme. La pluralité des langues est de plus en plus perçue comme une donnée essentielle à la compréhension de l'Homme. En conséquence, la recherche sur le plurilinguisme et ses modalités connait un fort développement. Cependant, il est intéressant de noter que des travaux récents sur le plurilinguisme dans l'enseignement se focalisent, d'une part, sur les représentions sociales ${ }^{174}$ du plurilinguisme et d'autre part, sur l'enseignement bilingue dans des écoles ${ }^{175}$. Ces études s'appuient essentiellement sur les projets du Conseil d'Europe ${ }^{176}$ ainsi que des études du Centre européen pour les langues vivantes à Graz en Autriche.

En gardant les deux grands axes de recherche et les travaux du Conseil d'Europe à l'esprit, nous nous proposons de réfléchir, dans l'optique du plurilinguisme, sur des concepts qui en découlent et des manières de leur opérationnalisation en lien avec Un Cadre de Référence pour les Approches Plurielles des Langues et des Cultures (CARAP, 2007) coordonné par Michel Candelier. Notre objectif est de combler des lacunes dans l'état des connaissances sur le sujet du plurilinguisme et plus particulièrement sur la présence de la compétence plurilingue et pluriculturelle dans la formation des diplomates.

La formation linguistique des diplomates est un sujet peu connu et pas approfondi dans la littérature académique. Il existe des cours pour enseigner le français de la diplomatie ${ }^{177}$ et des relations internationales, mais, à notre connaissance, il n’y a pas

${ }^{174}$ Il s’agit ici surtout des travaux menés par l'équipe de Véronique Castellotti au département de sociolinguistique et didactique des langues (SODILANG) à l'Université de Tours en France.

${ }^{175}$ Nous faisons ici référence aux études mentionnées dans les chapitres précédents, surtout celles menées en Suisse, au Canada, à Barcelone et dans le Val d’Aoste.

${ }^{176}$ Le Conseil de l'Europe mène ses activités de promotion du plurilinguisme, de la diversité linguistique et de l'apprentissage des langues dans le domaine de léducation dans le cadre de la Convention culturelle européenne (1954) ratifiée par 49 états.

${ }^{177}$ Nous nous sommes intéressés au sujet du français de la diplomatie quand nous avons commencé à faire partie de l'équipe d'enseignants travaillant au Collège d'Europe à Natolin (Pologne) en 2009. 
d'études qui approfondiraient le sujet du français de la diplomatie dans un contexte plurilingue. Néanmoins, il nous semble que l'émergence de la notion de " compétence plurilingue et pluriculturelle », et l'augmentation de sa valeur d'échange sur le marché du travail, invitent à repenser profondément les cadres d'analyse et à réfléchir à de nouveaux enjeux pour la formation des spécialistes. Le communiqué général des Assises européennes du plurilinguisme ${ }^{178}$ souligne le paradoxe suivant :

Si le besoin d'une langue internationale dans la vie des affaires ne saurait être contesté, ce besoin, de nombreuses enquêtes le confirment, est loin de se limiter à l'anglais. D'autres langues internationales existent et ont une réelle portée économique. Les langues locales et les « langues du voisin » ont elles aussi leur portée économique et ne peuvent être ignorées de la vie professionnelle.

Il est vrai que la diversité est actuellement à l'ordre du jour, et plurilinguisme n'est plus un concept abstrait, mais la réalité de l'Europe multiculturelle. Cela concerne tous les domaines de nos vies, y compris l'éducation ainsi que la formation des diplomates. Dans le cas des diplomates, nous nous focalisons sur leurs besoins linguistiques, en oubliant les enjeux interculturels accompagnant ce métier. En effet, la préparation des diplomates au dialogue interculturel, l'élaboration des schémas d'orientations culturelles, la nécessité d'abandonner la position dominante, un jugement dépréciatif d'autres cultures ou le besoin de diplomates ouverts à l'autre sont des questions qui, selon nous, devraient être discutées ou prises en compte avant l'élaboration du cours de langue de la diplomatie.

Ces sujets nous ont motivés pour définir de nouveaux problèmes et aborder de nouvelles questions traitant le Cadre de Référence pour les Approches Plurielles des Langues et des Cultures.

Dans les études du domaine, il existe plusieurs définitions du problème de recherche. Tadeusz Pilch et Teresa Bauman (2010 : 43) le définissent comme des questions qui concernent la nature de l'objet étudié comme l'essence des liaisons entre les événements. Autrement dit, « il s'agit de se rendre compte des difficultés qui résultent de l'explication et de la compréhension d'un fragment donné de la réalité ou encore la déclaration de notre manque de savoir exprimé sous forme d'une question " (Pilch et Bauman, $2010: 43)^{179}$.

Une autre définition est proposée par Stefan Nowak (1970:214) selon lequel, «le problème de recherche n'est qu'une question ou des questions auxquelles les réponses

${ }^{178}$ Le communiqué complet est accessible ici : https:/www.observatoireplurilinguisme.eu/images/ Evenements/4emes_Assises/Communiqué_final_complet_en.pdf.

179 „Chodzi o uświadomienie sobie trudności wynikającej z wyjaśnienia i zrozumienia danego wycinka rzeczywistości, to mówiąc jeszcze inaczej deklaracja naszej niewiedzy zawarta w gramatycznej formie pytania", notre traduction. 
devraient être fournies par une étude approfondie ${ }^{180}$. Cependant, il convient de souligner que cela ne veut pas dire que chaque question est un problème de recherche. Les méthodologues (Bauman (2010); Nowak (1970) ; Łobocki (2007)) constatent unanimement que l'on devrait en exclure toutes les questions auxquelles des réponses toutes prêtes pourraient être immédiatement données par d'autres personnes.

Compte tenu de cela, les problèmes de recherche devraient être compris comme des questions auxquelles les réponses sont fournies par un chercheur dans ses études détaillées. En outre, une question de recherche doit être "réalisable ", c'est-à-dire que les moyens pour y répondre devraient être à la disposition du chercheur. Cela concerne le nombre de sujets à inclure dans un cadre adéquat, mais aussi l'expertise indispensable, ainsi que le temps nécessaire à sa réalisation. Enfin, il faut pouvoir diriger le projet de recherche que la question de recherche sous-tend. Elle doit également susciter l'intérêt du chercheur. Cette caractéristique est importante car un projet peut parfois être étalé dans le temps. La réponse à la question de recherche devrait ainsi confirmer ou réfuter des résultats déjà connus, ou bien apporter des informations complémentaires, voire apporter des résultats tout à fait nouveaux. Finalement, n'oublions pas qu'une question de recherche devrait être originale, innovante.

Notre expérience didactique nous a menés à formuler des questions d'ordre général :

1. Quelles sont les représentations des étudiants sur le rôle de la compétence plurilingue/pluriculturelle dans le travail de futurs diplomates?

2. Comment développer la compétence plurilingue et pluriculturelle en classe de FOS pour les futurs diplomates?

Les deux questions ci-dessus sont celles qui ont orienté notre recherche.

De plus, elles nous ont aidés à trouver deux grands axes qui se croisent dans notre travail :

$\Rightarrow$ La nécessité du développement de la compétence plurilingue/pluriculturelle dans une classe de français de la diplomatie.

$\Rightarrow$ Le Cadre de Référence pour les Approches Plurielles des Langues et des Cultures (CARAP) comme support au développement de la compétence plurilingue et pluriculturelle.

Ces sujets ne se situent pas au même niveau d'analyse : le premier nous rapproche de la compétence plurilingue et pluriculturelle; il définit et limite l'objet de la recherche. Le second lance de nouveaux défis à la didactique des langues de spécialité qui vont se poser lors de la mise en œuvre des techniques et des méthodes du CARAP en classe de français de la diplomatie.

${ }^{180}$ „Problem badawczy to tyle, co pewne pytanie lub zespół pytań, na które odpowiedzi ma dostarczyć badanie”, notre traduction. 
Ensuite, nous avons concrétisé notre recherche et nous avons formulé des questions sous-jacentes ou des questions supplémentaires qui dérivent de nos questions centrales :

- Est-ce que selon les étudiants du cours de français de la diplomatie la compétence plurilingue/pluriculturelle est importante? Dans quelle mesure?

- Est-ce que les méthodes qui résultent des principes du plurilinguisme influencent la réflexivité des apprenants du français de la diplomatie envers les autres langues/ cultures? Si oui, comment et dans quelle mesure?

- Est-ce que le travail avec le Portfolio change la perspective plurilinguel pluriculturelle des apprenants du français de la diplomatie? Si oui, comment et dans quelle mesure?

- Est-ce que les méthodes et les techniques du CARAP réalisent les principes du plurilinguisme? Si oui, lesquelles en particulier?

Le tableau ci-dessous résume toutes les questions de recherche :

Tableau 10. Les questions de recherche.

\begin{tabular}{|l|c|}
\hline \multicolumn{1}{|c|}{$\begin{array}{c}\text { Question } \\
\text { centrale }\end{array}$} & $\begin{array}{c}\text { Quelles sont les représentations des étudiants sur le rôle de la compétence } \\
\text { plurilingue/pluriculturelle dans le travail de futurs diplomates? }\end{array}$ \\
\hline $\begin{array}{l}\text { Questions } \\
\text { sous- } \\
\text { jacentes }\end{array}$ & $\begin{array}{l}\text { - Est-ce que selon les étudiants du cours de français de la diplomatie la } \\
\text { compétence plurilingue/pluriculturelle est importante? Dans quelle mesure? } \\
\text { Est-ce que les méthodes qui résultent des principes du plurilinguisme influencent } \\
\text { la réflexivité des apprenants du français de la diplomatie envers les autres } \\
\text { langues/cultures? Si oui, comment et dans quelle mesure? }\end{array}$ \\
\hline $\begin{array}{c}\text { Question } \\
\text { centrale }\end{array}$ & $\begin{array}{c}\text { Comment développer la compétence plurilingue et pluriculturelle } \\
\text { en classe de FOS pour les futurs diplomates? }\end{array}$ \\
\hline $\begin{array}{l}\text { Questions } \\
\text { sous- } \\
\text { jacentes }\end{array}$ & $\begin{array}{l}\text { Est-ce que le travail avec le Portfolio change la perspective plurilingue/ } \\
\text { pluriculturelle des apprenants du français de la diplomatie? Si oui, comment et } \\
\text { dans quelle mesure? } \\
\text { Est-ce que les méthodes et les techniques du CARAP réalisent les principes du } \\
\text { plurilinguisme? Si oui, lesquelles en particulier? }\end{array}$ \\
\hline
\end{tabular}

Pour résumer, nous voulons vérifier s'il faut développer la compétence plurilingue et pluriculturelle dans une classe de français de la diplomatie et si oui, comment la développer. La réponse à cette question pourrait permettre de profiter de la richesse du CARAP ainsi que de contribuer à l'élaboration de nouvelles stratégies d'apprentissage dans un contexte professionnel, notamment en classe du français de la diplomatie. 


\subsection{Choix de la posture épistémologique}

La recherche en didactique des langues étrangères s'inscrit dans des finalités de connaissance qui répondent aussi et peut-être avant tout à des demandes sociales. Au-delà de la simple appréciation utilitariste au sens économique, au-delà des motivations et de l'efficacité de l'enseignement/apprentissage des langues, l'humanité a donné aux langues des fonctions multiples et variables : celles qui accompagnent la construction de l'individu et celles qui permettent l'organisation de la vie collective dans les sociétés. La manière dont nous concevons la société détermine le choix méthodologique que nous faisons lors de notre recherche. La centration sur l'apprenant (depuis l'approche communicative) semble être l'idéal didactique, car elle met au cœur de toutes les démarches la personne de l'apprenant dans sa dimension à la fois cognitive, sociale et affective. Cela a orienté notre recherche vers un paradigme interprétatif.

« Ce que finalement je m'approprie, c'est une proposition du monde ; celle-ci n'est pas derrière le texte, comme le serait une intention cachée, mais devant lui, comme ce que l'œuvre déploie, découvre, révèle. Dès lors, comprendre, c'est se comprendre devant le texte ».

(Paul Ricœur, 1986 : 116 dans Blanchet et Chardenet, 2011 : 118)

Le choix du paradigme ${ }^{181}$ est étroitement lié à l'objet de la recherche. Le paradigme interprétatif se caractérise par la volonté de mettre à jour les perspectives de sens qu'une personne ou qu'un groupe de personnes confère à son expérience. Les évènements sociaux diffèrent des évènements physiques. De ce fait, ils doivent être étudiés d'une façon différente.

La recherche interprétative ${ }^{182}$, qui traite de la présence des compétences réflexives plurilingues dans la formation auprès des étudiants du français de la diplomatie que

${ }^{181}$ En épistémologie, la notion de paradigme a été utilisée pour la première fois par Thomas Kuhn, un physicien converti à l'épistémologie des sciences. Selon lui, «la science ne se développe pas par accumulation de découvertes et d'inventions individuelles» (Khun 1983 : 18). Car toute science évolue par une succession de paradigmes incommensurables. Ces paradigmes sont des "découvertes scientifiques universellement reconnues qui, pour un temps, fournissent à une communauté de chercheurs des problèmes types et des solutions" (ibid. :19). Benoît Gauthier donne une définition un peu plus précise en écrivant qu'il s'agit d'un « ensemble de règles implicites ou explicites orientant la recherche scientifique, pour un certain temps, en fournissant, sur la base de connaissances universellement reconnues, des façons de poser les problèmes, d'effectuer les recherches et de trouver des solutions» (Gauthier dans de Ketele, $2004: 321$ ).

${ }^{182}$ Pendant longtemps, il était difficile de publier les résultats de recherches interprétatives sauf, peut-être, quand elles étaient l'œuvre de chercheurs reconnus. Ce n'est que lors des vingt dernières années que l'intérêt pour le qualitatif s'est fortement accru. Pierre Bourdieu (1982: 35 dans Soulé, 2007) remarque que « historiquement, l'approche interprétative sous forme de narration constitue la plus vieille forme de recherche utilisée pour trouver une explication aux phénomènes. Nous refusons alors d'accepter l'opinion selon laquelle la recherche qualitative adopte un devis méthodologique faible ou inférieur ». 
nous menons ici, met l'accent sur l'interprétation des faits observés, sur l'interaction empathique entre le chercheur et l'objet d'étude et sur le processus qui est reparti sur deux semestres.

Qui plus est, ce type de recherche traite parfaitement l'information quantifiable et possède une utilité et une pertinence qui lui est propre pour faire avancer le domaine de l'éducation (Wiersma, Jurs, 2009 : 21). La recherche interprétative se présente donc comme un choix logique, servant à étudier la réalité profondément interactive qui prévaut au sein même de l'objet de recherche. Elle permet de mieux comprendre les phénomènes étudiés, de voir comment les enquêtés vivent les choses et quelles sont leurs opinions et leurs visions individuelles.

Il est vrai que la nature et le contexte de l'approche interprétative tissent un lien étroit avec le paradigme qui, comme nous l'avons déjà mentionné, place l'apprenant au centre de toute action. En outre, s'inscrire dans un paradigme interprétatif permet au chercheur de dévoiler, d'analyser et finalement de mieux comprendre les effets des changements adoptés en classe de français de la diplomatie, de la perspective de l'apprenant et aussi du chercheur. Celui-ci est finalement à l'intérieur de la recherche, en profondeur, sur le terrain.

Pour résumer, nous synthétisons ci-dessous les caractéristiques du paradigme interprétatif et les principes qui le diffère du paradigme positiviste.

Tableau 11. De la position épistémologique à l’instrument de saisie des données.

\begin{tabular}{|l|l|}
\hline \multicolumn{2}{|c|}{ Position épistémologique } \\
\hline \multicolumn{1}{|c|}{ Positiviste } & \multicolumn{1}{c|}{ Interprétative } \\
\hline - faits observables & - phénomènes interprétables \\
- explication & - compréhension \\
- décontextualisation & - transférabilité184 \\
- objectivité du chercheur & - contextualisation \\
- implication du chercheur
\end{tabular}

Source : à partir de Wilczyńska, (2010 : 65)

${ }^{183}$ En recherche interprétative, comme nous l’avons mentionné, on évoquera principalement les paramètres de crédibilité (ang. trustworthiness), de transférabilité, et de fiabilité. 
(la continuation du tableau 11)

\begin{tabular}{|c|c|}
\hline \multicolumn{2}{|c|}{ Méthodes ou stratégies de recherche } \\
\hline $\begin{array}{l}\text { - expérimentale } \\
\text { - quasi-expérimentale }\end{array}$ & $\begin{array}{l}\text { - herméneutique } \\
\text { - approche critique } \\
\text { - recherche-action }\end{array}$ \\
\hline \multicolumn{2}{|c|}{ Les instruments de saisie et d’analyse des données ${ }^{185}$} \\
\hline $\begin{array}{l}\text { - questionnaires } \\
\text { - modèles mathématiques } \\
\text { - statistiques } \\
\text { - graphiques }\end{array}$ & $\begin{array}{l}\text { - observation participante } \\
\text { - journal de bord } \\
\text { - questionnaire } \\
\text { - histoires de vie } \\
\text { - recherche documentaire } \\
\text { - entretien } \\
\text { - groupe de discussion } \\
\text { - analyse de discours }\end{array}$ \\
\hline \multicolumn{2}{|c|}{ Mots clés } \\
\hline $\begin{array}{l}\text { - probabilité } \\
\text { - risque } \\
\text { - prédictif } \\
\text { - contrôle } \\
\text { - statistiques } \\
\text { - réplication } \\
\text { - objectiviste } \\
\text { - taille } \\
\text { - corrélations }\end{array}$ & $\begin{array}{l}\text { - complexité } \\
\text { - contexte } \\
\text { - signification } \\
\text { - perception } \\
\text { - compréhension } \\
\text { - subjectiviste } \\
\text { - profondeur } \\
\text { - ouvert } \\
\text { - dynamique }\end{array}$ \\
\hline
\end{tabular}

Source : basé sur Savoie-Zajc (2001: 17).

On peut voir ci-dessus une hiérarchie méthodologique qui prend racine dans la posture épistémologique du chercheur. Elle se concrétise ensuite par le choix d'instruments de saisie et d'analyse des données, en passant par celui de méthodes, c'est-à-dire de stratégies de recherche visant à mettre au jour des données crédibles au regard de l'objet de recherche. Nous analyserons dans ce qui suit des outils et des techniques utilisés dans le recueil des données.

${ }^{184}$ Lorraine Savoie-Zajc (2001 : 18) remarque que : «Les instruments de saisie de données peuvent être utilisés de façon complémentaire par l'une ou l'autre approche à condition que cette utilisation soit assujettie aux visées fondamentales de la recherche, c'est-à-dire à la position épistémologique du chercheur ». 


\subsection{Le choix de l'approche méthodologique}

La méthode de recherche est une procédure définie qui est utilisée en vue de développer la connaissance scientifique des phénomènes humains (Łobocki, 2007 : 27). En outre, Jean-Marie De Ketele (2004 : 10) constate que :

La méthodologie est une discipline qui s'établit elle-même comme objet d'observation, d'analyse, de réflexion et de contestation. La méthodologie ne reste pas un code stable, elle est sujette à des remaniements. Comme le droit évolue en fonction des changements sociaux, la méthodologie évolue en fonction des objets et des pratiques dominantes de recherche. Il n'y a pas et ne pourra jamais y avoir une unité méthodologique au sens où une seule méthode de recherche pourrait suffire pour codifier les règles utilisées dans les différents enjeux de la recherche ${ }^{185}$.

Différents types de recherche interpellent diverses méthodologies qui doivent varier et s'adapter. Il importe que nous précisions que notre recherche sera basée sur l'approche qualitative qui s'inscrit dans le paradigme interprétatif ${ }^{186}$ dont nous avons parlé plus haut.

Le choix de cette orientation méthodologique est dicté par le fait que l'approche qualitative aide à bien interpréter l'individualité des postures et des représentations, y compris des apprenants ou des enseignants (Wilczyńska 2010 : 133). Dans le cadre de la DLE, ce type d'approche nous permettra de reconsidérer, de remettre en question les données collectées. Cela facilitera aussi de saisir la diversité des significations qui peuvent être liées au phénomène étudié ainsi que d'approfondir certains aspects d'un sujet pour obtenir des informations sur les motivations et les raisonnements. L'orientation qualitative a fait émerger de nouvelles et précieuses pistes de recherche à différentes variantes, interprétables à plusieurs manières, lesquelles auraient été difficilement décelables avec d'autres méthodes de recueil comme les méthodes quantitatives. Qui plus est, le chercheur et la réalité de l'étude sont ici liés en se conditionnant mutuellement. Le chercheur accepte l'élément de la subjectivité dans son étude et essaie de le contrôler. Enfin, les recherches qualitatives se caractérisent par une gamme de techniques à caractère ouvert dont nous parlerons plus tard.

${ }^{185}$ C'est nous qui le soulignons.

186 «La recherche qualitative/interprétative épouse le paradigme interprétatif, en particulier l'approche naturaliste, en tentant de comprendre les phénomènes à létude à partir des significations que les acteurs de la recherche leur donnent dans leur milieu naturel (Denzin et Lincoln cité par Savoie-Zajc, 2000). De Ketele (2004:18) stipule que « le but des méthodes interprétatives n'est pas de faire une reproduction exacte du monde ou du phénomène étudié, mais d’offrir un portrait du monde étudié ». 


\subsubsection{Les critères en recherche qualitative}

Avant de procéder aux techniques de saisie et d'analyse des données, il nous semble nécessaire d'exposer ici les critères ${ }^{187}$ de notre recherche. Devant cet état de fait, les chercheurs anglo-saxons ont développé un ensemble de grilles et critères qui devraient permettre d'établir les «standards » de qualité d'une recherche qualitative. Nous nous limiterons ici aux critères qui nous semblent les plus importants et notamment :

Tableau 12. Critères en recherche qualitative.

\begin{tabular}{|l|l|}
\hline $\begin{array}{l}\text { Crédibilité } \\
\text { (ang.credibility) }\end{array}$ & $\begin{array}{l}\text { vérifie la similitude entre le sens véhiculé par le sujet et le sens dégagé } \\
\text { par le chercheur, notamment dans la collecte, l'analyse et l'interprétation } \\
\text { des données. }\end{array}$ \\
\hline $\begin{array}{l}\text { Transférabilité } \\
\text { (ang.transferability) }\end{array}$ & $\begin{array}{l}\text { vise à déterminer si les conclusions d'une recherche peuvent avoir un } \\
\text { sens dans un autre contexte que celui étudié. }\end{array}$ \\
\hline $\begin{array}{l}\text { Fiabilité } \\
\text { (ang.reliability) }\end{array}$ & $\begin{array}{l}\text { vise à démontrer la transparence du chercheur et, par le fait même, } \\
\text { l'indépendance de ses interprétations par rapport à ses biais. }\end{array}$ \\
\hline $\begin{array}{l}\text { Validité } \\
\text { (ang.validity) }\end{array}$ & $\begin{array}{l}\text { cherche à fournir un degré d'assurance que les résultats de la recherche } \\
\text { nont pas été influencés, par exemple, par la personnalité du chercheur, } \\
\text { les instruments utilisés ou les conditions de collecte de données. }\end{array}$ \\
\hline
\end{tabular}

Source : à partir de Savoie-Zajc, (2011 : 21) et Wilczyńska, Michońska-Stadnik (2010 : 140).

Enfin, il faut dire que ces quatre critères (crédibilité, transférabilité, fiabilité et constance interne) constituent le point de départ de la recherche qualitative et visent à soutenir sa rigueur méthodologique. Cela est très important puisque beaucoup de chercheurs (par exemple De Ketele (2004), Wilczyńska et Michońska-Stadnik (2010)) affirment que toute recherche interprétative doit d'abord respecter les critères de base de la recherche scientifique. Bien qu'il existe des protocoles bien établis en recherche, il n'empêche que le jugement du chercheur est primordial en recherche interprétative et que la charge de la preuve de rigueur lui revient ultimement. Afin d'atteindre ces objectifs, à chaque étape de notre recherche, nous nous demanderons si nos actions retiennent les critères de rigueurs qui lui sont propres.

${ }^{187}$ C’est dans le contexte du renouveau du paradigme interprétatif des années 1950 qu’ont commencé à émerger des critères de scientificité propres aux méthodes qualitatives (Laperrière, 1997). Le milieu du XXe siècle a marqué une période pendant laquelle les tenants du paradigme interprétatif cherchaient à redéfinir les critères de validité du positivisme conventionnel dans le but de tenir compte des caractéristiques particulières de la recherche interprétative. En effet, le but positiviste de chercher à neutraliser la subjectivité dans la recherche nétait pas pertinent à la recherche interprétative justement parce que celle-ci adhère à une position selon laquelle la connaissance est subjective puisqu’elle est liée au vécu du sujet (Guba et Lincoln, 2005). 


\subsubsection{Recherche qualitative : méthode recherche-action}

Comme nous l'avons mentionné plus haut, notre recherche est basée sur l'approche qualitative et s'inscrit dans le paradigme interprétatif. De ce fait, dans notre étude, nous aurons recours à la méthode recherche-action.

\section{- Le concept de la méthode recherche-action}

L'objectif principal de la recherche-action ${ }^{188}$ est de fournir un cadre aux pratiques qualitatives effectuées par les enseignants (praticiens) ${ }^{189}$ en situations complexes de classe. Cette méthode remet directement en question la dissociation que l'on remarque habituellement entre la théorie et la pratique puisqu'en recherche-action, la théorie supporte l'action ou encore émerge de l'action (Stringer, $2014: 35$ ). La théorie permet ainsi de comprendre et d'agir sur les problèmes réels que l'on rencontre concrètement sur le terrain. Cette méthode contribue à faciliter l'identification d'un problème ou l'émergence d'une question frappante et à apporter la solution par la mise en place de stratégies qui visent l'amélioration d'une situation insatisfaisante pour tous les participants de l'étude (Wilczyńska et Michońska-Stadnik 2010 : 151).

En outre, la recherche-action permet à l'enseignant d'apprendre à identifier ses besoins tout en restant en contact avec son terrain d'action (la classe). Pour Soulé (2007), l'implication du chercheur dans la recherche-action est une donnée de départ. Qu'il le veuille ou non, le chercheur est impliqué dans la recherche aux niveaux psychoactif, historico-existentiel et structuro-professionnel. Sa recherche commence par la reconnaissance de cette implication. La recherche-action provoque la réflexion personnelle et le dynamisme de l'étude menée. De ce fait, elle aide à sortir de l'enseignement statique qui consiste à renouveler une même stratégie sans parvenir à améliorer les résultats d'apprentissage (Montagne-Macaire, 2007 : 110). Elle permet également une meilleure prise de conscience de l'impact des interventions en classe, l'évolution des pratiques, etc.

Comme le remarque John Elliott (1991 cité par Michèle Catroux, 2002 : 14) :

La recherche-action représente un champ grandissant de la recherche éducative dont le but primordial est la reconnaissance des demandes des enseignants pour passer de l'étape de la réflexion organisée à la pratique de classe. La recherche-action est un processus destiné à doter tous les participants de la scène éducative, qu'il s'agisse des étudiants, des enseignants ou d'autres intervenants, des moyens d'améliorer leurs

188 "L'expression „recherche-action” est apparue il y a déjà plus de quarante ans sous la plume de Kurt Lewin (...). Parmi les travaux des psychosociologues nord-américains et britanniques, beaucoup ont repris, au cours des années quarante et cinquante, l'expression forgée par Lewin, pour le désigner. Si l'on en juge à sa seule fréquence d'utilisation, le succès de cette notion a fléchi ensuite, sans doute parce que beaucoup d'interventions subordonnaient une visée de recherche à lélaboration d'une méthodologie de changement » (Dubost et Lévy, 1984: 5).

${ }^{189}$ Lacteur principal de cette recherche peut être décrit sous les termes de accompagnantchercheur, chercheur-accompagnateur, ou praticien-chercheur; il devient, en anglais, Action Researcher ou, plus simplement, teacher-researcher, ou bien encore reflective practitioner. 
pratiques grâce à leurs expériences éclairées et nourries des savoirs théoriques en cours. Tous les participants deviennent acteurs consentants du processus de recherche.

En outre, il est intéressant de noter que la recherche-action suit un schéma cyclique ${ }^{190}$. Elle se présente comme une spirale de cycles de recherche de structure identique. Chacun débute par une observation de ce qui se passe sur le terrain. La réflexion qui suit permet de déterminer un plan d'action. Ce plan est mis en œuvre, ses effets analysés, puis altérés si nécessaire, et le cycle reprend en séquences similaires.

Des séquences ont été présentées sur le diagramme ci-dessous :

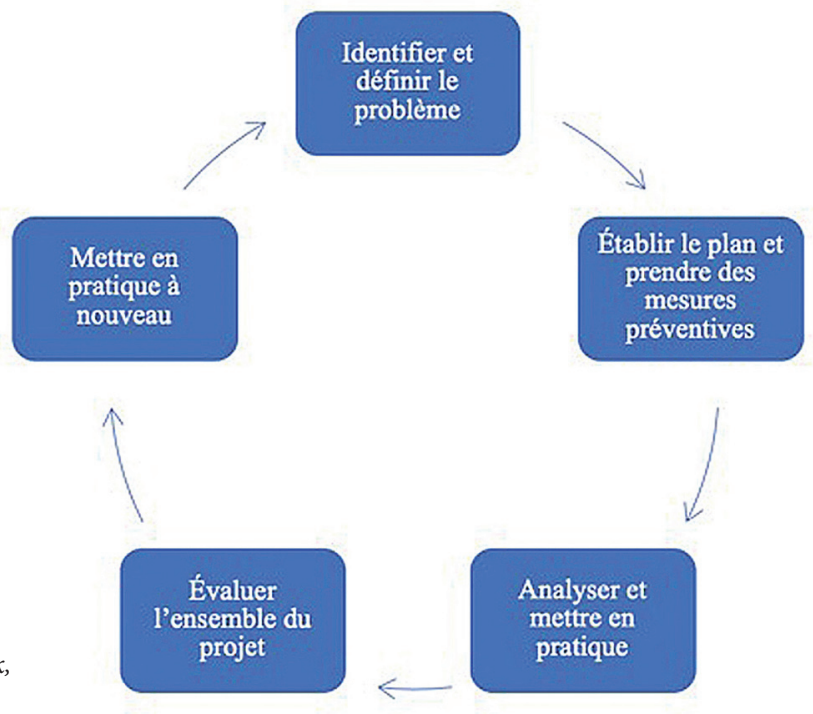

Figure 17. Schème des actions innovantes de l'enseignant dans la recherche-action.

Source: Wilczyńska, Michońska-Stadnik, $2010: 151$

nsemble du projet
Analyser et

metre en pratique

${ }^{190}$ La recherche-action se caractérise par un fonctionnement cyclique (ang. the action research spiral), selon le terme de Kemmis et Mc Taggart (1988), un fonctionnement en boucles. Les chercheurs théoriciens de la recherche-action à la suite de Kurt Lewin ont compté ces périodes. Certains s'accordent pour en considérer cinq, une phase diagnostique, une phase de planification, une phase de participation à une action, une phase de recul évaluatif et une phase de synthèse structuration. D’autres ont réduit le nombre de phases, tout en conservant la dynamique.

«Le processus de recherche-action s'installe par exemple lors de trois moments principaux que présente Stringer en ces termes:

Look - building a picture and gathering information. When evaluating we define and describe the problem to be investigated and the context in which it is set. We also describe what all the participants (educators, group members, managers etc.) have been doing.

Think - interpreting and explaining. When evaluating we analyse and interpret the situation. We reflect on what participants have been doing. We look at areas of success and any deficiencies, issues or problems.

Act - resolving issues and problems. In evaluation we judge the worth, effectiveness, appropriateness, and outcomes of those activities. We act to formulate solutions to any problems. (Stringer, 1999: 18; 43-44; 160)» Macaire, 2011, disponible sur: https://hal. archives-ouvertes.fr/hal-00580541/document. 
La figure ci-dessus montre cinq phases, inhérentes à chaque cycle de la rechercheaction.

Tout d'abord, un problème est identifié et des données sont rassemblées afin d'établir un diagnostic plus détaillé. Ceci est suivi par la formulation d'hypothèses désignant plusieurs solutions possibles, desquelles découle un plan unique d'action qui est ensuite mis en œuvre. On procède ensuite à la collecte et à l'analyse de données relatives aux résultats de l'intervention. Les conclusions sont interprétées à la lumière du succès ou de l'insuccès de l'opération. À ce stade, le problème est réévalué et un nouveau cycle peut commencer. Des cycles successifs sont répétés jusqu'à ce que le problème soit résolu.

\section{- Recherche-action dans notre étude}

Comme le but principal de notre recherche était de vérifier si selon les étudiants il faut développer la compétence plurilingue et pluriculturelle dans une classe de français de la diplomatie en profitant à la fois de la richesse du CARAP, la méthode recherche-action nous a semblé la plus adéquate. Malgré la critique ${ }^{191}$, cette orientation méthodologique permet de résoudre des problèmes concrets dans des situations authentiques. Dans la situation éducative, elle nécessite la participation et l'application active de l'enseignant et des apprenants. De ce fait, le praticien-chercheur se trouve inclus dans le processus à part égale avec les autres participants. L’enseignant monte des actions, mobilise les potentiels existants et résout des problèmes qu'il rencontre en classe. En outre, cette démarche permet de produire des informations de manière à répondre aux enjeux, même si les données existantes sont déficientes. Elle profite ici de l'expérience et la pratique de l'enseignant praticien. La recherche-action permet de mieux comprendre certains problèmes et, simultanément, de trouver des réponses plus rapides sur le terrain. C'est l'un des moyens dont dispose le système éducatif pour augmenter son efficacité et atteindre les objectifs qui lui sont fixés.

Vérifier à quel point de futurs diplomates ont besoin de travailler sur la compétence plurilingue et pluriculturelle était dicté par un besoin réel, rencontré lors de notre travail quotidien. Lobjectif était alors de résoudre un problème visible, aussi bien pour l'enseignant que pour les apprenants. De plus, puisqu'aucune recherche ou étude ne montrait l'usage du potentiel du CARAP en classe de FLE (encore moins en classe de

${ }^{191}$ La recherche-action est questionnée dans ses visées, ses résultats et ses effets. Elle est fréquemment considérée comme simple instrumentalisation pragmatique et ne jouit pas d'un statut très favorable dans le monde universitaire. Comme le remarque Dominique Macaire (2007 : 94) : "On lui concède même parfois celui de parent pauvre de la recherche. La variété des courants qui la traversent, les multiples formes qu'elle prend, les nombreuses sciences qui s'en sont emparées ont certes contribué au flou qui règne sur la notion. Sa méthodologie, considérée comme intuitive, menée par les praticiens, et peu construite, ne la sert guère dans un contexte de recherche „à la française", soucieux de précision, de cartésianisme et d'apports quantitatifs. En outre, comme le relève Hugues Bazin (Bazin, 2003), il n'existe pas de validation en recherche-action, même s'il existe des validations d'acquis par la recherche-action. Bref, la recherche-action ne jouit pas d'une réputation de scientificité très solide [...]. Elle est victime d'un déficit de clarification ». 
FOS), il nous semblait essentiel de nous pencher sur ce sujet qui, au vu notre pratique, nous intéressait particulièrement.

Pour résumer, l'approche recherche-action nous a permis de répondre à la question qui nous intéressait et ensuite de changer la méthode de l'enseignement du français de la diplomatie dans l'institution où nous travaillons. Puisque notre recherche était étalée dans le temps, cette méthode nous a tout d'abord donné la possibilité de porter un regard critique sur nos pratiques de classe et, après une réflexion approfondie et l'observation des dysfonctionnements, de mettre en place des stratégies correctrices.

\section{Étapes principales de la recherche}

\section{$\Rightarrow$ Identification et la définition du problème}

La première phase de notre démarche a commencé par l'identification du problème. La pratique pédagogique liée aux leçons données aux futurs diplomates ${ }^{192}$ ainsi que les observations de cours donnés au même public par d'autres enseignants ont dévoilé le besoin de développer chez ces apprenants la compétence plurilingue et pluriculturelle qui les aiderait dans leur futur travail de diplomate. Durant notre travail de professeur de français, nous avons remarqué que les apprenants ${ }^{193} \mathrm{du}$ cours de français de la diplomatie se focalisaient surtout sur la compétence linguistique. En effet, les apprenants percevaient ce cours comme un cours qui se réduit à l'apprentissage d'un vocabulaire de spécialité ${ }^{194}$.

De plus, l'analyse des matériaux pédagogiques dédiés au français des affaires et de la diplomatie nous a montré que certaines questions et problèmes pourraient inspirer les formateurs dans leur préparation du cours. Sur la base de nos observations et notre diagnostique ${ }^{195}$, nous avons émis l'hypothèse selon laquelle il fallait proposer

${ }^{192}$ Il s'agit du cours de français de la diplomatie au niveau B1 et B2 que nous donnons au Collège d'Europe (campus Natolin) depuis 2009 jusqu'à maintenant. Les cours ont lieu deux fois par semaine ; chaque leçon dure 90 minutes. Notre expérience ainsi que nos observations nous ont amenés à la constatation que le cours de français de la diplomatie qui fait partie des cours de langue « sur objectifs spécifiques » ne semble pas consacrer de place à un travail sur la compétence interculturelle et plurilingue/pluriculturelle.

${ }^{193}$ Voir à ce sujet la section 4.5

${ }^{194}$ Les résultats des enquêtes menées au Collège d'Europe à Bruges et à Natolin en 2012-2013 pour notre mémoire du Master 2 « Représentations du français de la diplomatie » de 2013, dirigé par Véronique Castellotti au département de sociolinguistique et didactique des langues (SODILANG) à 'Université François Rabelais à Tours, France. Le mémoire est disponible ici : https://dynadiv. univ-tours.fr/version-francaise/formations/masters-recherche/memoires-recemment-soutenus

${ }^{195}$ Ces observations proviennent de notre pratique pédagogique (plus que 10 ans d’expérience dans l'enseignement du français de la diplomatie) et de celle des enseignants travaillant au Collège d'Europe (campus Natolin et Bruges). En effet, depuis plusieurs années nous interrogeons les apprenants du cours de français de la diplomatie sur leurs représentations de ce type de cours. Nos 
un nouveau programme qui traiterait en profondeur des questions du plurilinguisme et de l'interculturalité.

\section{$\Rightarrow$ Établir le plan et prendre des mesures préventives}

Nous étions d'avis que les données recueillies durant notre pratique pédagogique avaient une valeur significative. C'est pourquoi nous nous sommes décidée à recourir à envisager des actions visant une amélioration des cours de français de la diplomatie. L'objectif était d'introduire des changements au niveau de la planification des leçons ainsi que de perfectionner les techniques et compétences de l'enseignant ${ }^{196}$. Cette phase de planification de la recherche est cruciale. En effet, plus l'enseignant a de possibilités pour anticiper sur l'action, plus il peut inclure de détails dans le plan. À ce stade, nous avons défini notre recherche.

Afin de pouvoir conduire nos recherches, nous avons, premièrement, dû obtenir l'accord auprès de la direction de l'établissement (le Collège d'Europe à Natolin) où nous avions l'intention de réaliser notre étude. En second lieu, une esquisse de recherche a été présentée aux collègues du département ${ }^{197}$. Ensemble, nous avons discuté du but de l'étude, du thème général, de la date, de la durée approximative etc. Les mêmes informations ont été ensuite présentées aux étudiants.

Deuxièmement, nous avons dû collecter, et souvent concevoir nous-mêmes des ressources didactiques qui nous ont servi à mener la recherche :

- Portfolio Européen des Langues adapté aux besoins du public professionnel ;

- Un pré-test et un post-test rédigé en anglais.

- 20 scénarios pédagogiques du français de la diplomatie qui ont pris en compte le développement de la compétence plurilingue et pluriculturelle selon les principes du CARAP ;

- Des sessions d'évaluation (des questions liées aux cours)

- un ordinateur, un dictaphone, un tableau blanc interactif.

observations, nos réflexions ainsi que celles fournies par d'autres praticiens nous ont permis de noter un caractère répétitif des idées des apprenants sur le français de la diplomatie. Les professeurs nous signalaient également le manque de dialogue et de réflexion sur la diversité des langues et des cultures parmi les apprenants du Collège d'Europe. Du point de vue des enseignants et du nôtre, l'unilinguisme favorise le conservatisme.

${ }^{196} \mathrm{La}$ recherche-action fournit aussi une réponse à la formation des enseignants. Hugon et Seibel (1988 : 10) précisent que : "Ainsi, les recherches-actions constitueraient une réponse originale aux besoins de formation continuée des travailleurs de l'éducation, qu'ils soient enseignants du premier ou du second degré, formateurs de maîtres ou encore chercheurs professionnels ».

${ }^{197}$ Gabriel Goyette et Michelle Lessard-Hébert (1987 : 40) de l'Université du Québec appellent cette procédure l'enquête feed-back. Ils remarquent également que la communication avec les gens $\mathrm{du}$ milieu a une fonction essentielle à la fois pour la recherche (confronter, discuter, clarifier) et pour l'action (comprendre une situation, se sensibiliser à différentes hypothèses de changement, élaborer des recommandations, décider, amorcer un processus de changement). 
Finalement, et conformément à la directive 95/46/CE, nous avons informé tous les participants de l'étude de leurs droits en matière de données personnelles ${ }^{198}$.

\section{$\Rightarrow$ Analyser et mettre en pratique}

En dépit de toutes les précautions que l'on a pu prendre au début du processus, il ne faut pas négliger le fait que même les plans les mieux établis nécessitent des modifications au fur et à mesure de la recherche. Tandis que l'information est collectée, des schémas commencent à apparaître, et des changements doivent être apportés en cours de route. La mise en place de procédures d'analyse des données s'est donc avérée indispensable.

Pendant tout le temps de la recherche, c'est-à-dire de septembre 2017 jusqu'à avril 2018, nous avons réalisé un plan envisageant les éléments suivants :

a) le programme d'enseignement a été basé sur des supports authentiques (des photos, des textes littéraires, des extraits d'une émission de radio, des articles de presse etc.) qui ont été adaptés aux besoins du public ;

b) Chaque scénario pédagogique envisageait d'utiliser des ressources du descripteur savoir-faire du CARAP, de telle sorte que la compétence plurilingue et pluriculturelle soit développée ;

c) Toutes les 6-7 leçons, nous organisions une session d'évaluation. Nous demandions aux apprenants de répondre à une ou deux questions de réflexion aux cours précédents

Il s'est avéré important de prendre le temps d'examiner en détail les données au fur et à mesure de leur collecte. En analysant les feuilles évaluatives remplies par nos apprenants, il nous est arrivé de modifier le scénario du prochain cours. À ce stade, analyse et réflexion sont nécessaires de manière à évaluer les effets des actions menées et d'y apporter des actions correctives.

\section{$\Rightarrow$ Évaluation des effets de l'action}

À la fin de la phase d'action, vient le moment de notre évaluation. Les questions ci-dessous nous ont permis d'orienter cette évaluation.

$\Rightarrow$ Quels changements ai-je observés?

$\Rightarrow$ Quel effet ce changement a-t-il exercé sur les étudiants?

$\Rightarrow$ Qu'ai-je appris à propos de mes étudiants ? À propos de l'apprentissage ? À propos de la matière enseignée?

$\Rightarrow$ Ce changement devrait-il désormais faire partie de ma pratique régulière?

L'objectif de l'évaluation était de définir si le cours de français de la diplomatie, fondé sur certaines ressources du descripteur savoir-faire du CARAP, développe la compétence plurilingue et pluriculturelle. Des détails ainsi que les résultats de cette étude ont été présentés dans le chapitre 5 de cet ouvrage.

${ }^{198}$ Les données personnelles sont confidentielles. La confidentialité des données est restreinte aux responsables de l'étude. 


\subsubsection{L'étude en groupe d'étudiants}

Dans le cadre de la recherche-action que nous avons menée au Collège d'Europe à Natolin, nous avons réalisé une étude sur un groupe d'étudiants participant au cours de français de la diplomatie. L'objectif était d'observer de potentiels changements qui s'effectueraient dans une cette classe exposée au phénomène dont les effets sont étudiés. Cette démarche est l'une des plus populaires et des plus efficaces dans les études de didactique des langues étrangères et sa valeur reste très élevée au regard des autres méthodes qualitatives (Wilczyńska et Michońska-Stadnik, 2010 : 156).

Remarquons que ce type de recherche visant un groupe d'étudiants est unique et sera à chaque fois différent, puisqu'il est impossible de répéter l'étude de manière identique, et ce même dans des conditions qui pourraient être comparables. Il n'en reste pas moins vrai que les résultats obtenus dans le cadre de l'étude en groupe montrent seulement des tendances qui apparaissent dans un groupe donné. Cela est dû au fait qu'il nous est impossible d'identifier et de contrôler tous les éléments ${ }^{199}$ qui pourraient influencer les résultats obtenus.

\subsubsection{Pré-test et post-test}

Dans la perspective de notre recherche sur le groupe d'étudiants du cours de français de la diplomatie, il serait tout aussi important de préparer les outils qui nous permettraient de définir le niveau de départ du groupe ainsi que de vérifier d'éventuels changements.

Avant de procéder à notre intervention pédagogique, nous avons proposé aux apprenants de répondre à un questionnaire écrit en guise de pré-test. Cet outil nous

${ }^{199}$ Campbell et Stanley (dans Babbie 2007 : 51-55) ont recensé des éléments qui pourraient avoir de l'influence sur létude en groupe d'apprenants :

- Histoire - l'impact des évènements spécifiques qui ont eu lieu pendant l'étude ;

- Devenir mature - il s'agit surtout des changements qui ont lieu pendant un temps donné ;

- Participation à une étude - la seule participation à une étude pourrait influencer la façon de penser et les comportements des sujets ;

- Techniques de recueil de données - si nous utilisons des techniques différentes, elles peuvent avoir influence sur notre variable ;

- Régression statistique - c'est la tendance à augmenter des résultats très bas après le post-test et baisser les résultats très élevés après le pré-test ;

- Formation du groupe -des fautes, résultats de mauvais choix des sujets participant à létude en groupes parallèles ;

- Absence - l'absence des sujets participant à une étude ;

- Imitation - le danger qui existe quand deux groupes peuvent se contacter et échanger des informations entre eux;

- Récompense - le groupe de contrôle peut avoir l'impression qu'il est moins important que le groupe expérimental. Ce sentiment peut changer le comportement des sujets participant à l’étude;

- La rivalité entre les groupes ;

- Le découragement des participants de létude. 
a servi à cerner le développement de la conscience plurilingue et pluriculturelle des étudiants avant la réalisation des activités pédagogiques. À la fin de l'année, nous avons à nouveau procédé à la vérification de la variable dépendante. Le questionnaire post-test était identique en tous points à celui présenté en pré-test et les conditions d'évaluation étaient les mêmes. Le pré-test et le post-test peuvent être présentés sous la forme du schéma suivant :

Tableau 13. Pré-test et post-test en groupe détudiants du français de la diplomatie.

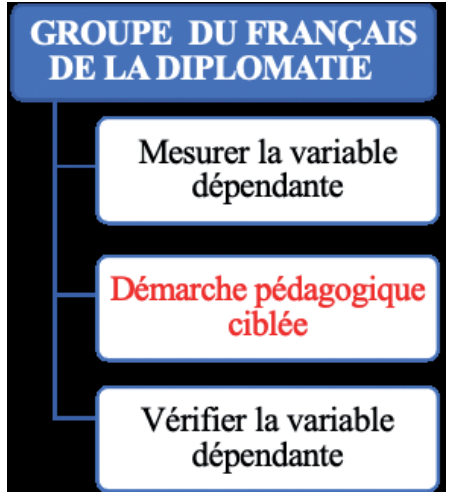

Source: élaboration propre basée sur Babbie (2007 : 248).

En conclusion de cette sous-partie, il serait encore nécessaire de mentionner que le pré-test, qui sert à faire démarrer l'étude et qui cherche à mesurer la variable, peut influencer les comportements des personnes participant à l'étude. L'application d'un pré-test peut, en effet, rendre le groupe plus sensible à l'influence de la variable expérimentale. De ce fait, les résultats obtenus sur ce groupe ne peuvent être généralisés à des sujets n'ayant pas passé le pré-test. Sans prétendre à l'omnipotence de l'étude en classe, nous avons donc complété nos données par d'autres techniques telles que le Portfolio européen des langues, l'observation et le questionnaire.

\subsubsection{Techniques de collecte de données}

Selon la définition donnée par Tadeusz Pilch et Teresa Bauman $\left(2001: 85^{200}\right)$ «les techniques de collecte de données sont des activités pratiques régulées par des directives méticuleuses qui permettent d'obtenir des informations, des faits, des opinions qui peuvent être idéalement vérifiées ». Pour Jean-Marc Mangiante et Chantal Parpette (2004: 46), la collecte des données « conduit l'enseignant à sortir de son cadre habituel de travail pour entrer en contact avec un milieu qu'il ne

200 „Są to czynności praktyczne, regulowane starannie wypracowanymi dyrektywami, pozwalającymi na uzyskanie optymalnie sprawdzalnych informacji, opinii, faktów”, notre traduction. 
connait pas, a priori, et auquel il doit expliquer ses objectifs et le sens de sa démarche pour obtenir les informations dont il a besoin ». Cette implication de l'enseignant porte également sur les aspects techniques et matériels de la collecte des données. Les savoir-faire que demande ce travail ne sont pas habituels pour des enseignants qui utilisent souvent des outils déjà construits comme des manuels de FLE ou des ressources disponibles sur la toile.

De ce qui précède, nous pouvons voir que la collecte de données n'est pas une activité facile pour un chercheur qui est avant tout un enseignant. Pour obtenir des données analysables et exploitables, l'enseignant devrait connaître et savoir utiliser des techniques de collecte de données qualitatives. Nous décrirons dans ce qui suit : le Portfolio européen des langues, l'observation et le questionnaire que nous avons utilisés dans notre étude de recherche-action.

\subsection{Portfolio européen des langues}

Étant donné le caractère et la spécificité de notre sujet d'étude ainsi que les questions de recherche que nous nous sommes posés, l'un des outils nécessaires qui documente le développement des compétences plurilingue et pluriculturelle utilisés dans notre étude est le Portfolio européen des langues (désormais PEL).

Tout d'abord, il convient de mentionner que les premiers PEL ont été élaborés au milieu des années 1990 en Suisse, en Allemagne et en France afin de prouver la faisabilité de ce type d'outil. De 1998 jusqu'à 2000, plusieurs projets expérimentaux de PEL ont été conduits dans plus de 15 États membres du Conseil de l'Europe et ceux-ci ont apporté des informations précieuses. En 2001, le Portfolio a été lancé dans toute l'Europe. Aujourd'hui, le PEL est utilisé dans de nombreux établissements et auprès de publics variés. Actuellement, les concepteurs du PEL disposent d'une grande marge de manœuvre pour adapter leurs modèles aux besoins et traditions relatifs à des contextes spécifiques. En d'autres termes, le PEL n'est pas un instrument unique, mais une grande famille d'instruments plus ou moins semblables et élaborés à partir d'un ensemble de principes directeurs.

Dans notre étude de recherche-action, le PEL joue un rôle double. D’un côté, il est un outil pédagogique ${ }^{201}$, de l'autre, un instrument de collecte de données.

${ }^{201}$ Il n'est pas anodin de mentionner que le Portfolio peut déclencher et soutenir des changements. En effet, l'expérimentation du PEL a montré que, dans certains contextes, le Portfolio agit comme un catalyseur en ce qu'il accélère les changements imminents dans la classe de langue, dans la conception des programmes et dans l'évaluation. En outre, le projet ELP - WSU du CELV a permis de démontrer que lorsque le Portfolio est utilisé au niveau de l'établissement scolaire pour soutenir l'apprentissage de toutes les langues secondes et étrangères enseignées dans le curriculum et pour stimuler la réflexion sur la langue de scolarisation et d'autres langues enseignées ou présentes au sein de l'établissement, il contribue dans une très large mesure à la réalisation des 


\section{- Buts et principes dominants du Portfolio européen des langues}

Selon les principes et lignes directrices publiés par le Comité de l'éducation du Conseil de l'Europe, le projet du PEL vise à :

- «approfondir la compréhension mutuelle entre citoyens en Europe ;

- respecter la diversité des cultures et des modes de vie ;

- protéger et encourager la diversité linguistique et culturelle ;

- favoriser le développement du plurilinguisme tout au long de la vie ;

- contribuer au développement personnel de l'apprenant en langues ;

- contribuer au développement de la capacité d'apprentissage autonome des langues $»^{202}$.

Il faut admettre que les aspects mentionnés ci-dessus sont cruciaux pour atteindre l'objectif de notre recherche, et notamment le développement de la compétence plurilingue et pluriculturelle en classe de FOS. En effet, le PEL est un instrument complémentaire au CECRL et il peut servir d'outil pour la mise en œuvre de plusieurs des principes développés tout au long du CECRL ainsi que du CARAP. Le Portfolio que nous avons élaboré est adapté aux besoins professionnels de notre public et nous permettra de mieux suivre le niveau de développement des compétences étudiées.

\section{- Création du Portfolio européen des langues au service des objectifs professionnels}

Tout d'abord, il convient de dire que les auteurs des premiers Portfolios se sont inspirés mutuellement de leurs travaux. Puisqu'il est évident qu'un seul modèle de PEL ne pourrait pas répondre aux besoins de tous les usagers dans des situations toutes différentes ${ }^{203}$, il est conseillé de le construire sur les fondations des Portfolios existants. Il s'agit de reprendre ou d'adapter les modèles disponibles ou de créer des éléments en fonction des buts des formateurs.

principaux objectifs poursuivis en matière déducation des langues dans le cadre du projet Langues dans l'éducation/Langues pour l'éducation.

${ }^{202}$ Le document est accessible ici : https://rm.coe.int/1680459f99.

${ }^{203}$ Raisons en faveur de versions différentes du Portfolio (source : http://culture.coe.int/ portfolio):

- L'âge des apprenants : de toute évidence, il s'agit là de la raison principale. Des Portfolios adaptés à l'âge tiendront compte du développement personnel et intellectuel ainsi que du changement de la situation et des besoins des apprenants au fur et à mesure qu'ils grandissent ;

- Groupes spécifiques : une orientation spécifique en éducation ou des caractéristiques sociales particulières peuvent inviter à l'élaboration de Portfolios plus adaptés. Sinon, il risque d'être impossible de toucher ces groupes avec le PEL tel quel (des apprenants handicapés, par exemple, ou des apprenants ayant des besoins professionnels d'apprentissage, ou des apprenants peu scolarisés, ou des spécialistes comme les traducteurs, etc.) ;

- Traditions et milieux différents : pour une meilleure acceptation du PEL dans un environnement donné, il faudra respecter les préférences du milieu en termes esthétiques et de présentation ainsi que ses traditions culturelles et éducatives. 
Afin d'élaborer de manière correcte une nouvelle version du Portfolio, il faut étudier avec soin les relations verticales (et horizontales) avec les Portfolios existants ou prévus ${ }^{204}$. La condition minimale à remplir pour chaque PEL est celle d'un certain degré de transférabilité ; bien que différent, il doit être reconnaissable, acceptable et approprié dans d'autres environnements. Nous avons adapté notre Portfolio en nous basant sur le PEL consacré aux adultes.

Le but était de concevoir un document qui répondrait aux besoins particuliers de nos apprenants suivant un cours de FOS et qui s'inscrirait dans notre démarche pédagogique. De ce fait, la première section de la Biographie langagière est intitulée "Moi et les langues étrangères/langues à visée professionnelle dans ma vie » et contient des éléments qui font référence aux objectifs professionnels.

Le diagramme ci-dessous nous servira d'exemple et nous permettra de comprendre le caractère professionnel de notre Portfolio.

- J’ai appris des langues à visée professionnelle:

\begin{tabular}{|c|c|c|c|}
\hline Langues & $\begin{array}{c}\text { Apprentissages } \\
\text { commencés en }\end{array}$ & $\begin{array}{c}\text { Lieux (école, auto- } \\
\text { apprentissage, stage...) }\end{array}$ & Horaire/semaine \\
\hline & $\ldots \ldots \ldots \ldots \ldots \ldots \ldots \ldots \ldots \ldots . \ldots . \ldots \ldots \ldots \ldots \ldots \ldots \ldots$ & & \\
\hline
\end{tabular}

- En dehors des cours de langue, j’utilise/ j’ai utilisé les langues que japprends ou que je connais dans les situations suivantes:

a) dans ma formation ou sur mon lieu de travail :

\begin{tabular}{|c|c|c|c|}
\hline Date & Langue(s) & $\begin{array}{c}\text { Quand? où? avec } \\
\text { qui? }\end{array}$ & $\begin{array}{c}\text { Ce que jen pense et ce } \\
\text { que cela mapporte }\end{array}$ \\
\hline$\ldots / . . / 20 \ldots$. & & & \\
\hline
\end{tabular}

Figure 18. Les fragments du PEL au service des objectifs professionnels. Source : élaboration propre.

${ }^{204}$ Parmi les aspects d'un Portfolio qui peuvent varier, le document le Guide à l'usage des concepteurs (Schneider et Lenz, $2001: 12$ ) mentionne :

- le degré d'intégration du PEL dans un contexte institutionnel (la tendance étant une étroite correspondance à l'école primaire, mais une indépendance par rapport aux institutions et une grande souplesse au niveau des adultes);

- le mode dominant d'apprentissage des langues ;

- les exigences cognitives qu'un PEL peut avoir (y compris la complexité de la langue);

- l'importance relative des deux fonctions de base du Portfolio ;

- l'importance et les fonctions concrètes des trois parties ;

- le degré de fiabilité attendu ;

- les exemples qui sont donnés ;

- la présentation matérielle et l'organisation du document. 
En principe, les techniques et stratégies d'apprentissage des langues, la conscience linguistique, la compétence interculturelle et socioculturelle ainsi que les descriptions personnelles d'objectifs ont été enrichis par certains éléments des langues à visée professionnelle.

Il est à noter que le Portfolio que nous avons élaboré intègre non seulement la prise en compte de parcours diversifiés d'apprentissage des langues, mais aussi la construction d'une compétence plurilingue et la prise de conscience de sa construction par exemple par la mise en regard, dans la même grille, de niveaux de compétence dans les différentes langues. Le portfolio permet d'enregistrer les progrès, de conserver des travaux réalisés pour l'une et l'autre langue étrangère, de réfléchir sur sa biographie langagière et sur son parcours d'apprenant plurilingue en devenir. Le recours à des formes de portfolios, favorise également les prises de conscience touchant à la fois aux convergences actuelles ou potentielles et aux différences relevées, quant aux langues, aux cultures et aux façons de les appréhender. Dans notre portfolio, un accent tout particulier est également mis sur l'importance des méthodes de travail et des stratégies mobilisées, notamment en ce qui concerne la question du passage d'une langue à une autre dans des situations de la vie quotidienne et professionnelle. Ces opérations impliquent de prendre appui sur le « déjà-là »en termes à la fois linguistique, culturel, métalinguistique et cognitif, c'est-à-dire en articulant le plan des pratiques et celui des représentations.

\section{- Types de questions dans le PEL au service des objectifs professionnels}

Le Portfolio doit amener l'apprenant à se questionner, à s'autoévaluer, à développer sa pratique réflexive et à rendre sa réflexion plus explicite, tout en examinant ses actions. Enrique Correa Molina et Chantal Gervais (2008 : 13) remarquent des avantages inappréciés de la réflexion dans le contexte du travail avec un Portfolio. Elle aide les apprenants à penser différemment et plus clairement; elle aide à justifier leurs choix et à régulariser leurs actions ou décisions. La réflexion vise également à examiner les apprentissages, à s'améliorer lors d'une tâche et à cheminer en tant qu'apprenant. La réflexion permet finalement d'identifier les difficultés et les progrès en fonction des buts à atteindre avant, pendant et après les apprentissages.

Afin que le Portfolio remplisse son rôle, il faut qu'il soit bien construit. Lors de l'élaboration, il est nécessaire que le concepteur choisisse des questions justes. Dans le Portfolio au service des objectifs professionnels, nous avons posé des questions d’ordre métacognitif et réflexif.

Cependant, les questions métacognitives et réflexives du Portfolio peuvent être orientées et avoir des visées diversifiées. Selon François Lacourse et Henri Hensler (2008 : 37), la réflexion peut se faire en trois temps. D'abord, il y a l'autoanalyse, c'està-dire un questionnement sur soi, sur ce que l'apprenant a fait. Les questions l'aident à se positionner. Ensuite, l'autodiagnostic se réfère à la perception de l'apprenant, à son interprétation au regard de ses apprentissages en lien avec les compétences. 
Enfin, l'autorégulation renvoit à l'ajustement, ce que l'apprenant doit faire pour s’améliorer.

Les questions métacognitives et réflexives que nous avons construites dans notre Portfolio aident l'apprenant à réfléchir sur ce qu'il a fait et appris. Ces questions tendent à porter un regard sur ses qualités ainsi que ses compétences et permettent de dresser une forme de bilan sur les situations d'apprentissages et évaluatives. La réflexion peut être centrée sur les forces de l'apprenant, ses faiblesses et peut aussi aider dans la recherche de solutions. La démarche de réflexion doit permettre de mettre en relief un certain contrôle de ses apprentissages et de son développement en déterminant les buts et en précisant les moyens pour les atteindre.

Finalement, le Portfolio, à travers les différents types de questions, prend la forme d'un outil qui guide sur les plans cognitif et métacognitif et qui permet à l'apprenant d'intérioriser et de réajuster ses apprentissages et de soutenir sa réflexion sur sa progression sur une période de temps.

\section{- Les principaux composants du Portfolio au service des objectifs professionnels}

En guise de synthèse de la partie consacrée au Portfolio, nous récapitulons ci-dessous les principaux composants du PEL au service des objectifs professionnels.

Tableau 14. Les composants du Portfolio au service des objectifs professionnels.

\begin{tabular}{|l|l|}
\hline Le type de Portfolio & $\begin{array}{l}\text { Portfolio d'apprentissage pour les adultes en } \\
\text { version papier }\end{array}$ \\
\hline $\begin{array}{l}\text { Le but du Portfolio } \\
\text { Quel est le but poursuivi ? le résultat } \\
\text { attendu? }\end{array}$ & $\begin{array}{l}\text { Documenter le développement de la compétence } \\
\text { plurilingue et pluriculturelle }\end{array}$ \\
\hline $\begin{array}{l}\text { Les composantes du Portfolio } \\
\text { Quels sont les éléments qui composent } \\
\text { le portfolio? }\end{array}$ & $\begin{array}{l}\text { - Page de couverture } \\
\text { - Titre du Portfolio } \\
\text { - Espace pour la présentation de l'apprenant } \\
\text { - Grilles d'autoévaluation }\end{array}$ \\
\hline $\begin{array}{l}\text { Les types de questions } \\
\text { Quels types de questions sont formulées } \\
\text { et à quel moment? }\end{array}$ & $\begin{array}{l}\text { Des questions métacognitives qui exigent des } \\
\text { explications. } \\
\text { Des questions orientées sur les apprentissages tout } \\
\text { au long du développement des compétences }\end{array}$ \\
\hline $\begin{array}{l}\text { Les grilles d'évaluation et les fiches } \\
\text { Quels sont les outils qui permettent de } \\
\text { recueillir les traces et de porter un jugement } \\
\text { sur le développement des compétences? }\end{array}$ & $\begin{array}{l}\text { Une grille d'évaluation à échelle uniforme pour } \\
\text { juger du son niveau de développement des } \\
\text { éléments de la compétence. } \\
\text { Fiche d'autoévaluation pour chaque preuve déposée. }\end{array}$ \\
\hline $\begin{array}{l}\text { La gestion du Portfolio } \\
\text { La gestion est-elle libre ou dirigée? }\end{array}$ & $\begin{array}{l}\text { La gestion est dirigée par les enseignantes et les } \\
\text { enseignants tout au long du cheminement de l'élève. }\end{array}$ \\
\hline
\end{tabular}

Source : élaboration propre. 
Comme nous venons de le voir, notre PEL n'est pas seulement un outil pédagogique, mais aussi un outil de recueil de données. Cependant, nous avons utilisé le Portfolio en parallèle avec des techniques plus «classiques » comme les observations et le questionnaire que nous décrivons ci-dessous.

\subsection{Observation}

L'une des techniques de recueil de données de recherche la plus appropriée pour tenter de comprendre la complexité d'un champ comme la DLE est l'observation participante ${ }^{205}$. L'observation ${ }^{206}$ semble être inhérente à toute démarche scientifique. Elle s'est affirmée comme une condition première de la construction du savoir en sciences sociales (tout comme dans les sciences pures), par une mise en rapport, mais aussi une mise à distance du sujet et de l'objet. Jean-Marie De Ketele remarque que dans l'observation "il s'agit d'un processus et non d'un mécanisme simple d'impression par reproduction comme celui de la photocopie » (2004 : 15). L'observation est donc un processus dont la fonction première et immédiate est de recueillir de l'information sur l'objet, pris en considération en fonction de l'objectif organisateur.

En ce qui concerne le domaine de l'éducation, l'observation implique, de la part du chercheur, une immersion active sur le terrain. Elle lui permet d'avoir accès à des informations peu accessibles et mieux comprendre certains fonctionnements difficilement appréhendables par quiconque est étranger au domaine. La participation entraîne inévitablement des relations de proximité, voire une intimité avec les acteurs d'un terrain (Bourdieu $1978: 28$ dans Soulé, $2007: 130^{207}$ ). Cela est particulièrement important en classe, un lieu d'intimité, où cette dernière ne laisse ni voir ni comprendre et ne laisse pas retravailler sans une certaine appréhension. Grâce au fait que les personnes observées nous connaissaient, nous avons réussi à mener nos observations sans changer la dynamique du cours et à être près de la réalité observée au point de la comprendre en profondeur.

${ }^{205}$ Lobservation participante a été mise en œuvre par des anthropologues dans le but d'étudier des sociétés exotiques et inconnues. Il s'agit d'une démarche inductive qui vise à découvrir par lobservation ce qui organise les rapports sociaux, les pratiques et les représentations des acteurs du terrain étudiés. Elle a été définie par Platt (1983) comme une technique de recherche dans laquelle le sociologue observe une collectivité sociale dont il fait lui-même partie.

${ }^{206}$ Jean Marie De Ketele, (2004 : 14) affirme que « il est curieux de remarquer que la plupart des spécialistes qui ont largement utilisé l'observation ou ont écrit à son propos (Meddley et Mitzel, 1963 ; Rosenshine, 1973) n’aient pas tenté de donner une définition de l'observation. Peutêtre estiment-ils le concept établi. Certains cependant s'y sont efforcés, mais leurs définitions sont à certains égards peu satisfaisantes : spécifiques et univoques dans leur énoncé, elles sont ensuite utilisées de façon équivoque avec attribution au particulier d'une valeur générale » (l'auteur souligne).

${ }^{207}$ Source : http://www.recherche-qualitative.qc.ca/documents/files/revue/edition_reguliere/ numero27(1)/soule.pdf. 
Dans le cadre de cette recherche, nous avons eu recours à l'observation ciblée ${ }^{208}$, c'est-à-dire que nous nous sommes limités à observer seulement un aspect du cours. L'objet de notre observation était le degré d'intérêt des apprenants pour des éléments du cours qui étaient basés sur les ressources du descripteur savoir-faire du CARAP.

\section{- Observation : limites du recueil des données}

Nous voudrions souligner que la méthode d'observation ciblée est souple ${ }^{209}$ et laisse beaucoup de liberté au chercheur (Wilczyńska, Michońska-Stadnik 2010 : 149). La validité de la méthode d'observation peut être atteinte de multiples façons. De ce fait, nous avons privilégié la prise de notes systématique, qui a revêtu la forme d'un journal et qui est l'une des techniques accompagnant l'observation (De Ketele, 2004 : 17). Afin de gérer simultanément des observations, des interventions, des lectures, des réflexions et des frustrations, tenir un journal semble primordial.

Il s'ensuit que l'observation se situe essentiellement dans le présent, en direct. Dans cette optique, nous n'avons pas voulu adopter de modèle a priori et donc une grille d'observation avec des catégories préétablies a donc été réalisée. Notre objectif était de relever, de façon exhaustive, tous les éléments intéressants et de les traiter a posteriori ( $c f$. chapitre 5). En outre, nous sommes d'accord avec Jean-Marie de Ketele (2001 : 322) que « en utilisant une grille, l'observateur ne peut voir que les faits prévus dans la grille, et tous les faits qu'il observe ne peuvent être rapportés que dans les termes de la grille». L'introduction de cet intermédiaire méthodique est, aux yeux de certains chercheurs, censée produire elle-même les données, en éloignant le chercheur des aspects intéressants qui n'ont pas été prévus dans la grille. L'existence de grilles ne garantit toutefois pas que l'observation soit une réussite et que cette technique soit meilleure que la prise de notes.

Finalement, nous pensons que la pertinence de l'observation suppose de trouver le «bon rythme » entre les techniques, qui sont dans notre cas la prise de notes et l'observation. Ce rythme dépend surtout du chercheur.

${ }^{208}$ Weronika Wilczyńska et Anna Michońska-Stadnik (2010 : 149) soulignent qu’il s'agit d'une observation qui ne soit pas totale. Elle l'appelle obserwacja ukierunkowana ou obserwacja skoncentrowana.

${ }^{209}$ " La souplesse de la notion d’observation, matérialisée par les formes extrêmement diverses que peut revêtir sa mise en œuvre, constitue un terrain propice aux variations terminologiques. Elle peut ainsi être ouverte ou clandestine, périphérique ou complète, entriste ou opportuniste; le chercheur, pour sa part, s'apparente plutôt à l'observateur en tant que participant, ou au participant en tant qu’observateur, parfois après avoir été 'participant pur'. Au regard de ces multiples configurations, le recours au terme de l'observation semble parfois résulter d'une acception rétrécie de la notion d'OP » (De Ketele, $2004: 18)$. 


\subsection{Enquête par questionnaire}

Le troisième instrument de cueillette de données dans notre étude rechercheaction qui complètera le Portfolio et l'observation sera le questionnaire ${ }^{210}$. Comme le remarque Géneviève Zarate (2003 : 40) le questionnaire comme instrument d'enquête doit répondre à des objectifs très précis. De fait, toute construction de questionnaire doit être précédée d'une formulation claire et précise du problème et des objectifs de l'étude.

\section{- Les phases d'élaboration d'un questionnaire}

\section{a) Définir les objectifs et les hypothèses de l'enquête}

La réflexion manifestée dans les questions que nous proposons dans notre questionnaire se base sur le référentiel du CARAP (cf. chapitre 3). L'objectif était de vérifier quelles sont les représentations des étudiants sur le rôle de la compétence plurilingue et pluriculturelle dans le travail de futurs diplomates et comment développer cette compétence en classe de FOS. En bref, nous formulons l'hypothèse que nos cours basés sur le référentiel du CARAP ainsi que sur le travail avec le PEL peuvent développer ou augmenter la compétence plurilingue et pluriculturelle chez les apprenants du cours de français de la diplomatie.

Pour y parvenir, il s'est avéré pertinent de réaliser une enquête par questionnaire (notre pré-test et post-test) afin de comparer les niveaux de départ et de sortie du groupe d'apprenants et vérifier d'éventuels changements après toute une année de cours inspirés du CARAP. Nous nous sommes adressés aux apprenants du cours de français de la diplomatie en leur demandant d'autoévaluer leur conscience plurilingue et pluriculturelle.

\section{b) Déterminer l'échantillon}

La détermination de l'échantillon à partir duquel sera effectuée l'enquête résulte d'une série d'opérations indispensables et précises dont la fonction est d'assurer la représentativité.

Pour ce qui est de notre recherche, le questionnaire a été donné deux fois aux 10 étudiants du Collège d'Europe à Natolin suivant les cours de français de la diplomatie.

\section{c) Le projet du questionnaire}

Tout d'abord, nous avons voulu que notre questionnaire soit le plus clair et succinct possible. Nous avons choisi des questions fermées qui sont aisées à comprendre et

${ }^{210}$ Le questionnaire s'est imposé depuis l'avènement de l'approche psychométrique dans le but d’enrichir les recherches visant une meilleure connaissance empirique et systématique de la réalité. Surtout utilisé en psychologie avec le développement des tests d'attitudes et de motivation, celui-ci s'est vite répandu en éducation étant donné sa capacité de maximiser les différences individuelles et de faciliter la comparabilité des résultats et la référence à la norme. Plus récemment, la sociologie se l'est appropriée comme moyen d'appréhension des faits sociaux ou dans le but de sonder les intentions des acteurs sociaux. 
auxquelles il est facile de répondre. Puisque nos questions énumèrent des choix possibles de réponses, elles sont à réponses multiples (un classement hiérarchique). Celles-ci permettent d'ordonner les réponses pour donner au choix un ordre de préférence ou d'importance en instaurant un minimum et un maximum de réponses à fournir. Dans notre questionnaire, nous avons renoncé aux chiffres $-2,-1,0,+1,+2$ en choisissant des couleurs (exemple ci-dessous) et en expliquant aux apprenants que la couleur rouge signifie que la ressource donnée est la plus développée et la bleue- la moins développée.

I'm able to understand written text in languages that I do not know or in languages I know very little. [fr. Je suis capable de comprendre des textes écrits dans une langue que je ne connais pas ou dans des langues que je connais un peu].

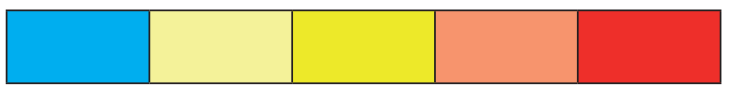

En outre, puisque nous avons eu des doutes sur le caractère compréhensible des questions, qui sont des descripteurs opérationnalisés du CARAP, pour des apprenants aux L1 diverses, nous les avons rédigées en anglais. À ce titre, Wilczyńska et Michońska-Stadnik (2010: 169) remarquent que «si nous pensons que l'usage de la langue étrangère peut limiter les réponses des enquêtés ou même rendre difficile la compréhension des questions, il serait mieux de construire le questionnaire dans la langue que l'apprenant connaît le mieux. Malgré les apparences, l'usage de la langue étrangère peut influencer la qualité de la réponse $»^{211}$.

Le questionnaire dans sa version définitive comporte 23 questions. Les questions sont composées des ressources opérationnalisées du descripteur savoir-faire du CARAP qui correspondent à des opérations telles que savoir observer / analyser; identifier / repérer, savoir comparer, savoir parler à propos des langues et des cultures, etc. Notre questionnaire comporte toutes les ressources du savoir-faire pour lesuelles l'apport des approches plurielles est « nécessaire $»^{212}$ pour développer la ressource selon les auteurs du CARAP.

\section{d) Le questionnaire initial}

Étant donné que notre questionnaire contient des questions variées, nous l'avons mis à l'épreuve et l'avons présenté à quelques personnes ne participant pas à l'étude.

${ }^{211}$ „Jeżeli mamy obawy, że użycie J2 w tekście ankiety może ograniczyć odpowiedzi respondenta czy nawet utrudniać mu zrozumienie pytań kwestionariusza, zdecydowanie lepiej jest posłużyć się językiem polskim. Wbrew pozorom, użycie J2 może wpływać także na obszerność i jakość wypowiedzi $[\ldots]$ ", notre traduction.

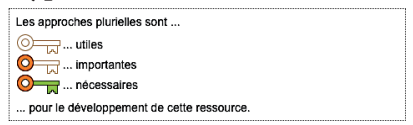

${ }^{212}$ CARAP, (2007 : 24). 
Il s’agissait d'évaluer la clarté et la précision des termes utilisés et des questions posées. Nous voulions voir si la forme des questions, l'ordre des questions et l'efficacité de la mise en page étaient suffisamment claire. Enfin, l'objectif était d'éliminer toutes les questions ambiguës ou refusées, de repérer les omissions ainsi que de déterminer si le questionnaire est jugé trop long, ennuyeux, etc.

\section{e) La rédaction définitive du questionnaire}

À partir des données du questionnaire initial, nous avons élaboré la version finale du questionnaire qui a été soumise aux enquêtés en septembre 2017 (pré-test) et en avril 2018 (post-test).

\section{f) L'analyse des résultats en relation avec les objectifs de l'enquête}

L'analyse des résultats de l'enquête permettra de confirmer ou d'infirmer les hypothèses émises au départ. Cette démarche est accompagnée d'une phase d'interprétation des résultats obtenus qui permet la compréhension de l'existence de relations entre diverses variables. Nous décrirons cette phase dans le chapitre 5.

\subsubsection{Le travail avec des séquences pédagogiques}

Comme nous l'avons déjà mentionné plus haut, notre étude qui cherchait à développer la compétence plurilingue et pluriculturelle en classe de Français sur Objectifs Spécifiques était basée sur des séquences inspirées des ressources du descripteur savoir-faire du CARAP et axées sur le développement de la compétence plurilingue et pluriculturelle. Nos séquences ont été réalisées avec un groupe d'étudiants du Collège d'Europe à Natolin prenant part aux leçons de français de la diplomatie. $25^{213}$ leçons (90 minutes chacune) que nous avons réalisées entre septembre 2017 et avril 2018 auprès de 10 étudiants participant à notre étude nous ont permis de recueillir des données dont les résultats qualitatifs seront interprétés dans le chapitre 5.

Afin de résumer toutes les actions entreprises auprès de nos apprenants pendant 2 semestres, nous proposons le tableau ci-après :

${ }^{213} \mathrm{Il}$ convient d'expliquer que nous avions prévu de préparer 30 leçons de 90 minutes chacune mais qu'à cause des voyages d'études et des conférences internationales organisées au Collège d'Europe pendant les horaires de nos cours, nous avons dû annuler 5 leçons. 
Tableau 15. Actions entreprises auprès de notre public.

\begin{tabular}{|l|c|l|l|l|}
\hline Dispositifs & $\begin{array}{l}\text { Pré-test } \\
\text { (questionnaire) }\end{array}$ & $\begin{array}{l}\text { Post-test } \\
\text { (questionnaire) }\end{array}$ & $\begin{array}{l}\text { Les séquences } \\
\text { axées sur les } \\
\text { ressources du } \\
\text { descripteur savoir- } \\
\text { faire du CARAP }\end{array}$ & $\begin{array}{l}\text { Le travail avec } \\
\text { le Portfolio au } \\
\text { service des objectifs } \\
\text { professionnels }\end{array}$ \\
\hline Date : & 8.09 .2017 & 20.04 .2018 & $\begin{array}{c}\text { du 8.09.2017 } \\
\text { au 20.04.2018 }\end{array}$ & $\begin{array}{c}\text { du 8.09.2017 } \\
\text { au 20.04.2018 }\end{array}$ \\
\hline $\begin{array}{l}\text { Groupe de } \\
10 \text { étudiants } \\
\text { participant au } \\
\text { cours de français } \\
\text { de la diplomatie }\end{array}$ & OUI & OUI & OUI & OUI \\
\hline
\end{tabular}

Pour être plus précis, il nous semble important de présenter le plan de cours que nous avons réalisé dans notre groupe. Nous nous limiterons ci-dessous aux documents distribués aux étudiants le premier jour du cours.

Tableau 16. Le plan du cours de français de la diplomatie.

COURS : FRANÇAIS DE LA DIPLOMATIE B1

Marta Wojakowska

Plan de cours

\begin{tabular}{|c|l|}
\hline DATE & \multicolumn{1}{c|}{ CONTENU } \\
\hline $\mathbf{8 . 0 9 . 2 0 1 7}$ & $\begin{array}{l}\text { Introduction au cours de français de la diplomatie (la distribution des Portfolios } \\
\text { et du pré-test). }\end{array}$ \\
\hline $\mathbf{1 5 . 0 9 . 2 0 1 7}$ & Qu'est-ce que la diplomatie ? Les regards croisés. \\
\hline $\mathbf{2 2 . 0 9 . 2 0 1 7}$ & Parcours professionnel des diplomates partie I - réaliser une enquête. \\
\hline $\mathbf{2 9 . 0 9 . 2 0 1 7}$ & $\begin{array}{l}\text { Parcours professionnel des diplomates partie II : les enjeux actuels de l'évolution } \\
\text { des métiers de la diplomatie. }\end{array}$ \\
\hline $\mathbf{6 . 1 0 . 2 0 1 7}$ & Labécédaire du bon diplomate (partie I). \\
\hline $\mathbf{1 3 . 1 0 . 2 0 1 7}$ & Labécédaire du bon diplomate. Les points communs et les différences. \\
\hline $\mathbf{2 0 . 1 0 . 2 0 1 7}$ & Vive la différence dans la diplomatie ! Parler du choc culturel. \\
\hline $\mathbf{2 7 . 1 0 . 2 0 1 7}$ & Trouver le candidat idéal : l'entretien d'embauche (un jeu en groupes). \\
\hline $\mathbf{1 0 . 1 1 . 2 0 1 7}$ & Comment rédiger un CV pour un poste dans une institution européenne? \\
\hline $\mathbf{1 7 . 1 1 . 2 0 1 7}$ & $\begin{array}{l}\text { Rédiger une lettre de motivation pour un poste dans une institution } \\
\text { européenne. }\end{array}$ \\
\hline $\mathbf{2 4 . 1 1 . 2 0 1 7}$ & Partir en mission (réaliser un carnet de voyage). \\
\hline $\mathbf{1 . 1 2 . 2 0 1 7}$ & Le protocole, c'est le protocole! Différents protocoles dans différents pays. \\
\hline $\mathbf{8 . 1 2 . 2 0 1 7}$ & Les institutions de l'UE partie I- préparer un projet comparatif. \\
\hline
\end{tabular}


(la continuation du tableau 16)

\begin{tabular}{|c|l|}
\hline $\mathbf{1 2 . 0 1 . 2 0 1 8}$ & Rencontrez des fonctionnaires de vos institutions préférées. \\
\hline $\mathbf{1 9 . 0 1 . 2 0 1 8}$ & Prendre la parole en public (partie I). \\
\hline $\mathbf{2 6 . 0 1 . 2 0 1 8}$ & Rédiger une lettre officielle - (l'écriture collaborative). \\
\hline $\mathbf{2 . 0 2 . 2 0 1 8}$ & $\begin{array}{l}\text { Comment négocier dans un environnement multiculturel ? } \\
\text { Rédiger la carte des stéréotypes. }\end{array}$ \\
\hline $\mathbf{9 . 0 2 . 2 0 1 8}$ & Organisations non gouvernementales dans le monde (le débat d'Oxford) \\
\hline $\mathbf{1 6 . 0 2 . 2 0 1 8}$ & $\begin{array}{l}\text { "Quai d'Orsay- les coulisses de la diplomatie » (le reportage de TV5 Monde et } \\
\text { ARTE). }\end{array}$ \\
\hline $\mathbf{2 3 . 0 2 . 2 0 1 8}$ & Discussion autour du reportage « Quai d'Orsay- les coulisses de la diplomatie ». \\
\hline $\mathbf{2 . 0 3 . 2 0 1 8}$ & $\begin{array}{l}\text { Politicien ou diplomate de mon pays - présentation du personnage et de son } \\
\text { parcours professionnel (travail en groupe). }\end{array}$ \\
\hline $\mathbf{9 . 0 3 . 2 0 1 8}$ & Comprendre les migrations vers l'Europe. \\
\hline $\mathbf{1 6 . 0 3 . 2 0 1 8}$ & Comprendre les migrations vers l'Europe (le débat d'Oxford). \\
\hline $\mathbf{6 . 0 4 . 2 0 1 8}$ & $\begin{array}{l}\text { La lutte contre les stéréotypes et les préjugés dans la diplomatie. } \\
\text { Pourquoi lutter? Comment lutter? }\end{array}$ \\
\hline $\mathbf{2 0 . 0 4 . 2 0 1 8}$ & Le bilan de toute l'année (le recueil des Portfolios et les post-tests). \\
\hline
\end{tabular}

Source : élaboration propre.

Nous pouvons voir que chaque séquence tend à développer la compétence plurilingue et pluriculturelle de l'étudiant. Les leçons sont axées sur la rencontre interculturelle et l'échange culturel. De surcroit, le travail de groupe que nous promouvons ici ouvre des pistes, émet des hypothèses, permet une circulation de la parole et une exposition de points de vue plus importantes que dans le cas de la classe entière.

Pour résumer, nous avons exposé jusqu'à présent les éléments qui ont nous aidés à trouver le lieu de notre recherche sur une échelle méthodologique ainsi que les techniques de recueil des données de recherche-action. Néanmoins, les observables que nous nous proposons d'interpréter ne sont pas détachables du lieu où nous avons mené nos recherches et de nos témoins, d'où la nécessité de décrire de plus près le contexte de notre étude.

\subsection{Le contexte de l'étude}

\subsubsection{Description du lieu d'intervention (le Collège d'Europe comme véritable 'microcosme' européen)}

En guise d'introduction, il convient de souligner que l'institution où nous menons nos recherches est le plus ancien institut de formation et d'études postuniversitaires spécialisé dans les matières européennes. En guise d'introduction historique, 
il s'agirait de dire que le Collège d'Europe a été fondé en 1949 par des figures de proue telles que Salvador de Madariaga, Winston Churchill ou encore Paul Henri Spaak dans le sillage du premier Congrès du Mouvement européen tenu à la Haye en 1948 (Bekemans 1999 : 39). Le but était de créer un institut où de jeunes universitaires issus de différents pays européens puissent venir étudier ensemble.

A titre d'exemple, Simone Veil (ouverture de la promotion Jean Monnet, 19801981) parlait du Collège de la manière suivante :

Depuis 64 ans, le Collège d'Europe, fidèle aux vœux de l'homme de réflexion et d'action qui en a inspiré la création, poursuit avec succès son objectif : approfondir l'identité européenne, la rendre vivante en l'inscrivant dans la réalité, en renouant avec la tradition des universités médiévales, c'est-à-dire en faisant non seulement travailler ensemble mais vivre ensemble, des professeurs et des élèves venus d'Europe ou, d'autres horizons pour échanger entre eux et enrichir encore davantage une solitude formation déjà acquise.

En 1993, quatre ans après la chute du communisme et les changements survenus en Europe centrale et orientale, le Collège d'Europe établissait un second campus à Natolin (Varsovie, Pologne) avec le soutien de la Commission européenne et du gouvernement polonais. Nous devons souligner à cette occasion que l'ensemble de nos observables a été recueilli sur le campus à Natolin. Le Collège d'Europe à Natolin accueille chaque année environ 120 étudiants dont l'âge moyen est de 25 ans. Ceux-ci représentent une cinquantaine de nationalités, mais aussi différentes régions au sein d'un même pays. Ainsi, les étudiants européens et non-européens apprennent à travailler ensemble et échangent idées et opinions dans le cadre de leurs études.

Aujourd'hui, l'objectif du Collège d'Europe est de préparer les étudiants à des emplois dans les administrations publiques européennes, internationales ou nationales, y compris les services diplomatiques et les organisations non gouvernementales. Les deux langues véhiculaires du Collège sont l'anglais et le français.

Il nous semble intéressant de préciser ici que, bien que le Collège d'Europe soit une institution bilingue, le niveau de français des étudiants qui désirent y étudier est de moins en moins élevé. Comme le remarque Małgorzata Wiśniewska, responsable du processus d'admission travaillant au Collège d'Europe depuis 20 ans : " par rapport aux années 90 et au début des années 2000, il est aujourd'hui de plus en plus difficile de trouver des candidats titulaires d'un diplôme universitaire approprié s'intéressant aux affaires étrangères et qui démontrent un niveau B1/B2 en français. En ce qui concerne l'anglais, deuxième langue de travail du Collège, nous n'avons pas rencontré de problèmes. Presque la totalité de nos candidats avaient un niveau de langue avancé en anglais ». 
Il faut donc bien admettre que la langue anglaise reste privilégiée et qu'elle est souvent une sorte de langue relais à partir de laquelle l'apprenant met en place et développe des capacités "méta " pour poursuivre les apprentissages et aborder d'autres langues (Castellotti, Coste, Duverger, 2008 : 23).

En outre, depuis 2010, et chaque année, le Service des Langues compare les résultats du Test de Connaissance du Français (TCF) organisé par ce Service au Collège d'Europe à Natolin. Le tableau suivant présente les résultats dont on parle ci-dessus :

Tableau 17. Les résultats du TCF organisé au Collège d'Europe entre 2010 et 2014.

\begin{tabular}{|l|c|c|c|c|c|}
\hline \multicolumn{1}{|c|}{ Année } & 2010 & 2011 & 2012 & 2013 & 2014 \\
\hline $\begin{array}{l}\text { Le nombre } \\
\text { d'étudiants passant } \\
\text { le TCF }\end{array}$ & 86 & 86 & 82 & 84 & 83 \\
\hline \multirow{7}{*}{ Niveau obtenu } & $\begin{array}{c}\text { A1-1 } \\
\text { étudiant }\end{array}$ & $\begin{array}{c}\text { A1-1 } \\
\text { étudiant }\end{array}$ & $\begin{array}{c}\text { A1-1 } \\
\text { étudiant }\end{array}$ & $\begin{array}{c}\text { A1-7 } \\
\text { étudiants }\end{array}$ & $\begin{array}{c}\text { A1-10 } \\
\text { étudiants }\end{array}$ \\
\cline { 2 - 6 } & $\begin{array}{c}\text { A2-1 } \\
\text { étudiants }\end{array}$ & $\begin{array}{c}\text { A2-1 } \\
\text { étudiant }\end{array}$ & $\begin{array}{c}\text { A2- } 1 \\
\text { étudiant }\end{array}$ & $\begin{array}{c}\text { A2-8 } \\
\text { étudiants }\end{array}$ & $\begin{array}{c}\text { A2-15 } \\
\text { étudiants }\end{array}$ \\
\cline { 2 - 6 } & $\begin{array}{c}\text { B1-8 } \\
\text { étudiants }\end{array}$ & $\begin{array}{c}\text { B1-10 } \\
\text { étudiants }\end{array}$ & $\begin{array}{c}\text { B1- 13 } \\
\text { étudiants }\end{array}$ & $\begin{array}{c}\text { B1-17 } \\
\text { étudiants }\end{array}$ & $\begin{array}{c}\text { B1-16 } \\
\text { étudiants }\end{array}$ \\
\cline { 2 - 7 } & $\begin{array}{c}\text { B2-20 } \\
\text { étudiants }\end{array}$ & $\begin{array}{c}\text { B2-19 } \\
\text { étudiants }\end{array}$ & $\begin{array}{c}\text { B2-20 } \\
\text { étudiants }\end{array}$ & $\begin{array}{c}\text { B2-22 } \\
\text { étudiants }\end{array}$ & $\begin{array}{c}\text { B2-23 } \\
\text { étudiants }\end{array}$ \\
\cline { 2 - 6 } & $\begin{array}{c}\text { C1-34 } \\
\text { étudiants }\end{array}$ & $\begin{array}{c}\text { C1-35 } \\
\text { étudiants }\end{array}$ & $\begin{array}{c}\text { C1-29 } \\
\text { étudiants }\end{array}$ & $\begin{array}{c}\text { C1-15 } \\
\text { étudiants }\end{array}$ & $\begin{array}{c}\text { C1-11 } \\
\text { étudiants }\end{array}$ \\
\cline { 2 - 6 } & $\begin{array}{c}\text { C2-24 } \\
\text { étudiants }\end{array}$ & $\begin{array}{c}\text { C2-22 } \\
\text { étudiants }\end{array}$ & $\begin{array}{c}\text { C2-19 } \\
\text { étudiants }\end{array}$ & $\begin{array}{c}\text { C2-15 } \\
\text { étudiants }\end{array}$ & $\begin{array}{c}\text { C2- } 8 \\
\text { étudiants }\end{array}$ \\
\hline
\end{tabular}

Source : le Service des Langues du Collège d'Europe de Natolin.

Ce tableau confirme ce que nous a dit la responsable du Comité d'Admission. Ainsi, les données publiées en 2017 par Eurostat à l'occasion de la Journée européenne des langues montrent que l'anglais s'impose de plus en plus dans les écoles européennes. «Dans l'UE 28 en 2014, 83\% des élèves de l'enseignement primaire et du premier cycle du secondaire ainsi que $94 \%$ de ceux du deuxième cycle de l'enseignement secondaire général ont étudié l’anglais comme langue étrangère » (Eurostat : 2017).

En outre, l'anglais, qui s'est surtout développé après la Seconde Guerre mondiale, est aujourd'hui de plus en plus utilisé dans les secteurs à orientation internationale en y remplaçant le français, jadis langue internationale des élites sociales et politiques. Par conséquent, il nous semble qu'il n'y a rien de surprenant dans le fait que les candidats voulant étudier au Collège d'Europe à Natolin parlent mieux l'anglais que 
le français. En tant que futurs fonctionnaires de l'Union européenne, ils choisissent d'apprendre l'anglais plutôt que le français comme première langue étrangère.

Enfin, il convient d'expliquer que l'apprentissage du français n'est pas obligatoire au Collège d'Europe. Tous les cours de langues sont facultatifs et sont suivis par les étudiants qui s'y sont inscrits au début de l’année académique.

\subsubsection{Le profil de l'échantillon}

L'échantillon ${ }^{214}$ étudié comprend 10 apprenants du Collège d'Europe à Natolin (promotion Simone Veil) qui ont suivi le cours de Français sur Objectif Spécifique (français de la diplomatie). Notre étude a été menée du 8 septembre 2017 au 20 avril $2018^{215}$ auprès d'un groupe d'étudiants du Collège d'Europe à Natolin ayant le niveau $\mathrm{B}^{216}$. Au total, nous avons réalisé 25 leçons de 90 minutes chacune.

Le public concerné était composé d'adultes (âge moyen de 26 ans), titulaires d'un diplôme universitaire approprié (Master 1 ou Master 2) et provenant principalement d'un cursus académique en sciences politiques, études européennes, relations internationales et/ou diplomatiques, droit, économie ou histoire. Quelques étudiants étaient également détachés d'organisations internationales ou d'administrations nationales.

En outre, il est intéressant de remarquer que, parmi les 10 enquêtés, nous avions des représentants de 9 nationalités différentes (1 Chinois, 2 Géorgiens, 1 Arménien, 1 Suédois, 1 Hollandais, 1 Espagnol, 1 Danois, 1 Allemand et 1 Polonais). De ce fait, il est certain que les représentations de nos apprenants ont été formées par des influences culturelles diverses.

Il est utile de noter que les attentes et les objectifs des étudiants du Collège d'Europe de Natolin concernant leur carrière professionnelle sont remarquablement partagés. Ainsi, même si les origines, les histoires et les langues de nos enquêtés sont différentes, ces derniers ressentent tous une certaine «familiarité voisine ». Par conséquent, nous serions plutôt enclin à nous pencher sur l'hypothèse que l'on assiste,

${ }^{214}$ Citons de Ketele (2001:38) qui remarque que « composer un échantillon, revient à s'interroger sur la validité statistique des opérations conduites, mais également au sens que cette opération prend au regard de la problématique et des hypothèses de départ ». Dans notre étude nous avons recours à un mode déchantillonnage empirique, qui consiste à déterminer les critères essentiels à l'enquête, et à choisir les individus sur la base de ces derniers.

${ }^{215}$ Durant le semestre, les cours de langues s'étalent de la deuxième semaine de septembre à la fin du mois d'avril.

${ }^{216}$ Résultat obtenu au cours du test de placement organisé le 2 septembre 2017 par le Service des Langues du Collège d'Europe à Natolin. 
au Collège, à une rencontre interculturelle partagée non seulement par des personnes de pays distincts, mais aussi par les citoyens d'un même pays, d'origines culturelles différentes, qu’elles soient régionales, linguistiques, ethniques ou religieuses.

Rappelons que la compétence plurilingue et pluriculturelle peut être définie d'une façon générale - en tant qu'ensemble des ressources langagières dont l'individu dispose et dans lequel il puise en fonction de ses besoins (Kucharczyk, 2018 : 72). De plus, elle est déséquilibrée (dans le sens que l'apprenant ne maîtrise jamais d'une manière égale toutes les langues construisant sa compétence plurilingue), évolutive et partielle. En effet, elle est une sorte de compétence hybride qui englobe toutes les ressources langagières dont l'individu dispose ; elle se compose de toutes les langues auxquelles l'individu a été confronté lors de son parcours scolaire, professionnel ou privé (y compris sa langue maternelle et ses variations).

Il en résulte qu'elle est fortement individualisée, fugitive et difficilement mesurable. Un individu plurilingue et pluriculturel agit et parle dans plusieurs communautés (académique, sociale, virtuelle, etc.) et son expérience de l'interculturel est faite d'appartenances à diverses communautés qui sont toujours à la charnière de plusieurs langues et cultures. L'apprentissage d'une nouvelle langue (y compris d'une nouvelle culture) devient un processus subjectif dans lequel les éléments personnels, individuels, sociaux, culturels et linguistiques de l'apprenant sont toujours en jeu et forment son apprentissage et ses actions. Il est également important de relever que l'apprenant peut activer des composantes de son répertoire plurilingue soit lors d'une situation de communication exolingue (dans le but d'arriver à un consensus communicatif), soit lors de l'apprentissage des langues (y compris sa langue maternelle) pour le renforcer et - par voie de conséquence - le rendre plus efficace (Kucharczyk, Szymankiewicz, $2018: 4$ ). Il résulte de ce qui précède que le développement de la compétence plurilingue fortement individualisée ne peut pas être effectué à une grande échelle. En outre, les didacticiens reconnaissent (Robert et Rosen, 2010 : 58) qu'il n'existe pas une méthode parfaite pour examiner le développement de ladite compétence; son caractère spécifique et déséquilibré la rend difficile à mesurer. Dans cette perspective, pour mieux cerner les occurrences remarquables dans notre étude qualitative ${ }^{217}$, nous avons privilégié une étude à petite échelle. Les résultats exploitables reposent sur le caractère individuel du développement de la compétence plurilingue chez chaque apprenant.

${ }^{217}$ Notons également que l'approche qualitative est souvent pratiquée dans les investigations concernant des phénomènes relativement nouveaux et peu explorés dans la didactique des langues comme c'est le cas de la compétence plurilingue. 


\subsection{Bilan}

Au terme de cette analyse, nous pouvons conclure que notre étude, qui a commencé en septembre $2017^{218}$ et a duré jusqu'à fin avril 2018, a concerné 10 étudiants du Collège d'Europe à Natolin qui ont suivi le cours de français de la diplomatie.

Dans un premier temps, nous avons défini l'objet d'étude, le problème de recherche ainsi que les questions de recherche. Cela nous a permis de nous référer à une démarche qualitative et d'orienter notre recherche sur l'apprenant. Notre recherche, touchant à la réalité éducative, va impliquer l'utilisation de stratégies de recherche qualitative. Le choix méthodologique qui se centre sur l'apprenant a inscrit notre recherche dans le paradigme interprétatif et nous a conduits vers la méthode de recherche-action qui a englobé des techniques d'accueil des données telles que : le travail des étudiants avec un Portfolio, l'observation et le questionnaire (pré-test et post-test). La spécificité et le caractère de l'objet d'étude ainsi que nos problèmatiques de recherche ont contribué au choix de la méthode de recherche et des techniques de recueil des données.

La formation du Portfolio au service des objectifs professionnels, qui a accompagné les étudiants pendant toute l'année académique, a permis aux apprenants de réfléchir sur leurs acquis de formation et sur leurs acquis den termes d'expérience professionnelle au niveau des langues étrangères. L'observation nous a aidés à tirer toutes les conséquences de l'orientation interprétative dans laquelle nous nous sommes inscrite. Nos observations nous ont permis d'interpréter les comportements, les réactions et les représentations des apprenants ainsi que mieux adapter le contenu des séquences didactiques du cours de français de la diplomatie. Finalement, le questionnaire « pré-test » nous a permis de définir le niveau de départ de nos apprenants en matière de compétence plurilingue et pluriculturelle et ensuite, d'observer d'éventuels changements (le post-test). Dans le cinquième chapitre, nous présenterons les résultats de notre recherche ainsi que leurs interprétations à la lumière de nos questions de recherche.

${ }^{218} \mathrm{Il}$ convient de souligner que le processus de recherche a commencé à germer 10 ans avant, lorsque nous avons commencé à donner des cours de français de la diplomatie au Collège d'Europe. 


\section{Chapitre 5}

\section{Présentation et interprétation des données recueillies dans la recherche empirique}

\section{Remarques liminaires}

Nous avons présenté dans les chapitres précédents le contexte dans lequel nous nous posons, celui de l'enseignement plurilingue et pluriculturel, ainsi que la perspective qui nous guide dans notre recherche empirique : le paradigme interprétatif et la méthode recherche-action. L'objectif du présent chapitre est d'interpréter et de présenter des données obtenues dans la recherche empirique telle qu'elle vient d'être présentée auparavant.

Dans les parties qui suivent, nous présenterons les résultats d'une recherche empirique menée auprès des étudiants de la promotion Simone Veil du Collège d'Europe à Natolin pendant toute l'année académique 2017/2018. La recherche a été menée dans un groupe de 10 apprenants de cours de français de la diplomatie entre le 8 septembre 2017 et le 20 avril 2018.

Tout d'abord, il convient de dire que la problématique de cette recherche est née de la conjonction d'observations, du travail pratique et de considérations théoriques. Durant notre travail de professeur de français au Collège d'Europe à Natolin, nous avons remarqué que les apprenants du cours de français de la diplomatie se focalisaient surtout sur les éléments grammaticaux et lexicaux. D’ailleurs, nous avons observé que la plupart des manuels de FOS existants posent comme objectif principal le développement de la compétence lexicale. Comme nous l'avons mentionné dans le chapitre précédent, l'enseignement du français des relations internationales et de la diplomatie est influencé par les traditions dans l'enseignement de langues à des 
publics spécifiques en Europe. Ces traditions s'expriment dans une centration sur le lexique et une méthodologie orientée vers le développement de la compétence de compréhension écrite.

Il en résulte que les apprenants perçoivent ce cours comme un cours qui se réduit à un vocabulaire de spécialité. Leur manque d'intérêt et de motivation pour la culture de l'Autre empêchait les enseignants de réaliser efficacement leurs objectifs didactiques.

Notre objectif était alors d'examiner si le cours de français de la diplomatie devrait traiter en profondeur les questions du plurilinguisme et de l'interculturel. Si oui, nous voulions ensuite réfléchir sur les méthodes qui pourraient développer la compétence plurilingue et pluriculturelle.

De ce fait, les résultats de l'étude empirique tendront à répondre aux questions de recherche suivantes :

\section{Selon les étudiants, faut-il développer la compétence plurilingue et pluriculturelle dans la formation linguistique des diplomates? Pourquoi ?}

1a) Est-ce que selon les étudiants de cours de français de la diplomatie la compétence plurilingue/pluriculturelle est importante? Dans quelle mesure?

1b) Est-ce que les méthodes qui résultent des principes du plurilinguisme influencent la réflexivité des apprenants de français de la diplomatie envers les autres langues/ cultures? Si oui, comment et dans quelle mesure?

2. S’il existe le besoin de développer la compétence plurilingue et pluriculturelle dans la formation linguistique des diplomates, quelles méthodes la développent ?

2a) Est-ce que le travail avec le Portfolio change la perspective plurilingue/ pluriculturelle des apprenants de français de la diplomatie? Si oui, comment et dans quelle mesure?

2b) Est-ce que les méthodes et les techniques du CARAP réalisent les principes du plurilinguisme? Si oui, lesquelles en particulier?

Dans un premier lieu, nous discuterons du besoin de développement de la compétence plurilingue et pluriculturelle auprès du public des diplomates. Ensuite, nous présenterons l'analyse des réponses fournies dans le Portfolio que les participants à l'étude remplissaient pendant toute la durée de l'étude. Nous analyserons également les éléments les plus importants des scénarios pédagogiques de cours exploitant le CARAP et en même temps les récits des étudiants librement liés au sujet proposé. Le chapitre terminera par la présentation et l'interprétation des résultats du post-test.

Toutes les données recueillies sont présentées dans le tableau ci-dessous : 
Tableau 18. Les outils utilisés pour recueillir des données dans la recherche-action.

\begin{tabular}{|l|l|l|l|}
\hline \multicolumn{1}{|c|}{ Outil } & \multicolumn{1}{|c|}{ Date } & \multicolumn{1}{c|}{ Objectifs } & \multicolumn{1}{c|}{ Données recueillies } \\
\hline Pré-test & 8.09 .2017 & $\begin{array}{l}\text { pour mesurer létat initial de } \\
\text { la compétence plurilingue } \\
\text { et pluriculturelle (désormais } \\
\text { CPLPC) }\end{array}$ & $\begin{array}{l}\text { données quantitatives } \\
\text { montrant l'intensité initiale } \\
\text { de la CPLPC }\end{array}$ \\
\hline $\begin{array}{l}\text { Portfolio } \\
\text { européen } \\
\text { des langues } \\
\text { au service } \\
\text { des objectifs } \\
\text { professionnels }\end{array}$ & $\begin{array}{l}\text { toute l'année } \\
\text { académique } \\
\text { pour accompagner } \\
\text { le développement de la } \\
\text { CPLPC des étudiants }\end{array}$ & $\begin{array}{l}\text { données quantitatives et } \\
\text { qualitatives }\end{array}$ \\
\hline $\begin{array}{l}\text { Scénarios } \\
\text { pédagogiques de } \\
\text { cours exploitant } \\
\text { le CARAP }\end{array}$ & $\begin{array}{l}\text { toute l'année } \\
\text { académique }\end{array}$ & $\begin{array}{l}\text { pour développer la CPLPC } \\
\text { des étudiants }\end{array}$ & $\begin{array}{l}\text { scénarios pédagogiques de } \\
\text { cours }\end{array}$ \\
\hline $\begin{array}{l}\text { Réflexion écrite } \\
\text { académique } \\
\text { (6 fois) }\end{array}$ & $\begin{array}{l}\text { pourtudiants sur l'expérience } \\
\text { plurilingue et pluriculturelle }\end{array}$ & $\begin{array}{l}\text { donnés qualitatives (récits } \\
\text { des étudiants) }\end{array}$ \\
\hline $\begin{array}{l}\text { Post-test } \\
\text { pour mesurer létat final de } \\
\text { la compétence plurilingue et } \\
\text { pluriculturelle }\end{array}$ & $\begin{array}{l}\text { données quantitatives } \\
\text { montrant l'intensité finale } \\
\text { de la CPLPC }\end{array}$ \\
\hline
\end{tabular}

\subsection{Les résultats du pré-test : diagnostic}

Tout d'abord, regardons de plus près les résultats du questionnaire d'auto-évaluation que les 10 apprenants du cours de français de la diplomatie ont rempli le premier jour du cours. Ce questionnaire vise à mesurer l'état initial de la compétence plurilingue et pluriculturelle des étudiants du Collège d'Europe à Natolin.

Tableau 19. La répartition des répondants par acquisition de la ressource.

\begin{tabular}{|l|l|l|l|}
\hline \multicolumn{1}{|c|}{ Questions du questionnaire } & $\begin{array}{c}\text { Ressource } \\
\text { non acquise }\end{array}$ & $\begin{array}{c}\text { Ressource } \\
\text { en voie } \\
\text { d'acquisition }\end{array}$ & $\begin{array}{c}\text { Ressource } \\
\text { acquise }\end{array}$ \\
\hline $\begin{array}{l}\text { 1. Savoir comprendre des textes écrits dans des } \\
\text { langues inconnues ou peu familières }\end{array}$ & 2 étudiants & 6 étudiants & 2 étudiants \\
\hline $\begin{array}{l}\text { 2. Savoir comparer la forme des emprunts à la } \\
\text { forme qu'ils ont dans la langue d’origine }\end{array}$ & 3 étudiants & 4 étudiants & 3 étudiants \\
\hline $\begin{array}{l}\text { 3. Savoir comparer les rapports phonie-graphie } \\
\text { entre les langues }\end{array}$ & 2 étudiants & 6 étudiants & 2 étudiants \\
\hline
\end{tabular}




\begin{tabular}{|c|c|c|c|}
\hline Questions du questionnaire & $\begin{array}{l}\text { Ressource } \\
\text { non acquise }\end{array}$ & $\begin{array}{l}\text { Ressource } \\
\text { en voie } \\
\text { d'acquisition } \\
\end{array}$ & $\begin{array}{l}\text { Ressource } \\
\text { acquise }\end{array}$ \\
\hline $\begin{array}{l}\text { 4. Savoir comparer les langues à lécoute par } \\
\text { exemple l'ukrainien et le polonais }\end{array}$ & 3 étudiants & 2 étudiants & 5 étudiants \\
\hline $\begin{array}{l}\text { 5. Savoir percevoir la proximité lexicale dans des } \\
\text { langues étrangères }\end{array}$ & 3 étudiants & 4 étudiants & 3 étudiants \\
\hline $\begin{array}{l}\text { 6. Savoir comparer les fonctionnements } \\
\text { grammaticaux de langues différentes }\end{array}$ & 3 étudiants & 5 étudiants & 2 étudiants \\
\hline $\begin{array}{l}\text { 7. Savoir percevoir la proximité et la distance } \\
\text { entre la graphie et des sons }\end{array}$ & 2 étudiants & 4 étudiants & 3 étudiants \\
\hline $\begin{array}{l}\text { 8. Savoir comparer les pratiques de } \\
\text { communication non verbales autres avec ses } \\
\text { propres pratiques }\end{array}$ & 2 étudiants & 5 étudiants & 3 étudiants \\
\hline $\begin{array}{l}\text { 9. Savoir comparer des phénomènes culturels } \\
\text { dans des langues ou cultures plus ou moins } \\
\text { familières }\end{array}$ & 3 étudiants & 5 étudiants & 2 étudiants \\
\hline $\begin{array}{l}\text { 10. Savoir repérer des spécificités, références ou } \\
\text { appartenances, au plan culturel }\end{array}$ & 3 étudiants & 3 étudiants & 4 étudiants \\
\hline $\begin{array}{l}\text { 11. Savoir utiliser les connaissances et } \\
\text { compétences acquises dans une langue } \\
\text { maternelle pour apprendre une autre langue }\end{array}$ & 3 étudiants & 4 étudiants & 3 étudiants \\
\hline $\begin{array}{l}\text { 12. Savoir utiliser un éventail de critères pour } \\
\text { établir la proximité ou la distance linguistiques } \\
\text { ou culturelles }\end{array}$ & 5 étudiants & 3 étudiants & 2 étudiants \\
\hline $\begin{array}{l}\text { 13. Savoir communiquer dans des groupes bi/ } \\
\text { plurilingues en tenant compte du répertoire de } \\
\text { ses interlocuteurs }\end{array}$ & 3 étudiants & 4 étudiants & 3 étudiants \\
\hline $\begin{array}{l}\text { 14. Savoir produire un texte en alternant les } \\
\text { registres, variétés ou langues de façon } \\
\text { fonctionnelle (lorsque la situation s'y prête) }\end{array}$ & 4 étudiants & 4 étudiants & 2 étudiants \\
\hline $\begin{array}{l}\text { 15. Savoir présenter dans une langue un } \\
\text { commentaire ou un exposé à partir d'un } \\
\text { ensemble plurilingue de documents }\end{array}$ & 2 étudiants & 8 étudiants & \\
\hline $\begin{array}{l}\text { 18. Savoir varier ou alterner les langues, les codes } \\
\text { ou les modes de communication }\end{array}$ & 1 étudiant & 8 étudiants & 1 étudiant \\
\hline $\begin{array}{l}\text { 17. Savoir utiliser les connaissances et } \\
\text { compétences acquises dans une langue pour } \\
\text { apprendre une autre langue }\end{array}$ & 2 étudiants & 7 étudiants & 1étudiant \\
\hline $\begin{array}{l}\text { 18. Savoir analyser les malentendus dorigine } \\
\text { culturelle }\end{array}$ & 1 étudiant & 7 étudiants & 2 étudiants \\
\hline $\begin{array}{l}\text { 19. Savoir utiliser différents techniques } \\
\text { d’apprentissage des langues }\end{array}$ & 4 étudiants & 6 étudiants & \\
\hline
\end{tabular}


(la continuation du tableau 19)

\begin{tabular}{|c|c|c|c|}
\hline \multicolumn{1}{|c|}{ Questions du questionnaire } & $\begin{array}{c}\text { Ressource } \\
\text { non acquise }\end{array}$ & $\begin{array}{c}\text { Ressource } \\
\text { en voie } \\
\text { d'acquisition }\end{array}$ & $\begin{array}{c}\text { Ressource } \\
\text { acquise }\end{array}$ \\
\hline $\begin{array}{c}\text { 20. Vouloir connaître différentes langues } \\
\text { étrangères }\end{array}$ & 2 étudiants & 6 étudiants & 2 étudiants \\
\hline $\begin{array}{c}\text { 21. Savoir élaborer un système interprétatif } \\
\text { permettant d'appréhender les particularités } \\
\text { d'une culture (p .ex. Les significations, les } \\
\text { croyances, les pratiques culturelles, etc. })\end{array}$ & 5 étudiants & 4 étudiants & 1 étudiant \\
\hline $\begin{array}{c}\text { 22. Savoir identifier des frontières linguistiques et } \\
\text { les frontières politiques }\end{array}$ & 4 étudiants & 4 étudiants & 2 étudiants \\
\hline $\begin{array}{c}\text { 23. Savoir analyser des schémas d'interprétations } \\
\text { (des stéréotypes) }\end{array}$ & 3 étudiants & 5 étudiants & 2 étudiants \\
\hline AU TOTAL: & $26 \%$ & $50 \%$ & $24 \%$ \\
\hline
\end{tabular}

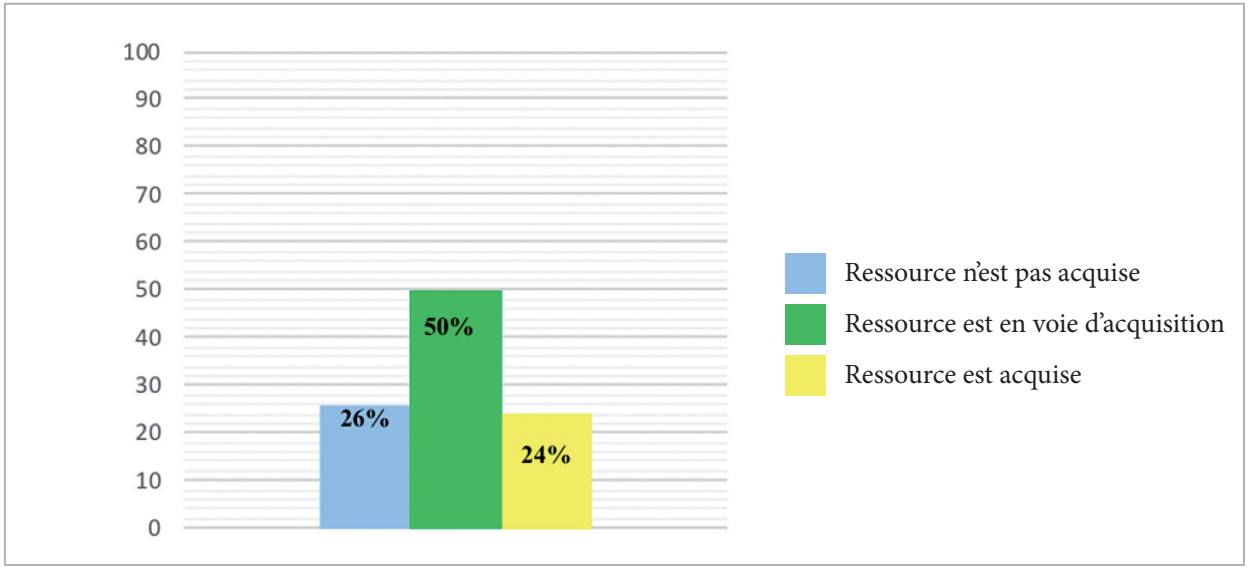

Figure 19. Le degré du développement de la CPLPC des participants à létude (pré-test).

Une analyse quantitative du questionnaire a montré que les ressources du descripteur savoir-faire de la moitié des apprenants du groupe participant au cours de français de la diplomatie sont en voie d'acquisition. $26 \%$ des participants à l'étude trouvent que leur CPLPC n'est pas acquise. Seulement 24\% des étudiants trouvent que leur CPLPC est développée.

Nous allons procéder à une distribution des données par étudiant et voir la moyenne qui prédomine afin de tirer des conclusions. 


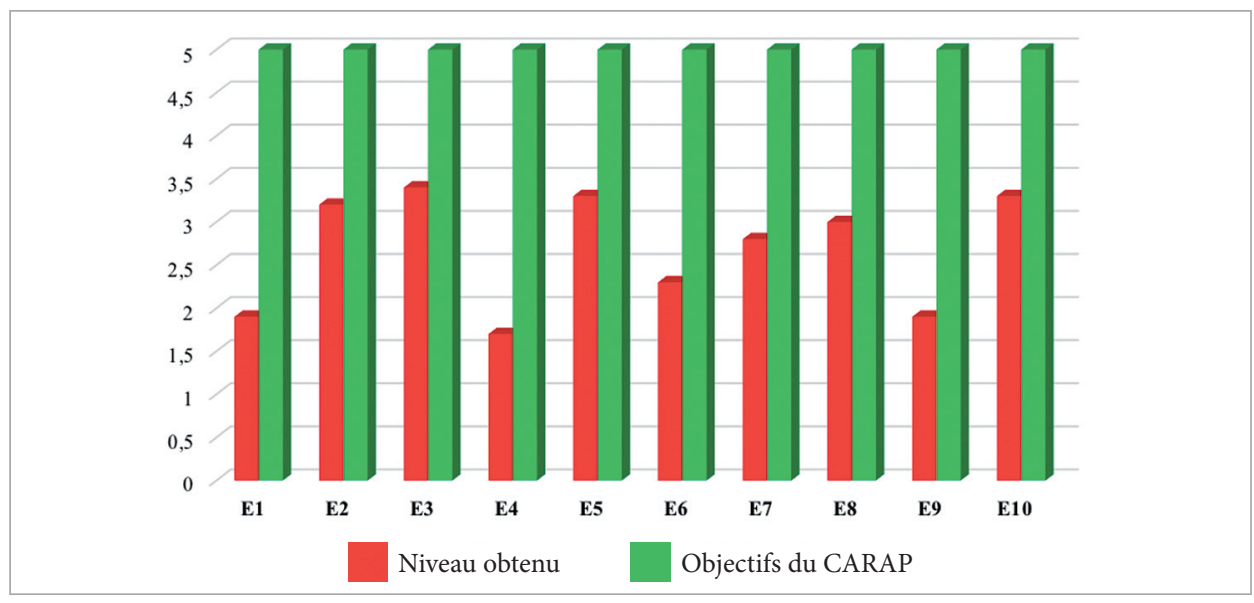

Figure 20. Létat initial de la CPLPC de participant à létude par rapport aux objectifs du CARAP.

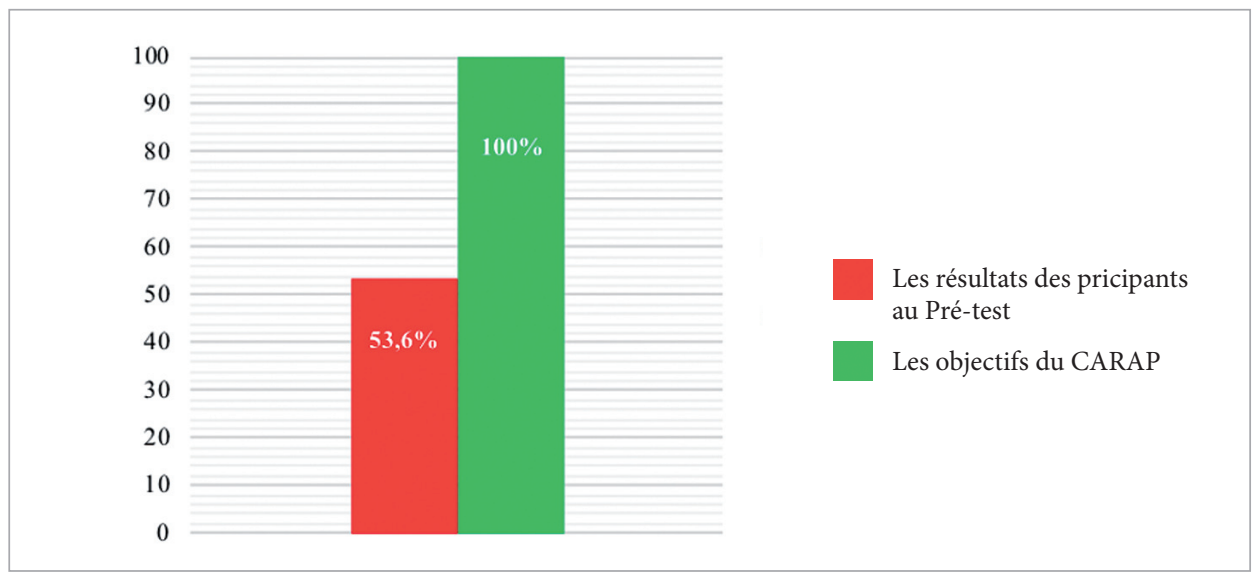

Figure 21. Degré d’acquisition de la CPLPC des répondants par rapport aux objectifs du CARAP.

Il s'ensuit que notre intuition concernant le besoin de développer la compétence plurilingue et pluriculturelle dans la formation linguistique des diplomates est entièrement confirmée puisque la majorité des répondants du cours de français de la diplomatie n'ont pas encore le niveau d'acquisition de la CPLPC demandée par le CARAP. Il est étonnant de constater que parmi 10 participants à l'étude, 4 apprenants (É1, É4, É6 et É9) ne répondent même pas à moitié aux objectifs du CARAP concernant le développement de la CPLPC. Par ailleurs, la figure 20 dévoile que seuls 5 apprenants (É2, É3, É5, É8 et É10) évaluent leur CPLPC sur 3 ou plus que 3 , ce qui donne $60 \%$ du total des objectifs du CARAP. Personne n'a jugé son niveau de développement de la CPLPC comme supérieur à 4 (soit 80\%). La figure 
21 permet de voir que la totalité des réponses des participants à l'étude se résume à 53,6\% des objectifs du CARAP. Étant donné la spécificité de notre public, ce résultat nous semble insuffisant.

En outre, il nous a également paru intéressant d'analyser les ressources du descripteur savoir-faire que la moitié (soit 5 personnes) des participants à l'étude jugent comme «non acquise ». Il s'agit avant tout de ressources :

12) Savoir utiliser un éventail de critères pour établir la proximité ou la distance linguistiques ou culturelles.

21) Savoir élaborer un système interprétatif permettant d’appréhender les particularités d'une culture (p .ex. Les significations, les croyances, les pratiques culturelles, etc. ).

Nous pouvons voir que ces deux ressources ont des traits communs. Il s'agit ici de la rencontre interculturelle qui peut être à l'origine de chocs profonds en dépit d'un capital de bonne volonté et des principes de tolérance et de respect de l'autre (CohenEmerique, $2011: 2$ ). Établir la proximité ou la distance linguistique/culturelle ainsi qu'élaborer un système qui permettrait d'appréhender les particularités d'une culture, ce sont des aspects qui ne sont pas développés ni en classe de FLE ni en classe de FOS. Découvrir le cadre de référence de l'Autre ne revient pas à se focaliser exclusivement sur les différences culturelles. Il faut plutôt s'intéresser aux identités liées aux trajectoires de ces personnes ainsi qu'aux processus d'acculturation intériorisés de façon unique dans une subjectivité (ibid. : 2) et aux rapports développés par son interlocuteur avec la société d'accueil. Sans cette connaissance du dedans qui exige un apprentissage, il n’y aura pas de véritable compréhension.

En outre, l'analyse approfondie des questions respectives montre que les ressources que la majorité des apprenants (toujours $50 \%$ ou $40 \%$ ) ont jugées comme acquises concernent la comparaison des éléments culturels.

\begin{tabular}{|l|}
\hline 1) Savoir comprendre des textes écrits dans des langues inconnues ou peu familières \\
\hline 2) Savoir comparer la forme des emprunts à la forme qu'ils ont dans la langue d'origine \\
\hline 3) Savoir comparer les rapports phonie-graphie entre les langues \\
\hline 4) Savoir comparer les langues à lécoute par exemple l'ukrainien et le polonais \\
\hline 5) Savoir percevoir la proximité lexicale dans des langues étrangères \\
\hline 6) Savoir comparer les fonctionnements grammaticaux de langues différentes \\
\hline 7) Savoir percevoir la proximité et la distance entre la graphie et des sons \\
\hline 8) Savoir comparer les pratiques de communication non verbales autres avec ses propres pratiques \\
\hline 9) Savoir comparer des phénomènes culturels dans des langues ou cultures plus ou moins familières \\
\hline
\end{tabular}

Ce résultat ne nous étonne pas puisqu'actuellement l'enseignement de l'interculturalité se focalise surtout sur la comparaison des éléments culturels ou linguistiques. 
En effet, aussi bien des manuels de FLE que de FOS comparent des cultures entre elles ou examinent des dynamiques interactionnelles qui impliquent plusieurs cultures. Il s'ensuit que l'on réduit souvent les problématiques interculturelles à la seule approche comparative de cultures (nationales). Pire, dans les formations à l'interculturalité, à destination de cadres d'entreprise par exemple, l'interculturel peut se trouver simplifié à une petite série de «dimensions": de clés à comprendre, à apprendre, pour qui souhaite devenir un «bon » communicant « interculturel ». Cependant, le simple fait qu'une étude évoque un autre pays et que les apprenants comparent des coutumes dans plusieurs cultures ne rend pas ce cours interculturel. Pour répondre à des impératifs de vulgarisation, de transmission et d'opérationnalité rapides, on gomme parfois la complexité et le caractère dynamique du processus interculturel intersubjectif, au risque de s'exposer aux recettes faciles et à leur lot de stéréotypes (Frame, $2017: 2$ ).

Pour résumer, il est intéressant de remarquer qu'au niveau numérique notre résultat semble démontrer l'idée que la compétence plurilingue et pluriculturelle des futurs diplomates étudiant au Collège d'Europe est en voie d'acquisition ou n'est pas encore acquise. Cela peut être d'autant plus surprenant que nous parlons d'un public spécifique dont le travail est composé en grande majorité des relations interculturelles avec différents partenaires diplomatiques.

Il en résulte que l'idée d'un fort investissement dans le développement de la CPLPC est justifiée. Ce diagnostic, confirmant le besoin bien-fondé de notre recherche, est le point de départ d’une analyse plus détaillée.

\subsection{Les résultats du Portfolio}

Voyant le besoin en développement de la compétence plurilingue et pluriculturelle, nous avons proposé à nos apprenants de travailler pendant toute l'année académique avec le Portfolio européen des langues au service des objectifs professionnels. En plus de tous les éléments que contient chaque Portfolio ayant pour but de favoriser l'autoévaluation, permettre de consigner le niveau de toutes les langues, aider à définir les objectifs d'apprentissage, plusieurs points ont été ajoutés à notre document. Il s'agissait surtout de stimuler la réflexion sur la manière de percevoir les langues, de développer la réflexion sur les objectifs professionnels des langues.

La première observation est que tous les questionnaires n'ont pas été remplis dans leur totalité. Si $40 \%$ des apprenants ont répondu à la majorité des questions, moins d'un quart ont répondu seulement aux premières questions concernant leurs connaissances langagières. Un seul Portfolio comporte des réponses à chacune des questions. Le manque de temps pour répondre à des questions, dont beaucoup ne requéraient qu'une coche, suffit-il à expliquer la quasi-absence de Portfolios complets ? 
Nous voudrions mentionner à cette occasion que les étudiants avaient été prévenus que le Portfolio serait utilisé dans l'étude de recherche. Il se peut que cela soit la cause de leur prudence et l'attitude conservatrice dans les réponses données.

À notre grande surprise, malgré la difficulté à travailler régulièrement avec le Portfolio, la majorité des étudiants déclarent avoir l'intention de l'utiliser ultérieurement, même si leur enseignant ne le leur demande pas. Nous pouvons nous interroger cependant sur la manière dont ils l'utiliseront : pour s'autoévaluer ou pour apprendre?

Après avoir récapitulé les idées générales sur le travail des étudiants avec le Portfolio, analysons maintenant les données qualitatives de cet outil qui a donné la possibilité aux apprenants de procéder à une introspection dans leur façon de penser aux langues et cultures étrangères.

\subsubsection{Analyse qualitative du Portfolio}

\section{Section I : comment j'utilise mes langues}

Dans un premier temps, nous avons discerné tous les passages qui montrent le multilinguisme des apprenants. Dans la plupart des cas (70\% des interrogés), les apprenants parlent au moins 3 langues (anglais, français et leur langue première). Certains viennent de familles bilingues. Nous pouvons alors constater qu'ils sont multilingues. Une question s'ensuit : sont-ils plurilingues ? C'est justement cette question qui attirera notre attention. Notons au passage qu'en parlant librement avec les apprenants en classe, comme on pouvait s'y attendre, ils admettaient tous se sentir parfaitement plurilingues et prêts à travailler dans un milieu multiculturel. Et pourtant, pour répondre à cette question, il est nécessaire de recourir aux données recueillies dans le Portfolio.

Rappelons que l'objectif de la première partie du Portfolio était de voir si l'apprenant a servi de médiateur entre des personnes parlant différentes langues et de cultures différentes. Parmi les réponses les plus intéressantes, nous pouvons noter les répliques suivantes ${ }^{219}$ :

${ }^{219}$ Nous avons gardé l’orthographe originale. 
Tableau 20. Section I du Portfolio.

Comment j’utilise mes langues

Il marrive d'utiliser plusieurs langues en même temps ou de servir de « médiateur » entre des personnes parlant différentes langues et de cultures différentes.

\begin{tabular}{|c|c|c|c|c|}
\hline & Date & Situation & $\begin{array}{l}\text { Langues que } \\
\text { j’ai utilisées }\end{array}$ & $\begin{array}{l}\text { Comment j’y suis parvenu? } \\
\text { Ce qui m’a posé problème. } \\
\text { Ce qui m’a aidé. }\end{array}$ \\
\hline É4 & 2014 & $\begin{array}{l}\text { Mon arabe ami qui était perdu } \\
\text { à Varsovie }\end{array}$ & $\begin{array}{l}\text { - arabe } \\
\text { - polonais }\end{array}$ & J'ai traduit \\
\hline É8 & 2018 & $\begin{array}{l}\text { Dans l'aéroport quelqu'un mia } \\
\text { demandé quelque chose qui } \\
\text { pour lui était bizarre en Géorgie }\end{array}$ & - russe & Rien \\
\hline É2 & 2000 & Impossible & - anglais & Tout le monde parle anglais \\
\hline É9 & always & Everyday & - english & English for everything \\
\hline
\end{tabular}

Ces réponses reflètent des clichés et des stéréotypes largement diffusés en ce qui concerne le rôle de médiateur. Deux tendances se dessinent. Tout d'abord, nous pouvons observer des réponses qui indiquent qu'être médiateur se réduit au rôle de traducteur. Selon É4 et É8 il suffit de traduire des phrases pour aider une personne perdue ou en difficulté venant d'une culture différente. Cependant, nous savons que le rôle de médiateur ne consiste pas uniquement en la transmission de savoirs issus du manuel. Il s'agit également pour l'étudiant de devenir un facilitateur, un guide qui aide les inconnus à surmonter leurs difficultés, à expliquer par exemple « quelque chose qui pour lui était bizarre en Géorgie».

Un autre point qui nous a intéressé ici était le rôle de la langue anglaise. Ce n'est pas la première fois que nous entendons chez les apprenants que l'anglais résout tous les problèmes interculturels. Pour É2, l'anglais est un passe-partout qui ouvre toutes les portes et qui est pour lui « une langue de monde». Il existe actuellement dans l'opinion populaire un sentiment répandu selon lequel les langues étrangères cèdent devant l'anglais parce que ce dernier possède des qualités le rendant plus apte à la création lexicale, plus facile. Néanmoins, cette tendance met en danger la richesse de la diversité linguistique et empêche le développement de la compétence interculturelle ${ }^{220}$.

${ }^{220}$ C'est ainsi qu'est apparue une nouvelle discipline dans le champ de la linguistique : la documentation des langues en danger. Cette discipline (soutenue, y compris financièrement, par de grandes fondations) commence à faire des émules en Asie et en Afrique puisque d'ici la fin du XXIe siècle, plus de la moitié des langues parlées aujourd'hui risquent de disparaître. L'UNESCO participe à ce combat : dans un document publié en 2003 sont déclinés neuf critères de vitalité transmission des parents aux enfants, nombre de locuteurs, etc. Ces critères permettent de mesurer les chances de vie ou de survie d'une langue. Et d'aider certaines „petites” langues à se maintenir, à se revitaliser, voire à se développer (Grinevald, $2003: 1$ ). 
Pour finir, nous avons remarqué qu'un nombre significatif de répondants (5 productions) n'ont pas répondu à cette question. Il nous semble cependant que cela ne veut pas dire que cette question n'a pas eu d'effet visé, celui de prendre conscience explicitement de ce qu'est le médiateur et de son rôle dans un dialogue interculturel.

\section{Section II : mes objectifs personnels/ professionnels}

Dans une deuxième partie, nous avons demandé aux participants à l'étude les raisons pour lesquelles ils apprennent les langues étrangères. La majorité des répondants (6 productions) se contentent de constater que les langues vont leur servir dans leur carrière professionnelle sans préciser des détails. Il y a également des réponses plus complexes qui nous font penser à l'approche plurielle. Cette posture peut être illustrée des phrases suivantes :

« J'apprends le latin pour comprendre l'histoire européenne » (É8);

« J'ai habité en Pologne pendant près de 3 ans. J'ai fait beaucoup d'amis. La langue m'aide comprendre le pays et mes amis » (É10);

« La traduction tout détruit, j’apprends l'espagnol car je veux comprendre la politique espagnole»(É1).

Nous pouvons voir que parmi les répondants, il y en a ceux qui voient la langue comme un élément clé pour comprendre une culture, comme un outil pour acquérir de nouvelles connaissances et des expériences d’autres personnes, qui sont véhiculées dans différentes langues. L'expérience vécue par É10 montre qu'il comprend qu'il est impossible de résumer le processus d'enseignement/apprentissage d'une langue étrangère à la simple acquisition d'un instrument de communication. De plus, É1 semble savoir qu'il s'agit plutôt d'un processus interdisciplinaire dont l'objectif est de familiariser l'apprenant à un univers de l'autre et de faire découvrir la réalité socioculturelle qui sous-tend tout énoncé linguistique.

Il est intéressant de remarquer que la conscience interculturelle de ces trois étudiants est largement différente de celle du reste du groupe.

Un autre élément qui a attiré notre attention sont les réponses des apprenants à la question concernant leurs projets liés à l'usage de la langue en voie d'acquisition.

Tableau 21. Section II du Portfolio.

J'aimerais savoir faire les choses suivantes avec les langues que j’apprends :

\begin{tabular}{|c|c|l|}
\hline Apprenant & Langue & \multicolumn{1}{c|}{ Réponses } \\
\hline É4 & français & $\begin{array}{l}\text { Ce que j'aimerais savoir faire : comment débattre en français dans } \\
\text { des institutions de l'UE } \\
\text { Comment je compte y parvenir : no idea }\end{array}$ \\
\hline
\end{tabular}




\begin{tabular}{|c|c|l|}
\hline Apprenant & Langue & \multicolumn{1}{c|}{ Réponses } \\
\hline É6 & français & $\begin{array}{l}\text { Ce que j'aimerais savoir faire : analyser le discours politique } \\
\text { Comment je compte y parvenir : lire des textes politiques } \\
\text { intensivement }\end{array}$ \\
\hline É10 & français & $\begin{array}{l}\text { Ce que j'aimerais savoir faire : parler avec les diplomates } \\
\text { Comment je compte y parvenir : apprendre le vocabulaire } \\
\text { diplomatique }\end{array}$ \\
\hline É1 & français & $\begin{array}{l}\text { Ce que j'aimerais savoir faire : travailler en français } \\
\text { Comment je compte y parvenir : lire, lexique, vocabulaire }\end{array}$ \\
\hline
\end{tabular}

L'analyse des réponses démontre qu'il s'y cache une image figée et traditionnelle de la langue spécialisée. Il est visible que l'enseignement du français de la diplomatie est pour nos étudiants (et pour la majorité des auteurs des manuels de FOS) surtout centré sur le lexique, en privilégiant la compétence de réception de textes écrits. Selon ces opinions, l'enseignement/apprentissage se fait à travers la simple lecture-analysetraduction de textes spécialisés. Nous avons ici affaire à la théorie construite dans les années 1960 qui prônait une démarche essentiellement lexicologique. Les études sur l'enseignement du FOS montrent bien la difficulté à sortir d'une vision traditionnelle, imprégnée par les approches des années 1960 et 1970. Or, les approches didactiques ont subi un développement significatif au cours des dernières décennies, se centrant surtout autour de la communication et, à présent, de l'action. L'approche focalisée sur le vocabulaire ne laisse pas une large place aux variations interculturelles. En nous bornant uniquement à l'apprentissage du lexique, nous n'amènerons pas nos futurs hauts fonctionnaires au dialogue qui développe des modalités de coopération, qui noue des relations avec les citoyens d'un autre pays.

En outre, remarquons qu'interrogés sur l'expérience d'apprentissage linguistique positive, les enquêtés indiquent surtout l'authenticité.

Tableau 22. Section II b du Portfolio.

Expériences d’apprentissage linguistique que j’ai trouvé particulièrement positives ou marquantes pendant le cours de français de la diplomatie:

\begin{tabular}{|c|l|}
\hline Apprenant & \multicolumn{1}{c|}{ Réponses } \\
\hline É2 & $\begin{array}{l}\text { Conversations comme avec des natifs, leçons naturelles (not fake), lecture dans la } \\
\text { langue originale }\end{array}$ \\
\hline É6 & Des articles, des comptes sur Twitter des politiciens \\
\hline É7 & $\begin{array}{l}\text { La connaissance des autres politiciens et leur culture que je ne connais pas; } \\
\text { «l'anglais et l'italien accepté par la prof }\end{array}$ \\
\hline É8 & Nos présentations \\
\hline
\end{tabular}


D’après les données réunies, tous les étudiants cités remarquent que le motif principal de nos cours était l'authenticité. Effectivement, nous avons uniquement utilisé des documents authentiques tels que les discours des politiciens, des vidéos des sessions plénières du Parlement européen, des entretiens avec des diplomates venant du monde entier, etc. Les étudiants ont travaillé régulièrement à l'acquisition des compétences interculturelles dans le contexte réel. Rappelons encore que le document authentique permet l'acquisition de la compétence sociolinguistique en permettant l'analyse des mêmes éléments que ceux utilisés par les locuteurs natifs. Ceci est encore plus important dans les situations où les apprenants ont rarement l'occasion d'utiliser leur langue cible comme authentique instrument de communication en dehors de la classe de langue. La variation sociolinguistique à laquelle les apprenants sont exposés dans la classe de langue est donc relativement limitée.

Par ailleurs, nous avons noté un commentaire intéressant sur l'importance des langues étrangères en classe. L'É7 apprécie le fait que nous n’avons pas interdit l'usage des langues étrangères en classe de français de la diplomatie. Bien au contraire, nous avons incité les apprenants à mobiliser différentes ressources et plusieurs méthodes telles que les réflexions sur leurs propres expériences et stratégies d'apprentissages pour faciliter l'acquisition d'une nouvelle langue. Nous sommes d'accord avec Wokusch et Lys (2007 : 262) que l'apprentissage d'une langue inconnue, surtout si celle-ci n'est pas la première langue étrangère, ne part pas de zéro ; l'apprenant bénéficie de certaines connaissances préexistantes comme des connaissances (méta) linguistiques, des stratégies d'apprentissages, des connaissances générales qu'il peut transférer pour l'acquisition de la nouvelle langue. Dans ce sens, tout le répertoire linguistique de l'apprenant peut fonctionner comme source de transfert $^{221}$; non seulement les langues scolaires, mais aussi les dialectes, les langues minoritaires ou les langues de la migration. C'est l'un des aspects fondamentaux de la didactique du plurilinguisme que nous avons voulu développer avec nos apprenants.

\section{Section III : apprendre à apprendre - la réflexion sur les acquis}

La troisième partie du Portfolio nous apporte des données liées à la réflexion sur les acquis. Ce fragment est une sorte de journal intime ou d'auto-narration où les participants à l'étude sont invités à développer et à mettre en œuvre des conduites réflexives et autonomes. Les répondants devraient pouvoir interpréter leurs résultats, déterminer les performances à prendre en compte, comparer les résultats atteints aux résultats prévus, porter et adapter leur jugement.

À notre grande surprise, cette partie a été remplie par presque 70\% des apprenants. La demande a été formulée de la façon suivante : pensez à ce que vous avez appris au cours de ces 2 semestres. Donnez un exemple des différentes ressources et démarches employées pour vous aider à apprendre le français de la diplomatie.

Premièrement, certains répondants soulignent qu'ils ont beaucoup apprécié le travail en groupes multiculturels et qu'ils voudraient continuer ce type

${ }^{221}$ Nous parlons ici d'un phénomène de transfert positif. 
d'apprentissage dans l'avenir : « J'ai adoré travailler avec d'autres personnes » (É1); "Les mieux étaient rôles dans un groupe de travail »; (É3) « J’ai remarqué que je prefere travailler avec un amis après les cours " (É4); «Les autres personnes étaient motivants " (É8). Nous croyons que le travail en sous-groupes ou en petits groupes est une pratique pédagogique fortement recommandée en didactique des langues étrangères. Dans le contexte du FLE, l'enseignement peut se faire sous de multiples formes en réutilisant différentes techniques pour intérioriser certains comportements culturels ou linguistiques où le travail individuel et le travail en groupe sont alternés. Le travail en groupe favorise chez l'apprenant la prise de conscience du processus d'appropriation des apprentissages, le plaisir de partager des idées, de confronter des points de vue et de se valoriser.

Deuxièmement, nous avons trouvé que dans presque la moitié des productions est abordée la question de la difficulté de la matière étudiée : "Le français de la diplomatie est trop difficile » (É3) ; «Je ne sais pas comment je pourrais travailler avec les Français » (É8) ; « Je voudrais être diplomate, mais c'est difficile, merci pour ce cours » (É7). Nous sommes contents que les répondants aient mentionné ce sujet. La prise de conscience d'un déficit linguistique et d'un déficit interculturel est cruciale et, selon nous, plus importante que le savoir linguistique acquis. De plus, il est nécessaire que les apprenants prennent conscience des asymétries linguistiques qu'ils vont rencontrer dans leur futur travail et s'y préparent, puisque cela pourrait être facteur de stress et de vulnérabilité dans l'échange. Nous trouvons que pour pallier ces déficits, les locuteurs devraient savoir mobiliser certaines stratégies permettant de les compenser par la saisie des indices de contextualisations, des indices interculturels et sociolinguistiques.

Finalement, nous devons constater que dans cette panoplie de propositions, un extrait attire une attention particulière, car son auteur semble dépasser les généralités et parle de ses émotions. Le répondant remarque que "I don't know if it was the purpose of this classes but after all this portfolio stuff, strange classes, I've the mess in my head $»^{222}$ (É9). Il est intéressant de voir que le travail avec le Portfolio provoque chez cet apprenant beaucoup d'émotions. C'est compréhensible, nous savons qu'il n'est pas facile de changer ou d'abandonner le style d'apprentissage, le rythme du cours que nous connaissons et commencer à voir le cours de langue d'une manière complètement différente.

\subsubsection{Le travail avec le Portfolio- bilan}

Les affirmations des étudiants ont permis de voir et de comprendre les concepts avec lesquels ils partent dans leur travail sur la langue et l'interculturel. À ce stade, il nous semble que le travail avec le Portfolio a amené les apprenants à réfléchir différemment

${ }^{222}$ « Je ne sais pas si cétait l'objectif de ce cours, mais après le travail avec le Portfolio, des classes hors commun, il y a un pêle-mêle dans ma tête " notre traduction. 
sur leur processus d'apprentissage, à se remettre en question et peut-être à valoriser des trajectoires plurilingues.

En remplissant régulièrement le Portfolio, les étudiants ont certainement renforcé l'autonomie et la motivation. Nous croyons que les éléments interculturels, qui y apparaissaient explicitement et implicitement ont influencé d'une certaine manière leur vision de la langue étrangère qui n'est plus détachée de l'Autre.

\subsection{Scénarios pédagogiques de cours exploitant le CARAP}

La prochaine étape du développement de la compétence plurilingue et pluriculturelle a consisté en la conception de séquences basées sur des ressources du descripteur savoir-faire du CARAP. Rappelons que nos séquences ont été réalisées avec un groupe de 10 étudiants du Collège d'Europe à Natolin aux leçons de français de la diplomatie.

Avant d'entrer dans le vif du sujet, rappelons le plan entier du cours que nous avons réussi à réaliser entre septembre 2017 et avril 2018.

COURS : FRANÇAIS DE LA DIPLOMATIE B1

Marta Wojakowska

Plan de cours

\begin{tabular}{|c|l|}
\hline DATE & \multicolumn{1}{c|}{ CONTENU } \\
\hline $\mathbf{8 . 0 9 . 2 0 1 7}$ & $\begin{array}{l}\text { Introduction au cours de français de la diplomatie (la distribution des } \\
\text { portfolios et du pré-test). }\end{array}$ \\
\hline $\mathbf{1 5 . 0 9 . 2 0 1 7}$ & Qu'est-ce que la diplomatie ? Les regards croisés. \\
\hline $\mathbf{2 2 . 0 9 . 2 0 1 7}$ & Parcours professionnel des diplomates partie I - réaliser une enquête. \\
\hline $\mathbf{2 9 . 0 9 . 2 0 1 7}$ & $\begin{array}{l}\text { Parcours professionnel des diplomates partie II : les enjeux actuels de } \\
\text { l'évolution des métiers de la diplomatie. }\end{array}$ \\
\hline $\mathbf{6 . 1 0 . 2 0 1 7}$ & L'abécédaire du bon diplomate (partie I). \\
\hline $\mathbf{1 3 . 1 0 . 2 0 1 7}$ & Labécédaire du bon diplomate. Les points communs et les différences. \\
\hline $\mathbf{2 0 . 1 0 . 2 0 1 7}$ & Vive la différence dans la diplomatie ! Parler du choc culturel. \\
\hline $\mathbf{2 7 . 1 0 . 2 0 1 7}$ & Trouver le candidat idéal : l'entretien d'embauche (un jeu en groupes). \\
\hline $\mathbf{1 0 . 1 1 . 2 0 1 7}$ & Comment rédiger un CV pour un poste dans une institution européenne? \\
\hline $\mathbf{1 7 . 1 1 . 2 0 1 7}$ & $\begin{array}{l}\text { Rédiger une lettre de motivation pour un poste dans une institution } \\
\text { européenne. }\end{array}$ \\
\hline $\mathbf{2 4 . 1 1 . 2 0 1 7}$ & Partir en mission (réaliser un carnet de voyage). \\
\hline $\mathbf{1 . 1 2 . 2 0 1 7}$ & Le protocole, c'est le protocole! Différents protocoles dans différents pays. \\
\hline $\mathbf{8 . 1 2 . 2 0 1 7}$ & Les institutions de l'UE partie I- préparer un projet comparatif. \\
\hline $\mathbf{1 2 . 0 1 . 2 0 1 8}$ & Rencontrez des fonctionnaires de vos institutions préférées. \\
\hline
\end{tabular}




\begin{tabular}{|c|l|}
\hline DATE & \multicolumn{1}{c|}{ CONTENU } \\
\hline $\mathbf{1 9 . 0 1 . 2 0 1 8}$ & Prendre la parole en public (partie I). \\
\hline $\mathbf{2 6 . 0 1 . 2 0 1 8}$ & Rédiger une lettre officielle - (l'écriture collaborative). \\
\hline $\mathbf{2 . 0 2 . 2 0 1 8}$ & $\begin{array}{l}\text { Comment négocier dans un environnement multiculturel ? } \\
\text { Rédiger la carte des stéréotypes. }\end{array}$ \\
\hline $\mathbf{9 . 0 2 . 2 0 1 8}$ & Organisations non gouvernementales dans le monde (le débat d'Oxford) \\
\hline $\mathbf{1 6 . 0 2 . 2 0 1 8}$ & $\begin{array}{l}\text { "Quai d'Orsay- les coulisses de la diplomatie » (le reportage de TV5 Monde et } \\
\text { ARTE). }\end{array}$ \\
\hline $\mathbf{2 3 . 0 2 . 2 0 1 8}$ & Discussion autour du reportage « Quai d'Orsay- les coulisses de la diplomatie ». \\
\hline $\mathbf{2 . 0 3 . 2 0 1 8}$ & $\begin{array}{l}\text { Politicien ou diplomate de mon pays - présentation du personnage et de son } \\
\text { parcours professionnel (travail en groupe). }\end{array}$ \\
\hline $\mathbf{9 . 0 3 . 2 0 1 8}$ & Comprendre les migrations vers l'Europe. \\
\hline $\mathbf{1 6 . 0 3 . 2 0 1 8}$ & Comprendre les migrations vers l'Europe (le débat d'Oxford). \\
\hline $\mathbf{6 . 0 4 . 2 0 1 8}$ & $\begin{array}{l}\text { La lutte contre les stéréotypes et les préjugés dans la diplomatie. } \\
\text { Pourquoi lutter ? Comment lutter? }\end{array}$ \\
\hline $\mathbf{2 0 . 0 4 . 2 0 1 8}$ & Le bilan de toute l'année (le recueil des portfolios et les post-tests). \\
\hline
\end{tabular}

Figure 22. Le plan du cours de français de la diplomatie.

Source : élaboration propre.

\section{Organisation de la séquence : l'interculturel}

Voyons maintenant les éléments qui ont constitué notre séquence didactique et analysons la façon dont elle a été structurée.

Tout d'abord, il convient de dire que nous avons décidé d'organiser nos séquences selon des thèmes ${ }^{223}$. Le cours de français de la diplomatie commence avec la réflexion autour de la notion de la diplomatie. Plus tard, les leçons dévoilent les coulisses du travail des diplomates du monde entier, différentes institutions européennes, etc. D’autres thèmes autour desquels se focalisent les séquences sont les suivants : le protocole diplomatique, le français professionnel (la rédaction du CV et de la lettre de motivation), le Brexit, les défis liés aux migrations, les stéréotypes, etc.

Il est important de remarquer que les thèmes choisis ne diffèrent pas complètement de ceux qui sont abordés dans le manuel Objectif Diplomatie B1/B2 : le Français des relations européennes et internationales. La question qui s'impose est donc celle de savoir en quoi consiste la différence entre nos séquences inspirées du CARAP et celles du cours plus traditionnel comme celui proposé par le manuel ci-mentionné.

${ }^{223}$ Cuq (2003 : 161-162) distingue les leçons, les unités, les séquences, les modules ou les dossiers qui peuvent être divisés selon les objectifs de communication, des structures grammaticales, des thèmes ou on peut $y$ croiser plusieurs entrées. 
Il paraît que la différence la plus importante réside dans les objectifs de la séquence. À titre d'exemple, voyons les objectifs de la séquence que nous avons conçus pour le cours en question.

\section{Qu'est-ce que la diplomatie?}

Objectifs :

$>$ Prendre conscience des différences ou des points communs dans un groupe multiculturel et multilingue.

Prendre conscience de l'appartenance à plusieurs groupes d'identification.

Activer les connaissances lexicales et vérifier que les apprenants connaissent les mots et les expressions liés au thème de la diplomatie

Travailler l'éveil aux langues (CARAP)

Figure 23. Séquence $n^{\circ} 1$ « Qu’est-ce que la diplomatie?».

Nous pouvons voir que chaque objectif de la séquence tend à développer la compétence plurilingue et pluriculturelle. En effet, la leçon est axée sur la rencontre interculturelle ${ }^{22}$ et l'échange culturel. Étant donné que c'était la première séquence du cours, nous avons voulu dès le début accentuer la présence de l'interculturel et habituer les apprenants à travailler de manière différente. Voyons comment ces objectifs ont été insérés dans la totalité de cette séquence.

\section{Étape 1 - Découvrir la thématique du cours}

\section{Consigne :}

Écrivez sur une petite feuille les trois mots qui vous viennent immédiatement à l'esprit quand vous pensez à la diplomatie.

Formez des groupes de deux et comparez vos réponses.

${ }^{224}$ Que se passe-t-il lorsque « Je » rencontre « Autrui »? Schématiquement, trois démarches peuvent être identifiées.

- Dans une première démarche, on projette inconsciemment notre système de références culturelles sur autrui qui est considéré comme un être étrange et aux comportements bizarres. Lapproche est souvent méfiante, voire craintive.

- Dans une deuxième démarche, autrui est appréhendé comme un individu ayant des normes propres, différentes des nôtres ; la différence est donc reconnue, mais aucun retour sur ses propres référents culturels n'est opéré.

- Dans la troisième démarche, la relativité du système culturel d'autrui est accompagnée d'un retour réflexif sur sa propre culture et par conséquent, le système culturel de référence personnel n'est plus érigé en modèle unique et supérieur.

Dans une rencontre interculturelle, le locuteur évolue au sein d'un espace où cohabitent et s'entrecroisent plusieurs cultures. Le locuteur interculturel devient à la fois conscient de sa propre identité et de celle de ses interlocuteurs. Il est en mesure d'accepter la réciprocité des regards. En ce sens, il est capable de vivre avec et dans la diversité culturelle. 
Maintenant formez des groupes de trois, trouvez un point commun et une différence entre vous. Puis, choisissez ensemble le mot qui sera le plus important pour votre groupe. Partagez-le ensuite en classe et argumentez pourquoi ce mot semble clé pour le terme «la diplomatie».

\section{Étape 2 - Doter l'apprenant de connaissances. Mobiliser et mutualiser les savoirs factuels en rapport avec le sujet traité.}

\section{Consigne :}

Lisez le titre du texte ci-dessous.

Que vous évoque ce titre? Que savez-vous sur la langue française dans la diplomatie? Lisez tout le texte et répondez aux questions qui se trouvent au-dessous du document.

\section{Langue française et diplomatie : des alliées de longue date}

Depuis le milieu du XVIIe siècle, la règle voulait que pour tous les actes diplomatiques l'usage de la langue française soit général. Et si au lendemain de la Première Guerre mondiale les circonstances historiques n'ont permis plus à aucune langue une hégémonie, la langue française a quand même gardé tout son prestige. Pourquoi ?

Au XVIIe siècle, la France était la plus grande puissance démographique et militaire de l'Europe, alors que le pays était gouverné avec autorité par de fortes personnalités: Henri IV, le cardinal de Richelieu, puis le cardinal de Mazarin et Louis XIV. C'est avec Henri IV (1553-1610) qu'a commencé l'absolutisme royal en France. Imposé par les souverains de France, le français était considéré à égalité avec ce qu'on croyait être alors comme les trois « langues du Bon Dieu » : l'hébreu, le grec et le latin.

À Vienne en 1815, comme à Berlin en 1878, comme à Algésiras en 1906, comme à La Haye en 1907, on écrivait et on parlait français. Pourquoi n’en a-t-il pas été de même en 1919 à Versailles ? Les ministres plénipotentiaires anglais ont demandé que la langue anglaise soit employée et fasse foi, comme la langue française, dans le traité de Versailles, et le Conseil Suprême a cru devoir leur donner satisfaction.

Le traité de Westphalie (1648) est encore rédigé en latin. Mais tout de suite après, dans presque tous les traités, c'est le français qui est employé.

Les Français ont regretté cette dérogation aux usages traditionnels. C'était le commencement d'une diminution pour le prestige de la langue française, mais les Français ont essayé de marquer en d'autres occasions que le français restait la langue diplomatique. Lorsque le traité de Saint-Germain et le traité de Trianon ont été discutés, l'Italie qui y était directement intéressée a demandé qu'il y soit un texte italien. Ces actes internationaux ont donc été rédigés en trois langues : français, 
anglais et italien ; mais il a été décidé que seul le texte français ferait foi. En plus, parmi les nombreuses conventions qui ont dû être rédigées à la suite du traité de Versailles, figure un acte international qui réglemente le commerce des armes dans le monde et qui met au point un certain nombre de mesures antérieures qui figurent dans les actes de Bruxelles et de Berlin. Ce document a été rédigé uniquement en français.

Selon les linguistes le prestige de la langue française se trouvait, il est vrai, singulièrement facilité par les circonstances historiques. La gloire du règne de Louis XIV l'avait grandement servi. Dans les années suivantes le rayonnement intellectuel de la France qui s'étendait à l'Europe entière. Après cette période, les années de la Révolution et l'épopée napoléonienne ont donné à la langue française une expansion nouvelle. Mais si les circonstances historiques ne permettent plus à aucune langue une hégémonie qui ne s’accorde désormais pas aux mœurs générales des États, une langue qui a par sa qualité même un caractère incontestable d'universalité garde tout son prestige.

Quant à la diplomatie, d'où vient donc que le français ne soit plus employé avec la même facilité qu'autrefois?

Il y a lieu de distinguer aujourd'hui entre les conversations diplomatiques, les correspondances de chancellerie et la rédaction des traités. Autrefois conversations, correspondances, traités tout était en français. C'est que le personnel dirigeant de l'Europe était peu nombreux et qu'il appartenait aux mêmes classes sociales. Les grandes affaires étaient réglées par quelques ministres ou quelques ambassadeurs, qui avaient en commun une certaine formation professionnelle. Le monde a bien changé. Les négociations qui ont suivi la Première Guerre mondiale nous ont fait assister à une assemblée des nations sans précédent dans l'histoire.

En outre, dans chaque nation il s'est produit une évolution politique qui conduit au pouvoir un personnel beaucoup plus nombreux, beaucoup plus varié par ses origines et par sa culture que le personnel de l'Europe d'autrefois. Il en résulte que les hommes d'État s'expriment dans leur langue et qu'il n'y a plus de réunion sans interprète. Il en résulte aussi, sans qu'il y ait de règle absolue, que la correspondance de certaines chancelleries est écrite dans la langue du pays d'où elle vient.

Source : http://www.france-pittoresque.com

\section{Questions au texte :}

- Depuis quand l'usage de la langue française dans la diplomatie était général ?

- Pourquoi le français jouissait d'un grand prestige?

-A l'époque, le français était considéré à égalité avec les autres langues, lesquelles?

- Depuis quel événement peut-on parler de la diminution pour le prestige du français?

- Après la Première Guerre mondiale le monde a changé, aussi au niveau linguistique. Pourquoi au niveau linguistique? 


\section{Étape 4 - Pour aller plus loin}

\section{Consigne:}

Dans le tableau ci-dessous, vous allez trouver 18 parties de textes écrits dans 6 langues (3 parties de texte dans chaque langue). Essayez de reconnaître ces langues et de placer les parties dans le bon ordre. Répondez à l'aide de la grille.

\section{Quelques langues d'Europe... et d'ailleurs.}

Source : CARAP, auteur : Michel Candelier

\section{Grille pour la réponse}

\begin{tabular}{|l|c|c|c|}
\hline \multirow{2}{*}{ Nom de la langue } & \multicolumn{3}{|c|}{ Placez le texte dans le bon ordre } \\
\cline { 2 - 4 } \multirow{2}{*}{} & $1^{\text {ère }}$ partie & $2^{\text {de }}$ partie & $3^{\text {ème }}$ partie \\
\hline (Exemple) anglais & 1 & 16 & 9 \\
\hline
\end{tabular}

Tableau 1 (6 langues)

\begin{tabular}{|c|c|}
\hline 1) & $\begin{array}{l}\text { Euro banknotes and coin should be considered purely as "pieces of paper and metal" } \\
\text { until the date on which they are put into circulation by the banks (ie on or after }\end{array}$ \\
\hline 2) & $\begin{array}{l}\text { På grundval av rådets rekommendation som antogs föregående dag och i enlighet med } \\
\text { Europaparlamentets yttrande som avgavs på morgonen beslutade rådet }\end{array}$ \\
\hline 3) & $\begin{array}{l}\text { O Conselho congratula-se com a atenção dada aos aspectos práticos da introdução do } \\
\text { euro. As três recomendações da Comissão, de } 23 \text { de Abril de 1998, podem constituir um } \\
\text { complemento útil aos preparativos em curso a nível nacional nos }\end{array}$ \\
\hline 4) & 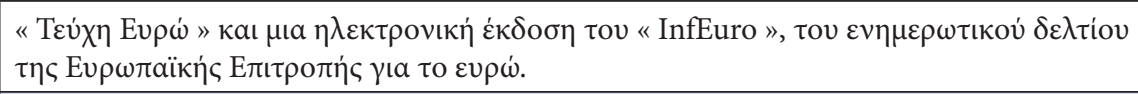 \\
\hline 5) & $\begin{array}{l}\text { van de schuldquote. Het primaire overschot is van wezenlijk belang voor het handhaven } \\
\text { van de duurzame neerwaartse tendens van de schuldquote }\end{array}$ \\
\hline 6) & $\begin{array}{l}\text { sarà premiato dal maggiore benessere derivante dall'introduzione dell'euro. } \\
\text { Si apriranno nuovi mercati e gli interessi dei consumatori saranno meglio tutelati grazie }\end{array}$ \\
\hline 7) & $\begin{array}{l}\text { enhälligt - på stats- eller regeringschefsnivå - att elva medlemsstater, nämligen Belgien, } \\
\text { Tyskland, Spanien, Frankrike, Irland, Italien, Luxemburg, Nederländerna, }\end{array}$ \\
\hline 8) & $\begin{array}{l}\text { práticas recomendadas podem, enquanto base adequada para essa abordagem, ajudar } \\
\text { a facilitar a transição para o euro nestas áreas, especialmente à luz das actuais }\end{array}$ \\
\hline 9) & $\begin{array}{l}\text { bank to debit a particular commercial bank's account for the euro banknotes } \\
\text { by the appropriate amount only when its national banknotes are returned to the } \\
\text { national central bank by that commercial bank }\end{array}$ \\
\hline
\end{tabular}




\begin{tabular}{|c|c|}
\hline 10) & $\begin{array}{l}\text { alla maggiore concorrenza. Quando saremo in grado di valutare i benefici reali, } \\
\text { tra 10-15 anni, ci renderemo conto che i vantaggi per le imprese e per i singoli cittadini }\end{array}$ \\
\hline 11) & $\begin{array}{l}\text { Österrike, Portugal och Finland uppfyller de nödvändiga villkoren för införande av den } \\
\text { gemensamma valutan den } 1 \text { januari 1999. Dessa länder kommer därför att delta i den } \\
\text { tredje etappen av Ekonomiska och monetära unionen }\end{array}$ \\
\hline 12) & 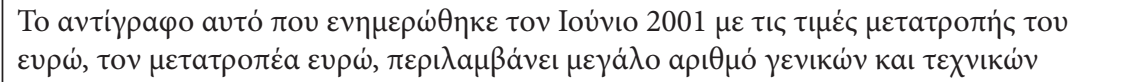 \\
\hline 13) & $\begin{array}{l}\text { países em causa, na medida em que favorecem uma abordagem voluntária às questões } \\
\text { das comissões bancárias de conversão para o euro e da dupla afixação de preços e de } \\
\text { outros montantes monetários, ao mesmo tempo que respeitam a liberdade dos Estados- } \\
\text { Membros para tomarem as medidas que considerarem necessárias. As normas de boas }\end{array}$ \\
\hline 14) & $\begin{array}{l}\text { De vermindering van het tekort en met name de gestage toename van het primaire } \\
\text { overschot, dat in } 1997 \text { meer dan } 6 \% \text { van het BBP bedroeg, hebben ertoe }\end{array}$ \\
\hline 15) & 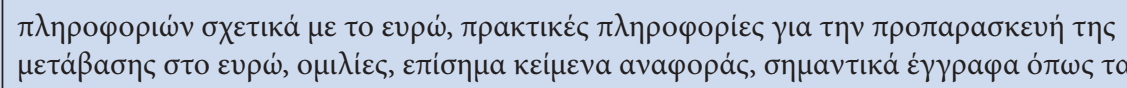 \\
\hline 16) & $\begin{array}{l}\text { a day), when they should be given value on a "step by step" basis, in an incremental way } \\
\text { rather than on a "one-off" basis. One option would be for the national central }\end{array}$ \\
\hline 17) & $\begin{array}{l}\text { Alcuni costi sono inevitabili, ad esempio quelli determinati dalla sostituzione dei } \\
\text { programmi dei computer. Tali costi vanno tuttavia visti come un investimento che }\end{array}$ \\
\hline 18) & $\begin{array}{l}\text { bijgedragen dat de schuldquote een neerwaartse tendens is gaan vertonen. De Italiaanse } \\
\text { regering heeft onlangs opnieuw haar toezegging bevestigd dat zij het primaire overscho } \\
\text { op een niveau zal houden dat in sterke mate bijdraagt tot de vermindering }\end{array}$ \\
\hline
\end{tabular}

Qu'est-ce qui vous a fait décider quelles parties relevaient de la même langue (ou à quelle langue une langue était apparentée) et qu'est-ce qui vous a fait choisir l'ordre?

Il est visible que les matériaux fournis sont stimulants, accessibles et garantissant la «saillance » des connaissances à acquérir. En outre, tous les supports utilisent différents types de ressources authentiques; la nature et les objectifs des activités varient en faisant alterner des activités d'expression, des activités créatives, etc. Nous avons également essayé de varier la difficulté des activités proposées, pour permettre aux apprenants de réfléchir et prendre confiance entre les moments de travail plus intense. La séquence se termine avec l'activité inhabituelle qui a été conçue par Michel Candelier, le coordinateur scientifique du CARAP. Cette activité qui s'inscrit dans les approches plurielles ${ }^{225}$ vise à traiter parallèlement plus d'une langue et, par conséquent, à aider les apprenants à établir des liens entre les langues.

${ }^{225}$ Ces activités développent les ressources du descripteur savoir-faire et savoir :

$S$ 3.1.1. savoir établir des mises en relation de ressemblance et de différence entre les langues ou les cultures, à partir de l'observation, de l'analyse, de l'identification ou du repérage de certains de leurs éléments

K 4.1 savoir que les langues sont liées entre elles par des relations dites « de parenté », savoir qu'il existe des « familles » de langues

K 4.1.1 connaitre quelques familles de langues et quelques langues qui en font partie 
Il est intéressant de mentionner qu'après avoir discuté avec les apprenants de cette activité, on a remarqué que les étudiants se rendaient compte qu'avoir conscience des différences aide à éviter des interférences. Cependant, beaucoup d'entre eux restaient influencés par des principes didactiques établis au cours de la seconde moitié du siècle dernier et pensaient que chaque langue doit être enseignée isolément. Au début, nous avons eu l'impression qu'ils en arrivaient à se sentir coupables lorsqu'ils se réfèrent à d'autres langues en classe de français. Et pourtant dans les extraits du Guide pour le développement et la mise en cuvre de curriculums pour une éducation plurilingue et interculturelle $(2010: 22)$ nous pouvons lire que :

toutes les occasions pertinentes doivent être utilisées pour encourager la mobilisation des acquis dans les langues enseignées ou connues des élèves afin de faire émerger des convergences, de faciliter la compréhension du fonctionnement des langues et de gérer au mieux le développement de leur répertoire plurilingue.

Analysons maintenant d'autres activités qui ont également suscité beaucoup de discussions.

Pendant le cours consacré au parcours professionnel des diplomates dont l'objectif était, entre autres, " apprendre à réagir à des propositions des autres venant de cultures différentes », nous avons proposé aux apprenants les exercices suivants ${ }^{226}$ :

\section{Étape 1 - Découverte du document}

Consigne :

Formez des groupes de quatre. Vous êtes responsables du recrutement dans un ministère de l'Europe et des Affaires étrangères en France et vous devez recruter de nouveaux collaborateurs dans différents services

- un conseiller des Affaires étrangères

- un chef du personnel diplomatique

${ }^{226}$ Ces activités développent les ressources du descripteur savoir-faire:

S 3.10 savoir comparer des phénomènes culturels (ou percevoir la proximité ou distance culturelle)

S 3.10.1 savoir utiliser un éventail de critères pour repérer la proximité ou la distance culturelles

S 3.10.2 savoir percevoir quelques différences et similitudes concernant divers domaines de la vie sociale (par exemple conditions de vie, vie professionnelle, vie associative, respect de l'environnement, etc.)

S 3.10.3 savoir comparer les signifiés ou connotations correspondant à des faits culturels (par exemple comparer les conceptions du temps, etc.

S 3.10.4 savoir comparer diverses pratiques culturelles

S 3.10.5 savoir relier des documents ou événements d'une autre culture à des documents ou événements de sa propre culture 
- un/une responsable de communication

- une/un secrétaire des Affaires étrangères

Quels vont être vos critères de recrutement pour chaque poste? Pourquoi ? le travail avec le document authentique : ("Les métiers du Ministère des Affaires étrangères »).

\section{Étape 2 - Discussion}

\section{Consigne :}

En groupes de 3 discutez sur les sujets suivants:

En quoi le travail en commun entre personnes de différentes nationalités peut-il être enrichissant, complexe, difficile, parfois impossible?

Une bonne entente dans une équipe signifie-t-il qu'il n’y a jamais de conflits entre ses membres?

À votre avis, ces difficultés ou cette richesse pour travailler ensemble sont-elles les mêmes pour les personnes de mêmes nationalités, mais issues de milieux sociaux, d'origines géographiques ou d'univers religieux différents?

Cette activité de décentration ${ }^{227}$ s'est avérée fructueuse, car les étudiants ont eu la possibilité de découvrir que ce qu'ils avaient l'habitude de pratiquer est marqué culturellement. Leurs pratiques pédagogiques étaient relatives et singulières, elles leur ont été transmises par l'enseignement. Ils les ont intégrées, convaincus qu'elles étaient universelles. Grâce à ces activités et au travail dans des groupes multiculturels, ils rencontrent d'autres habitus pédagogiques, ce qui soulève des interrogations sur ce qui, jusque là, semblait naturel, irréfutable, définitif.

Il est possible de parler dans certains cas du choc culturel qui fait partie intégrante du processus de décentration inhérent à l'approche interculturelle. Les attitudes ou comportements de l'Autre qui nous paraissent étranges agissent alors comme un miroir réfléchissant et révélant nos normes et valeurs. Legault et Lafrenière (1992:15)

${ }^{227}$ La décentration possède trois niveaux :

- le niveau ethnologique, qui représente la lutte contre l'ethnocentrisme;

- la lutte contre le sociocentrisme, soit le fait que chaque couche sociale pense que sa manière de voir et concevoir le monde est la meilleure, la seule façon de voir. Les enseignants doivent attention au sociocentrisme, et ne pas croire que leur façon de définir et concevoir la culture est la meilleure;

- la lutte contre l'égocentrisme et la tendance à considérer que les choses sont telles que nous les voyons. 
remarquent que ces chocs, essentiellement au niveau des valeurs, font référence à des représentations, à des modes de pensée, à des images souvent inconscientes, à une vision du monde finalement qui déterminent les conduites et orientent les actions; ces chocs entraînent des incompréhensions, des malentendus et peuvent donner lieu à des difficultés d'interventions s'ils ne sont repris et analysés. Cela nous paraît essentiel pendant le cours de français de la diplomatie.

\section{Organisation de la séquence : les stéréotypes et les préjugés}

En concevant les séquences du cours de français de la diplomatie qui développeraient la CPLPC, nous avons consacré une place importante aux activités qui visent à dépasser les stéréotypes et préjugés.

À titre d'exemple, analysons le fragment de la leçon «L'abécédaire du bon diplomate »:

\section{Étape 4- Discussion : les stéréotypes dans le monde diplomatique ${ }^{228}$}

Vidéo : Regardez la vidéo http://www.prejuges-stereotypes.net/main.htm et dites ce que les Français disent sur les préjugés et les stéréotypes.

Ettes-vous d'accord avec ce qu'ils pensent?

Formez des groupes de trois et discutez sur les questions ci-dessous.

- D’où proviennent les stéréotypes?

- Sont-ils inévitables?

- Pouvons-nous les éliminer, comment?

- Sont-ils en voie d'extinction?

- Peut-on les mesurer?

- Quelles sont leurs conséquences dans la vie quotidienne?

Nous pouvons voir que l'objectif de cet exercice est de prendre conscience du caractère réducteur et simplificateur des stéréotypes ainsi que de réfléchir à la relation entre les stéréotypes et l'identité. Cela nous paraît particulièrement important chez le diplomate dont les visions devraient se heurter à ses stéréotypes et préjugés.

${ }^{228}$ Nous avons travaillé ici sur les ressources suivantes : (CARAP : 50-58).

S 1.7.2 savoir analyser des schémas d'interprétations (des stéréotypes)

K 10.5.1. savoir que ses propres pratiques culturelles peuvent être interprétées par les auteurs sous la forme de stéréotypes

K 10.5.1.1 connaître quelques stéréotypes des autres cultures à propose de sa propre culture 
D'autre part, il faut souligner que selon les principes du CARAP et du CECRL, le rôle de l'institution éducative devrait être d'aider les apprenants, mais également les enseignants ${ }^{22}$ à apprendre à regarder la réalité en objectivant le plus possible le regard. Nous sommes conscients qu'éliminer, éradiquer totalement les stéréotypes et les préjugés n'est pas une option pédagogique réaliste. Néanmoins, il est possible de prendre conscience, puis d'interroger et de relativiser les représentations stéréotypées et les préjugés afin de permettre d'aller à la rencontre de l'Autre, de faire évoluer les comportements vers plus de compréhension, de curiosité et de volonté de partage. Il s'agit aussi de réfléchir à ses propres valeurs, ses propres convictions ${ }^{230}$.

Nous avons également consacré une place importante à la pédagogie des langues proches. Les activités étaient telles que celle ci-dessous :

Voici les phrases qui servent à exprimer l'opinion en anglais. Trouvez ses équivalents lexicaux en français ou dans une autre langue que vous connaissez.

1) I believe that ...

2) I'm sure that ...

3) In my opinion ...

4) I'm certain that ...

5) I've never really thought about this before, but ...

6) I would say that ...

7) To be honest ...

8) I could be wrong, but ...

9) I'd say that...

10) I'm no expert (on this), but ...

11) I'm (absolutely) convinced that

12) I disagree.

13) I take a different view

14) He's off his head!

${ }^{229}$ Soulignons que nous-mêmes enseignants, sommes soumis aux mêmes mécanismes de pensée que les autres membres de la communauté. Nous jouons aussi un rôle important dans la transmission volontaire ou inconsciente des idées et valeurs collectives au groupe de référence, donc aussi des stéréotypes et préjugés.

${ }^{230}$ Une expérience intitulée " La leçon de discrimination " a été réalisée au Canada et a été présentée en 2006 dans un documentaire produit par Radio Canada. Lors de cette expérience, une enseignante de l'école élémentaire avait séparé sa classe d'enfants en deux groupes selon le critère de la taille : le groupe des " petits » et celui des " grands ». Lors de la première étape de l'expérience, le groupe des « petits » était déclaré comme ayant toutes les qualités, alors que les « grands » étaient dépréciés. Lors de la deuxième étape de l'expérience, les rôles étaient inversés. L'objectif de cette activité était de faire ressentir la discrimination, l'injustice de la valorisation et du favoritisme d'un groupe par rapport à un autre. Dans l'expérience canadienne, c'est la qualité des discussions sur le vécu et la réflexion conduites a posteriori avec les formateurs des groupes qui a été mise en valeur par les initiateurs du projet. 
Avez-vous noté beaucoup de ressemblances et de différences entre le français et d'autres langues? Lesquelles?

Ce type d'activité permet de découvrir la proximité des langues et aide les apprenants à passer d'une langue à l'autre à tout moment (l'alternance des langues est une ressource à disposition des locuteurs et ne devrait plus être bannie). L'intercompréhension peut alors fournir à chacun les clés pour s'ouvrir aux langues et à la dimension plurilingue et multiculturelle.

Pour conclure, nous voyons avec ces divers exemples que notre programme du cours de français de la diplomatie est en grande partie inspiré du CARAP. Dans chaque séquence, nous plaçons des activités qui développent des ressources du descripteur savoir-faire ou savoir. Cela amène les apprenants à réfléchir au processus d'apprentissage, à mobiliser leurs connaissances déclaratives et, si possible, leurs connaissances procédurales et fait émerger les quatre approches plurielles : l'approche interculturelle, l'éveil aux langues, l'approche intercompréhensive des langues parentes et la didactique intégrée des langues. Néanmoins, il faut souligner que ces séquences comportent également des activités qui travaillent d'autres compétences : linguistique, sociolinguistique, pragmatique.

\subsection{Réflexions écrites}

En intégrant les approches plurielles dans l'enseignement des langues, il est bien de créer un cadre où les apprenants pourraient réfléchir en groupe mais aussi individuellement sur leurs acquis. De ce fait, nous avons proposé aux répondants de s'exprimer par écrit ${ }^{231}$ sur des questions ouvertes liées aux sujets abordés pendant le cours. Toutes les 6-7 leçons,ils ont eu à parler sur leur expérience plurilingue et pluriculturelle et sur les observations liées au cours en tant que tel. Ainsi, nous avons réussi à obtenir des récits des étudiants, ce qui serait notre quatrième outil utilisé pour recueillir des données en recherche-action.

Nous avons posé 6 questions (la première question a été posée en français et les autres en anglais $\left.{ }^{232}\right)$ :

${ }^{231}$ La forme écrite soutient tout particulièrement la réflexion et l' « extériorisation » (absence du chercheur durant la rédaction, intimité, temps non limité). Par l'entremise d'un récit, sont transmis des valeurs, des convictions, des jugements, des aspirations, etc., de plus, l'acte de rédaction facilite la prise de conscience de ses atouts et de ses points faibles, de ses aptitudes dites spéciales, de ses schémas de comportement et leurs origines, par exemple dans l'apprentissage d'un domaine particulier ou du point de vue du fonctionnement dans un contexte donné (Sujecka-Zając et Smuk, $2019: 6)$.

${ }^{232}$ Après avoir analysé les premiers récits et après en avoir discuté avec les apprenants, nous avons décidé de poser les autres questions en anglais. Par ailleurs, Weronika Wilczyńska et Anna Michońska-Stadnik (2010 : 169) remarquent que si nous pensons que l'usage de la langue étrangère 
Tableau 23. Les questions libres posées aux apprenants du français de la diplomatie.

1. Les réflexions sur vos langues maternelles et les langues que vous connaissez vous facilitentelles l'apprentissage du français ou au contraire? Argumentez

2. Did the use of other languages during lessons help you perceive the lexical proximity between those languages and French? How could you argue that ?235

3. Which are the qualities of a diplomat? Did this course help you develop some ideas? Motivate your answer ${ }^{236}$.

4. Did the last lessons sensitize you of diversity between students in the classroom and helped you better understand other cultures or different points of view? ${ }^{237}$

5. Did this course help you reflect upon about some aspects of your own culture? If yes, how? If no, why not?238

6. Did the work with portfolio help you look through/reflect your language and intercultural knowledge? If yes, how? If not, why? ${ }^{239}$

Dans un premier temps, nous avons discerné tous les passages qui montrent la réflexion des apprenants sur le transfert des connaissances et des structures préexistantes d'une langue à une autre. Soulignons, que dans la plupart des cas, nous les avons trouvés dans les premiers incipit des productions répondant à la première question. Les constatations de témoins se référaient à l'importance de la connaissance de l'anglais, de son influence sur la langue française. Cette approche peut être illustrée par les phrases suivantes ${ }^{238}$ :

« Knowing English does help sometimes, because French and English tend to borrow from each other» (É6).

«Since there are many words that are similar» (É7).

"I notice that very often, I make a literal translation between English and French » (É4).

(ici, le français) peut limiter les réponses des enquêtés ou même rendre difficile la compréhension des questions, il serait mieux de construire le questionnaire dans la langue que l'apprenant connaît le mieux. Malgré les apparences, l'usage de la langue étrangère peut influencer la qualité de la réponse.

${ }^{233}$ Est-ce que l'usage des autres langues pendant la leçon vous a aidé à percevoir la proximité lexicale entre ces langues et le français? Argumentez.

${ }^{234}$ Quelles sont les qualités du diplomate? Est-ce que ce cours vous a aidé à développer des idées sur ce sujet? Argumentez.

${ }^{235}$ Est-ce que les dernières leçons vous ont sensibilisé à la diversité entre les étudiants en classe et vous ont aidé à comprendre mieux autres cultures ou différents points de vue?

${ }^{236}$ Est-ce que ce cours vous a aidé à réfléchir sur certains aspects de votre propre culture? Si oui, comment? Sinon, pourquoi pas selon vous?

${ }^{237}$ Est-ce que le travail avec le Portfolio vous a aidé à réfléchir sur votre langue et votre savoir interculturel ? Si oui, comment? Sinon, pourquoi pas selon vous?

${ }^{238}$ « Connaitre le français aide parfois parce que le français et l'anglais ont beaucoup en commun ». (É6)

«Il y a beaucoup de mots qui sont similaires ». (É7) 
En outre, un nombre significatif de répondants évoquent des éléments déjà discutés en classe. Ils repèrent des éléments linguistiques, essayent de comparer des langues, en mentionnant quelques familles de langues et quelques langues qui en font partie, par exemple chez É3, É8 ou É2 239 .

«Very often, I use the technique of associations (with the words in different languages) to remember certain words » (É3).

Words in different languages have the same origin (Italian or French), I will try now to search for it more than before our classes » (É8).

« Knowing many languages helps because we can find any similarities or the things that are different, as well as false friends » (É2).

Si tous les répondants mentionnent l'existence des liens entre différentes langues étrangères, personne ne remarque - à nouveau - le domaine de transfert autre que celui lexical. $^{240}$

Il importe d'observer des changements de point de vue dans les récits des répondants et cela seulement après deux mois de cours de français de la diplomatie. En analysant les réponses des participants à la deuxième question, nous avons constaté que leurs commentaires sont plus élaborés, plus complexes. Rappelons que la seconde question concernait l'utilité de l'usage des autres langues pendant la leçon de français de la diplomatie.

Dans presque toutes les productions, les répondants soulignent que l'usage d'autres langues étrangères enrichit le cours ${ }^{241}$ :

« Je le remarque souvent, je peux m’aider en traduisant littéralement les mots de l’anglais vers le français ». (É4)

239 " J'utilise souvent la technique d'association (avec les mots venant de diverses langues). Cela maide à mémoriser certains mots ». (É3)

"Les mots dans des langues différents ont l'origine commune (l'italien ou le français). Je vais essayer d'en chercher beaucoup plus maintenant qu'avant le début de notre cours ». (É8)

"Connaître plusieurs langue aide parce qu'il est possible de trouver aussi bien des similaires ou des éléments différents ainsi que de faux amis ». (É2)

${ }^{240}$ Nous voulons souligner à cette occasion que selon Cummins (2000: 74), il y a cinq différents domaines de transfert :

- le transfert d'éléments conceptuels ;

- le transfert de stratégies métacognitives ;

- le transfert d'aspects pragmatiques liés à la communication (par exemple les gestes) ;

- le transfert déléments linguistiques ;

- le transfert du savoir phonologique.

${ }^{241}$ «Si le mot était inconnu, le professeur utilisait d'autres langues jusquà ce que tout le monde comprenne, cela nous a beaucoup aidés ». (É9)

«Des similarités entre l'espagnol et le français mont beaucoup aidé. C’est bien que je pouvais poser la question en espagnol ». (É4)

«C'est plus facile de comprendre la grammaire ou des expressions figées s'il y a des parallèles entre d’autres langues que l'on parle mieux ». (É6)

"Parfois, si nous n'utilisons pas d'autre langue, on peut être bloqué et découragé ». "Selon moi, une ambiance positive en classe de langue est la plus importante ». (É9) 
"When the word was unknown, professor used other languages till everybody understands, it helped a lot »(É9).

«Similarity between Spanish and French helped me a lot, great that I could ask about something in Spanish » (É4).

« It is easier to comprehend grammar or fixed expressions which have parallels in other better spoken languages » (É6).

"Sometimes, if we don't use other language, we can be stuck and get discouraged, « in my view, a positive learning attitude and atmosphere matters the most » (É9).

Il est possible de constater que la représentation des autres langues en classe est généralement positive. Il nous semble que les apprenants trouvaient des exercices plurilingues utiles et les percevaient maintenant comme un élément "standard " du cours. Par ailleurs, la réponse de l'É9 permet de comprendre que pour certains étudiants la possibilité d'utiliser leurs langues maternelles ou les langues qu'ils connaissent bien aide à surmonter des obstacles et l'anxiété linguistique « if we don't use other language, we can be stuck and get discouraged ».

Néanmoins, il y avait un répondant pour qui l'usage d'autres langues en classe de français de la diplomatie n'était pas utile (É1) ${ }^{242}$ :

«I would prefer if we don't use other language than French in the classroom ».

Nous percevons ici une certaine méfiance vis-à-vis de la langue différente que la langue cible en classe de langue. Selon les approches singulières, la langue, par exemple maternelle, en classe de langue est un obstacle, voire un blocage ou un frein à l'acquisition d'une autre langue. Or, l'un des changements majeurs en matière de langue qui acquiert aujourd'hui une importance incontournable concerne précisément la pluralité linguistique.

La troisième question posée après 3 mois de cours cherchait à savoir quelles sont les qualités du diplomate et si le cours de français de la diplomatie aide les apprenants à développer des idées sur ce sujet. On voit ici que la représentation du diplomate chez nos témoins est celle d'une personne multilingue, communicative, ambitieuse, flexible, ouverte, bien éduquée et sensible ${ }^{243}$ :

\footnotetext{
${ }^{242}$ « Je préfèrerais ne pas utiliser en classe d’autres langues que le français ». (É1)

243 "Diplomate devrait être patient, calme, ouvert d'esprit et communicatif». (É10)

"C'est une profession très sérieuse et un travail responsable. Les gens qui décident d'être diplomates devraient avoir certaines qualités comme p.ex. Le dévouement, l'ambition. Ils devraient aussi savoir travailler dur». (É3)

«Le tact et la sensibilité sont les plus importants pour les diplomates ». (É7)

"L'une des plus importantes qualités du diplomate et la capacité à communiquer dans plusieurs langues». (É8)

«Savoir débattre». (É2)
} 
« A diplomat should be patient, calm, open-minded and communicative» (É10).

«It is a very serious profession and responsible job. People who choose to become diplomates should have certain values such as dedication, ambition, hardworking " (É3).

« Tact and sensitivity are the most important for diplomats » (É7).

"One of the key qualities of a diplomat is an ability to communicate in numerous languages " (É8).

«Strong skills of debating» (É2).

Ce que nous voulons mettre en lumière ici est la maturité des réponses des apprenants qui n'était pas visible au début du cours de français de la diplomatie. Il importe de mentionner que les propos des répondants rejoignent les représentations mentionnées dans le chapitre 2.

En outre, il est intéressant d'analyser la deuxième partie de la question portant sur le cours. Ici, la majorité des répondants constatent que le cours les a beaucoup aidés à développer la conception du travail dans les relations internationales. En voici trois propos cités en exemple ${ }^{244}$ :

« This course helped me to develop the idea that a diplomat should know how to behave himself in the difficult and challenging situations » (É7).

«It gave me the opportunity to discuss controversial issues in the environment of people with surprisingly different viewpoints» (É1).

«This course helped me to discuss with my colleagues about important and sometimes sensible issues » (É5).

Les affirmations des étudiants montrent bien que, à part les compétences linguistiques, le cours les a incités à prendre conscience des fonctionnements de la pensée des représentants de cultures différentes. Cette décentration nous semble primordiale dans le travail dans un milieu multiculturel.

Des propos similaires sont présents dans les réponses à la quatrième question concernant la sensibilisation à la diversité entre les étudiants venant de pays différents. Ce qui est surprenant, c'est la totalité du groupe qui répond comme dans les exemples qui suivent ${ }^{245}$ :

${ }^{244}$ « Ce cours m’a aidé à développer l'idée qu’un diplomate devrait savoir se comporter de façon appropriée dans des situation difficiles ». (É7)

"Cela m’a donné la possibilité de discuter sur des sujets controversés avec des gens qui, à ma grande surprise, ont des points de vue complètement différents ». (É1)

"Ce cours m’a aidé à discuter avec mes camarades des sujets importants et parfois sensibles ». (É5)

245 «Dans notre groupe, il y a beaucoup de cultures et nationalités différentes. Nous avons eu beaucoup de présentations, des discussions sur des traditions, cultures, habitudes et stéréotypes ». (É8)

«Des débats et des questions ouvertes ont été très bonne idée pour découvrir des points de vue différents ». (É10) 
" there are many different cultures and nationalities represented in our group and we had many presentations, talks about traditions, cultures, habits and stereotypes » (É8).

"The debates and open questions have been very good for exploring different points of views » (É10).

«Multicultural environment has allowed me to have a better understanding of other cultures and enjoyed listening to different points of view and different perspectives view » (É9).

Cet état de choses dévoile une visible évolution des idées sur le milieu multiculturel des apprenants. De plus, ces réponses, une sorte de feedback pour l'enseignant, permettent de voir l'utilité des certaines techniques utilisées en classe pour développer la CPLPC comme les présentations, les débats, les productions écrites, etc.

Vient ensuite la dernière question sur la culture, et notamment si le cours a aidé les apprenants à relativiser leur propre culture. À ce point, l'étude montre que les répondants deviennent, pour beaucoup d'entre eux, plus responsables, plus autonomes, plus conscients de la diversité culturelle et linguistique. Les étudiants semblent unanimes et leurs propos font penser qu'ils sont déjà prêts à s'approcher de la culture d'autrui ${ }^{246}$ :

«It helped me to understand what others thinks about my country » (É3).

«This class allowed me to reflect on the differences and similarities of my country and other countries » (É7).

«It helped me to broaden my own horizons » (É10).

Finalement, passons à la dernière question relative au travail avec le Portfolio. Nous avons constaté quelques controverses à ce sujet. D’après la moitié des apprenants, le travail avec le Portfolio favorise l'autonomie et la prise de conscience du processus d'apprentissage ${ }^{247}$ :

«It made me to think that, what languages I am speaking in various occasions. In that sense it increased my awareness » (É8).

«It helped me to better understand how and why I learn languages » (É5).

«It made me realize how little I know of other cultures and how much I have to learn $»($ É8).

«L'Lnvironnement multiculturel m'a permis de mieux comprendre d'autres cultures. J'ai apprécié d'entendre d’autres points de vue et différentes perspectives ». (É9)

246 "Cela m’a aidé à comprendre ce que les autres pensent de mon pays ». (É3)

"Ce cours m’a permis de réfléchir sur des différences et similarités entre mon pays et d'autres pays ». (É7)

"Cela m’a aidé à élargir mes horizons ». (É10).

247 «Il m’a fait penser aux langues que j’utilise à différentes occasions. Dans ce sens, cela a augmenté ma sensibilisation ».(É8)

"Cela m’a aidé à comprendre comment et pourquoi j’apprends des langues». ( É5)

"Cela m'a fait comprendre que je ne sais pas beaucoup sur d'autres cultures. Je me suis également rendu compte de ce que je dois encore apprendre ». (É8) 
Cependant, l'autre moitié des répondants trouve le travail avec le portfolio inutile, difficile, désagréable ou fatigant. Ces opinions peuvent être illustrées par les phrases suivantes ${ }^{248}$ :

« I didn't see a point of filling » (É2).

«It was boring and required very specific answers » (É7).

«It was confusing and childish, I didn't enjoy it at all (É6).

À la lumière de ces témoignages, nous devons continuer les recherches et voir auprès d'un groupe plus nombreux comment cela se présente.

Pour conclure, les récits écrits des participants à l'étude ne nous ont pas fourni beaucoup de nouvelles informations, mais ont plutôt confirmé nos résultats du prétest et de nos observations venant de notre expérience professionnelle. Cependant, ils ont permis aux répondants de s'exprimer librement, de commenter nos actions didactiques ainsi que le cours. Ces écrits sont ainsi devenues une sorte d'évaluation du cours de français de la diplomatie.

\subsection{Les résultats du post-test}

Nous terminons notre recherche empirique avec le post-test, dont le questionnaire était identique en tous points à celui présenté en pré-test. L’objectif du post-test était de mesurer l'état final de la compétence plurilingue et pluriculturelle.

Voyons maintenant comment répondaient les apprenants en avril 2018 au posttest.

Tableau 24. Les résultats des participants au post-test.

\begin{tabular}{|c|l|l|l|}
\hline \multicolumn{1}{|c|}{ Questions du questionnaire } & \multicolumn{1}{|c|}{$\begin{array}{c}\text { Ressource } \\
\text { non acquise }\end{array}$} & $\begin{array}{c}\text { Ressource } \\
\text { en voie } \\
\text { d'acquisition }\end{array}$ & $\begin{array}{c}\text { Ressource } \\
\text { acquise }\end{array}$ \\
\hline $\begin{array}{c}\text { 1. Savoir comprendre des textes écrits dans } \\
\text { des langues inconnues ou peu familières }\end{array}$ & 1 étudiants & 3 étudiants & 6 étudiants \\
\hline $\begin{array}{c}\text { 2. Savoir comparer la forme des emprunts } \\
\text { à la forme qu'ils ont dans la langue dorigine }\end{array}$ & 2 étudiants & 3 étudiants & 5 étudiants \\
\hline $\begin{array}{c}\text { 3. Savoir comparer les rapports phonie-graphie } \\
\text { entre les langues }\end{array}$ & 1 étudiant & 4 étudiants & 5 étudiants \\
\hline
\end{tabular}

${ }^{248}$ « Je n’ai pas vu de sens à le remplir ». (É2)

"C'était ennuyeux et a demandé des réponses spécifiques ». (É7)

«C’était troublant et enfantin. Je ne l’ai pas aimé du tout ». (É6) 
(la continuation du tableau 24)

\begin{tabular}{|c|c|c|c|}
\hline Questions du questionnaire & $\begin{array}{l}\text { Ressource } \\
\text { non acquise }\end{array}$ & $\begin{array}{l}\text { Ressource } \\
\text { en voie } \\
\text { d'acquisition }\end{array}$ & $\begin{array}{l}\text { Ressource } \\
\text { acquise }\end{array}$ \\
\hline $\begin{array}{l}\text { 4. Savoir comparer les langues à l'écoute } \\
\text { par exemple l'ukrainien et le polonais }\end{array}$ & 1 étudiant & 3 étudiants & 6 étudiants \\
\hline $\begin{array}{l}\text { 5. Savoir percevoir la proximité lexicale dans } \\
\text { des langues étrangères }\end{array}$ & 1 étudiant & 4 étudiants & 5 étudiants \\
\hline $\begin{array}{l}\text { 6. Savoir comparer les fonctionnements } \\
\text { grammaticaux de langues différentes }\end{array}$ & 3 étudiants & 5 étudiants & 2 étudiants \\
\hline $\begin{array}{l}\text { 7. Savoir percevoir la proximité et la distance } \\
\text { entre la graphie et des sons }\end{array}$ & 2 étudiants & 4 étudiants & 4 étudiants \\
\hline $\begin{array}{l}\text { 8. Savoir comparer les pratiques de } \\
\text { communication non verbales autres avec } \\
\text { ses propres pratiques }\end{array}$ & 1 étudiant & 7 étudiants & 2 étudiants \\
\hline $\begin{array}{l}\text { 9. Savoir comparer des phénomènes culturels } \\
\text { dans des langues ou cultures plus ou moins } \\
\text { familières }\end{array}$ & 1 étudiant & 7 étudiants & 2 étudiants \\
\hline $\begin{array}{l}\text { 10. Savoir repérer des spécificités, références } \\
\text { ou appartenances, au plan culturel }\end{array}$ & 2 étudiants & 4 étudiants & 4 étudiants \\
\hline $\begin{array}{l}\text { 11. Savoir utiliser les connaissances et } \\
\text { compétences acquises dans une langue } \\
\text { maternelle pour apprendre une autre langue }\end{array}$ & 2 étudiants & 5 étudiants & 3 étudiants \\
\hline $\begin{array}{l}\text { 12. Savoir utiliser un éventail de critères } \\
\text { pour établir la proximité ou la distance } \\
\text { linguistiques ou culturelles }\end{array}$ & 3 étudiants & 5 étudiants & 2 étudiants \\
\hline $\begin{array}{l}\text { 13. Savoir communiquer dans des groupes } \\
\text { bi/plurilingues en tenant compte } \\
\text { du répertoire de ses interlocuteurs }\end{array}$ & 2 étudiants & 5 étudiants & 3 étudiants \\
\hline $\begin{array}{l}\text { 14. Savoir produire un texte en alternant } \\
\text { les registres, variétés ou langues de façon } \\
\text { fonctionnelle (lorsque la situation s'y prête) }\end{array}$ & 2 étudiants & 5 étudiants & 3 étudiants \\
\hline $\begin{array}{l}\text { 15. Savoir présenter dans une langue un } \\
\text { commentaire ou un exposé à partir } \\
\text { d'un ensemble plurilingue de documents }\end{array}$ & 2 étudiants & 6 étudiants & 2 étudiants \\
\hline $\begin{array}{l}\text { 18. Savoir varier ou alterner les langues, } \\
\text { les codes ou les modes de communication }\end{array}$ & 1 étudiant & 8 étudiants & 1 étudiant \\
\hline $\begin{array}{l}\text { 17. Savoir utiliser les connaissances } \\
\text { et compétences acquises dans une langue } \\
\text { pour apprendre une autre langue }\end{array}$ & 2 étudiants & 7 étudiants & 1 étudiant \\
\hline $\begin{array}{l}\text { 18. Savoir analyser les malentendus d'origine } \\
\text { culturelle }\end{array}$ & & 7 étudiants & 3 étudiants \\
\hline $\begin{array}{l}\text { 19. Savoir utiliser différents techniques } \\
\text { d'apprentissage des langues }\end{array}$ & 2 étudiants & 6 étudiants & 2 étudiants \\
\hline
\end{tabular}




\begin{tabular}{|c|c|c|c|}
\hline \multicolumn{1}{|c|}{ Questions du questionnaire } & $\begin{array}{c}\text { Ressource } \\
\text { non acquise }\end{array}$ & $\begin{array}{c}\text { Ressource } \\
\text { en voie } \\
\text { d'acquisition }\end{array}$ & $\begin{array}{c}\text { Ressource } \\
\text { acquise }\end{array}$ \\
\hline $\begin{array}{c}\text { 20. Vouloir connaître différentes langues } \\
\text { étrangères }\end{array}$ & 2 étudiants & 6 étudiants & 2 étudiants \\
\hline $\begin{array}{c}\text { 21. Savoir élaborer un système interprétatif } \\
\text { permettant d'appréhender les particularités } \\
\text { d'une culture (p.ex. Les significations, } \\
\text { les croyances, les pratiques culturelles, etc.) }\end{array}$ & 3 étudiants & 6 étudiants & 1 étudiant \\
\hline $\begin{array}{c}\text { 22. Savoir identifier des frontières linguistiques } \\
\text { et les frontières politiques }\end{array}$ & 2 étudiants & 5 étudiants & 3 étudiants \\
\hline $\begin{array}{c}\text { 23. Savoir analyser des schémas d'interprétations } \\
\text { (des stéréotypes) }\end{array}$ & 1 étudiants & 6 étudiants & 3 étudiants \\
\hline AU TOTAL: & $\mathbf{1 7 , 5 \%}$ & $\mathbf{5 0 \%}$ & $\mathbf{3 2 , 5 \%}$ \\
\hline
\end{tabular}

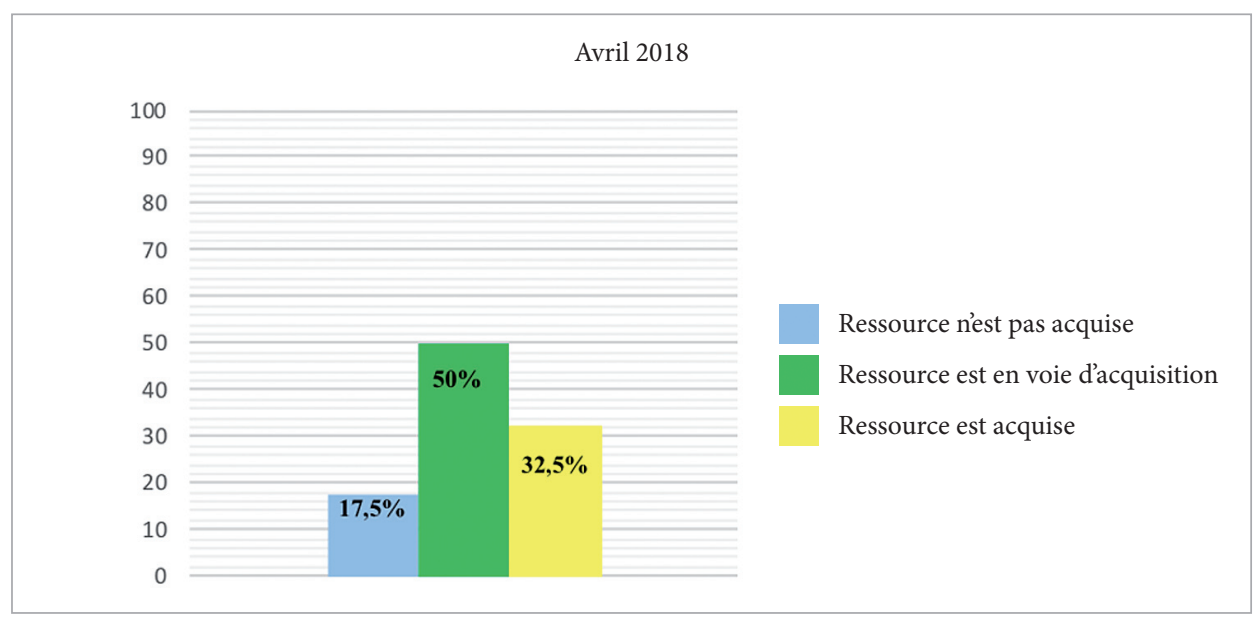

Figure 24. Le degré du développement de la CPLPC des participants à létude (post-test).

Il est intéressant de remarquer que les données obtenues dans le post-test diffèrent de celles recueillies en septembre 2017. Les changements sont observables dans la première et dernière colonne. Comparons maintenant ces résultats. 


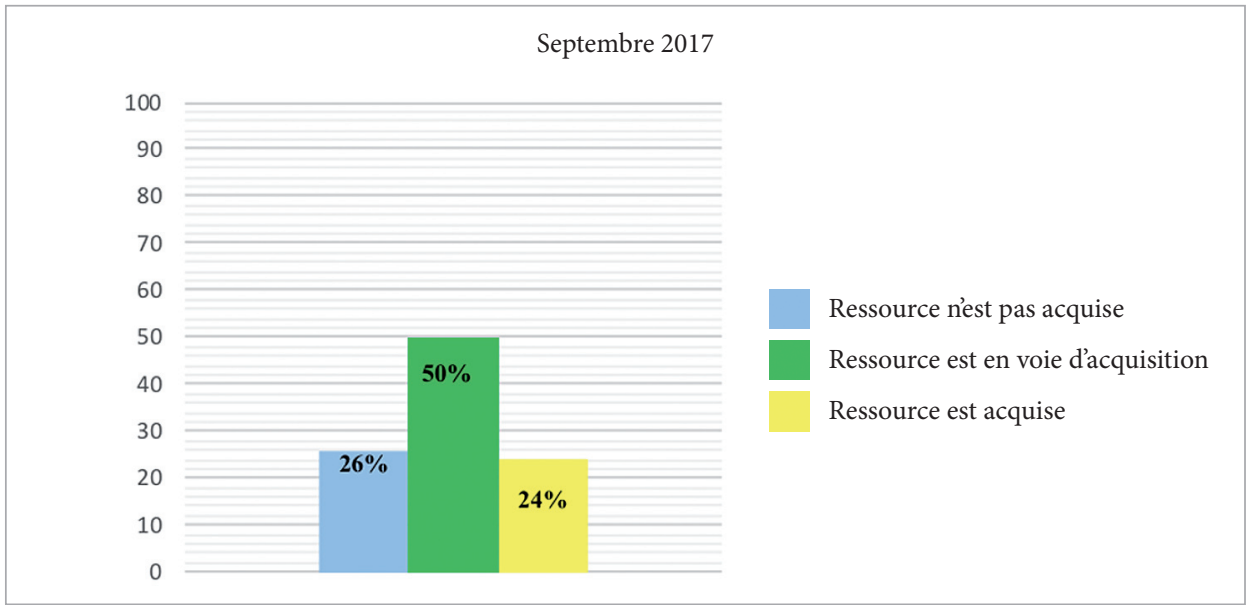

Figure 25. Le degré du développement de la CPLPC des participants à létude (pré-test).

Il est visible que le degré du développement de la compétence plurilingue et pluriculturelle des participants à l'étude a augmenté par rapport à l'état initial mesuré en 2017. En septembre 2017 environ 2 sur 10 répondants jugeaient leurs ressources du descripteur savoir-faire du CARAP comme acquises. Par contre, en avril 2018, il y en a plus que 3. Le nombre de participants à l'étude selon lesquels leurs ressources sont en voie d'acquisition n'a pas changé. Nous notons cependant une diminution qu'il y a un répondant chez lequel la ressource n'est pas acquise.

Ci-dessous nous présentons le degré d'acquisition de la CPLPC des répondants par rapport aux objectifs du CARAP.

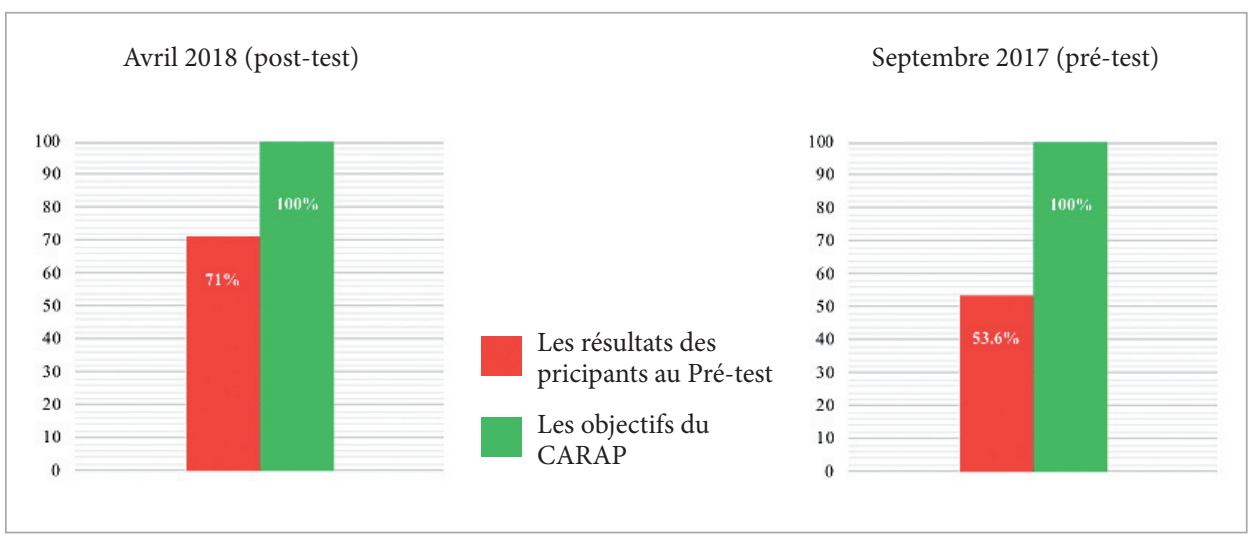

Figure 26. Le degré d'acquisition de la CPLPC des apprenants par rapport aux objectifs du CARAP. 
Il faut noter une différence importante entre les résultats de 2017 et 2018. Il en résulte qu'en avril 2018, plus de deux tiers des participants à l'étude répondent aux objectifs du CARAP liés au développement de la CPLPC. Cela fait presque $18 \%$ de plus qu'en septembre 2017 quand nous avons commencé le cours.

\subsection{Interprétation qualitative et quantitative des données - bilan}

Dans ce chapitre nous nous sommes concentrée sur l'analyse des résultats des données quantitatives (le pré-test et le post-test) ainsi que qualitatives (le portfolio, les séquences pédagogiques et les récits écrits) recueillies entre septembre 2017 et avril 2018.

Suite à cette étude empirique, nous pouvons apporter des éléments suivants à nos questions de recherche:

Tableau 25. Les réponses aux questions de recherche.

Question de recherche

Réponse obtenue dans l'étude empirique

1. Selon les étudiants, faut-il développer la compétence plurilingue et pluriculturelle dans la formation linguistique des diplomates? Et pourquoi ?

1a) Est-ce que selon les étudiants de cours de français de la diplomatie la compétence plurilingue/pluriculturelle est importante? Dans quelle mesure?

16 Est-ce que les méthodes qui résultent des principes $d u$ plurilinguisme influencent la réflexivité des apprenants $d u$ français de la diplomatie envers les autres langues/ cultures? Si oui, comment et dans quelle mesure?
Oui, les apprenants mentionnaient explicitement et implicitement dans les portfolios et dans les récits écrits que la compétence plurilingue et pluriculturelle est l'une des compétences essentielles dans le métier de diplomate.

Oui, durant les leçons, les apprenants soulignaient qu'il leur serait impossible de partir travailler dans les institutions européennes sans la connaissance de la culture de leurs futurs collègues.

Les résultats du pré-test ont montré qu'il existe une grande nécessité d'investissement dans le développement de la compétence plurilingue et pluriculturelle.

Oui, nous avons noté que la mise en œuvre de démarches pédagogiques a influencé de façon satisfaisante la réflexivité des apprenants du français de la diplomatie envers d'autres langues. Cela se reflète dans les résultats du post-test. Grâce aux séquences pédagogiques, la diversité des langues et des cultures présente dans la classe a commencé à être considérée par l'ensemble des apprenants comme normale et ordinaire (expérience d'activités propices à l'éveil au langage et à louverture aux langues; prise de conscience des distances et des proximités entre les langues, des possibilités d'intercompréhension partielle entre langues voisines ; expérience d'activités propices à la comparaison de phénomènes propres à diverses cultures; expérience de phénomènes propres à une culture exprimés dans la langue étrangère et comparaison avec des phénomènes similaires dans l'expérience des étudiants). 
(la continuation du tableau 24)

Question de recherche

\begin{tabular}{|c|c|}
\hline $\begin{array}{l}\text { 2. S’il existe le besoin de } \\
\text { développer la compétence } \\
\text { plurilingue et pluriculturelle } \\
\text { dans la formation linguistique } \\
\text { des diplomates, quelles } \\
\text { méthodes la développent? }\end{array}$ & $\begin{array}{l}\text { Oui, la recherche a montré qu'il existe le besoin de } \\
\text { développer la compétence plurilingue et pluriculturelle dans } \\
\text { la formation linguistique des diplomates. } \\
\text { Les méthodes qui peuvent développer la CPLPC sont les } \\
\text { suivantes : } \\
\text { - Portfolio européen des langues au service des objectifs } \\
\text { professionnels; } \\
\text { - Scénarios pédagogiques de cours exploitant le CARAP; } \\
\text { - Réflexion écrite. }\end{array}$ \\
\hline $\begin{array}{l}\text { 2a) Est-ce que le travail avec } \\
\text { le portfolio change la } \\
\text { perspective plurilinguel } \\
\text { pluriculturelle des } \\
\text { apprenants du français } \\
\text { de la diplomatie? Si oui, } \\
\text { comment et dans quelle } \\
\text { mesure? }\end{array}$ & $\begin{array}{l}\text { Oui/ Non. } \\
\text { Les réponses fournies dans les Portfolios indiquent que cet } \\
\text { outil a posé des difficultés à certains apprenants. D’autres } \\
\text { soulignaient que le Portfolio a développé leur aptitude à } \\
\text { l'autoévaluation, leur autonomie d'apprentissage ainsi qu'une } \\
\text { prise de conscience de la réalité de leur répertoire langagier. }\end{array}$ \\
\hline $\begin{array}{l}\text { 2b) Est-ce que les méthodes et } \\
\text { les techniques du CARAP } \\
\text { réalisent les principes du } \\
\text { plurilinguisme? Si oui, } \\
\text { lesquelles en particulier? }\end{array}$ & $\begin{array}{l}\text { Oui. } \\
\text { Il paraît que les séquences pédagogiques inspirées de } \\
\text { différents descripteurs du CARAP et les récits que les } \\
\text { apprenants écrivaient tout au long de l'année académique ont } \\
\text { apporté de meilleurs résultats. }\end{array}$ \\
\hline
\end{tabular}

Nous avons vu dans cette recherche qu'une éducation plurilingue et interculturelle va de pair avec le développement des capacités réflexives, des aptitudes à l'autoévaluation et de l'autonomie d'apprentissage ainsi qu'avec une prise de conscience de l'altérité. L'étude a montré que l'approche plurielle avec ses dimensions plurilingues et interculturelles mène au développement de la compétence plurilingue et pluriculturelle (dans notre recherche le développement de la CPLPC par rapport au niveau initial a augmenté de plus de 17,5\%).

De notre point de vue, la conclusion suivante s'impose : la compétence plurilingue et pluriculturelle de futurs diplomates étudiant au Collège d'Europe à Natolin demande à être développée (chez la moitié des étudiants) ou dans certains $\operatorname{cas}^{249}$,

${ }^{249}$ Il faut mentionner que chez certains apprenants la CPLPC était déjà développée au début de la recherche, mais était encore renforcée durant l'étude. Selon nous, cela est sans doute lié au pays d'origine de cet apprenant. De notre côté, nous avons remarqué que certains pays postsoviétiques possèdent des cultures éducatives qui prônent encore la méthodologie structuroglobale audiovisuelle. Nous trouvons qu'une telle prise de conscience de ce qui est déjà présent dans le système éducatif du pays des apprenants est de première importance, surtout s'il s'agit de mettre en œuvre des principes d'une pédagogie « innovante » et d'adapter des démarches encore peu présentes dans le système éducatif concerné. Selon Puren $(2013: 28)$ « si la culture éducative des apprenants n'est ni circonscrite, ni prise en compte par le professeur, les zones de tensions 
approfondie. Néanmoins, les résultats collectés pendant toute l'année académique montrent qu'il est possible de le faire en travaillant avec des outils utilisés dans notre recherche empirique. Il s'ensuit que c'est aux enseignants et aux formateurs en FOS que revient la tâche d'élaborer des modèles didactiques relatifs à l'enseignement/ apprentissage de l'interculturel en tant que compétence autonome à plein titre.

Enfin, la dernière question qui se pose est alors de savoir si ce changement dans les résultats entre le pré-test et le post-test relève de nos démarches pédagogiques tout au long de l'année ou s'il est le résultat de l'année académique passée au campus où les étudiants sont tout le temps exposés à la diversité culturelle et sociale.

Nous pensons que le succès est la somme de ces deux éléments. Bien évidemment, vivant au sein d'une véritable communauté internationale faite d'étudiants, d'assistants académiques, de professeurs et de personnel originaire du monde entier, les étudiants du Collège d'Europe se construisent un répertoire langagier et culturel pluriel de manière non guidée (plutôt implicite) et ainsi se préparent à un métier de diplomate. Cependant, nous trouvons que la construction de la compétence plurilingue et pluriculturelle de manière guidée dans le processus de formation est le pivot autour duquel le répertoire langagier et culturel pluriel se construit plus consciemment et ainsi évolue tout au long de la vie.

Nous sommes conscients que nos conclusions ne sont pas représentatives pour l'ensemble des apprenants du FOS (échantillon peu nombreux, réticence à remplir les portfolios), mais nous espérons qu'elles peuvent tracer le chemin pour les futures recherches menées en didactique des langues.

se transformeront irrémédiablement en blocages, voire en conflits rendant ainsi impossible une congruence entre le plan enseignement et apprentissage ». 


\section{Conclusion générale}

Nous ne parlerons ici que d'un bilan d'étape dans la mesure où, comme nous l'avons signalé auparavant, une recherche-action ne pourra à elle seule répondre entièrement à une question didactique, mais uniquement apporter des éléments de réflexion pour des recherches futures ou présentes allant dans le même sens. Ces recherches pourront prendre plusieurs formes en didactique, car ainsi que Jolanta Zając (2010 : 42 , notre traduction ${ }^{250}$ ) l'affirme :

L'activité scientifique n’a pas toujours pour objectif la découverte de nouvelles théories, mais aussi la systématisation d'un domaine et sa mise en forme scientifique ainsi que "l'insertion des acquis venant d'autres disciplines » (Duraj-Nowakowa, Gnitecki 1997 : 45 dans ibid.).

Rappelons que la dimension interculturelle, dont l'importance de l'intégration dans les pratiques pédagogiques est régulièrement mise en exergue depuis les années 1990, se trouve actuellement au cœur des réflexions concernant la didactique du FLE. Or, il est de notoriété commune que le développement de l'éducation interculturelle avec toutes les ambiguiités et les débats qu’amène cette expression - lance également de nouveaux défis à la didactique des langues y compris à la didactique de cours sur objectifs professionnels. En théorie, il paraît qu'il n'y a pas de meilleur lieu que la classe de FOS pour un échange intersubjectif multiple, pour la réflexion sur les représentations de l'Autre et la rencontre de l'altérité. Il s'ensuit que c'est la compétence plurilingue qui devrait constituer l'un des principaux objectifs des démarches didactiques entreprises en classe de FOS, car non seulement elle permet aux apprenants de faire face à des situations de communication professionnelle

${ }^{250}$ Działalność naukowa może polegać nie tylko na odkrywaniu nowych teorii, ale także na usystematyzowaniu przedmiotu i nadaniu mu formy naukowej, a także na „wprzęgnięciu do współpracy osiągnieć z innych dziedzin wiedzy” (Duraj-Nowakowa, Gnitecki 1997 : 45 dans Zając 2010). 
exolingues, mais elle rend aussi l'apprentissage des langues plus rapide et plus efficace. Même si les chercheurs en la matière se penchent souvent sur l'analyse des traits caractéristiques de la compétence en question, et sur les profits qui en découlent, on manque pour le moment de modèles didactiques qui permettraient de l'opérationnaliser dans le contexte de l'enseignement/apprentissage des langues étrangères en classe de FOS. Ainsi, l'intégration de cette composante représente un vaste champ d'expérimentation ouvrant les portes à la créativité pédagogique.

Remarquons que l'intérêt que nous portons à la langue à visée professionnelle résulte de nos observations. Cet ouvrage est né de notre expérience pédagogique ainsi que nos recherches menées au Collège d'Europe à Natolin (Pologne). En tant que membre de l'équipe d'enseignants travaillant dans une institution où existe une rencontre interculturelle partagée non seulement par des personnes de pays distincts, mais aussi par des individus du même pays mais d'origines culturelles différentes, nous sommes en charge de donner des cours de français de la diplomatie. L'interrogation sur la meilleure façon de préparer nos étudiants à communiquer avec les représentants d'autres cultures et ceci en milieu professionnel était un point de départ de cette recherche.

Dans le présent ouvrage nous avons cherché à illustrer l'idée que la compétence plurilingue et pluriculturelle est un élément crucial en classe de français de la diplomatie et qu'il mérite d'être développé. Ceci est directement lié au profil d'un utilisateur potentiel du français de spécialité diplomatique que nous avons réussi à dresser grâce à l'analyse approfondie des compétences exigées des candidats à un poste dans les organismes publics européens. Il en résulte que ce public doit posséder des savoir-faire qui lui permettent d'interagir et de négocier en respectant le code socioculturel de la communication formelle et non formelle caractéristique du milieu pluriculturel européen.

Dans la suite de notre recherche, nous avons mis en place un modèle construisant un parcours de formation de qualité adapté aux besoins d'un public de (futurs) spécialistes des questions européennes. Les démarches pédagogiques et le programme de formation appliqués tout au long de l'année académique 2017/2018 (le travail avec le Portfolio, les récits écrits des étudiants, les séquences pédagogiques qui mettent en scène la diversité linguistique et culturelle) montrent qu'il est possible de développer la compétence plurilingue et pluriculturelle en classe de français de la diplomatie. Dans notre recherche le développement de la CPLPC par rapport au niveau initial a augmenté de presque $20 \%$. En outre, nous avons constaté que ce sont des séquences pédagogiques ciblant la CPLPC et l'autonarration écrite qui ont le plus influencé la réflexivité des apprenants du français de la diplomatie envers d'autres langues et cultures. De ce fait, la diversité des langues et des cultures présente dans la classe a commencé à être considérée par l'ensemble des apprenants comme normale et 
ordinaire. La recherche a également mis en lumière le fait que les apprenants n'ont jamais travaillé avec le Portfolio auparavant et que cet outil, qui devrait, en principe, développer l'autoévaluation et l'autonomie d'apprentissage, ne pouvait pas être exploité comme nous l'avions imaginé251.

Le travail effectué nous fait constater que le domaine du français (et pas seulement) à visée professionnelle intégrant l'interculturalité est la terra incognita de l'enseignement/apprentissage des langues étrangères. L'approche privilégiée se centre d'habitude sur le lexique, en privilégiant la compétence de réception de textes écrits. L'enseignement/apprentissage se fait surtout à travers la simple lectureanalyse-traduction de textes spécialisés et ainsi les aspects culturels sont négligés. Or, les approches didactiques ont subi un développement significatif au cours des dernières décennies. Nous pensons que l'objectif interculturel et, par conséquent, la compétence plurilingue et pluriculturelle, ne doivent pas être perçus comme un supplément des formations à des publics de professionnels, mais comme l'objectif " organisateur » des dimensions techniques, lexicales, grammaticales, phonétiques/ phonologiques et discursives. Il serait souhaitable d'examiner ce sujet dans une étude plus longue dans d'autres domaines professionnels comme le français de la médecine ou de l'hôtellerie.

Finalement, il est à noter que comme c'est le cas de toute innovation pédagogique, la mise en œuvre des approches plurielles a provoqué des réactions émotionnelles vives et même une résistance ce à quoi les enseignants devraient être préparés pour gérer des incidents critiques par des réponses appropriées. Certes, la promotion de la compétence interculturelle soulève des questions concernant l'évolution des pratiques pédagogiques mais, avant tout, elle impose des changements dans le système de formation des enseignants. Les formateurs, sont-ils prêts à abandonner l'approche singulière et à développer avec leurs apprenants la compétence plurilingue et pluriculturelle?

Même si les concusions que nous tirons de notre étude ne sont que de futures hypothèses d'une recherche plus solide, elles prouvent qu'une nouvelle voie est ouverte en didactique des langues.

${ }^{251} \mathrm{Il}$ est surprenant de voir que les étudiants ont ressenti une réticence face au remplissage du portfolio. Il nous semble que beaucoup détudiants ont commencé à remplir le document seulement avant la date de remise. Bien sûr, il reste un nombre considérable de facteurs qui influent cette situation. Nous pensons que les apprenants ne sont pas habitués à travailler avec des documents d'auto-évaluation. Dans cette optique, la question se pose d'introduire ou pas le portfolio en classe de FOS. Rappelons que c'est un domaine mouvant où l'expérience semble devancer les longs préparatifs issus de travaux de réflexion et de théorie. "C'est aussi une aventure qui ne permet pas que l’on se fie à l'expérience des autres et ce, parce que les contextes d'application sont variés et noffrent pas toujours des éléments interchangeables. Pour une vision plus globale de l'utilisation du portfolio, il serait intéressant délargir cette étude auprès d'autres publics des adultes » (Scallon, 2000 : 19). 


\section{Streszczenie}

W dzisiejszych czasach kwestia interkulturowości oraz wiążaca się z nią kompetencja różnojęzyczna i międzykulturowa znajdują się w centrum uwagi dydaktyki języków obcych. Lekcja języka obcego wydaje się być najlepszym miejscem na omawianie treści kulturowych zwiększających m.in. świadomość różnic i podobieństw między kulturą rodzimą i obcą czy budujących umiejętność dystansowania się wobec konwencjonalnych nastawień do różnic kulturowych. Kształcenie takiej wrażliwości językowej i kulturowej wiąże się z odrzuceniem dominującego przez długi czas w Europie ideału jednojęzyczności, a co za tym idzie z promowaniem nowego paradygmatu dydaktycznego opisanego szczegółowo w dokumencie FREPA (2007): System opisu pluralistycznych podejść do języków i kultur (wersja polska 2017), stanowiący uzupełnienie Europejskiego Systemu Opisu Kształcenia Językowego (ESOKJ).

Niniejsza praca pokazuje sposoby wdrażania działań dydaktycznych mających na celu kształcenie bądź rozwijanie wrażliwości interkulturowej na lekcji języka francuskiego dla przyszłych lub obecnych dyplomatów. Kluczowe dla niniejszej pracy stały się badania przeprowadzone wśród studentów Kolegium Europejskiego w Natolinie. Pytania badawcze pracy wpisują się w dwa obszary: glottodydaktyka języków specjalistycznych, a w szczególności FOS (Français sur Objectif(s) Spécifique(s)) oraz w podejście interkulturowe.

Celem niniejszej pracy jest ukazanie, że kompetencja różnojęzyczna i międzykulturowa wiążąca się bezpośrednio z podejściem interkulturowym zasługuje na specjalne miejsce w procesie kształcenia językowego dla potrzeb zawodowych. Warto podkreślić, że różnojęzyczność i różnokulturowość to bez wątpienia kluczowe zagadnienia polityki edukacji językowej w większości krajów europejskich. Niewątpliwie wpływ na to miało sporządzenie i opublikowanie Systemu opisu pluralistycznych podjeść do języków i kultur (FREPA), który stanowił przyczynek 
do popularyzacji edukacji różnojęzycznej i międzykulturowej. Niezwykle istotne wydaje się zatem wdrożenie konkretnych treści edukacji różnojęzycznej promowanej przez Radę Europy także na lekcji języka specjalistycznego ujmującego tematykę dyplomacji. Niniejsza praca składa się z 5-ciu rozdziałów.

$\mathrm{W}$ rozdziale pierwszym (L'enseignement du français à des publics professionnels en tant qu'objet d'études) została przedstawiona refleksja nad dydaktyką języków specjalistycznych oraz próba chronologicznego usystematyzowania rozbieżności terminologicznych, które uwypukliły się w XX wieku. Ta część kończy się analizą podręcznika do nauczania języka francuskiego dla przyszłych dyplomatów: Objectif diplomatie A1/A2 : le français des relations européennes et internationales oraz analizą zbioru ćwiczeń Diplomatie.com przeznaczonego dla studentów wydziałów stosunków międzynarodowych. Rozdział drugi (Des besoins aux compétences. Le rôle des compétences dans la construction du programme du français de la diplomatie) przedstawia szczegółowy profil dyplomaty, którego charakteryzują wspólne cechy i określony zestaw umiejętności powiązanych z koncepcją różnojęzyczną i międzykulturową. Celem rozdziału jest wskazanie, że język specjalistyczny nie może być dłużej nauczany w duchu dominującego podejścia leksykalno-tłumaczeniowego. Ponadto pokazuje, że przy tworzeniu kursu nie należy ignorować wspólnych cech osobowości profesjonalistów pracujących $\mathrm{w}$ dziedzinie dyplomacji. W rozdziale trzecim (Opérationnalisation de la compétence plurilingue et pluriculturelle dans l'optique d'un Cadre de Référence pour les Approches Plurielles des Langues et des Cultures. L'exemple du français de la diplomatie) została przedstawiona koncepcja podejść pluralistycznych do języków i kultur oraz ich ważna rola w edukacji różnojęzycznej i różnokulturowej. W rozdziale zaprezentowana jest propozycja operacjonalizacji założeń powyższego narzędzia w programie zajęć języka francuskiego dla przyszłych dyplomatów. Dwa ostatnie rozdziały to opis badania empirycznego przeprowadzonego w Kolegium Europejskim w Natolinie. Rozdział czwarty (Choix méthodologique pour la recherche empirique) to szczegółowy opis metodologii postępowania badawczego. Główną metodą stosowaną w pracy były badania własne, których podstawę stanowi badanie w działaniu wzmocnione innymi jakościowymi metodami zbierania danych takimi jak skonstruowanie własnego portfolio, obserwacja oraz kwestionariusz. Rozdział piąty (Présentation et interprétation des données recueillies dans la recherche empirique) to raport $\mathrm{z}$ badania, które miało za zadanie zdiagnozowanie jak wprowadzone działania dydaktyczne wpływają na rozwój kompetencji różnojęzycznej i międzykulturowej w procesie kształcenia językowego dla potrzeb zawodowych na przykładzie lekcji francuskiego dla przyszłych dyplomatów. W rezultacie prowadzonych działań badawczych udało się osiągnąć większość założonych celów. 


\section{Summary}

Nowadays, the intercultural dimension and plurilingual and pluricultural competence are central to the didactics of foreign languages. Some evidence suggests that the foreign language classes are the perfect place to links cultures: learners have the opportunity to experience and analyse cultural otherness, and to use this experience to reflect on matters that are usually taken for granted within one's own culture and environment. This, in turn, requires the abandonment of the monolingual ideal (which has long dominated Europe) and the promotion of pluralistic approaches, a new paradigm for language teaching/learning described in detail in the Framework for Pluralistic Approaches (2007).

This study explores the idea of integrating an intercultural approach in the teaching-learning process of French for Diplomats. This work is focused on the foreign student public attending a 1-year Master's programme at the College of Europe in Natolin, and this work constitutes a contribution to the didactics of French for Specific Objectives (FOS). The didactic questions raised here are aim at clarifying the manner in which "French for Specific Objectives" and "Interculturality" are articulated to each other.

The purpose of this publication is to demonstrate that plurilingual and pluricultural competence deserves serious attention with regard to the process of French language teaching for young professionals. The appearance of the Reference Framework for Plural Approaches to Languages and Cultures (FREPA) has notably prompted a more in-depth analysis of plurilingual and pluricultural competence, a crucial competence in the modern didactics of foreign languages. It is therefore essential to take this new reality into account, and to adapt to it also in the case of training for young adults, including future diplomats. It is with this in mind that this thesis develops its analysis over five chapters. 
Chapter 1 (L'enseignement du français à des publics professionnels en tant qu'objet d'études) facuses on the importance of language for professional purposes as well as the evolution of different linguistic currents over the 20th century. The most fundamental theories of professional French learning are presented. The chapter concludes with an analysis of the A1 / A2 Diplomacy Workbook: Objectif diplomatie A1/A2: le français des relations européennes et internationales and a Diplomatie. com workbook for learning French in the context of international and European relations. Chapter 2 (Des besoins aux compétences. Le rôle des compétences dans la construction du programme du français de la diplomatie) provides a detailed profile of a diplomat who notably relies upon plurilingual and pluricultural competences, as well as sociolinguistic and pragmatic capacities. In the chapter it is argued that the professional language is not reduced to a limited vocabulary and that courses of French for diplomacy should not be limited to linguistic aspects, as it currently the case. Chapter 3 (Opérationnalisation de la compétence plurilingue et pluriculturelle dans l'optique d'un Cadre de Référence pour les Approches Plurielles des Langues et des Cultures. L'exemple du français de la diplomatie) first focuses on theoretical concepts and the application of the pluralistic approaches that contribute to the development of plurilingual and pluricultural competence. It also shows how pluralistic approaches can be implemented in the course of French for diplomacy. Chapter 4 (Choix méthodologique pour la recherche empirique) describes in detail the problems linked to the empirical research conducted. Research on the development of plurilingual and pluricultural competence is pursued through analysing the most suitable qualitative methods and data collection techniques. The above-mentioned chapters lay the foundations for illustrating the core of this research, which is analysed in Chapter 5 (Présentation et interprétation des données recueillies dans la recherche empirique). In this last latter it is argued that a plurilingual and intercultural education goes hand in hand with the development of reflexive capacities, self-assessment skills and learning autonomy, as well as awareness of cultural alterity. 


\section{Résumé}

À l'heure actuelle, la dimension interculturelle et la compétence plurilingue et pluriculturelle se trouvent au centre des réflexions concernant la didactique des langues étranges. La classe de langue, où la réflexion sur les représentations de l'Autre, sur la rencontre de l'altérité et la prise de conscience que nous sommes tous soumis à des structures de pensée simplificatrices, permettrait d'acquérir un regard plus objectif, plus conscient de l'Autre ou d'autres groupes. Il en résulte l'abandon de l'idéal monolingue (qui a longtemps dominé en Europe) et la promotion des approches plurielles, un nouveau paradigme pour l'enseignement/apprentissage des langues décrit en détail dans le Cadre de Référence pour les Approches Plurielles des Langues et des Cultures (CARAP, 2007).

Cet ouvrage se propose de réfléchir à l'intégration d'une démarche interculturelle dans un enseignement/apprentissage de français de la diplomatie. Axé sur le public de futurs diplomates venant suivre un an au Collège d'Europe à Natolin, ce travail constitue une contribution à la didactique du français sur objectif spécifique (FOS). Les questions de recherche abordées visent à éclairer la manière dont s'articulent l' « interculturalité » et le « FOS».

L'objectif du présent ouvrage est de démontrer que la compétence plurilingue et pluriculturelle mérite d'avoir une place à part dans le processus d'enseignement/ apprentissage de langue française à destination d'un public de jeunes professionnels. C'est notamment l'apparition du Cadre de Référence pour les Approches Plurielles des Langues et des Cultures (CARAP) qui a incité une analyse beaucoup plus poussée de la compétence plurilingue et pluriculturelle, une compétence cruciale dans la didactique moderne des langues étrangères. Il est donc fondamental de prendre en considération cette nouvelle réalité et de s'y adapter également dans le cas d'une formation qui s'adresse à de jeunes adultes comme c'est le cas du public de futurs diplomates. C'est d'un tel point de vue que part cet ouvrage divisé en 5 chapitres. 
Dans le premier chapitre (L'enseignement du français à des publics professionnels en tant qu'objet d'études), il est question de l'importance de la langue à des fins professionnelles ainsi que l'évolution de différents courants linguistiques du XXe. Les théories les plus fondamentales de l'apprentissage du français à visée professionnelle y ont été présentées. Le chapitre se clôt par l'analyse du manuel Objectif diplomatie A1/A2 : le français des relations européennes et internationales et un cahier d'activité Diplomatie.com permettant l'apprentissage du français dans le contexte des relations internationales et européennes. Le deuxième chapitre (Des besoins aux compétences. Le rôle des compétences dans la construction du programme du français de la diplomatie) dresse un profil détaillé d'un diplomate qui mobilise avant tout la compétence plurilingue et pluriculturelle ainsi que la compétence sociolinguistique et pragmatique. Cette partie mettra en œuvre le fait que la langue professionnelle ne se réduit pas à un vocabulaire de spécialité et que le cours de français de la diplomatie ne devrait pas être limité aux aspects linguistiques comme c'est aujourd'hui le cas. Le troisième chapitre (Opérationnalisation de la compétence plurilingue et pluriculturelle dans l'optique d'un Cadre de Référence pour les Approches Plurielles des Langues et des Cultures. L'exemple du français de la diplomatie) analysera dans un premier temps les concepts théoriques et la mise en pratique des approches plurielles qui contribuent au développement de la compétence plurilingue et pluriculturelle. Ensuite, nous observerons comment les approches plurielles peuvent être implantées dans le cours de français de la diplomatie. Le quatrième chapitre (Choix méthodologique pour la recherche empirique) expliquera en détail la problématique de la recherche empirique menée. La recherche sur le développement de la compétence plurilingue et pluriculturelle sera poursuivie à travers l'examen des méthodes qualitatives ainsi que des techniques de recueil des données qui conviennent le mieux au sujet de l'étude. Tout ceci préparera la recherche principale, dont les résultats seront analysés dans le cinquième chapitre (Présentation et interprétation des données recueillies dans la recherche empirique). Ce dernier chapitre montre qu'une éducation plurilingue et interculturelle va de pair avec le développement des capacités réflexives, des aptitudes à l'autoévaluation et de l'autonomie d'apprentissage ainsi qu'avec une prise de conscience de l'altérité. 


\section{Bibliographie}

- Abdallah-Pretceille, M. (1986) : Vers une pédagogie interculturelle. Paris : Publications de la Sorbonne.

- Abdallah-Pretceille, M. (1996a) : «Compétence culturelle, compétence interculturelle: pour une anthropologie de la communication", le Français dans le Monde. Recherches et Applications, numéro spécial janvier 1996, pp. 28-38.

- Abdallah-Pretceille, M. (1996b) : Vers une pédagogie interculturelle. Paris : Antropos.

- Abdallah-Pretceille, M. (2004) : L'éducation interculturelle, Paris : PUF.

- Abdallah-Pretceille, M., Porcher L. (2001) : Éducation et communication interculturelle [2e éd.]. Paris : PUF.

- Abry, D. (2007) : Phonétique. Paris : CLE.

- Aleksandrowicz-Pędlich, L. (2005) : «Interkulturowość w kształceniu językowym w Polsce i innych krajach europejskich», [dans:] H. Komorowska, Nauczanie języków obcych - Polska a Europa. Warszawa: Wydawnictwo SWPS Academica, pp. 39-56.

- Androulakis, G., Wilczyńska, W. (2007) : Pour le multilinguisme. Exploiter à lécole la diversité des contextes européens. Liège : Editions de l'Université de Liège.

- Aupecle, M., Alvarez, G., Moctezuma, S., Diaz-Alvarez, N., Locastro-High, V. (1977) : Français instrumental et français fonctionnel. Strasbourg : AUPELF.

- Babbie, E. (2007) : Badania społeczne w praktyce. Warszawa : Wydawnictwo PWN.

- Bardovi-Harlig, K. (1996) : Input in an Institutional Setting. Studies in Second Language Acquisition, 18(2), 171-188.

- Bandura, A. (1977) : Self-Efficacy. The exercice of control. New York: Freeman.

- Bandura, A. (2007) : A History of Psychology in Autobiography (9thed.).Washington: American Psychological Association.

- Beacco, J-C. (1986). "La civilisation entre idéologie et méthode » [dans :] L. Porcher (dir.), La civilisation. Paris : CLE International, pp.101-117.

- Beacco, J.-C., Chevalier, J.-C. (1988) : « Les rapports de la linguistique et de la didactique des langues» [dans:] D. Lehmann (coord.), La didactique des langues en face à face. Paris : Crédif / Hatier, pp. 31-48.

- Beacco, J-C. (2000). Les dimensions culturelles des enseignements de langue. Des mots au discours. Paris, France: Hachette.

- Beacco, J.-C. (2007) : L’approche par compétences dans l’enseignement des langues. Paris : Didier, coll. Langues et didactique.

- Beacco J.-C., Byram, M. (2007) : Guide pour lélaboration des politiques linguistiques éducatives en Europe. Strasbourg : Conseil de l'Europe. 
- Beacco, J.-C. (2010) : La didactique de la grammaire dans l'enseignement du français et des langues. Paris: Didier.

- Beacco, J.-C. (dir.) (2013) : Ethique et politique en didactique des langues. Autour de la notion de responsabilité. Paris : Didier.

- Beacco, J.C. (2015) : Guide pour le développement et la mise en ouvre de curriculums pour une éducation plurilingue et interculturelle. Strasbourg : Conseil de l' Europe.

- Bélisle, M. (2009). «L'autonomie de l'étudiant : une condition essentielle pour un apprentissage en profondeur ". Actes du 29e colloque de l'Association québécoise de pédagogie collégiale (AQPC), Trois Rivières, Canada, 3-5 juin.

- Benveniste, M., Di Vito, S. (2012) : « Multilinguismo e sviluppo delle indetità culturali nella prima infanzia », Studi e ricerche N.6. Venezia : Edizioni Ca’Foscari, pp.168-180.

- Berthele, R., Lambelet, A., Schedel, L. (2017) : "Effets souhaités et effets pervers d'une didactique du plurilinguisme : l'exemple des inférences inter-langues ", Recherches et applications, N. 61. Paris : CLE International, pp.147-155.

- Besse, H. (1984) : « Sur quelques aspects culturels et métalinguistiques de la compréhension d'un document en classe de langue » Tranel no.6, pp.135-145.

- Besse, H. (1993) : "Cultiver une identité plurielle », le français dans le monde, N. 254, pp. 4248.

- Besse, H. (2012) : " Éléments pour une "archéologie» de la méthode directe ", Documents pour l'histoire du français langue étrangère ou seconde, N. 49, pp. 11-30.

- Bigot, V., Vasseur, M. (2014) : «La réflexivité sur les pratiques langagières : d’où vient-elle et qu'en ferons-nous? " [dans :] Ch.Troncy (éd), Didactique du plurilinguisme, Approches plurielles des langues et des cultures., Presses Universitaires de Rennes, pp. 281-289.

- Blanchet, P., Chardenet, P. (2011) : Guide pour la recherche en didactique des langues et des cultures: approches contextualisées. Éditions des archives contemporaines (EAC).

- Bolten, J. (2007) : Interkulturelle Kompetenz. Erfurt : Landeszentrale für politische Bildung.

- Boutet, J. (2001) : Paroles au travail. Paris : L'Harmattan.

- Bryła-Cruz, A. (2017) : «Autentyczne teksty słuchane w nauczaniu pragmatyki », Języki Obce w Szkole, Vol. 4, pp. 4-8.

- Burns, A. (1997) : "Authentic Spoken Texts in the Language Classroom ». Prospect, Vol. 12, N. 2, pp. 72-86.

- Byram, M. (1997). Teaching and Assessing Intercultural Communicative Competence. Bristol : Multilingual Matters.

- Byram, M., Zarate, G., Neuner, G. (1997) : La compétence socioculturelle dans l'apprentissage et l'enseignement des langues. Strasbourg, Conseil de l'Europe.

- Byram, M., Tost Planet, M. (2000) : Social identity and the European dimension : intercultural competence through foreign language learning. Strasbourg \& Graz, ECML, Council of Europe.

- Byram, M., Gribkova, B., Starkey, H. (2002). Développer la dimension interculturelle dans l'enseignement des langues - Une introduction pratique à l'usage des enseignants. Strasbourg : Conseil de l'Europe.

- Cadre de Référence pour les Approches Plurielles des Langues et des Cultures, (2007) : CELV, Graz.

- Cadre européen commun de référence pour les langues - apprendre, enseigner, évaluer, (2001): Strasbourg: Conseil de l'Europe.

- Candelier, M. (red.) (2003), L'introduction de l'éveil aux langues dans le curriculum, Centre européen pour les langues vivantes, Édition du Conseil de l'Europe, Strasbourg.

- Candelier, M., Kervran, M., Rémy-Thomas, F., (2003) : « Une approche plurielle des langues à l'école primaire. Construire de nouvelles compétences préparatoires à la traduction ", le français aujourd'hui, Vol. 3, N. 142, pp. 55-67.

- Candelier, M., (2006). "Éveil aux langues, formation plurilingue et enseignement du français », Synergies Monde, N. 1, pp. 67-76. 
- Candelier, M. (2007) : « Awakening to languages and language policy », [dans :] J. Cenoz, N. Hornberger (dir.), Encyclopedia of language and education, Vol. 6, pp. 219-232.

- Candelier, M., Castellotti V. (2008) : "Didactique(s) du(des) plurilinguisme(s) », [dans :] J. Simonin, S. Wharton (dir.). Sociolinguistique des langues en contact, modèles, théories. Dictionnaire encyclopédique des termes et concepts. Lyon : ENS Éditions.

- Candelier, M., (2014) : «La « réflexion sur la langue ». D’où vient-elle et qu’en ferons-nous? », [dans :] Ch. Troncy, (dir.), Didactique du plurilingusime. Approches plurielles des langues et des cultures., Presses Universitaires de Rennes, pp. 71-87.

- Candelier, M. (2016) : «Activités métalinguistiques. Pour une didactique intégrée des langues ", le français aujourd'hui, Vol. 1, N. 192, pp. 107-116.

- Carroll, R. (1987) : Les évidences invisibles. Paris : Seuil.

- Castellotti, V. (2001) : La langue maternelle en classe de langue étrangère. Paris : CLE International.

- Castellotti, V., Moore, D. (2001) : «Le proche et le lointain dans les représentations des langues et de leur apprentissage ", Les représentations des langues et de leur apprentissage. Références, modèles, données et méthodes, Collection Crédif-Essais. Paris : Didier, pp. 101-131.

- Castellotti, V., Moore, D. (2002) : Représentations sociales des langues et enseignements. Strasbourg: Conseil de l'Europe.

- Castellotti, V. (2006) : «Pratiques réflexives en contexte plurilingue : le portfolio européen des langues pour le collège ", [dans :] M. Molinie, M.F.Bishop, (dir.), Autobiographie et réflexivité, Encrage / Les Belles Lettres, pp. 69-82.

- Castellotti, V. (2008) : "Vers une école et une société plurielle : des notions en débat, des orientations à construire ", Insertion scolaire et insertion sociale des nouveaux arrivants, Glottopol, Vol. 11, pp. 2-12.

- Castellotti, V., Coste, D., Duverger, J. (2008) : Propositions pour une éducation au plurilinguisme en contexte scolaire. Tours/ Paris : ADEB et Université François Rabelais.

- Castellotti, V., Moore, D. (2008) : «Contextualisation et universalisme. Quelle didactique des langues pour le 21ème siècle? ", [dans :] P. Blanchet, D. Moore, (eds). Perpectives pour une didactique des langues contextualisée. Paris : Éditions des Archives Contemporaines et AUF, pp.183-203.

- Catroux, M. (2002) : «Introduction à la recherche-action : modalités d'une démarche théorique centrée sur la pratique ", Recherche et pratiques pédagogiques en langues de spécialité, Vol. 21, N. 3, pp.8-20.

- Cavalli, M. (2003) : « Discours bilingue et apprentissage des disciplines : réflexions d’après les expériences du Val d'Aoste ", Lidil, pp. 31-46.

- Cavallli, M. (2005) : Education bilingue et plurilinguisme. Le cas du Val d'Aoste, Paris : Didier CREDIF.

- Challe, O. (2002) : Enseigner le français de spécialité, Paris : Economica.

- Chaves, R.-M., Favier, L., Pélissier, S. (2012) : L'Interculturel en classe. Grenoble : PUG.

- Cohen-Emerique M., (2011) : Pour une approche interculturelle en travail social, théories et pratiques, Presses de l'EHESP.

- Cohen, A., Olshtain, E. (1982) : «Developing a Measure of Sociocultural Competence : the case of Apology ", Language Learning, Vol. 31, Issue 1, pp. 113-134.

- Conseil de l'Europe (1995) : Contre les stéréotypes et les préjugés. Les travaux du Conseil de l'Europe sur l'enseignement de l'histoire et les manuels d'histoire.

- Constanze, V. (2006) : Le discours diplomatique. Paris : L’Harmattan.

- Correa Molina, E., Gervais, C. (2008) : Stages en formation à l'enseignement: Pratiques et perspectives théoriques. Presses de l'Université du Québec.

- Costa-Giomi, E., Descombes, V. (1996) : « Pitch Labels with Single and Multiple Meanings: A Study with French-Speaking Children ", Journal of Research in Music Education, Vol. 44, N. 3, pp. 204-214. 
- Coste, D., (1995) : "Curriculum et pluralité », Études de linguistique appliquée, N 98, pp. 68-84.

- Coste, D., Moore, D., Zarate, G. (1997) : Compétence plurilingue et pluriculturelle. Strasbourg : Conseil de l'Europe.

- Cummins, J. (1980) : «The Cross-Lingual Dimensions of Language Proficiency: Implications for Bilingual Education and the Optimal Age Issue ». ESOL Quarterly, Vol. 14, N. 2, pp. 175-187.

- Cummins, J. (2000) : Language, Power and Pedgogy: Bilingual Children in the Crossfire. Bristol: Multilingual Matters.

- Cuq J. P., (2003) : Dictionnaire de didactique du français langue étrangère et seconde. Paris : CLE International.

- Cuq, J.P., Gruca, I. (2005) : Cours de didactique du français langue étrangère et seconde, Grenoble : PUG.

- Dabène, L. (1992) : «Le développement de la conscience métalinguistique : un objectif commun pour l'enseignement de la langue maternelle et des langues étrangères ", Repères. Recherches en didactique du français langue maternelle, n. 6, pp. 13-21.

- Daniel, F. (1997) : "Mise en scène d'histoires de vie ", le français dans le monde, n. 290, pp. 49-52.

- De Ketele, J.-M., (2001) : "Place de la notion de compétence dans l'évaluation des apprentissages ", [dans :] G. Figari, M.Achouche (dir.), Lactivité évaluative réinterrogée. Regards scolaires et socioprofessionnels. Bruxelles : De Boeck Université, pp. 39-43.

- De Ketele, J.-M., Roegiers, X. (2004) : Méthodologie du recueil d'informations. Fondements des méthodes d'observations, de questionnaires, d'interviews et d'études de documents. Nouvelle édition. Bruxelles : De Boeck Université.

- Degache, C., Masperi, M. (1998) : "La communication plurilingue en toile de fond de l'entraînement à la compréhension des langues romanes ", [dans :] J. Billiez, (éd.). De la didactique des langues à la didactique du plurilinguisme - Hommage à Louise Dabène. Grenoble, CDL-LIDILEM, pp. 361-375.

- Degache, C., Garbarino, S. (2012) : Actes du colloque IC2012. Intercompréhension : compétences plurielles, corpus, intégration. Université Stendhal Grenoble 3 (France), 21-22-23 juin 2012.

- Degache, C. (2017) : "Enjeux des modalités télécollaboratives dans un scénario pour l'intercompréhension : chronique d'un changement annoncé », [dans :] C. Jeoffrion et M.-F. Narcy-Combes (éd.), Contributions au développement de perspectives plurilingues en éducation et formation. Presses Universitaires de Rennes.

- Delcorde, R. (2009) : "L'Évolution du Métier de Diplomate », Annuaire Français de Relations Internationales, Vol. X, pp. 27-46.

- Dewaele, J-M., Wourm, N. (2002) : "L'acquisition de la compétence sociopragmatique en langue étrangère ", Revue française de linguistique appliquée. Vol. 7, N.2, pp. 129-143.

- Dewaele, J.-M. (2002) : " Emotion Vocabulary in Interlanguage. Language Learning, Vol. 52, N. 2, pp. 263-322.

- Díaz, C. G. (2007) : « Pour la mise en place de l'interculturel en classe de LE », Ela. Études de linguistique appliquée, N. 146, pp. 189-204.

- Doyé, P. (2005) : L'Intercompéhension. Guide pour lélaboration des politiques linguistiques éducatives en Europe - De la diversité linguistique à l’éducation plurilingue. Strasbourg : Conseil de l'Europe.

- Dubost, J. (1984) : «Une analyse comparative des pratiques de recherche-action », Connexions, N. 43, pp. 9-28.

- Dubost, J., Lévy, A. (2002) : "Recherche-action et intervention », Vocabulaire de la psychosociologie. Toulouse : Erès, pp. 391-415.

- Escudé P., Janin, P. (2010) : Le point sur l'intercompréhension, clé du plurilinguisme. Paris : CLE International. 
- Feldhendler, D. (1999a) : "La dramaturgie relationnelle ", le français dans le monde, Sondernummer Recherches et applications, pp. 125-133.

- Feldhendler, D. (2001) : " A Culture of Remembrance », Interplay, Volume XII, 2, York, 2001, pp. 8-10.

- Forlot, G. (2012) : «Critique de l'éducation plurilingue et interculturelle, ou comment ne pas se tromper de cible ", Langage et société, Vol. 140, N. 2, pp. 105-114.

- Frame, A. (2015) : "Quelle place pour l'interculturel au sein des SIC? », Les Cahiers de la SFSIC, Société française des sciences de l'information et de la communication, 2015, pp. 85-91.

- Frandsen, F. (1998) : "Langue générale et langue de spécialité - une distinction asymétrique ? », [dans :] Y. Gambier, Discours professionnels en français. Bern : Peter Lang, pp. 15-34.

- Gajewska E., Sowa M. (2008) : « Cadre Européen Commun de Référence et enseignement sur objectifs professionnels », Synergies Sud-Est européen, N. 1, 2008, pp. 101-111.

- Gajewska E. (2011) : Techniki nauczania języka obcego. Tarnów : PWSZ.

- Gajewska E., Sowa M., (2014) : LSP, FOS, Fachsprache... Dydaktyka języków specjalistycznych. Lublin: Wydawnictwo Werset.

- Gajo, L. (2006) : « Types de savoirs dans l’enseignement bilingue: problématicité, opacité, densité ", Éducation et sociétés plurilingues, Vol. 20, pp. 75-87.

- Gambier, Yves (1998) : "Le français dans les communications spécialisées : un bilan mitigé », Discours professionnels en français. Bern : Peter Lang,.

- Gass, S. M., Bardovi-Harlig, K., Magnan. S.,Walz, J. (2002) : Pedagogical norms for second and foreign language teaching. Amsterdam: John Benjamins Publishing Company.

- Gębal, P. E., (2013) : Model kształcenia nauczycieli języków obcych w Polsce i w Niemczech. W stronę glottodydaktyki porównawczej. Kraków : Księgarnia Akademicka.

- Gohard-Radenkovic, A., (1999) : Communiquer en langue étrangère. Bern : P. Lang.

- Goyette, G., Lessard-Hébert, M. (1987) : Recherche qualitative : fondements et pratiques. Paris : Broché.

- Grinevald, C. (2011) : Langues en danger: le phénomène et la réponse des linguistes. Paris : Ophrys.

- Guba, E.G., Lincoln, Y.S. (2005) : « Paradigmatic Controversies, Contradictions, and Emerging Confluences », [dans :] N. K. Denzin, Y. S. Lincoln (éd), The Sage handbook of qualitative research, pp. 191-215. Thousand Oaks, Canada : Sage Publications Ltd.

- Harley, B., Allen, P., Cummings, K. et Swain, M. (1990) : «The Development of Second Language Proficiency »; Cambridge: Cambridge University Press.

- Henao, M., (1989) : «Formation linguistique professionnelle », Revue Reflets, N. 31, juin 1989, pp.18-23.

- Holtzer, G. (2004) : Du français fonctionnel au français sur objectif spécifiques. Histoire des notions et des pratiques. Paris : CLE International.

- Hugon, M.-A., Seibel, C. (1988) : Recherches impliquées, Recherches action: le cas de léducation. Belgique : De Boeck Université.

- Hulley, S., Cummings, S. (2006) : Designing clinical research. New York : Lippincott Williams \& Wilkins.

- Hutchinson, T., Waters, A., (1987) : English for Specific Purposes. Cambridge University Press.

- Hymes, D. H. (1991) : Vers une compétence de communication. Paris, France: Crédif.

- Jamet, M.C. (2013) : "La complexité linguistique est-elle complexe pour l'apprentissage? Nature et interprétation des erreurs, et en particulier des erreurs de syntaxe dans des productions écrites d'apprenants italophones du français ». La complexité en langue et son acquisition. Lublin : Towarzystwo Naukowe KUL \& KUL, pp. 1-15.

- Jastrzębska, E. (2011) : "Linterculturel dans la formation des enseignants de langues ", L'interculturel en pratique, N. 1, Seria 12/15, pp. 33-39. Lublin : Wydawnictwo Werset. 
- Kasper, G., Blum-Kulka, S. (1993) : Interlanguage Pragmatics. New York: Oxford University Press.

- Kecskes, I., Papp, T. (2000) : Foreign language and mother tongue. Mahwah, NJ, US: Lawrence Erlbaum Associates Publishers.

- Kic-Drgas, J. (2017) : «A jeśli uczeń wie więcej-trudna interakcja na zajęciach z języka Specjalistycznego ", Neofilolog, Vol. 2, N. 49, pp. 207-216.

- Kramsch, C. (2015) : «A Theory of the Practice », Applied Linguistics, Volume 36, Issue 4, 1 September 2015, pp. 454-465.

- Krashen, S. D. (1981) : Second language acquisition and second language learning. University of Southern California : Pergamon press Inc.

- Kucharczyk, R. (2018) : Nauczanie języków obcych a dydaktyka wielojęzyczności. Na przykładzie francuskiego jako drugiego języka obcego. Lublin : Wydawnictwo Werset.

- Kucharczyk, R., Szymankiewicz, K. (2018) : „Świadomość własnego procesu uczenia się języków obcych przyczynkiem do innowacyjnych działań dydaktycznych", Neofilolog, no. 51/1, pp. 89-108.

- Kuhn, T. (1983) : « Rationality and Theory Choice », The Journal of Philosophy, N. 80 (10), pp. 563-570.

- Lacourse, F., Henri Hensler, H. (2008) : L'usage du portfolio de compétences autour des stages comme catalyseur de la réflexion et du développement professionnel. Québec : Presses de l'Université du Québec.

- Legault, G., Lafrenière, M. (1992) : «Situations d'incompréhensions interculturelles dans les services sociaux : problématique ", Santé mentale au Québec, Vol. 17, N. 2, pp. 113-131.

- Lehmann, D. (1980) : «Français fonctionnel, enseignement fonctionnel de français » [dans :] R. Galisson (éd), Lignes de force du renouveau actuel en didactique des langues étrangères. Remembrements de la pensée méthodologique. Paris, CLE International.

- Lehmann, D., (1993) : Objectifs spécifiques en langue étrangère. Paris : Hachette.

- Lenz, P., Berthele, R. (2010) : Guide pour le développement et la mise en ouvre de curriculums pour une éducation plurilingue et interculturelle, Division des Politiques Linguistiques, DGIV, Strasbourg: Conseil de l'Europe.

- Lerat, Pierre (1995) : Les langues spécialisées, coll. «Linguistique nouvelle», Paris, PUF.

- Lerat, P. (1997) «Approches linguistiques des langues spécialisées », ASp, 15-19, 1-10.

- Lerat, P. (2016) : Langue et technique, Paris : Hermann, coll. «Vertige de la langue».

- Łobocki, M. (2007) : Metody i techniki badań pedagogicznych. Kraków: wydawnictwo Impuls.

- Lüdi G., Höchle, K., Yanaprasart P. (2016) : Managing plurilingual and intercultural practices in the workplace. The case of multilingual Switzerland. Amsterdam : John Benjamins Publishing Company.

- Lüdi G., Py, B. (2003) : Être bilingue. Berne: Peter Lang

- Lyster, R. (1994) : "The Effect of Functional-Analytic Teaching on Aspects of French Immersion Students' Sociolinguistic Competence », Applied Linguistics, Vol. 15, Issue 3, pp. 263-287.

- Mariani, L. (2015) : « Tra lingua e cultura: la competenza pragmatica interculturale», Italiano LinguaDue, N. 1, pp. 111-130.

- Mariet, F., Porcher, L. (1978) : Apprendre à devenir citoyen à l’école. Paris : ESF.

- Maurer, B. (2011) : Enseignement des langues et construction européenne - le plurilinguisme, nouvelle idéologie dominante. Paris : Archives Contemporaines.

- Maurer, B. , Puren, C. (2019) : CECR : par ici la sortie !, Éditions des archives contemporaines, France.

- Mayrhofer, U. (2001) : Les rapprochements d'entreprises, une nouvelle logique stratégique? Une analyse des entreprises françaises et allemandes, Berne : Peter Lang. 
- Mercelot, G. (2013) : «Que peut apporter l'analyse d'interactions orales à l'enseignementapprentissage des langues sur objectifs spécifiques? ", Recherche et pratiques pédagogiques en langues de spécialité, Vol. XXXII N.1, pp. 130-141.

- Merkelbach, C. (2009) : «Quelle place pour la didactique intégrée dans le Plan d'études romandes ", Babylonia, revue pour l'enseignement et l'apprentissage des langues, N.4 'Didactique intégrée et plurilinguisme', pp.50-53.

- Moirand, S. (1978) : Analyse textuelle et objectifs didactiques. Washington : ERIC Clearinghouse.

- Moirand, S., (1990) : Enseigner à communiquer en langue étrangère. Paris : Hachette, coll F.

- Moore D., Castellotti, V., (2001) : «Comment le plurilinguisme vient aux enfants »[dans :] V. Castellotti, (éd.), D’une langue à d'autres : Pratiques et représentations, Dyalang, Rouen, pp. 151-190.

- Moore, D. (2001) : «Une didactique de l'alternance pour mieux apprendre? », Ela. Études de linguistique appliquée, 2001/1, N.121, pp. 71-78.

- Moore, D. (2006) : Plurilinguismes et école. Paris : Didier.

- Mourlhon-Dallies, F. (2003) : «Former à enseigner le français de spécialité : l'exemple du français médical », Les Cahiers de l'Asdifle N.14., pp.175-192.

- Mourlhon-Dallies, F. (2006) : «Penser le français langue professionnelle », le français dans le monde, $\mathrm{n}^{\circ} 346$ de juillet. FIPF et CLE International, pp. 25-28.

- Mourlhon-Dallies F. (2008). Enseigner une langue à des fins professionnelles. Paris : Didier.

- Mourlhon-Dallies F. (2011) : «Le français sur objectifs universitaires, entre français académique, français de spécialité et français pré-professionnel », Synergies monde, Vol. 8, pp.135-143.

- Nowak, S. (1970) : Metodologia badań socjologicznych. Warszawa: Państwowe Wydawnictwo Naukowe.

- Orłowski, T. (2016) : Protokół dyplomatyczny. Między tradycją a nowoczesnością. Warszawa : Polski Instytut Spraw Międzynarodowych.

- Parpette C. , Mangiate J.M. (2004) : le Français sur objectif spécifique : de l'analyse des besoins à l'élaboration d'un cours. Paris : Hachette.

- Parpette C. (2005). «Le Français sur Objectif Spécifique : de l'enseignement à la conception de programmes », Les Cahiers de l’ASDIFLE, pp.130-141.

- Parpette C., Mangiante J.M. (2004) : «Le Français sur Objectif Spécifique ou l'art de s'adapter », le français langue étrangère et seconde: des paysages didactiques en contexte,, L'Harmattan, (Coll. Espaces discursifs), pp.275-282.

- Parpette, C. (2006) : "L'influence d'un environnement homoglotte sur l'enseignement du FLE : d'une réalité diffuse à une méthodologie constituée », [dans :] M.Fievet, D.Abry (éds), Lenseignement/ apprentissage du Français Langue Étrangère en milieu homoglotte : spécificités et exigences. Grenoble: PUG.

- Parpette C., Stauber J. (2014) : Réussir ses études déconomie-gestion en français.Grenoble : PUG.

- Perrichon L. (2008) : Agir d'usage et agir d'apprentissage en didactique des langues-cultures étrangères : enjeux conceptuels, évolution historique et construction d'une nouvelle perspective actionnelle. Thèse de doctorat sous la direction de Christian Puren.

- Pilch, T., Bauman, T. (2010) : Zasady badań pedagogicznych. Warszawa : Wydawnictwo Żak.

- Platt, J. (1983) : "The Development of the 'Participant Observation' Method in Sociology : Origin Myth and History », Journal of the History of the Behavioral Sciences, N.19, pp. 379393.

- Porcher, L. (1976), « M. Thibault et le Bec Bunsen », Etudes de Linguistique Appliquée, N.23, pp. 6-13.

- Porcher, L. (1976), Lenseignement de la civilisation en questions, Etudes de Linguistique Appliquées, N.47, pp. 39-49.

- Porcher L. (2013) : La didactique en blog. Paris : CLE International.

- Puren, C. (1988) : Histoire des méthodologies. Paris : Nathan. 
- Puren, C. (1994) : La didactique des langues étrangères à la croisée des méthodes. Essai sur l'éclectisme. Paris : Didier.

- Puren, C. (2005) : "Domaines de la didactique des langues-cultures. Entrées libres », Les Cahiers pédagogiques, N.437, pp. 41-44.

- Puren, C. (2009) : «Variations sur la perspective de l'agir social en didactique des languescultures étrangères ", Le français dans le monde. Recherches et applications, Vol. 45, pp.154-168.

- Puren, C. (2013) : « Perspective actionnelle et pédagogie de projet, apports historiques de deux mouvements pédagogiques ", l'article accessible sur le site de C. Puren : http://christianpuren. com (consulté, le 2 janvier 2021).

- Puren L., Maurer B. (2018), La crise de l'apprentissage en Afrique francophone subsaharienne. Regards croisés sur la didactique des langues et les pratiques enseignantes. Bruxelles : Peter Lang.

- Py, B. (1997) : «Pour une perspective bilingue sur l'enseignement et l'apprentissage des langues », Études de linguistique appliquée, N.108, pp. 495-503.

- Qotb, H. (2008) : «Un site pour l'enseignement du français sur objectifs spécifiques : le FOS. COM », Synergies, Chine N.3, pp. 81-94.

- Rehner, K., Mougeon, R. (1999) : « Variation in the Spoken French of Immersion Students: To ne or not to ne. That Is the Sociolinguistic Question ", Canadian Modern Language Review, Vol. 56 Issue 1, pp. 124-154.

- Richer, J.J. (2005) : "Le Cadre européen commun de référence pour les langues : Des perspectives d'évolution méthodologique pour l'enseignement/ apprentissage des langues ?", Synergies Chine, N.1, pp. 15-30.

- Richer, J.-J. (2008) : « Le français sur objectifs spécifiques (F.O.S.) : une didactique spécialisée ?", Synergies Chine, N.3, pp. 15-30.

- Richer, J.-J. (2011) : « De l'enseignant de langue(s) au professionnel des langues », Ela. Études de linguistique appliquée, Vol. 1, N.161, pp. 63-77.

- Riehl, L., Soignet, M., Amiot, M.H. (2006) : Objectif Diplomatie 1 : le français des relations européennes et internationales, Paris : Hachette-Français langue étrangère.

- Robert, J.-P., Rosen, E. (2010): Dictionnaire pratique du CECR. Paris : Édition Ophrys.

- Roulet, E. (1980) : Langue maternelle et langues secondes, vers une pédagogie intégrée, EParis : Hatier-Crédif, 1980.

- Róg, T. (2016) : "Language and culture learning strategies in a study abroad context ", Neofilolog N.46/1, pp. 11-27.

- Savoie-Zajc, L. (2001) : Les TIC... au coeur des pédagogies universitaires. Diversité des enjeux pédagogiques et administratifs. Québec: Presses de l'Université du Québec.

- Scallon, G. (200) : «Le portfolio ou dossier d'apprentissage : propos et reflexions », Canada, Dossiers de l'Université de Laval.

- Schieffelin, B., Woolard, K.A., Kroskrity, P.V. (1998) : Language Ideologies: Practice and Theory. New York : Oxford University Press.

- Schneider, G., Lenz, P. (2000) : Portfolio européen des langues. Guide à l'usage des concepteurs, Conseil de l'Europe, Strasbourg : Conseil de l'Europe.

- Siek-Piskozub, T. (2013) : "Enhancing autonomy in the context of an ICC development seminar ", [dans :] M. Jodłowiec, E. Mańczak-Wohlfeld (dir.), Exploring the microcosm and macrocosm of language teaching and learning. Kraków: Wydawnictwo Uniwersytetu Jagiellońskiego, pp. 217-228.

- Soulé, B. (2007) : "Observation participante ou participation observante ? Usages et justifications de la notion de participation observante en sciences sociales ", Recherches qualitatives, Vol. 27(1), pp. 127-140.

- Sowa M. (2005) : Parler et écrire en français. Construction de la temporalité dans le discours narratif par des apprenants polonais avancés en français. Towarzystwo Naukowe KUL: Lublin 2005. 
- Sowa, M. (2011) : D’une activité pédagogique à l'activité professionnelle. Le cheminement vers la compétence. Lublin : TN KUL.

- Sowa, M. (2014) : Enseigner le français sur objectifs spécifiques : de la théorie à la pratique. Lublin : Werset.

- Sowa, M. (2017) : « Kształtowanie kompetencji w nauce języka obcego a profesjonalizacja, czyli co łączy ucznia i profesjonalistę ", Roczniki Humanistyczne, Tom LX, zeszyt 5, pp. 161-177.

- Stringer, E. (2014) : Action Research, California : SAGE.

- Sujecka-Zając, J. (2004) : Du communicatif au discursif. Apports de la pragmatique du discours à la didactique des langues étrangères (exemple FLE), Warszawa : Instytut Romanistyki / Uniwersytet Warszawski.

- Sujecka-Zając, J. (2010) : "Glottodydaktyka w ujęciu epistemologicznym », Neofilolog, N.4, pp. 37-48.

- Sujecka-Zając, J. (2011) : "Interculturalité en classe de langue ", L'interculturel en pratique. N.1, Seria 12/15, pp. 24-33. Lublin : Wydawnictwo Werset.

- Sujecka-Zając, J. (2016), Kompetentny uczeń na lekcji języka obcego. Wyzwania dla glottodydaktyki mediacyjnej. Lublin/Warszawa : Werset/Instytut Romanistyki UW.

- Sujecka-Zając, J. etSmuk, M.(2019): «Importance dela normelinguistique dansl'autonarration des étudiants en philologie romane. Cas des étudiants de la lère année l'Institut d'Études romanes à Varsovie ", [dans : ] Karpińska-Szaj K., Wojciechowska B. (red.). Studia Romanica Posnaniensia 46/2. La narration en didactique des langues, Poznań, pp. 111-122.

- Troncy, C. (2014) : Didactique du Plurilinguisme. Approches Plurielles des Langues et des Cultures. Autour de Michel Candelier, Presses Universitaires de Rennes.

- Tyne, H. (2012) : «La variation dans l'enseignement-apprentissage d'une langue 2 », le français aujourd'hui, N.176, pp. 103- 112.

- Wiersma,W., Jurs, S.-G. (2009) : Research Methods in Education: An Introduction. London : Pearson.

- Wilczyńska, W., Michońska-Stadnik, A. (2010) : Metodologia badań w glottodydaktyce. Wprowadzenie. Kraków: Wydawnictwo Avalon.

- Wilczyńska, W. (2007) : Powszechna dwu-czy kilkujęzyczność? Europejska polityka edukacyjna a oczekiwania uczących się, [dans :] Dokumenty Rady Europy a nauczanie w polskim systemie edukacji, M. Pawlak, J. Fisiak (red.), Łódź 2007, pp. 11.

- Wokusch, S. (2008) : «Didactique intégrée des langues (étrangères) à l'école: vers l’enseignement des langues de demain », Prismes. Revue pédagogique de la HEP, pp. 30-34.

- Wokusch, S. (2008) : "Didactique integrée des langues: la contribution de l'école au plurilinguisme des élèves ", Babylonia / Revue pour l'enseignement et l'apprentissage des langues, N.1, pp. 12-14.

- Wokusch, S., Lys, I. (2007) : « Überlegungen zu einer integrativen Fremdsprachendidaktik », Beiträge zur Lehrerbildung, Vol. 25, N. 2, pp. 168-179.

- Wokusch, S. (2014) : Integrative Fremdsprachendidaktik (IFSD; didactique intégrative des langues étrangères). Fremdsprache Deutsch, Vol. 50, pp. 69-69.

- Wygocki, L.S. (1934/1971) : " Myślenie i mowa », [dans :] Wybrane prace psychologiczne. Warszawa : PWN, pp. 159-488.

- Zarate, G. (1995) : Représentations de l'étranger et didactique des langues, Paris : Didier.

- Zarate, G. (2003) : «Identités et plurilinguisme : conditions préalables à la reconnaissance des compétences interculturelles " [dans :] M. Byram, (éd.), La Compétence interculturelle. Strasbourg: Conseil de l'Europe.

- Zarate, G., Gohard-Radenkovic, A., Lussier, D., Penz, H. (2003) : Médiation culturelle et didactique des langues. Strasbourg : Conseil de l'Europe.

- Zarate, G., Kramsch, C., Lévy, D. (2008) : Précis du plurilinguisme et du pluriculturalisme. Paris : Éditions des archives contemporaines. 


\section{Liste des tableaux}

Tableau 1. Répertoire des appellations du FLE dans le contexte professionnel.

Tableau 2. Approches méthodologiques relatives à l'enseignement des langues à des fins professionnelles.

Tableau 3. Indicateurs de la compétence plurilingue et pluriculturelle.

Tableau 4. Compétences globales du CARAP.

Tableau 5. Exemples de descripteurs de ressources.

Tableau 6. Implantation de quelques principes clés de l'approche éveil aux langues dans le processus d'apprentissage des langues étrangères.

Tableau 7. Fonctions didactiques de l'approche d'intercompréhension entre langues parentes.

Tableau 8. Typologie des activités promouvant l'approche d'intercompréhension entre langues parentes.

Tableau 9. Concepts fondamentaux de la didactique intégrée des langues.

Tableau 10. Les questions de recherche.

Tableau 11. De la position épistémologique à l'instrument de saisie des données. 141

Tableau 12. Critères en recherche qualitative. 144

Tableau 13. Pré-test et post-test en groupe d'étudiants du français de la diplomatie. $\quad 152$

Tableau 14. Les composants du Portfolio au service des objectifs professionnels. 157

Tableau 15. Actions entreprises auprès de notre public. 163

Tableau 16. Le plan du cours de français de la diplomatie. 163

Tableau 17. Les résultats du TCF organisé au Collège d'Europe entre 2010 et 2014.

Tableau 18. Les outils utilisés pour recueillir des données dans la recherche-action. $\quad 172$

Tableau 19. La répartition des répondants par acquisition de la ressource. 172

Tableau 20. Section I du Portfolio. $\quad 179$

Tableau 21. Section II du Portfolio. $\quad 180$

Tableau 22. Section II $b$ du Portfolio. $\quad 181$

Tableau 23. Les questions libres posées aux apprenants du français de la diplomatie. 196

Tableau 24. Les résultats des participants au post-test. 201

Tableau 25. Les réponses aux questions de recherche. 205 


\section{Liste des figures}

Figure 1. Répertoire de diplômes de français professionnel organisés par la Chambre de commerce et d'industrie de Paris (2017).

Figure 2. Caractéristiques du FOS.

Figure 3. Modèle de la langue de spécialitél technique et scientifique de R-F.Gaultier de 1961.

Figure 4. Exemples des documents déclencheurs authentiques dans le manuel "Objectif diplomatie A1/A2 : le Français des relations européennes et internationales."

Figure 5. Exemples de la réalisation de tâches dans le manuel "Objectif diplomatie A1/A2: le Français des relations européennes et internationales.

Figure 6. Exemples de thèmes qui prennent en compte des savoir-être dans une perspective interculturelle dans le manuel "Objectif diplomatie A1/A2 : le Français des relations européennes et internationales."

Figure 7. Fragment du manuel présentant les plus importantes institutions européennes. $\quad 43$

Figure 8. Fragment de l'ouvrage Diplomatie.com présentant les plus importantes institutions européennes.

Figure 9. Profil de l'apprenant du français de la diplomatie.

Figure 10. Tableau des contenus du "l'Objectif Diplomatie B1/B2 : le Français des relations européennes et internationales."

Figure 11. Apports de l'analyse du profil du diplomate et de l'apprenant du français de la diplomatie à notre cours.

Figure 12. Mobilisation des compétences dans le cours de français de la diplomatie. $\quad 80$

Figure 13. Formes d'approches didactiques dans l'enseignement des langues étrangères. $\quad 92$

Figure 14. Progression des compétences dans l'approche traditionnelle et dans l'approche d'intercompréhension.

Figure 15. Différents niveaux de l'intégration suivant la typologie des langues. 116

Figure 16. La classification des sciences.

Figure 17. Schème des actions innovantes de l'enseignant dans la recherche-action. $\quad 146$

Figure 18. Les fragments du PEL au service des objectifs professionnels.

Figure 19. Le degré du développement de la CPLPC des participants à l'étude (pré-test). 174

Figure 20. L'état initial de la CPLPC de participant à l'étude par rapport aux objectifs du CARAP.

Figure 21. Degré d'acquisition de la CPLPC des répondants par rapport aux objectifs du CARAP. 
Figure 22. Le plan du cours de français de la diplomatie.

Figure 23. Séquence $n^{\circ} 1$ "Qu'est-ce que la diplomatie?".

Figure 24. Le degré du développement de la CPLPC des participants à l'étude (post-test). 203

Figure 25. Le degré du développement de la CPLPC des participants à l'étude (pré-test). 204

Figure 26. Le degré d'acquisition de la CPLPC des apprenants par rapport aux objectifs du CARAP. 

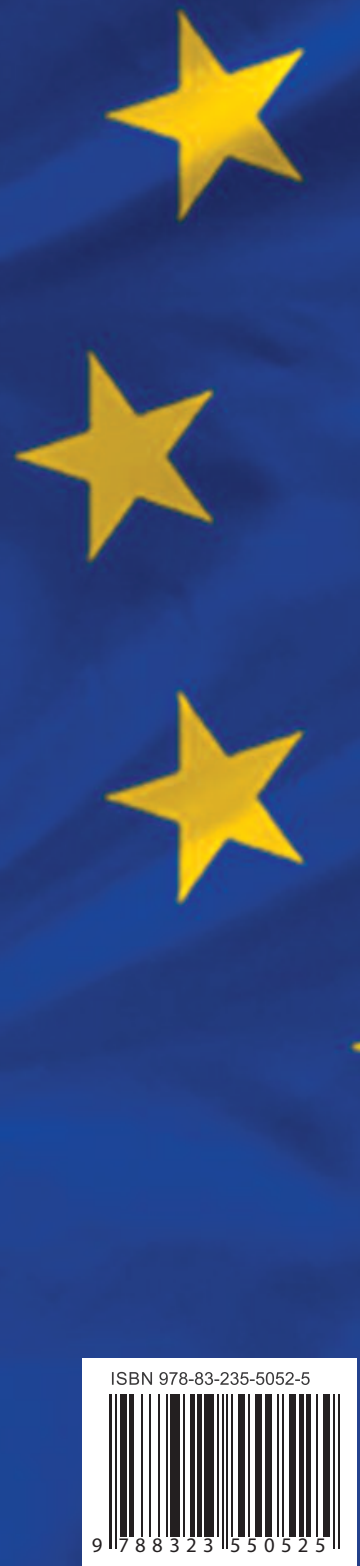
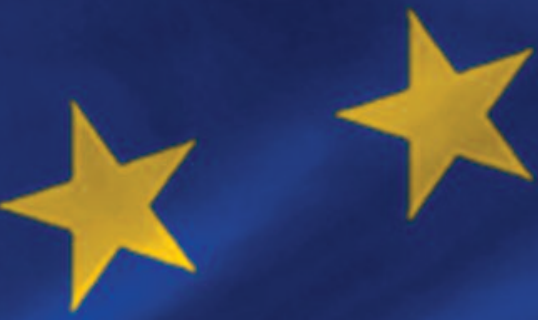

Ce livre se propose de réfléchir à l'intégration d'une démarche interculturelle dans un enseignement/apprentissage de français de la diplomatie. L'objectif de l'ouvrage est de dé nontrer que la compétence plurilingue et pluriculturelle mérite d'avoir une place à part dans le processus d'enseignement/ apprentissage de langue française à destination d'un public de jeunes professionnels. C'est notamment l'apparition du Cadre de Référence pour les Approches Plurielles des Langues et des Cultures (CARAP) qui a incité une analyse beaucoup plus poussé ede la compé ence plurilingue et pluriculturelle, une compé tencecruciale dans la didactique moderne des langues é trargè res. Il est donc fondamental de prendre en considé ration cette nouvelle ré dité et de s'y adapter également dans le cas d'une formation qui s'adresse à de jeunes adultes comme c'est le cas du public de futurs diplomates.
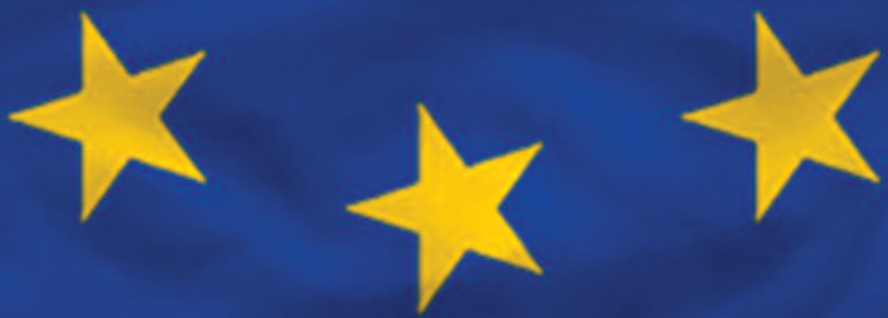

www.wuw.pl 